PROSPECTS FOR COMMUNITY-BASED MARINE CONSERVATION IN NAURU:

ATTITUDES, POLICIES \& INSTITUTIONS

by

Margo Deiye

Thesis

ENVIRONMENTAL STUDIES 593

[2015]

A 90-point thesis submitted to Victoria University of Wellington as partial fulfilment of requirements for the degree of Master of Environmental Studies

School of Geography, Environment and Earth Sciences

Victoria University of Wellington

[2015] 


\title{
PROSPECTS FOR COMMUNITY-BASED MARINE CONSERVATION IN NAURU: ATTITUDES, POLICIES \& INSTITUTIONS
}

\author{
Margo Deiye
}

\begin{abstract}
This paper is about Nauru and its people, institutions, policies and in particular the communitybased fisheries management programme (CBFM). This study aims to identify those elements in the CBFM that makes it successful, where the institution endures overtime with a well-managed and thriving fisheries resource. This study explores the success criteria of community-based resource management.
\end{abstract}

The literature review covered broad and interdisciplinary literatures including the commons, comanagement, adaptive co-management and complex social-ecological systems in an attempt to identify some elements of success in community-based and co-management systems.

The study explores some of the current co-management practices and approaches in the Pacific region. A small number of Pacific fisheries experts and community-based practitioners were interviewed to share their views and experiences on lessons learnt and the implications of climate change for fisheries management in the region.

The study undertook a dwelling survey of 270 individuals and a gender-based focus group interviews in Nauru. This is to further investigate the willingness and capacity of the Nauruan people to participate in the CBFM while facing the poor economic conditions, the loss of traditional ecological knowledge and customary marine tenure, poor information about the state of marine resources, and limited opportunities for livelihood diversification.

An enabling environment is critical for development of such a framework, a functioning of institutions and having appropriate policies and legislation in place. Adaptive learning is important in successful a management framework. It can foster the development of an individual through social learning institutions within and between governments and communities and further promotes information sharing and awareness-raising.

Key words: Nauru, community-based fisheries management (CBFM), adaptive learning 


\section{Acknowledgements}

This Masters programme has proven one of the most challenging journey of my life. This challenge has not been without its rewards. Reflecting now on my journey, there are so many people who have helped along the way. Without your support, understanding, and faith in me, completing this journey would not have been possible.

First and foremost, I would like to thank NZAid for making this part of my journey a reality, especially to Inge De Leeuw and Julia Harrison. Your support throughout my studies has been instrumental.

Thanks to NFMRA, especially to my colleagues and the Institutional Strengthening Project (ISP), for all your support to this research.

To Cath Wallace, my supervisor, thank you for your professionalism and continued faith in me.

I thank my family for their love, support and encouragement in my studies especially to my husband Pyon and daughter Emma-rae, including Leo, Mum, Alex and Grandma.

To my friends (too many to mention here) both old and new, especially those of you who have been consistently encouraging me throughout my journey, a very warm thanks!

Finally, I am very grateful to all those who have supported and willingly participated in the research. Thank you, thank you, thank you! 
To my children with love 


\section{Table of Contents}

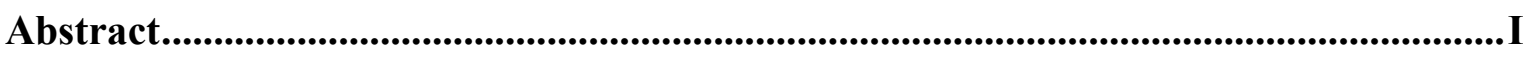

Acknowledgements .............................................................................................................................. II

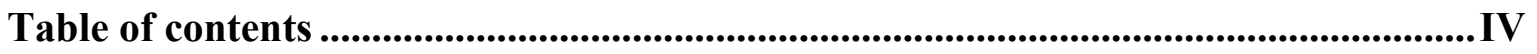

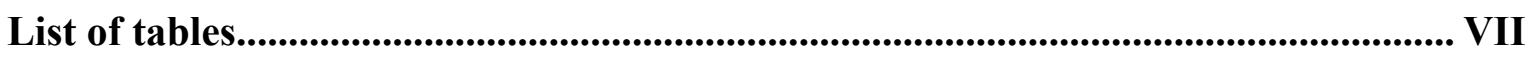

Acronyms .................................................................................................................................... IX

Chapter 1 ...................................................................................................................................... 1

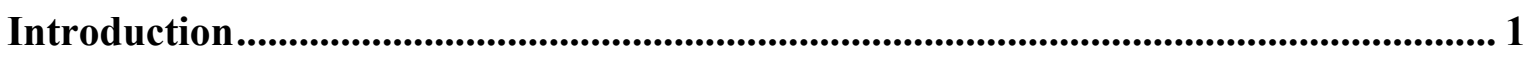

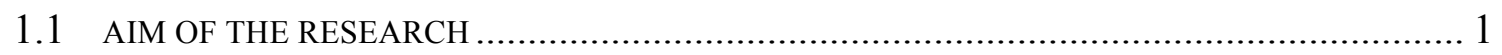

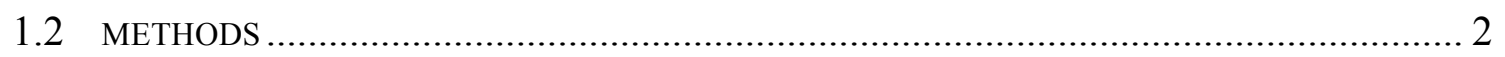

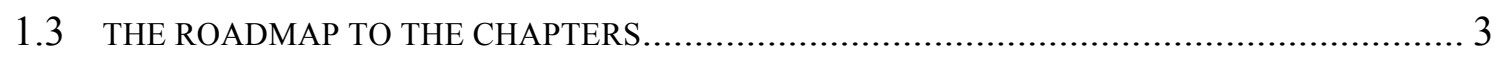

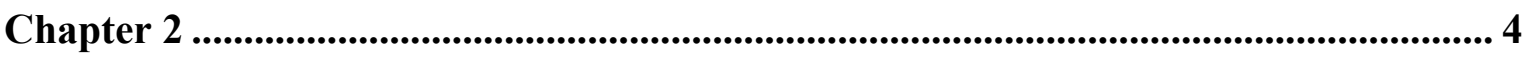

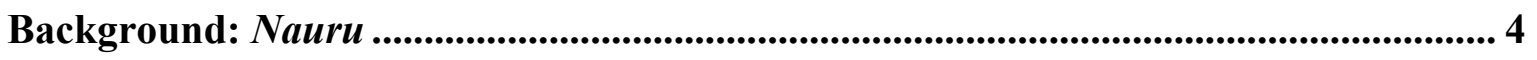

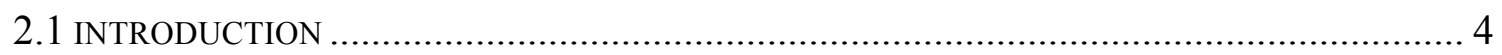

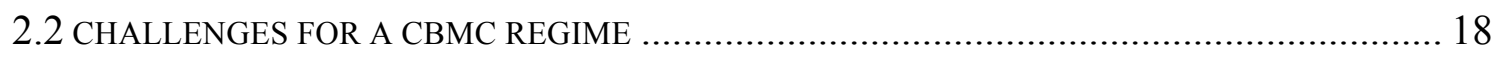

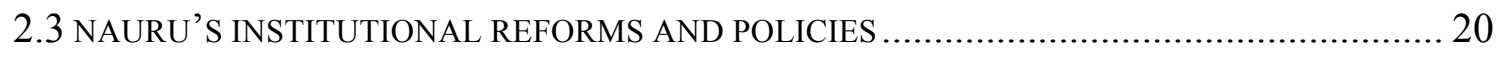

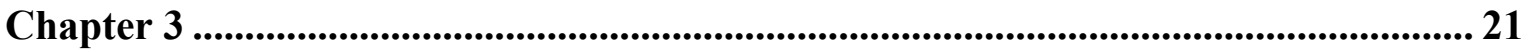

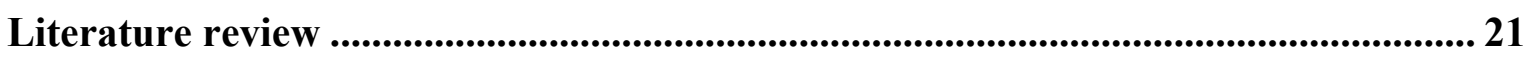

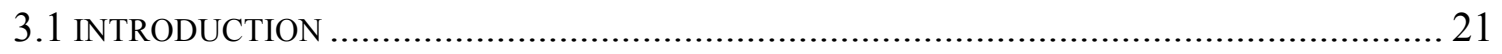

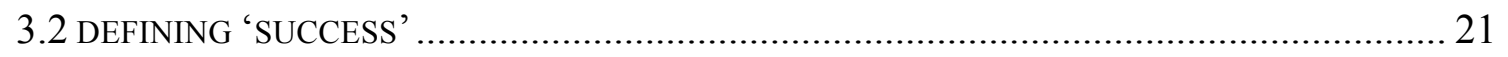

3.3 DESIGN PRINCIPLES AND THE CRITICAL CONDITIONS FOR SUCCESS ............................ 22

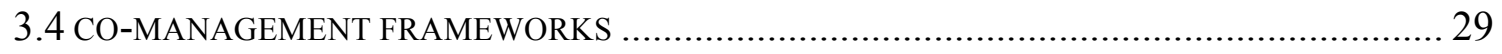

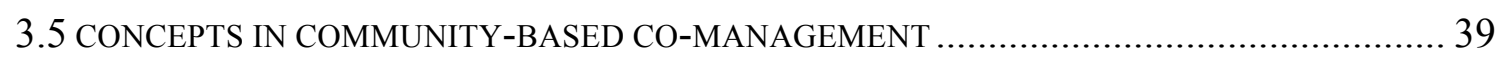

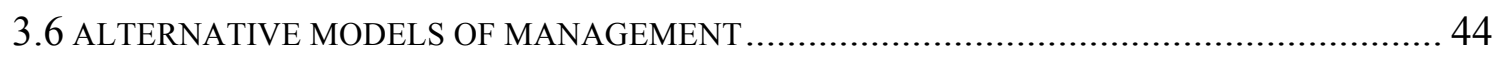

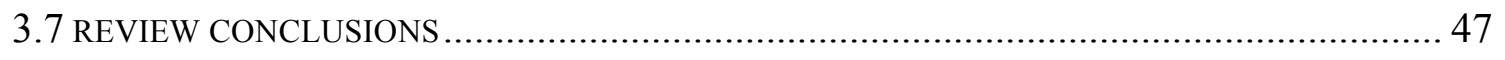

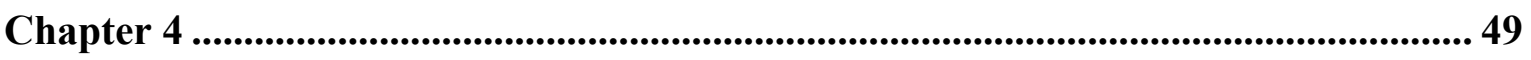

Practices in the Pacific.............................................................................................................. 49

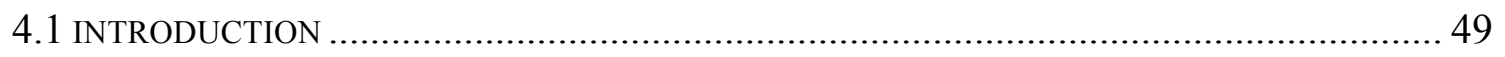

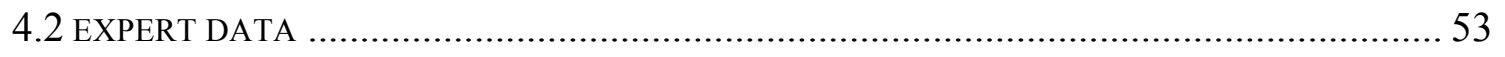

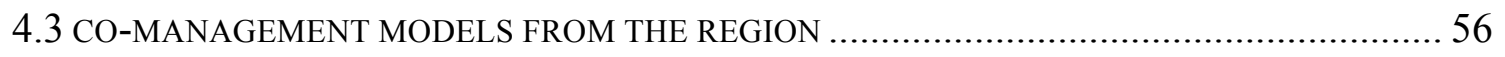

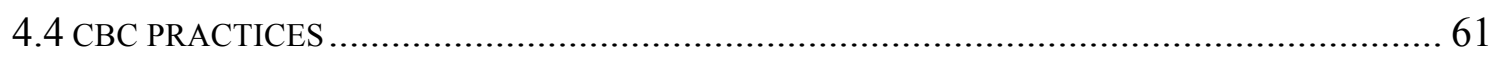

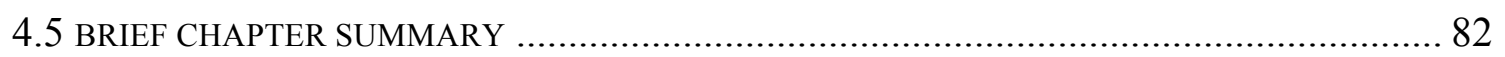

Chapter 5 ............................................................................................................................................ 84

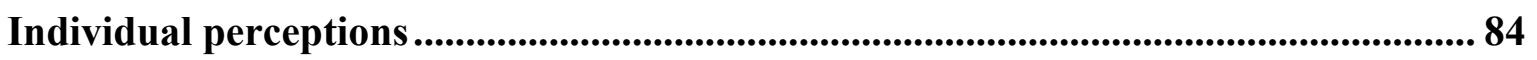

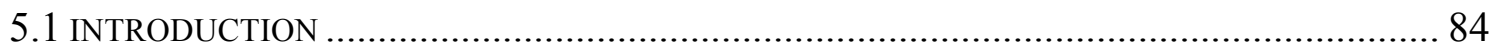

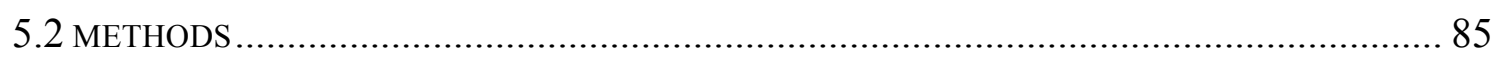




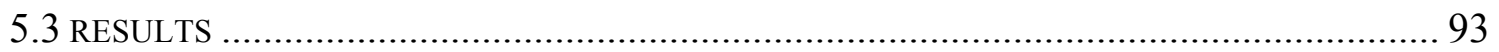

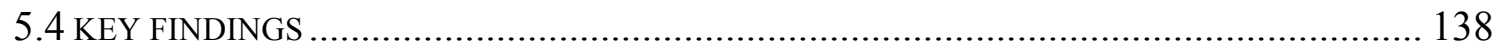

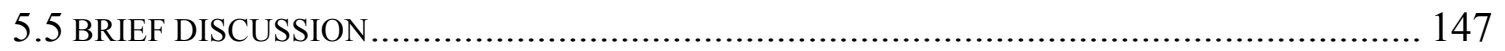

Chapter 6 .............................................................................................................................................. 149

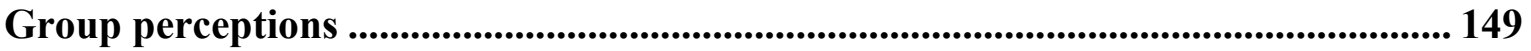

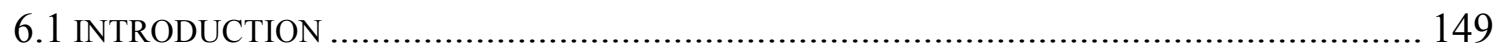

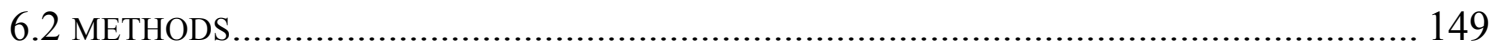

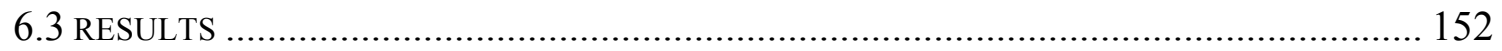

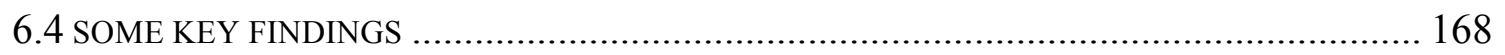

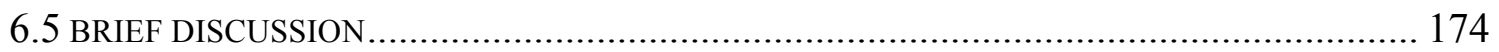

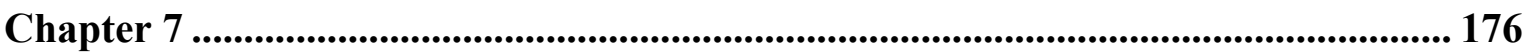

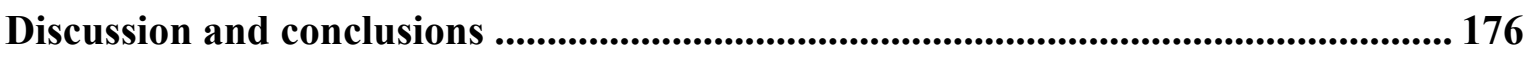

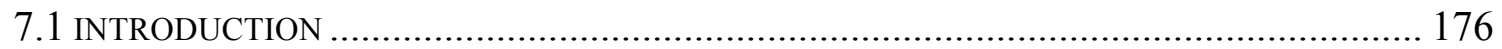

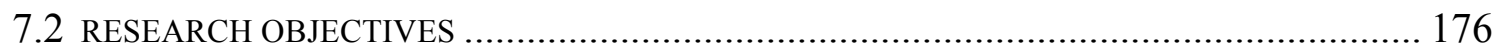

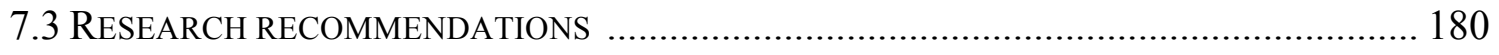

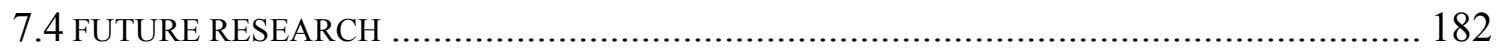

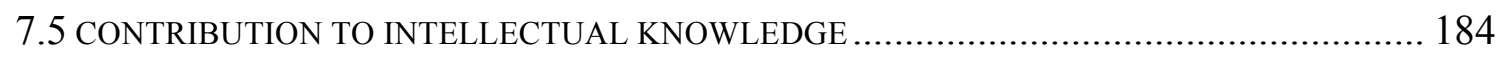

References............................................................................................................................................ 185

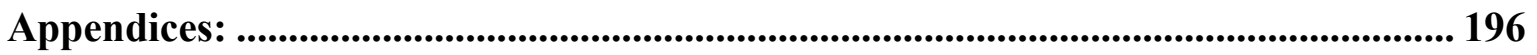

Appendix 1: Critical enabling conditions for sustainability on the commons .............. $i$

Appendix 2: Conditions to successful co-management arrangements ......................... iii

Appendix 3: Summary of expert interviews ........................................................

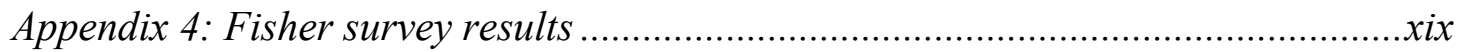

Appendix 5: Non-fishers survey results .......................................................................

Appendix 6: Fishers \& non-fishers survey results................................................xxviii

Appendix 7: Survey field notes ..............................................................................

Appendix 8: Focus group information \& results..................................xxxvii

Appendix 9: Survey questionnaires........................................... xxxviii 


\section{List of Figures}

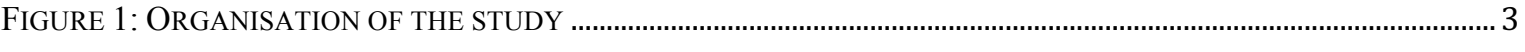

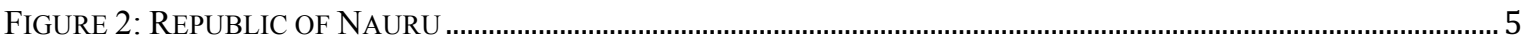

FIGURE 3: CROSS-SECTION OF MARINE COASTAL INSHORE AREA ……..................................................................... 6

FIGURE 4: POPULATION PROJECTION FOR NAURU (1992-2027) ……......................................................................

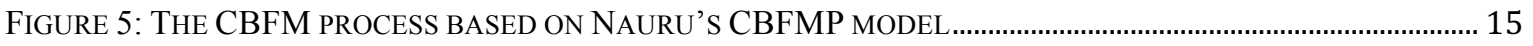

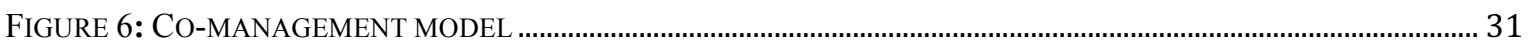

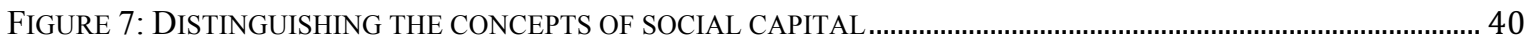

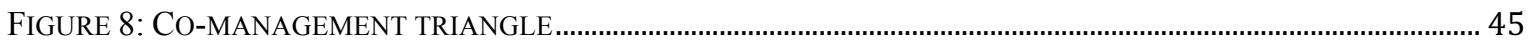

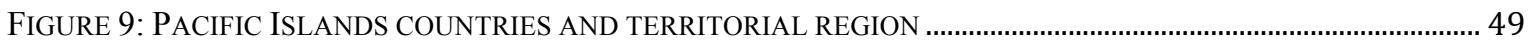

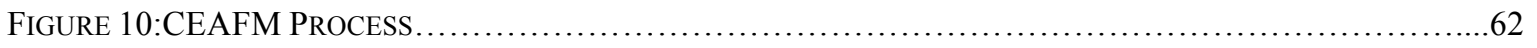

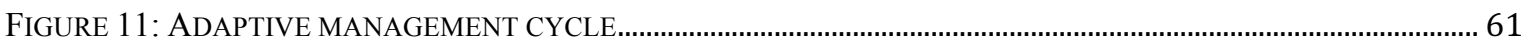

FIGURE 12: FISHERS (\%) PERCEIVED EFFICIENCY OF FISHING GEAR .......................................................................104

FIGURE 13: FISHERS' (\%) RESPONSE TO CONTROL GEAR TYPE ...............................................................................104

FIGURE 14: RANKING INDIVIDUALS VALUES TO A SET OF VARIABLES................................................................127

FIGURE 15: PHOTO OF BUADA DISTRICT WITH ITS LAGOON.................................................................................155

FIGURE 16: FOCUS GROUP I: SEATING ARRANGEMENT …….......................................................................XXXV

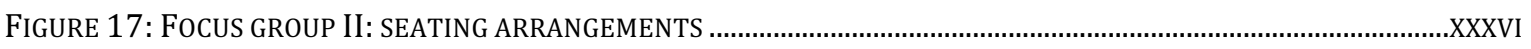




\section{List of Tables}

TABLE 1: NEMS RECOMMENDATIONS AND PLAN OF ACTIONS FOR NAURU ............................................................. 10

TABLE 2: EIGHT DESIGN PRINCIPLES, THE REVISIONS AND LEVEL OF SUPPORT ....................................................... 23

TABLE 3: EIGHTEEN CONDITIONS FOR SUCCESSFUL CO-MANAGEMENT ................................................................. 36

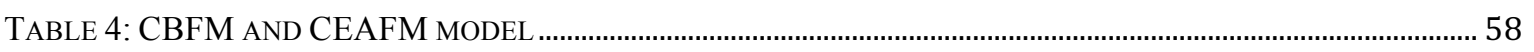

TABLE 5: MARINE MANAGEMENT MEASURES CONTROLLED BY COMMUNITIES IN THE PACIFIC ISLANDS........... 72

TABLE 6: RECOMMENDED SAMPLE SIZES FOR NAURU......................................................................................... 89

TABLE 7: SURVEY SAMPLE SIZE BASED ON DWELLING AND COMPOSITION OF RESPONDENTS ..............................90

TABLE 8: COMPARISON OF INDIVIDUALS INTERVIEWED COMPARED TO THE INITIAL TARGET ..............................92

TABLE 9: PERCENTAGE OF TOTAL INTERVIEWS BASED ON DWELLINGS ................................................................ 92

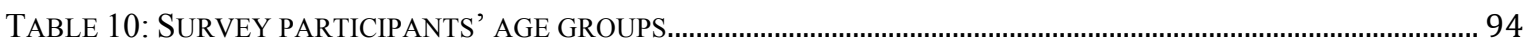

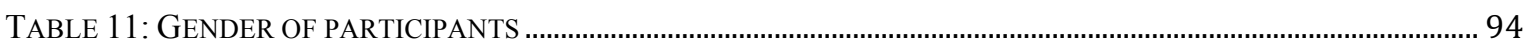

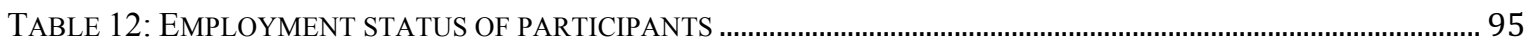

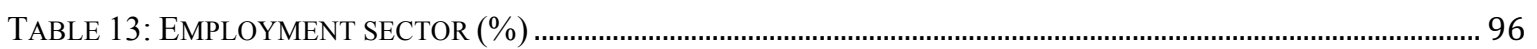

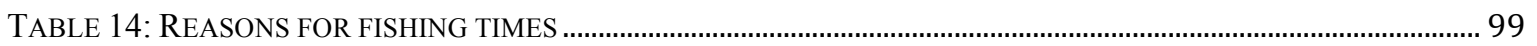

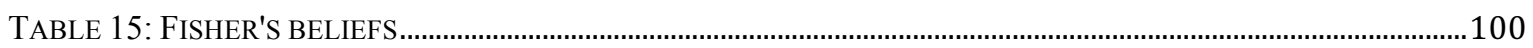

TABLE 16: EFFICIENCY AND CONTROL OF FISHING GEAR AND METHODS ..............................................................102

TABLE 17: SPECIES OF CONCERN AND ABUNDANCE .........................................................................................109

TABLE 18: AVERAGE CATCH GIVEN AWAY .......................................................................................................... 113

TABLE 19: PERCEPTIONS OF NON-FISHERS ON THE STATUS OF THE COASTAL MARINE ENVIRONMENT ...............115

TABLE 20: NON-FISHERS' REASONS OF THEIR PERCEPTIONS REGARDING THE STATUS OF THE MARINE

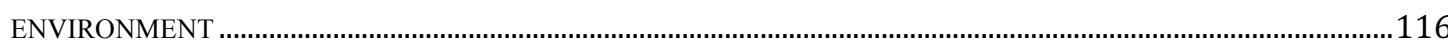

TABLE 21: NON-FISHERS IDENTIFIED THE MAJOR CAUSERS OF DETRIMENTAL IMPACTS AND ACTIVITIES FOUND

IN THE COASTAL MARINE ENVIRONMENT …….................................................................................................118

TABLE 22: NON-FISHERS IDENTIFIED THOSE THAT SHOULD BE RESPONSIBLE........................................................119

TABLE 23: NON-FISHERS IDENTIFIED A) TRADITIONAL RULES AND B) NATIONAL RULES AND REGULATION..120

TABLE 24: NON-FISHERS REASONS FOR COMPLIANCE AND NON-COMPLIANCE ................................................121

TABLE 25: NON-FISHERS IDENTIFIED THEIR SOURCES OF KNOWLEDGE AND INFORMATION REGARDING

COASTAL MARINE CONSERVATION ............................................................................................................123

TABLE 26: NON-FISHERS' IDENTIFIED TYPES OF INFORMATION TO RECEIVE ...........................................................123

TABLE 27: NON-FISHERS' RESPONSES TO THE TYPE OF MEDIUM BEST FOR AWARENESS.......................................124

TABLE 28: NON-FISHERS IDENTIFIED CURRENT KNOWN MARINE CONSERVATION GROUPS .................................125

TABLE 29: NON-FISHERS AGAINST COASTAL ZONING AS A MEANS OF MARINE CONSERVATION.........................126

TABLE 30: NON-FISHERS IDENTIFIED THOSE RESPONSIBLE TO MANAGE COASTAL ZONING..................................126

TABLE 31: RANKING ORDER OF THE SIGNIFICANCE OF THE MARINE ENVIRONMENT OF EACH VARIABLE AS

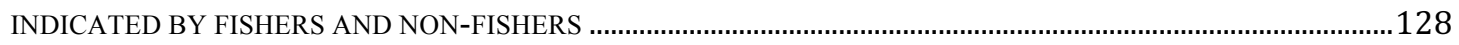

TABLE 32: TYPES OF CUSTOMARY MARINE TENURE SYSTEMS IN NAURU …..........................................................130

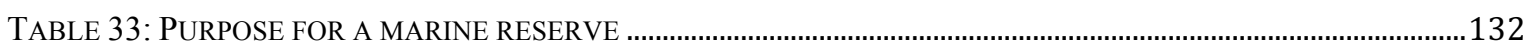

TABLE 34: COASTAL RESOURCE MANAGEMENT AND RESPONSIBILITIES ...............................................................133

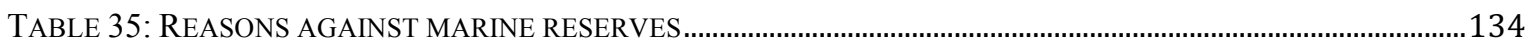

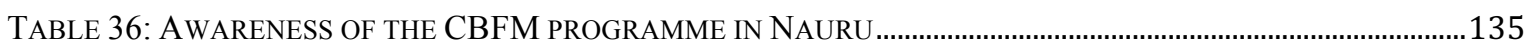

TABLE 37: REASONS FOR SUPPORT OF THE CBFM PROGRAMME .........................................................................136

TABLE 38: REASONS FOR THE LACK OF SUPPORT OF THE CBFM PROGRAMME.....................................................137

TABLE 39: SUMMARY OF PROBLEMS FOUND IN COASTAL MARINE ENVIRONMENT............................................... 140

TABLE 40: TRADITIONAL FISHING GEAR ……........................................................................................................

TABLE 41: TARGET SPECIES BY GEAR/METHODS............................................................................................... XIX

TABLE 42: PROBLEMS OF SITES AND AREAS IDENTIFIED BY FISHERS ....................................................................XXII

TABLE 43: POSSIBLE SOLUTIONS TO PROBLEMS IDENTIFIED BY FISHERS..............................................................XXV

TABLE 44: BENEFITS AND LOSS FROM FISHING VERSUS IMPROVEMENTS ................................................................XXV 
TABLE 45: ESTIMATED COST OF FISHING GEAR IN NAURU

XXVII

TABLE 46: RANKING 'CAUSERS' OF MAJOR PROBLEMS BASED ON MEAN SCORES

XXVII

TABLE 47: SITE-SELECTION FOR MARINE RESERVE(S) IN NAURU

XXVIII

TABLE 48: PARTICIPANTS REASONS FOR SELECTING SPECIFIC SITES TO HOST A MARINE RESERVE.....................XXX

TABLE 49: COMMENTS ON QUESTIONNAIRE …...................................................................................................XXI

TABLE 50: ROLE AND OBJECTIVES OF NFMRA AND THE COMMUNITY IN THE CBFM PROCESS ..................... XXXVII 


\section{Acronyms}

ACM

AM

CBAM

$\mathrm{CBC}$

CBD

CBFM

CBMC

CCA

CBRM

CEAFM

CIE

CMT

CPR

DEC

DHS

DWFNs

EEZ

FADs

FLMMA

FMC

IDI

ISP

IUCN

LMMA

MAB

MDG
Adaptive co-management

Adaptive management

Community-based adaptive management

Community-based conservation

Convention of Biological Diversity

Community-based fisheries management

Community-based marine conservation

Community Conserved Areas

Community-based resource management

Community-based ecosystem approach to fisheries management

Department of Commerce, Industry and Environment

Customary marine tenure

Common-pool resources

District Executive Committee

Nauru Demographic and Health Survey

Distant Water Fishing Nations

Exclusive Economic Zone

Fish Aggregation Devices

Fiji Locally Managed Marine Area

Fisheries Management Committee

Department of Island Development and Industry

Institutional Strengthening Project-Nauru

The World Conservation Union

Locally Managed Marine Area

Man and the Biosphere Reserve

Millennium Development Goals 
MMA Marine Managed Area

MPA Marine Protected Area

NBSAP Nauru Biodiversity Strategy Action Plan

NEAP National Environmental Action Plan

NEMS National Environmental Management Strategy

NFMRA Nauru Fisheries \& Marine Resources Authority

NGO Non Government Organisation

NIANGO Nauru Island Non Government Organisation

NLGC Nauru Local Governing Council

NPC Nauru Phosphate Corporation

NSDS National Sustainable Development Strategy

PICTs Pacific Island Countries \& Territories

ProcFISH Pacific regional Oceanic and Coastal Fisheries Development

Programme

PSU Primary sampling unit

SC Social capital

SOE State-owned Entity

SPC Secretariat of the Pacific Community

TEK Traditional Ecological Knowledge

WCPO Western Central Pacific Ocean

WSSD World Summit on Sustainable Development 


\section{Chapter 1}

\section{Introduction}

Introduces the thesis, its purpose and concepts including its organisation in order to orient the reader.

\subsection{Aim of the research}

The aim of this research is to inform resource managers and communities the criteria for success in community-based management fisheries management. The objective is to determine the success criteria of community-based management in sustaining the management of its institution and its resources.

Firstly, the thesis presents the case of Nauru and its community-based fisheries management (CBFM) programme. The research questions for the case study:

Does the CBFM process take sufficient account of the context and situation in Nauru?

Do individuals (attitudes and behaviours) within communities play a significant role in sustaining the institution and/or the resources?

The thesis explores and examines those success factors and their criteria across the broad and relevant interdisciplinary theoretical and empirical frameworks of communities involved in natural resource management (Plummer \& Armitage, 2007). Drawing from the diverse international literature to address the above questions including the following.

\section{Does the process and methods used in the Nauru CBFM meet the criteria for sustaining the common pool resources?}

Communities in practice where practice is a key significant process in community-based institutions and this research takes the study further to examine the community-based practice in the Pacific region. The work is derived from expert opinions to address the following question: 


\section{Does the process and methods used in the Nauru CBFM meet the criteria for sustaining the institution?}

To conclude the thesis brought together all the different sets of information and findings to provide the policy and institutional suggestions as ways to strengthen the communitybased fisheries management in Nauru and to ensure its endurance over time.

\subsection{Methods}

There are different designs and research methods given the different sets of research questions identified aiming to address the different levels of community-based institutions. This thesis used Creswell's (2009) conceptual design of a mixed methods approach (Creswell, 2009). The emergence of the mixed methods approach as a third paradigm to social research is relevant for 'communities in practice'(Descombe, 2008). One of the advantages in using mixed methods is that it is pragmatic and allows the use of diverse tools in order to address the research problem. The biggest critique of mixed methods approach in traditional research is that the quantitative data is given more credibility than that of the qualitative data. It can be argued that "qualitative data can be used to expand and elaborate on quantitative findings" (Creswell, Shope, Clark, \& Green, 2006, p. 5).

A review of the literature was undertaken in this research and there is an extensive literature on conservation frameworks that intersect with the management of the commons, co-management and adaptive co-management of complex social-ecological systems. These theories and their applications are the focus of this study (Figure 1).

A semi-structured interview was conducted with four experts from the Pacific region to investigate communities in practice.

For the case study a sequential mixed methods format was used. A quantitative perception monitoring survey was undertaken and complemented with a qualitative gender-based focus group interview. These methods were chosen in order to determine the willingness and capacity of individuals within communities themselves and understand if these are factors that may contribute to the success of sustaining the community institutions and or the common pool resources. 


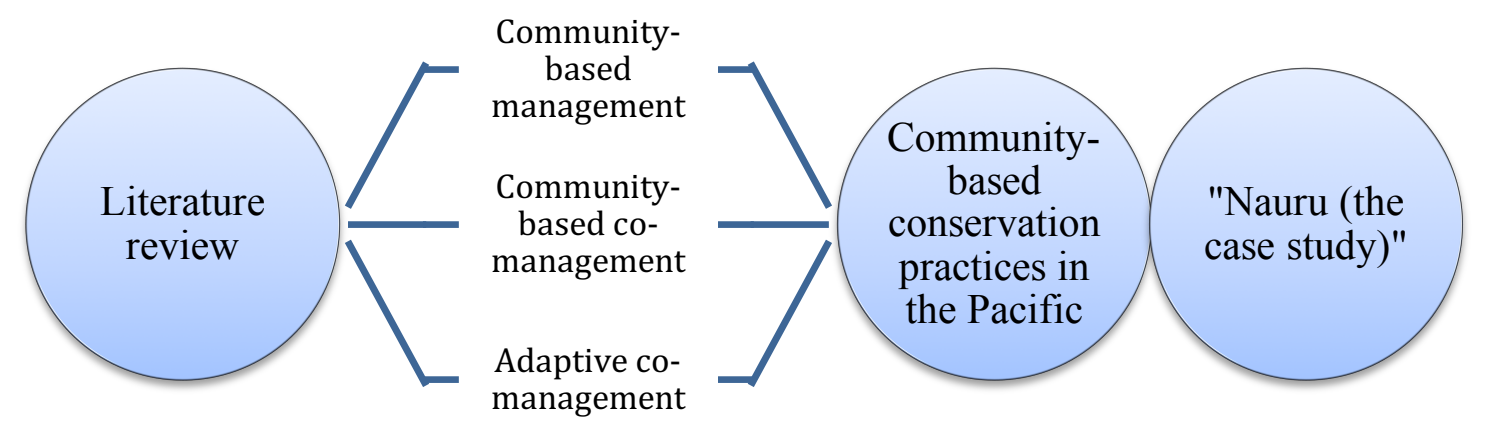

Figure 1: Organisation of the study

\subsection{The roadmap to the chapters}

The present study is structured around these specific research objectives:

Chapter 2: Introduce Nauru the case study, the context and elaborates the current challenges in implementing the CBFM.

Chapter 3: To explore through the relevant literature, key factors of success in communitybased co-management of natural resources, particularly coastal and marine management.

Chapter 4: To examine community-based fisheries management strategies and marine conservation practices in the Pacific region using both the literature and expert interviews to complement the literature.

Chapters 5 \& 6: To examine, based on a perception-monitoring survey and focus group, the degree of willingness and the capacity of individuals in Nauru to involve themselves in the coastal marine co-management arrangements.

Chapter 7: To provide recommendations for policy, practice and institutions that will strengthen the Nauru CBFM. 


\section{Chapter 2}

\section{Background: NAURU}

\subsection{Introduction}

This chapter provides the background setting to help the reader understand the context of Nauru. It introduces the nation, its people, the population and the current economic climate. This chapter also discusses some of the national policies, strategies and systems in place that may affect coastal marine resource management and conservation in Nauru; specifically, the 1996 National Environmental Management Strategy (NEMS) and the 2010 National Biodiversity Strategy and Action Plan (NBSAP). This is followed by an exploration of the current nature of the land tenure system and coastal fisheries management. Central to this is the mandate of the Nauru Fisheries \& Marine Resources Authority (NFMRA) with respect to coastal fisheries management. The recently introduced national strategy, known as the community-based fisheries management (CBFM) programme, put in place to address the current challenges in managing and conserving Nauru's coastal marine resources, is discussed in detail. A brief overview of the current resource management and conservation challenges facing Nauru that affect the performance of the CBFM follows. At the end of this chapter, it will be bring together the broad contextual issues of Nauru's institutional reforms and environmental policies to be discussed.

\subsubsection{Geography and location}

The Republic of Nauru is a single island $21 \mathrm{~km}^{2}$ in total land area, measuring $6 \mathrm{~km}$ long and $4 \mathrm{~km}$ wide, and situated in the Western Central Pacific Ocean (WCPO) about $60 \mathrm{~km}$ south of the equator, at latitude $0^{\circ} 31^{\prime} \mathrm{S}$ and longitude $166^{\circ} 55^{\prime} \mathrm{E}$. The closest neighbour is Ocean Island (Banaba), part of the Republic of Kiribati, located $306 \mathrm{~km}$ to the east. About $80 \%$ of the island of Nauru is a central plateau, with the highest point at $70 \mathrm{~m}$ above sea level (

Figure 2). 


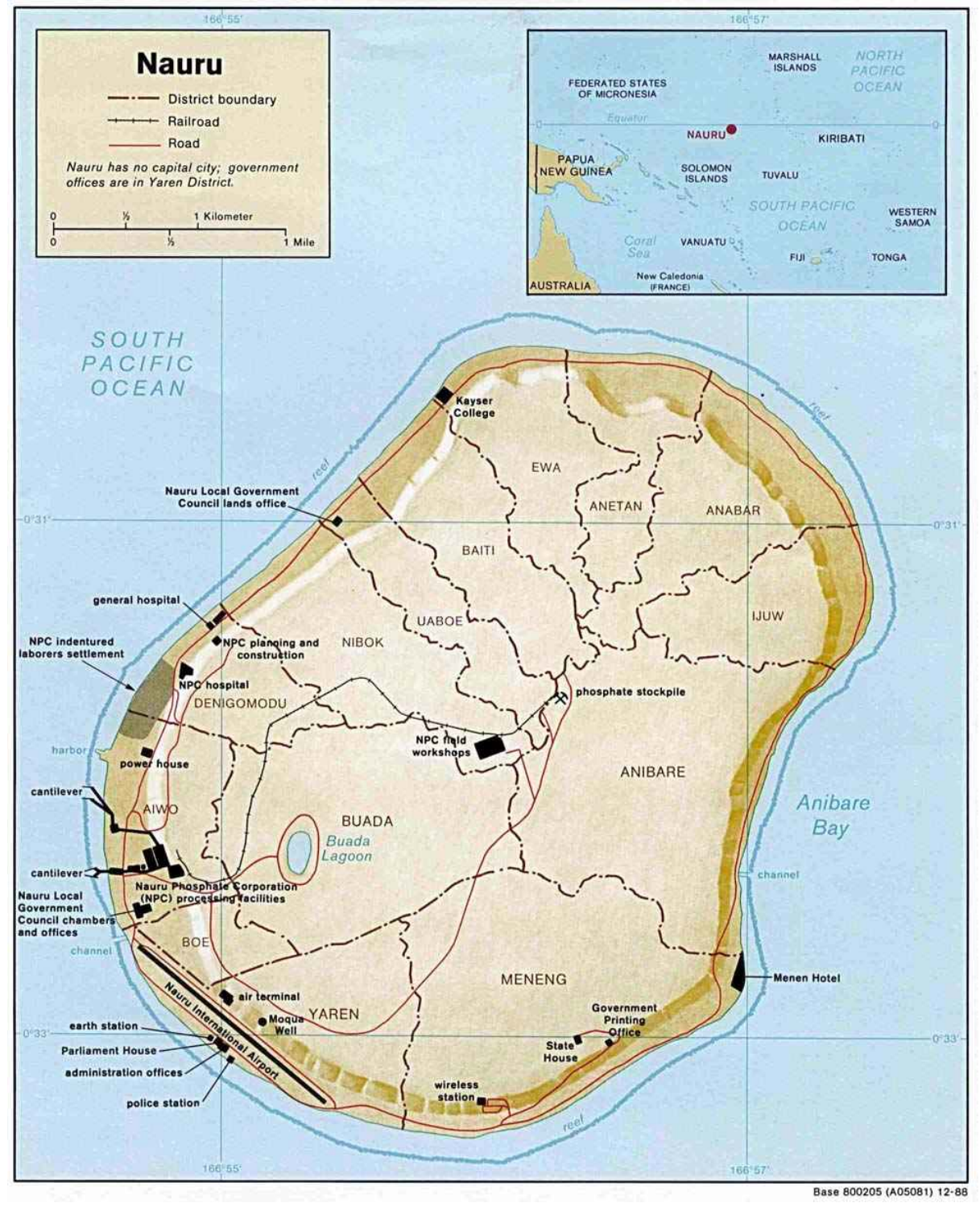

Figure 2: Republic of Nauru (Google images, 2012)

The flat coastal terrace measures $300-1000 \mathrm{~m}$ in width with a mean elevation of about $3 \mathrm{~m}$ above sea level. The fringing reef measures at 110-320 $\mathrm{m}$ in width with the total intertidal reef area estimated at $7.4 \mathrm{~km}^{2}$, measuring down to the depths of $200 \mathrm{~m}$ isobath (Dalzell \& Debao, 1994) (Figure 3). 


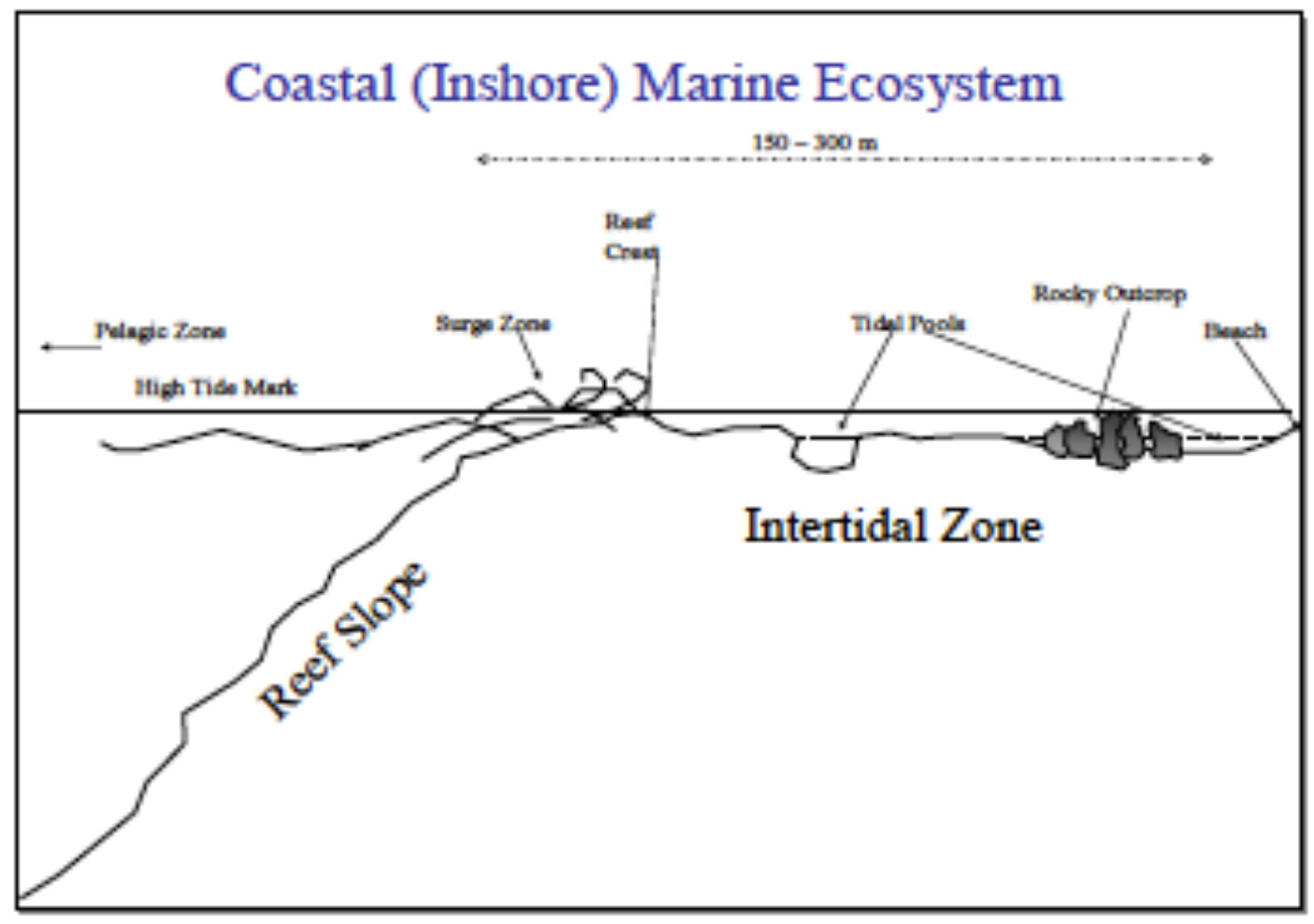

Figure 3: Cross-section of marine coastal inshore area [taken from (Jacob, 2005)]

\section{Economic situation}

In the mid 1970s to the 1980s, Nauru was one of the richest countries in the world per capita due to its export of phosphate (FinancialStandardsFoundation, 2009;

FreedomHouse, 2008). In 2000, the economic crisis altered the living standards of the population. At the time, $95 \%$ of the workforce were public servants and mainly relied upon phosphate royalties as sources of income(FinancialStandardsFoundation, 2009).

According to the population report, during the peak years of phosphate mining, Nauruans had enjoyed a high standard of living where household needs, including food and drinking water, were imported from overseas and distributed through local retail outlets (Nauru, 2005b). In 2000, when the large-scale commercial mining of phosphate ceased but residual mining continued, both government revenue and average household income was reduced dramatically (Quanchi, 2009).

The consequences of this economic crisis included insufficient government revenue that limited the capacity of the government to maintain public and private buildings, and pay public service salaries (Nauru, 2005b; Quanchi, 2009). Slow growth in the public and 
private sectors meant fewer opportunities for employment and development. Those families who were once highly privileged in comparison with much of the world's population are now finding it difficult to provide for their day-to-day needs (Nauru, 2005b). An Australian Agency for International Development (AusAID) socioeconomic assessment report (2004) also revealed that since 2004 there has been a significant deterioration in the living conditions of Nauruans (Nauru, 2004).

\section{Population and marine resources}

A demographic and health survey report (DHS, 2007) identified Nauru as a rapidly growing population, with the bulk of the population found between 15 and 59 years and $49 \%$ of the population distribution is younger than 20 years (Nauru, SPC, \& MACROInternational, 2009). Nauru's population was 10,065 in 2002 (Nauru \& SPC, 2002) and reduced to 9,257 in 2006 , as a result of the repatriation of foreign phosphate workers (Nauru, et al., 2009).

The population is found living on the coastal belt around the island (Figure 2). Population density has increased significantly, from 98 person $/ \mathrm{km}^{2}$, since 1921 to 479 person $\mathrm{km}^{2}$ in 2002 . Figure 4 shows that the projected population will increase to 12,147 for Nauru in 2027 with the potential density to increase to 593 person $\mathrm{km}^{2}$ (Jacob, 2005).

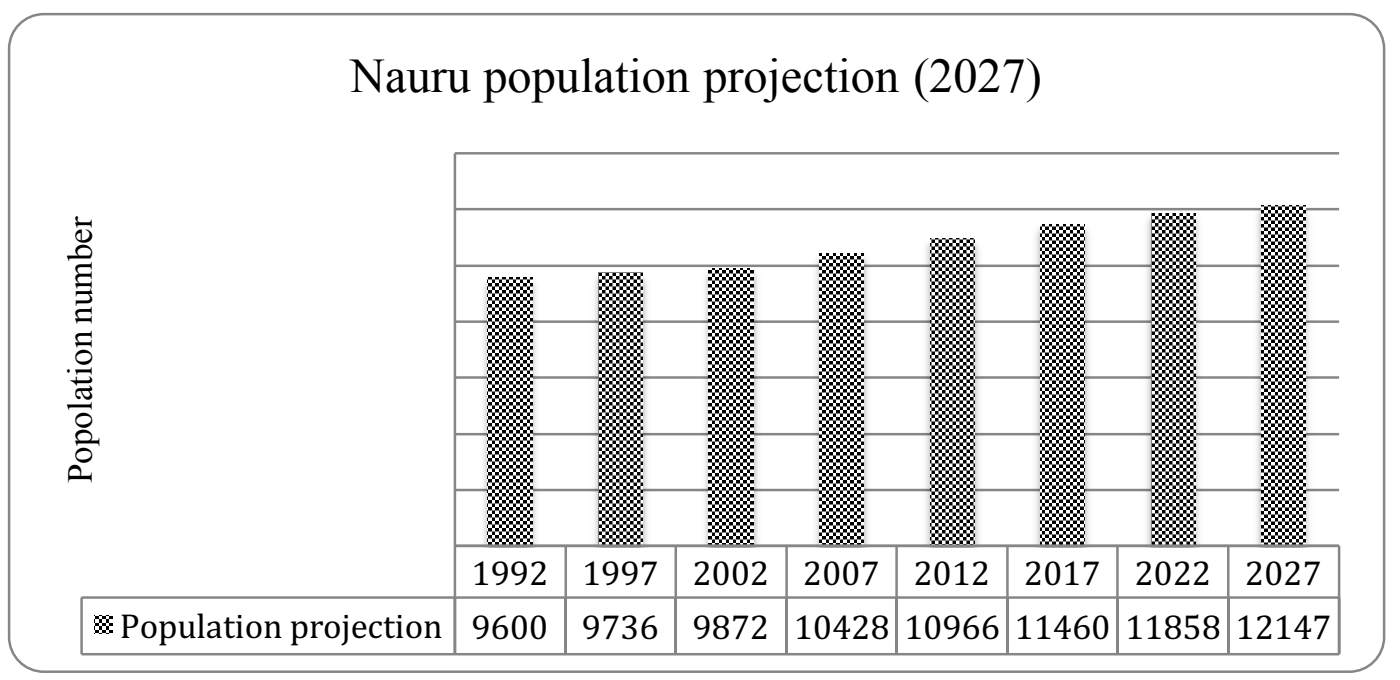

Figure 4: Population projection for Nauru (1992-2027) taken from (Nauru \& SPC, 2002)

This has significant implications for a small island country experiencing an economic recession, with much of its land mined and degraded from its phosphate mining, and with a high population density, 
The repercussions of a young and growing population (Nauru, et al., 2009) along with the impacts of the national economic crisis (Quanchi, 2009) has seen the Nauruan people revert to fishing and the gathering of coastal marine resources for their daily source of protein and livelihoods (Nauru, 2004). This has increased the people's dependency on the marine resources (Nauru, 2004; Vunisea et al., 2008).

In 2005, the Pacific Regional Oceanic and Coastal Fisheries Development Programme (ProcFISH) report found an average of 3.7 fishers at the household level in Nauru. This figure was extrapolated to estimate the total number of fishers to be 4,513 (Vunisea, et al., 2008). Based on these estimates fishers are shown to represent $45 \%$ of the 2002 population. There were 2,947 men and 1,566 women fishers involved in the small-scale fishery. There are no commercial fisheries export markets in Nauru. This means that virtually all catches are consumed, given away and sold locally (Vunisea, et al., 2008).

Anthropogenic impacts on coastal marine resources are not well recorded in Nauru but based on the demographic growth rate and the increased dependency on its coastal resources conveys the increasing pressures on the coastal and inshore areas. Bell and colleagues (2009) identified Nauru as among 11 Pacific Island Countries and Territories (PICTs) where coastal fisheries are forecasted as insufficient to ensure food security in the future (Bell et al., 2009).

In order to understand the paths for strengthening as well as improving the communitybased fisheries management to sustain the marine resources it is necessary for this study to understand the context in particular Nauru's existing national environmental policies and plans.

\subsubsection{Nauru sustainable development plan}

Thaman and Hassall (1996) prepared the 1996 National Environmental Strategy (NEMS) and National Environmental Action Plan (NEAP) as the first sustainable development plan. For the purpose of this study, this sustainable development plan will be referred throughout this paper as the 1996 NEMS report. The aim of the NEMS report was to ensure that Nauruans have continued access to goods and services of urban-industrial societies while protecting the island's environment and cultural traditions (Thaman \& Hassall, 1996). The NEMS report provided a cross-scale recommendations and programs for Nauru. Some of the recommendations and plans of action of interest to this study are provided in Table 1. 
Since its publication, the 1996 NEMS report and the establishment of the Nauru Fisheries \& Marine Resources Authority (NFMRA) in 1997, there have been some coastal marine monitoring programs in place. Such as a coral monitoring program, a finfish census, monitoring of ciguatera outbreaks and seawater salinity levels (Jacob, 2005). Some baselines studies also have been carried out for example the coral reef status report (Deiye, 2004) and the coastal marine resource status report (Vunisea, et al., 2008).

Since the establishment of NFMRA a legislative framework was developed. The NFMRA Act of 1998 and the Nauru Fisheries Regulation of 1997, which do mention the requirements for management and conservation of marine resources but remain inadequate to support conservation programmes (Jacob, 2005). For example, the regulation of fishing gear and equipment is absent.

\section{Status of Nauru's marine biodiversity}

Nauru's marine biodiversity has been previously described as a relatively rich marine biota (Thaman \& Hassall, 1996). Jacob (2005) identified that threats to marine biodiversity are largely anthropogenic, such as overfishing, pollution and environmental degradation. The marine fauna and flora are poorly documented and understood in Nauru because of the lack of available information. Jacob's (2005) report suggested this is largely attributed to the orientation of the economy, which has primarily focused on phosphate mining since 1906 (Jacob, 2005). There is documentation that foreign researchers have visited Nauru for example the Cousteau Society that developed a documentary film on the marine resources in 1992, but did not share their findings with the government and the people (ibid). It has been argued that the threats to Nauru's marine biodiversity cannot be solely attributed to overfishing alone but due to the geographical isolation of Nauru (Deiye, 2004). Nauru's marine biodiversity remains poorly documented and understood.

The NEMS report recommended a plan of action to reverse further loss of Nauru's marine biodiversity and promote the sustainable use of its marine resources. The report five key issues that warrant addressing, population and urban control, strengthen environmental education and environmental institutions and legislation, conserve marine biodiversity and promote sustainable use of marine resources. The plans of action are further elaborated in Table 1. 


\subsubsection{National Biodiversity Strategy and Marine Resources}

This section highlights those environmental strategies that may have implications to the management and conservation of coastal marine resources in Nauru. Onorio and Deiye (2010) prepared the National Biodiversity Strategy and Action Plan (NBSAP) as part of Nauru's strategy to meet the Biodiversity Convention (1992). This strategy was formulated over two years from February 2008 to July 2010. Commitments and proposal in NBSAP 2010 report include:

1. The mainstreaming of biodiversity into national and sectoral planning by promoting an integrated approach through policy development, horizontal cross-scale planning, as well as the development of appropriate environmental legislation.

2. The commitment to increase protected and conserved areas of both land and coastal areas to $30 \%$ by 2025 . The plan is to incrementally increase the number of protected or conserved areas by $2 \%$ per annum.

3. Promotion of native species management and sustainable use of important species found both on the land and in the marine environment.

4. Recognition of communities play a significant role to implementing the strategy and to provide the means of empowering of district communities to protect, conserve and sustainably use and manage land ${ }^{1}$ biodiversity. The empowerment of communities includes promoting the use of local traditional knowledge and practices to protect and conserve biodiversity. Where appropriate, institutional mechanisms should be developed to assist the decentralisation of the monitoring and enforcement of environmental legislation to local communities under customary resource tenure.

5. Recognition of the need for research and development is required. At the same time, capacity building is required for both local communities and government staff to achieve the stipulated goals.

6. A public awareness campaign strategy was suggested throughout the NBSAP strategy to maintain the plan of actions identified.

7. Implementation will be limited without funding mechanisms in place. Thus securing financial resources and assistance from international and bilateral

\footnotetext{
${ }^{1}$ Land refers to both coastal dwellings and rehabilitated phosphate fields.
} 
partners is required.

Understanding Nauru's environmental policy development and direction is critical to this study as these policies may overlap.

\subsubsection{Land tenure system}

The 1996 NEMS report identified that the current land tenure system remains one of the main obstacles to both rehabilitation of the mined land areas and implementing protected areas system in Nauru. All land is parcelled and owned in Nauru. The island is divided into 14 districts. Historically, there are three types of land tenure systems but only two of these land tenure systems remain legitimate today.

1. Coconut land comprises flat coastal terraced land used for residential dwellings.

2. Pandanus land is land found in the central area of the island where the phosphate mining operation takes place (Viviani, 1970). Pandanus land forms the upper inland plateau area which is about 70 metres above sea-level and forms about $80 \%$ of the whole island.

3. According to Detudamo (2008) customary marine tenure (CMT) exists in Nauru and tenure extended about 500 yards off the coconut land seawards. This is clearly gone since the advent of the Nauru Fisheries \& Marine Resources Act of 1998.

Traditional land ownership practices showed that the eldest daughter in a family inherited land in Nauru and this has changed today (Thaman \& Hassall, 1996). Rights to land ownership are equally divided among siblings with shareholding rights rather than individual rights to whole pieces of land (ibid). Land ownership passes down through generations from parents to children. As the generations expand with larger families these land shares become smaller and largely dependent upon the size of the family.

This effect creates complex land tenure systems where land endowments are unequally distributed because of the large number of legal shareholders to whole pieces of land. This type of land tenure system was maintained to ensure a share in phosphate royalties from the mined pieces of land (Thaman \& Hassall, 1996). One of the recommendations of the 1996 NEMS report suggests that a review and reform of the current land tenure system to allow for effective land planning and management in Nauru (ibid).

\subsubsection{Coastal fisheries management}

Since the establishment of NFMRA and the enactment of its 1998 Act, the state has claimed ownership rights over the coastal marine areas and waters within the exclusive 
economic zone (EEZ). Coastal waters boundaries are defined from the high-water mark to a 12 nautical mile radius. From the 12 to 24 nautical mile radius these are termed as offshore areas and are tuna fishing grounds for licenced distant water fishing nations (DWFN).

The NFMRA Act of 1998 was developed without public consultation. This has caused much discord between the local people and the government and only reinforces that the former customary marine tenure (CMT) systems in Nauru went unrecognised and have become illegitimate. The local people did express their grievances on this issue during the CBFM induction process (discussed in the latter chapters). Another related issue is to the loss of CMT is loss of traditional ecological knowledge (TEK) (Jacob, 2005). Jacob (2005) suggested since the inception of the phosphate mining the loss of CMT and TEK may have resulted from their lack of economic value when compared against phosphate land and thus marine tenure were poorly documented.

There is evidence of the existence of CMTs in Nauru as documented by Weeramantry (1992) and Detudamo (2008). It is unclear whether CMTs can be recognised and reinstated in Nauru at this time without causing further conflict and dispute among and between the local people and the government. Despite the loss of CMTs, Nauru's coastal marine resources remains under an open access regime. Nauru's coastal marine areas have been left to resource users' own devices without much state interventions to date (as discussed later in this chapter). As stipulated earlier the current legislation in place remains inadequate to manage and conserve the marine resources (Jacob, 2005).

\section{Status of Nauru's coastal marine resources}

In 2005, the first-ever status report of Nauru's coastal marine resources was conducted by the Pacific Regional Oceanic and Coastal Fisheries Development Programme (ProcFISH project). This report aimed to determine the current status of marine resources and provide recommendations for its management. The ProcFISH project undertook a comprehensive survey of the local people to determine their level of dependency on the resources, and a survey on the status of the finfish and invertebrates. The report findings:

1. Monitoring fishing effort while implementing effective management measures that affect catch and fishing practices is necessary. For example, introduce a ban or 
regulate the use of SCUBA ${ }^{2}$ in spearfishing. This is needed because of the efficiency of the gear that has had a drastic effect on fish stocks.

2. Having a species-specific management system in place to allow for the recovery of invertebrate stocks and heavily fished finfish stocks is recommended.

3. A coastal fisheries management regime should be conducted and controlled by communities at scales larger than the current district boundaries where the establishment of one or two marine protected areas (MPA) should be undertaken. Enough resources outside the MPA(s) should be provided for people to fish for their needs.

4. Fostering of offshore fishing opportunities to alleviate pressure on inshore resources should be encouraged. Examples are the use of fish aggregation devices (FADs) by (non-motorised means) canoes and the improvement of access to fuel for fishers who use motorised boats.

5. The development of the aquaculture sector for example to increase the productivity of milkfish (Chanos chanos) culturing should be promoted.

6. A possible re-introduction of Giant clams (Tridacna maxima) for potential mariculture opportunities in Nauru.

7. An assessment of the potential development of a sustainable and feasible aquarium fish trade for the private sector with appropriate management measures.

Based on the ProcFISH findings the report clearly underscored the need for Nauru to urgently manage and conserve its coastal and marine resources.

\subsubsection{CBFM process}

The Fisheries Authority looked to the Secretariat of the Pacific Community (SPC) for assistance. SPC assisted Nauru in setting up its coastal fisheries management regime by establishing the community-based fisheries management (CBFM) programme that builds upon community systems and traditions. SPC's programme is taken from Samoa's fisheries management where Samoan communities have intact customary marine tenure (CMT) and own those adjacent coastal marine areas (King \& Lambeth, 2000). The Samoan communities are built upon social kinship and hierarchical structures of clans, where a traditional leader or chief is still regarded as the guardian of the land, inshore

\footnotetext{
${ }^{2}$ SCUBA is short for self-contained underwater breathing apparatus.
} 
areas and people living within the area. NFMRA and SPC worked together to introduce the district ${ }^{3}$ community-based fisheries management (CBFM) programme in Nauru.

Ropeti and Deiye (2006) conducted a preliminary assessment that consulted both members of the District Executive Committee/Council (DEC) and the larger community about the potential of the CBFM programme for Nauru. The findings of the assessment suggested that Nauru is a good candidate for the CBFM programme (Ropeti \& Deiye, 2006).

This section is an account of the author as the former SPC's national counterpart. A national workshop with community representatives from each district community in Nauru was jointly hosted by the Fisheries Authority and SPC. The purpose of the workshop was for the NFMRA staff and community representatives develop a model management plan. Secondly, to foster and develop relations between the NFMRA staff and community representatives who will be the potential contact within the district communities. Nauru's CBFM model is the template for the district CBFM plans. As part of the CBFM process community reps were informed if they had an interest to develop their own management plan they could by submitting a letter of interest from their leaders to the Fisheries Authority.

In 2007, SPC assisted NFMRA carry out its first-ever district workshop for Meneng community as a result of their community interest. The process used in the Meneng CBFM plan is discussed below and illustrated in Figure 5.

The CBFM Process (see Figure 5):

1. The District Executive Committee or Council (DEC) needs to express their interest to develop their CBFM plan to NFMRA. An initial meeting would be held between the NFMRA and DEC to formally express their interests in using the CBFM programme to manage and conserve their coastal marine areas. NFMRA would make the final decision whether to continue the process for the community.

2. NFMRA and the community are to determine the key problems, causes and solutions using the problem-tree approach through workshopping.

\footnotetext{
${ }^{3}$ Nauru is officially divided into 14 districts that form the basis of a democratic electorate where Nauruans are registered into a particular district at birth Thaman, R., \& Hassall, D. (1996). Republic of Nauru: National Environmental Management Strategy and National Environmental Action Plan. Apia: SPREP.
} 
3. A fisheries management committee (FMC) appointed by the DEC should help NFMRA prepare the CBFM plan. On completion of the District CBFM plan, it is presented back to the DEC for their final decision and approval.

4. This decision-making process can continue until the final CBFM plan is approved by the DEC.

5. The FMC is the community body responsible for monitoring and enforcing the undertakings in the fisheries management plan.

6. A set of community undertakings is an agreement that the community are held responsible for the activities under the fisheries management plan.

7. A set of NFMRA undertakings is an agreement that NFMRA should provide the technical assistance, such as enabling policies and generate research information as required by the community. NFMRA acts as an advisory body to the DEC.

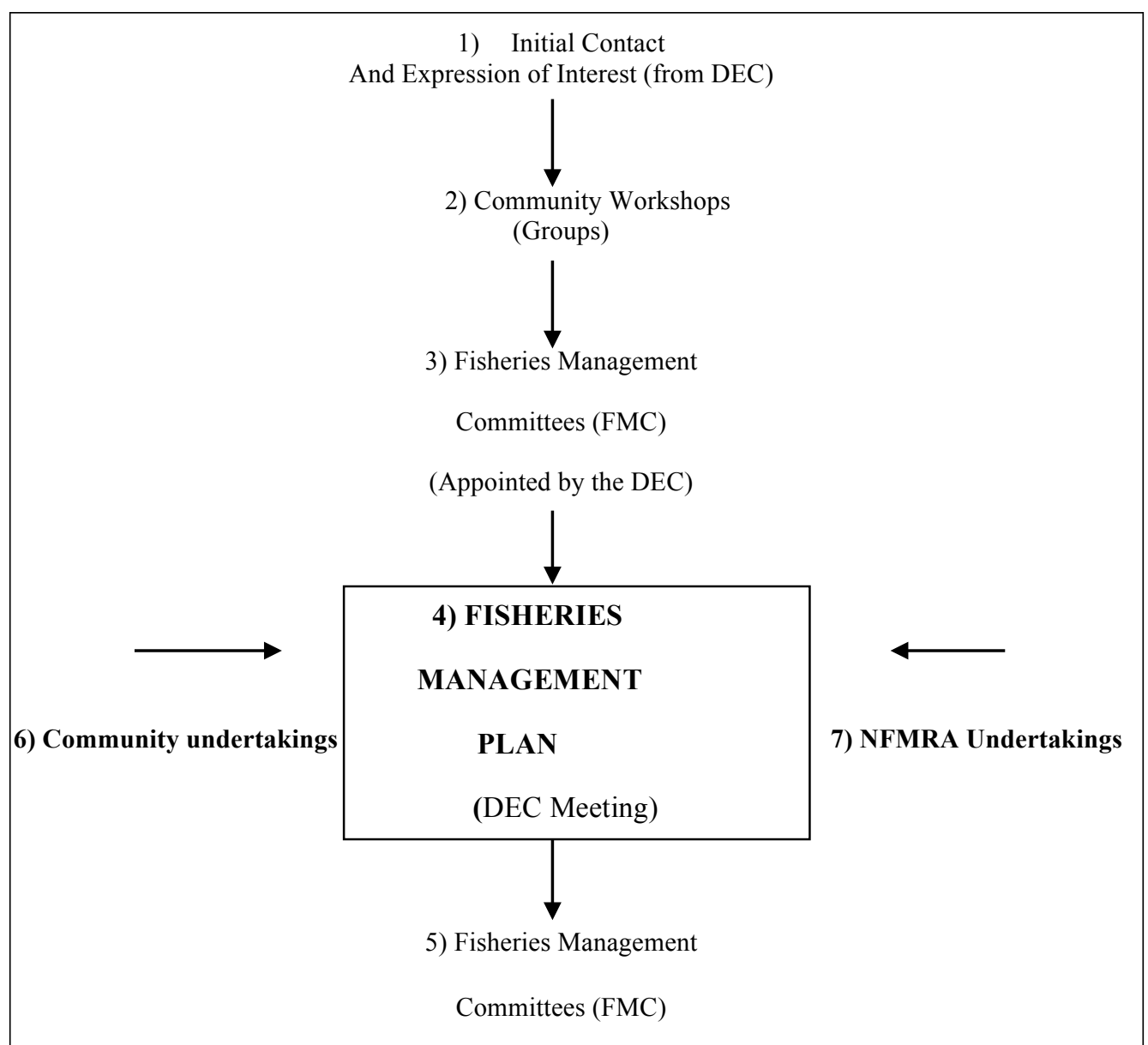

Figure 5: The CBFM process based on Nauru's CBFMP model (Deiye \& Tsiode, 2007) In this section, the author has taken a real example from the Meneng plan. One of the Fisheries Authority undertakings is to provide Meneng community fishers the opportunity 
to fish in near-shore areas and around the deployed fish aggregation devices (FADs) using non-fuel dependent means, for example fishers to use canoes rather than motorised boats. This action plan seeks to redirect the pressures of fishing to offshore fishing as an alternative to inshore fishing and is perceived to help alleviate the intensive fishing pressures on the coastal inshore areas. This is one tangible outcome of the Meneng community plan. SPC assisted NFMRA to source the funds and set up the canoe-building project. The project demonstrated the commitment of NFMRA to the communities.

As a result, the canoe-building project attracted the interests of other district communities who wanted to participate in the programme. However, on completion of the canoebuilding project, similar to most donor-dependent projects, NFMRA could not continue to source funds for the canoe project. One of the benefits of this project is that there is now a group of skilled locals in canoe building.

Ropeti and Deiye's (2006) assessment also identified the need for coastal fisheries law in order to support the CBFM programme. As a result, SPC hired a consultant to assist the Fisheries Authority develop and draft the coastal fisheries law for Nauru. This drafted law has remained with the Board of Directors and management (NFMRA) since its development and still remains subject for approval. This resulted in a new NFMRA policy established post drafted coastal legislation stating that for the Board of Directors to seriously consider the drafted coastal legislation, there needs to be at least 7 districts interested in participating in the CBFM programme (NFMRA, 2009).

In 2010, the author found on her return to conduct her fieldwork the Fisheries Authority had inducted five more communities with completed management plans totalling six district communities within three years. This high rate of induction could be attributed as a success of the programme and could even reflect the communities' interests and willingness to manage their coastal marine resources. The implementation part of the community management plans made little to no progress at all.

Before the author left for her post-graduate studies she assisted Meneng community's project application to implement one of its undertaking in its CBFM plan. The project application was to the Global Environment Facility-Small Grants Project (GEF-SGP) and submitted through the Nauru Island Association Non-Government Organisation (NIANGO). The project application was successful but on the author's return to conduct 
her fieldwork two years later, there was no progress. Based on the author's personal communication with a member of Meneng's DEC (in 2010), it appears there was a disagreement between the community representative and the NGO representative as a result of misunderstandings and miscommunication the project never started.

The Fisheries Authority since the author's fieldwork has acquired seven district communities out of the fifteen district communities who are interested to participate in the programme and have also completed the required seven district community-based fisheries management plans. NFMRA needs to revisit and consider legislating the drafted coastal law.

\subsubsection{District as drivers of the CBFM process}

The ProcFish report findings recommended that the coastal management regime should be controlled and managed by communities at scales larger than the current district boundaries (Vunisea, et al., 2008). While Ropeti and Deiye's (2006) assessment report suggested that district communities should be the drivers of the CBFM process. Both findings agreed that communities should be the drivers of the process and their point of departure is by the methods. This section clearly indicates the approach taken.

Districts in Nauru are the foundation of democratic electorate that represents sociopolitical units. Since 1951, Councillors were elected as members of the Nauru Local Government Council (NLGC) and since Nauru's Independence in 1968 Members of Parliament were also elected through this process (Thaman \& Hassall, 1996). While the former body was abolished in 1992, the latter are still elected under this process (ibid).

District community institutions have become the focal units for redistributing funds and resources, to the community such as small kitchen garden projects. These institutions are still very new and young. District community institutions have emerged as a result of a change in economic circumstances when the government could not provide and maintain welfare systems in place. With the $90 \%$ unemployment rate in 2004 (CIA, 2008), Members of Parliament (MP) began to inject support funds to their district constituencies respectively.

The legitimacy of these district community organisations has grown as institutions for community development and the DEC have become more resourceful. Sourcing of projects at national and international levels has been successful through government 
bodies and NGOs. For example, in 2008 one district community received a grant to set up a community piggery farm from the Food and Agriculture Organisation (FAO) food security project. DECs can be seen as replacing the former local councils, which were abolished in 1992.

Nauru is officially divided into 14 districts but has a distinct community straddling the districts of Denigomodu (Denig) and Aiwo, called Location. The Location settlement was a by-product of the mining industry. Location is comprised of apartment blocks ranging from one to two bedrooms that formerly hosted foreign labourers working in the mining industry. In 2000 to 2003, these foreign industry workers were repatriated to their home countries because of the cessation of the Nauru Phosphate Corporation (NPC), which had hired expatriate workers and could no longer pay for their services.

Since the repatriation of the phosphate labourers this has changed the resettlement patterns of the local population. Local people moved in, and Location has formed its own DEC and community organisation. Location continues to be perceived as separate from the district communities living outside the compound area. For example, the Nauru Bureau of Statistics along with the demographic and health survey (DHS, 2007) enumerated districts as primary sampling units (PSU). Location was recognised as a separate PSU. In addition to the 14 official districts, Location brings the total of communities to 15 PSUs in Nauru (Nauru, et al., 2009).

The Fisheries Authority took the opportunity to use the existing district communities to drive the CBFM programme based on notion that the districts are well-defined social units than any other social groupings in Nauru. It is argued using existing social mechanisms in place rather than creating new institutions increases the chance for success (Plummer \& Armitage, 2007).

\subsection{Challenges for a CBMC regime}

As highlighted earlier in this chapter there are many challenges facing Nauru in implementing its community-based marine fisheries management programme and moving beyond the management regime to a conservation regime may prove difficult at this time but be considered in the future. This section provides a summary of the challenges why Nauru needs to manage its coastal and marine resources: 
Nauru needs to meet the demands of its growing population by ensuring that food security is met, as fish is the main source of protein. This is stipulated as one of the goals of NFMRA in the National Sustainable Development Strategy (NSDS) 20052025 (Nauru, 2005a).

- Increased population growth and density, growing efficiencies in fishing gear and methods, and limited alternatives for cash income are perceived as the main factors influencing resource over-exploitation (Bell, et al., 2009; Kronen, et al., 2010).

- The pressures from a growing recognition that Nauru requires an effective coastal fisheries management and conservation regime in place (Jacob, 2005; Vunisea, 2007; Vunisea, et al., 2008). Sustainable fishing of coastal marine resources are essential to ensure the productivity and functionality of coastal habitats into the future (Seidel, 2009).

- Lack of coastal planning and development; poor infrastructure, land management practices and the lack of a waste management system in place (Thaman \& Hassall, 1996). All these factors could further exacerbate pressures on the coastal marine environment such as the problem of coastal erosion and pollution.

- Nauru clearly needs to review its existing body of legislation and regulation for coastal marine management and conservation (Jacob, 2005; Onorio \& Deiye, 2010; Thaman \& Hassall, 1996). The need to strengthen and enforce existing legislation. For example, the Littering Act of 1983 prohibits littering in coastal areas but this is not enforced (ibid). The NFMRA Act of 1998 recognises the ban on destructive fishing methods and NFMRA has the right to licence local fishing boats, but this has not been implemented to date. These two laws remain inadequate to support marine conservation programmes (Jacob, 2005).

- Other factors related to the political, economic and social climate in Nauru. It is well known in conservation and resource management literature that governments often do not believe that local peoples are capable 'stewards' of coastal marine resources. Governments find it difficult to accede or share power of management over natural resources (Hauck \& Sowman, 2003).

- Communities themselves play a critical role in the process. The author observed throughout the introduction of the CBFM programme that communities looked to their own interests, rather than recognise CBFM's real purpose, which is promoting sustainable use and practices. The loss of CMTs and TEK could also be attributed 
to the community's limited ability or capacity to manage and conserve their marine resources in Nauru.

\subsection{Nauru's institutional reforms and policies}

According to the United Nations Convention to Combat Desertification (UNCCD) report, Nauru's economy is facing and adjusting to a post-phosphate transition (UNCCD, 2003). As a way to meet the national circumstances in Nauru the government developed the National Sustainable Development Strategy (NSDS) 2005-2025 in partnership with its people and borne out of the economic crisis. The NSDS aims to seek sustainable improvement to the quality of life for the Nauruans (Nauru, 2009). The Government of Nauru has undergone a reevaluation of its fiscal policies and objectives, a review of its constitution and education and health reforms (ibid).

Government reforms have taken place over time, the 1996 NEMS report still remains as the first-ever national blueprint for national sustainable development, which has not been fully realised. For the NSDS since its publication in 2005, it has undergone a review in 2009 and based on the review, the findings show that Nauru has made progress and improved its circumstances. It highlighted that Nauru was able to transition from the economic crisis into a period of growth (Nauru, 2009).

As mentioned earlier Nauru has completed its National Biodiversity Strategic Action Plan (NBSAP) a broad-based framework for environmental action. The NBSAP strategy focuses on policy and planning to meet the international targets under the Biodiversity Convention. This plan proposes to decentralise environmental management to local communities.

Since the Nauru CBFM is inclusive of local communities in coastal marine resource management it is important to consider incorporating environmental management in the CBFM work programme and focus on marine biodiversity. Such a complementary approach involves cross-scale governance of environment and natural resources may work effectively for the case of Nauru. 


\section{Chapter 3}

\section{Literature review}

\subsection{Introduction}

This chapter draws from the vast international literature of common pool resources, community-based institutions, co-management and adaptive management arrangements to determine the success criteria. The concept of "success" is defined in this chapter to help focus the review.

This review uses the work of Ostrom (1990) and her design principles of common-pool resources (CPR) that have challenged Hardin's (1968) tragedy of the commons theory. Ostrom's work is not without its critiques. This review has taken into account those works that have critiqued Ostrom's work from Agrawal's (2002) enabling conditions to Cox and colleagues (2010) findings from 91case studies and Berkes (2006) work. The review also looked at the works of Pinkerton (1989), Pomeroy and colleagues $(2001,2007)$ on the preconditions for success in fisheries managment.

The review also looks at the management approaches from common-pool resource management, community-based, co-management, adaptive management and adaptive comanagement.

This chapter attempts to develop an evaluative criteria and approaches that can be applied to the case of Nauru.

\subsection{Defining 'success'}

Most studies identified that successful community-based institutions are "those that last over time, constrain users to safeguard the resource and produce fair outcomes"(Agrawal, 2002, p. 1650). It has been argued that community-based management systems are often taken to be successful based on their endurance and survival over periods of time rather than on their actual ability to promote conservation or sustainability (Berkes, 2006). Berkes (2006) poses a critical question: "Is the long-term survival of a community-based 
management system a good indicator of its sustainability?" This is critical for this study in determining the criteria and approaches for success in natural resource management.

"Success" refers to the ability of institutions to sustain common-pool resources (Agrawal, 2003), where common pool resources (CPRs) are defined as natural or man-made resources where exclusion is difficult or costly and yield is subtractable (Gardner, Ostrom, $\&$ Walker, 1990). An example of a CPR is the inshore fisheries where management is difficult and expensive to exclude people's access to the resource (in this case, the resource unit is fish). If one person removes all the fish from a CPR then this fish will not be available to others (Ostrom, 1990); it is a rival but non-excludable resource for harvest. For biodiversity conservation, the resource is for non-harvest, then the fish becomes a nonrival and largely non-excludable resource.

\subsection{Design principles and conditions for success}

Consider a group of people in a collective attempting to manage a CPR for optimal sustainable production of their natural resource. Ostrom (1990) stipulated that in order for this group to succeed, it must create institutions for collective action. Ostrom (1990) also stated that following a small set of design principles can help to create those institutions while allowing the group to avoid the common problems of creating institutions for collective action (Ostrom, 1990).

Ostrom (1990) proposed eight design principles based on her empirical studies examining CPR management (provided in Table 1). Cox and colleagues (2010) examination of 91 community-based studies used Ostrom's (1990) design principles to investigate their relevance since their introduction. The findings showed that Ostrom's (1990) principles remain relevant and arguably are becoming universal principles that are found in most successful and enduring CPR arrangements. The authors reformulated some of the design principles (Cox, Arnold, \& Tomas, 2010) for example the authors suggests that of Ostrom's (1990) eight design principles 1, 2 and 4 are two conditions rather than one (see Table 2). Further the review identified the level of support required for each of the design principles across the 91 case studies. The findings indicate that the strongly supported design principles are well-defined boundaries (1), congruent between appropriation and provision of rules and local conditions (2) and monitoring (4) while the rest indicates moderate support (Table 1). These findings are summarised in Table 1. 
Table 1: Ostrom's (1990) eight design principles and Cox et al's (2010) reformulation and their degree of support

\begin{tabular}{|c|c|c|}
\hline $\begin{array}{l}\text { Ostrom's (1990) Eight } \\
\text { Design Principles }\end{array}$ & $\begin{array}{l}\text { Reformulation of Ostrom's principles by Cox et } \\
\text { al (2010) }\end{array}$ & $\begin{array}{l}\text { Degree of support } \\
\text { for each principle } \\
\text { based on } 91 \text { cases }\end{array}$ \\
\hline \multirow[t]{2}{*}{$\begin{array}{l}\text { 1. Well-defined } \\
\text { boundaries }\end{array}$} & $\begin{array}{l}\text { 1A. Refer to individuals or households who have } \\
\text { rights to withdraw resource units from the CPR } \\
\text { must be clearly defined }\end{array}$ & Strong \\
\hline & $\begin{array}{l}\text { 1B. The boundaries of the CPR must be well } \\
\text { defined }\end{array}$ & Moderate \\
\hline \multirow{2}{*}{$\begin{array}{l}\text { 2. Congruence between } \\
\text { appropriation and } \\
\text { provision rules and local } \\
\text { conditions }\end{array}$} & $\begin{array}{l}\text { 2A. The appropriation of rules restricting time, } \\
\text { place, technology, and/or quantity of resource units } \\
\text { match the local conditions. }\end{array}$ & Strong \\
\hline & $\begin{array}{l}\text { 2B. The benefits gained by users in a CPR is to be } \\
\text { determined by appropriation rules that are } \\
\text { proportional to the amount of inputs required. } \\
\text { (Inputs could include labour, material, or money, as } \\
\text { determined by the provisional rules). }\end{array}$ & Strong \\
\hline $\begin{array}{l}\text { 3. Collective-choice } \\
\text { arrangements where most } \\
\text { individuals affected by } \\
\text { the operational rules can } \\
\text { participate and modify the } \\
\text { operational rules. }\end{array}$ & No revision & Moderate \\
\hline \multirow[t]{2}{*}{ 4. Monitoring } & $\begin{array}{l}\text { 4A. Have monitors present and actively check CPR } \\
\text { conditions and appropriator behaviour. }\end{array}$ & Moderate \\
\hline & $\begin{array}{l}\text { 4B. Monitors are accountable to or are the } \\
\text { appropriators. }\end{array}$ & Strong \\
\hline $\begin{array}{l}\text { 5. Graduated sanctions } \\
\text { include appropriators who } \\
\text { violate operational rules } \\
\text { are likely to be punished } \\
\text { using graduated sanctions } \\
\text { (depending on the } \\
\text { seriousness of the } \\
\text { offence) by other } \\
\text { appropriators or officials } \\
\text { accountable to these } \\
\text { appropriators, or both. }\end{array}$ & No revision & Moderate \\
\hline 6. Conflict-resolution & No revision & Moderate \\
\hline
\end{tabular}




\begin{tabular}{|c|c|c|}
\hline $\begin{array}{l}\text { mechanisms where } \\
\text { appropriators and } \\
\text { officials have quick } \\
\text { access to low-cost local } \\
\text { places to resolve conflicts } \\
\text { among appropriators or } \\
\text { between appropriators } \\
\text { and officials. }\end{array}$ & & \\
\hline $\begin{array}{l}\text { 7. Minimum recognition } \\
\text { of rights where the rights } \\
\text { of appropriators to devise } \\
\text { their own institutions are } \\
\text { not challenged by } \\
\text { external governmental } \\
\text { authorities. }\end{array}$ & No revision & Moderate \\
\hline $\begin{array}{l}\text { 8. Nested enterprises } \\
\text { where appropriation, } \\
\text { provision, monitoring, } \\
\text { enforcement, conflict } \\
\text { resolution, and } \\
\text { governance activities are } \\
\text { organized in multiple } \\
\text { layers of nested } \\
\text { enterprises. }\end{array}$ & No revision & Moderate \\
\hline
\end{tabular}


Numerous studies (Agrawal, 2002; Berkes, 2006; Cox, et al., 2010) have criticised Ostrom's (1990) design principles but Ostrom's work was instrumental in developing the model of institutional choice-theory or collective action theory that has helped advance our understanding of people's behaviour and actions in a collective.

Ostrom (1990) challenged Hardin's (1968) theory of the "tragedy of the commons" which has been the basis of our understanding of commons management for decades (Leathers, 2008). Ostrom found that people will choose to work cooperatively in managing the CPR under certain conditions, such as having their expected long-term benefits of cooperating to be greater than those of the long-term costs (Ostrom, 1990).

The study looks at other works that have elaborated Ostrom's design principles to develop a robust evaluative criteria and approaches for the case.

Agrawal's (2002) work synthesised the three works of Wade (1988), Ostrom (1990) and Baland and Platteau (1996) and Agrawal (2002) examined and compared them with other studies of the commons and developed 24 factors that will lead to success for a group of self-organised users in managing the common-pool resources (see APPENDIX). Agrawal (2002) also recognises that his work needs further systematic testing to draw out the importance of these factors and connect them to different variables in order to propose causal mechanisms.

This study does not refer to each of the 24 individual factors but rather looks at the four broad categories that Agrawal (2002) positioned these factors under: (1) resource system characteristics, (2) group characteristics (3) institutional arrangements and (4) external arrangements.

1. Resource system characteristics

The characteristics of a resource system need to be small in size and have well-defined boundaries conducive for management identified by Wade (1988) and Ostrom (1990). Agrawal (2002) argued that the two physical features of resource systems of relevance are the mobility and storage of a resource. Agrawal (2002) states that resource systems need to have low levels of mobility and storage. In addition, he suggests predictability of resource systems is important. He argues that this allows ease of management and conservation of resources if information is known and will help resource-users to anticipate and act proactively rather than in hindsight. 


\section{Group characteristics}

Characteristics of the group of resource-users that are favourable for sustainable management suggested by the three authors include small size, clarity of group membership, shared norms, social capital built upon successful past experiences, appropriate leadership and interdependence among group members. It is argued that heterogeneity of endowments and groups having shared common objectives of the resources is important (Baland \& Platteau, 1996). Some of the debated issues include group size, intra-community heterogeneity (Agrawal \& Gibson, 1999) and the lack of shared objectives in the use of the resources that may affect commons management. This would seem to be the case, as Agrawal (2002) suggested low-levels of poverty. Agrawal suggests that poverty plays a pivotal role in CPR management where population and market pressures may undermine the importance of local institutions. McKean (1992) study examined the historical experience of communities in managing Japanese forests. She found that rich and poor subgroups can support the commons institutions through shared norms and interdependence among users as a way that could help overcome the different levels (McKean, 1992).

\section{Relationship between resource and group characteristics}

Overlap of user-groups from the residential and resource location, where group proximity to the resource system can affect their use and demand of the resources. Equitable distribution or allocation of benefits from the commons resources is necessary for successful CPR management. It is argued that high levels of dependence on resource systems can also affect users' cooperative behaviour if their welfare is at stake (Pinkerton $\&$ Weinstein, 1995). Agrawal (2002) found that a gradual change to low-levels of demand on the resource system is necessary.

\section{Institutional arrangements}

Institutions are significant to the success of commons management. Institutions are conventions, norms, and formally sanctioned rules of a society (Vatn, 2007). The rules for management should be kept simple and easy to understand, locally devised and easy to enforce. Graduated sanctions should have low-cost adjudication and dispute resolution mechanisms where monitors are accountable to users, as stipulated in Ostrom's design 
principles (Ostrom, 1990). There should be an identification of "users" in resource management systems as there are extractive and non-extractive users. The former extract resource units from the resources and latter are those who enjoy the use of resources without subtracting from others' use and enjoyment of the resource (for example, swimming). The latter type of activity can also be referred to as non-rival use. Nonmarket values include active and passive non-extractive uses with respect to resource management systems. Rival uses include goods and services used in an activity such as fishing while non-rival is having a picnic on the beach. The passive-use values include existence values, where people appreciate the marine areas without using them; bequest values, where people may want, for example, the turtles to be available for others or their future generations, and option value, which is the value of retaining options for the future (Pearce, 1990).

\section{$\underline{\text { Relationship between resource characteristics and institutional arrangements }}$}

Social norms can work as incentives (Kahan, 2003) for monitoring systems and applying graduated sanctions. Costs can be further reduced if the institutional design allows resource users to participate in mutual monitoring. The argument is that graduated sanctions may not be required when strong social capital exists within the group (Welzel, Inglehart, \& Deutsch, 2005). Social capital is addressed later in this chapter.

\section{External environment}

Technology, markets and state governments can also affect CPR management. Introduction of technology such as efficient gear and extraction methods can affect management, so low-cost exclusion of gear and methods is required while time is taken to adapt to this new technology. Agrawal (2002) explicitly argues that limited attention was given to the external social, institutional and physical environment in these analyses. For example, demographic issues and market demand increase the pressures on resources and their management. The need to buffer the system from external market forces and to introduce graduated technology allows for institutional adaptation to take place. There have been a number of cases where conflict situations arise between the government and resource users because of external or exogenous factors that often occur outside the control of resource users, such as market institutions. The role of the state plays a significant role in CPR management but should not undermine local governance. The state needs to 
support the sanctions by providing the means through compensation or alternatives and diversification for conservation. This is needed to encourage "nested" levels of governance to support CPR management (Ostrom, 1990).

The primary critiques of Ostrom's design principles are summarised:

1. The design principles have been found to be incomplete (Cox, et al., 2010). It is argued that the design principles are only conditions or characteristics of the community or the institution and not what keeps an institution durable such as trust, legitimacy and transparency (Harkes, 2006). Agrawal (2002) highlights two problems, the first is that the design principles suffer from a lack of context that frames all local-level institutions. Secondly, the lack of attention given to the external environment or the factors of population pressures and market integration. Market integration has been known to affect cooperative behaviour (Bardhan, 2000) and that market forces can destabilise CPR arrangements (Klooster, 2000).

2. Ostrom's (1990) design principles are based on small-scale CPR management that cannot be scaled-up and generalised to regional or global commons (Berkes, 2006). Agrawal (2002) supports this concern by warning that conclusions from case studies and comparative studies of the commons may be relevant only to each case, and not suitable for general application.

3. Ostrom's design principles have also been argued to lack the historical, social and environmental embeddedness of actors and their perspectives and conceived actors as rational decision-makers (Agrawal, 2002; Cox, et al., 2010). The principles are not the "glue" that keeps institutions together. Moreover communities are not the coherent whole as alluded to in her principles, rather they are made of individuals that form a heterogeneous group (Agrawal \& Gibson, 1999).

4. Berkes (2006) recommends that local-level institutions need to expand and embrace these critiques, as commons research has focused on communities of resource users who are capable of solving exclusion and subtractable problems of the commons through their ability to limit access of outsiders and self-regulate their own use. Berkes (2006) states, "[There is a] need for commons theory to look beyond local-level community-based resource management (p.16). 
The critiques of Ostrom's work conveys the depth of work undertaken in the successes of common-pool resource management. The scholars in commons literature do not agree that enduring community institutions in the management and sustaining the common-pool resources necessarily require the same prerequisites or conditions and/or characteristics to succeed.

\section{Section Summary: The commons}

This section defined success as the ability of community-based institutions to sustain common-pool resources. The criteria for success was drawn from the theoretical and empirical works of Hardin's (1968) tragedy of the commons to Ostrom's (1990) eight design principles and model of institutional choice-theory or collective action theory to Agrawal's (2002) synthesis of common-pool resources. The critiques of Ostrom's design

principles suggest that these principles may not be relevant for general application to other cases (Agrawal, 2002) however it does not take away their significance in helping us understand the design principles behind a CPR management. Cox and his colleagues argues that Ostrom's design principles is best used as a diagnostic tool rather than a blueprint (Cox, et al, 2010), while Berkes critiques the limitation of Ostrom's principles and their application and suggests moving beyond local-level institutions. Berkes (2006) work moves beyond the local-level institutions.

\subsection{Co-management frameworks}

For this section of the review, upon reflecting on the existing gaps of common-pool resource management the study needs to look at the co-management approaches and their arrangements. Co-management model is of interest to Nauru' The study defines comanagement and its arrangements and then reviews the elements that make a comanagement successful in order to develop the evaluative criteria for Nauru's CBFM.

Co-management involves "the sharing of power and responsibility between government and local resource users"'(Berkes, George, \& Preston, 1991, p. 12). Co-management is a variation of what governments define as group rights that govern inter-group interactions, while local organizations govern interactions among the members within particular groups 
(Swallow \& Bromley, 1994). Co-management involves a restructuring of state management to institutionalise collaboration and cooperation between resource users and governing bodies (Baland \& Platteau, 1996). Sen \& Nielson (1996) argues against those cases that do not include governments in the decision-making processes because comanagement is an arrangement where the responsibility for resource management is shared between governments and user groups. The difference between CPR and comanagement arrangements is that in the latter governments are involved in the arrangements that includes another institutional level of resource management (Sen \& Nielsen, 1996).

Gavin, et al (2007) offers a simplified version of the complex situations that can occur within the co-management model (Figure 6). The model illustrates the types of the different arrangements that can exist between government or a non-local NGO and the community. Figure 6 depicts a broad spectrum of existing possibilities of the relationships in a co-management framework where at the lower end of the continuum protectionist forms of conservation such as external agents (i.e. government) instruct communities about management rules. In the middle of this spectrum are collaborative arrangements where both external agencies and communities share power and responsibilities. The more participatory management models are found in the upper part of the continuum. The significance of this model is that it helps break down much of the complexity of the interactions that occurs in the co-management arrangement and provides a view of arrangements that can help to identify those factors and enable conditions influencing successful decentralised management.

Plummer and Armitage (2007) argue that co-management is a novel governance arrangement that fosters sustainable development. For some countries or communities comanagement can replace state and market-based incentives. However co-management can be a slow process to build upon which is largely dependent upon the local context. If locallevel institutions were intact prior to introducing the co-management approach then the management framework would only involve a merging of institutions without creating whole new institutions. Moreover the authors argued that a co-management approach provides the opportunity for appropriate decision-making process that can access all types of knowledge and further enhance legitimacy of community objectives and actions in resource management. The credibility of the co-management framework lies in 
transforming decision-making processes towards a participatory democracy that encourages accountability (Plummer \& Armitage, 2007).

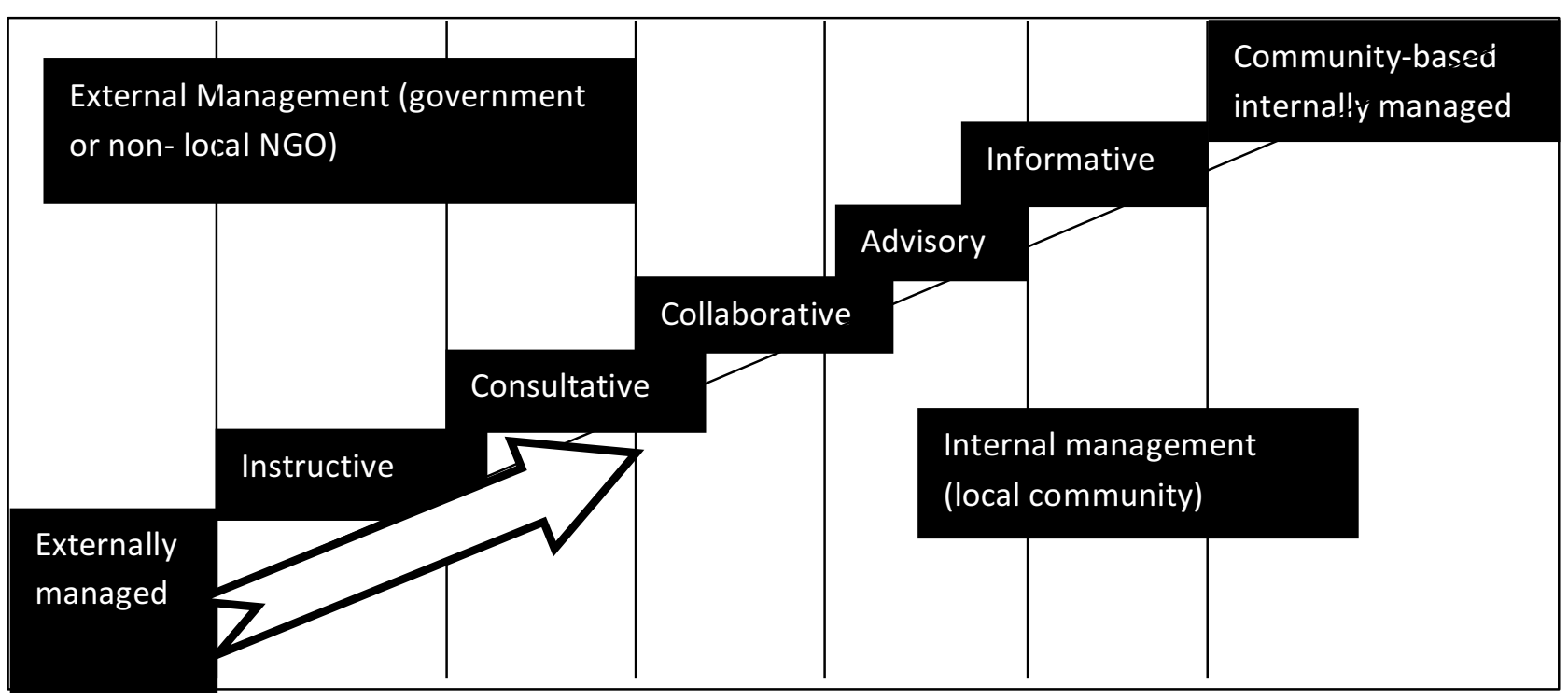

Figure 6: Co-management model [taken from (Gavin, Wali, \& Vasquez, 2007, p. 60)]

Empirical studies in co-management literature have identified that there exists a set of preconditions or conditions that can enhance positive outcomes in resource management beyond the local-level. For example, the empirical work of Pinkerton (1989), Pomeroy (2001) and colleagues (2007) in fisheries management have made critical progress in looking at such conditions for successful co-management arrangements.

The works of Pinkerton and Pomeroy is important to this study because they focus on fisheries management which is relevant to the case including those conditions required to make the co-management a success- its governance, the processes and their arrangements.

\subsubsection{Pre-conditions for success}

Pinkerton's (1989) work identified those pre-conditions for success in the co-management and based on her findings Pinkerton points out that success in a co-management rests on relationships among human actors that are nurtured by the formal institutions and informal arrangements that makes these relationships possible (Pinkerton, 1989). Pinkerton's (1989) work and focus is different from Ostrom (1990) in that she deals with commons management at two or more levels. Berkes (2006) on the otherhand supports Pinkerton's work multi-dimensional approach and states that there are a number of diverse institutional forms of multi-level commons. 
The next section identifies those pre-conditions Pinkerton found in order for the comanagement to work overlapping with Ostrom's design principles.

\section{Management functions and their purpose}

Pinkerton's work linked the benefits of co-management to the functions of resource management such as: (1) Data gathering, (2) decision-making on who can harvest and when, (3) allocation decisions, (4) protection of resources from environmental damage, (5) enforcement regulations (6) enhancement of long-term planning and (7) inclusive decision-making processes.

Pinkerton (1989) found that there are two key management functions that have contributed to the success in community-based development: 1) enhancement and planning and 2) habitat protection. These two functions have been instrumental in creating the opportunities for fishing communities to influence their own development and prevent further destruction of their resources.

2. Some of the pre-conditions for successful co-management

a) Management has to be developed out of a real or imagined crisis such as stock depletion

Based on Cohen's (1986) study of the co-management of US Pacific Northwest salmon between the Indian tribes and Washington State, stock depletion drove the two groups of people to engage in the management process. The crisis created the opportunity for the two groups (state and community) to come together to manage and conserve the salmon. Both groups shared the same objectives, for example the desire to protect and conserve the salmon stock in crisis that led to a novel governance arrangement (Cohen, 1986). Shared objectives for the resource is mentioned in Agrawal's (2002) group characteristics.

b) Agreements need to be formalised, legal and multi-year

Using legal and formal multi-year agreements are based on the principle of equity and these enhance legitimate objectives and actions in the management as stipulated earlier by Plummer and Armitage (2007).

c) Have a mechanism for wealth generation to be recirculated back into the communities 
Pinkerton (1989) proposed that should be a mechanism for wealth generation to be recycled back into some of the communities based on shared benefits. One of Ostrom's (1990) strongly supported design principle 2B stipulates that benefits obtained by users should be proportional to the amount of users' inputs and these inputs can take many forms from labour to money. The notion that communities can benefit from participating in management of the resource can help provide the incentives for individuals to act in a collective.

d) Have a mechanism for conserving and enhancing a fishery while at the same time conserving and enhancing the operation of a cultural system

Monitoring of the resources is a mechanism for conservation but Pinkerton recognises the need to enhance cultural systems at the same time. This further supports the notion that indigenous groups' traditional knowledge should be infused into resource management. There should be the acknowledgement that other forms of knowledge can be used in the decision-making processes for resource management.

e) Management operates best where external support can be recruited such as scientists or universities

External assistance such as scientists and universities was identified as important to the development of the resource management and this was illustrated in Cohen's (1986) work where the fisheries scientists and communities both shared information that further enhanced the salmon stock recovery. Based on the findings research and development ( $R$ $\& \mathrm{D})$ is important in enhancing the co-management arrangement.

f) Size of the government bureaucracy is small and has a local mandate

Pinkerton identified that the size of the state governing body should be small with a local mandate to allow the fostering of inter-group interaction so local-level issues are addressed more effectively. The designs principle in CPR management identified that a small size of a group can lead to successful community-based management. Pinkerton (1989) suggests that the size of the state involved in the co-management arrangement should be small with a local mandate. These characteristics relate to matching the scale of state management to the group and resource systems involved in the co-management arrangement.

\section{Some of the group characteristics for those who will succeed in a co-management}


Pinkerton's (1989) group characteristics identified are similar to those highlighted previously in Agrawal's (2002) work on group characteristics. One of particular interest is Pinkerton's suggestion for:

- Creating an energy centre where a dedicated person or core group applies consistent pressure to keep the momentum going and to make the co-management work.

An observation of Pinkerton's work on group characteristics is her failure to elaborate on how harvest and non-harvest interactions operate within the institution and focuses only on resource users (such as fishers) and the state.

\section{Emerging roles of actors in co-management}

Pinkerton (1989) pointed out that successful cooperation will lead to the commitment of groups to co-management. A successful negotiation process enhances the position of communities that will develop into a mutual commitment. There are two outcomes of the process: a) creation of the willingness between the diverse interests of multiple users and the state and b) creation of a higher degree of trust between the groups in the arrangement. Overall, Pinkerton's work (1989) can be seen to overlap the work of Ostrom's (1990) and Agrawal's (2002). It is logical that the success criteria of community-based institutions in resource management overlaps between common-pool resource management and comanagement approaches, however Pinkerton's work is a multi-level approach.

The review takes into account the work of Pomeroy and colleagues (2001) who identified 18 conditions that have been found in the success of co-management-based arrangements in fisheries management which was a part of a research project in Asia. The authors stipulated that these 18 conditions are found within the three distinct levels of community (Table 2). Pomeroy et al's (2001) categories are as follows:

1. Supra-community level conditions that include those external to the community such as enabling legislation, supporting administration at the national level and market forces.

2. Community level conditions including the physical and social environment of the community's relationship with fisheries and coastal management. 
3. Individual and household level conditions where the individual is responsible for making the decision to carry out co-management decisions. The decisions and behaviour of individuals or households are central to the success of comanagement.

Pomeroy and his colleagues' use a different approach to develop the conditions identified. Their work takes into account the contextual variables of the comparative cases in fisheries management in Asia. Earlier in this chapter the concept of communities and external factors have been identified as lacking in Ostrom's (1990) design principles as mentioned by Agrawal (2002). Table 3 provides a summary of the different community levels identified by Pomeroy and colleagues and the 18 conditions affecting the co-management compared to the works of the others previously mentioned in this chapter.

Moreover, Pomeroy (2007) expanded his work from Asia to Africa and the wider Caribbean on adaptive management as a key development in the co-management framework (Pomeroy, 2007). He suggests that Ostrom and Pinkerton's work have been critical to identify those conditions for sustainable community governance of the commons and his work identified key conditions for successful implementation in a co-management (ibid). 
Table 2: Pomeroy and colleagues $(2001 ; 2007) 18$ conditions for successful co-management [adapted from (Pomeroy, 2007; Pomeroy, Katon, \& Harkes, 2001)]

\begin{tabular}{|c|c|c|}
\hline $\begin{array}{l}\text { Level of } \\
\text { institutions }\end{array}$ & $\begin{array}{l}\text { Eighteen conditions affecting successful co- } \\
\text { management }\end{array}$ & Similar to the works of: \\
\hline \multirow[t]{3}{*}{$\begin{array}{l}\text { Supra-community } \\
\text { level }\end{array}$} & Enabling policies and legislation & $\begin{array}{l}\text { Pinkerton (1989), Agrawal } \\
\text { (2002) }\end{array}$ \\
\hline & External agents & $\begin{array}{l}\text { Agrawal (2002), Pinkerton } \\
\text { (1989) }\end{array}$ \\
\hline & Alliances and networks & Ostrom (1994) \\
\hline \multirow[t]{15}{*}{ Community level } & Appropriate scale and defined boundaries & Ostrom (1990) \\
\hline & Membership is clearly defined & $\begin{array}{l}\text { Ostrom (1990) as revised by } \\
\text { Cox et al (2010) }\end{array}$ \\
\hline & Participation by those affected & $\begin{array}{l}\text { Ostrom (1990), Pinkerton } \\
\text { (1989), }\end{array}$ \\
\hline & Leadership & \\
\hline & $\begin{array}{l}\text { Empowerment, capacity building and social } \\
\text { preparation }\end{array}$ & $\begin{array}{l}\text { Pinkerton (1989), Berkes } \\
\text { (2001) }\end{array}$ \\
\hline & Community organizations & Ostrom (1990) \\
\hline & $\begin{array}{l}\text { Long-term support of the local government unit } \\
\text { and political elites }\end{array}$ & Agrawal (2002) \\
\hline & Property rights over the resource & $\begin{array}{l}\text { Ostrom (1990), Pinkerton } \\
\text { (1989) }\end{array}$ \\
\hline & Adequate financial resources/budget & \\
\hline & $\begin{array}{l}\text { Partnerships and partner sense of ownership of the } \\
\text { co-management process }\end{array}$ & Pinkerton (1989) \\
\hline & Accountability & Pinkerton (1989) \\
\hline & Conflict management mechanism & Pinkerton (1989) \\
\hline & Clear objectives from a well-defined set of issues & $\begin{array}{l}\text { Pinkerton (1989), Agrawal } \\
\text { (2002) }\end{array}$ \\
\hline & Management rules enforced & Ostrom (1990) \\
\hline & Knowledge of resource & $\begin{array}{l}\text { White et al (1994), } \\
\text { McConney and colleagues } \\
(2003) \text { and Gehab and Sarch } \\
\text { (2002) }\end{array}$ \\
\hline \multirow{2}{*}{$\begin{array}{l}\text { Individual and } \\
\text { household level }\end{array}$} & Individual incentive structure & Pomeroy (2001) \\
\hline & Benefits exceed costs & $\begin{array}{l}\text { Ostrom (1990) collective- } \\
\text { action theory }\end{array}$ \\
\hline
\end{tabular}


This study considered the findings of Pomeroy and colleagues (2001) and has highlighted those conditions important to the case study: (1) enabling policies and legislation, (2) leadership, (3) adequate financial resources, (4) knowledge of resource and (5) an individual incentive structure.

\section{Enabling policies and legislation}

As described in Chapter 1, one of the challenges in Nauru is for the government to establish enabling policies and supporting legislation for the co-management initiative to be successful. Pomeroy and colleagues (2007) highlight the issues that governments need to address in such an arrangement. The legislation itself needs to indicate jurisdiction and control, provide the legitimate communal rights to the district community for decisionmaking processes, the needs to be clear rights and responsibilities of partners in the process, the need for support to local enforcement and accountability mechanisms and the local groups need to have the right to organize themselves, make the rules and legitimize their participation in the management.

\section{Leadership}

Leaders need to direct others and provide the energy to set the course of action. Agrawal (2002) highlighted the need for good leadership skills for community-based institutions to function effectively as discussed earlier in this chapter. The work of Berkes and his colleagues (2003) investigated how an adaptive co-management emerged in Sweden. They found that it was one individual who had a vision and goal was instrumental in shaping the management of the wetlands from a reserve to a Man and the Biosphere (MAB) reserve Berkes, Colding, \& Folke, 2003). Their findings showed that the key driver for the change was a devoted individual with leadership qualities (Deiye, 2010; Olsson, Folke, \& Hahn, 2004).

Marschke and Berkes (2005) examined Cambodian villagers' perceptions of sustainability from two resource management committees. They identified that villagers were willing to engage in community-based management process only if they believe that their livelihoods were going to improve. The current community-based management was being carried without formal legalisation but with recognition from the authority. The findings suggested the local level support, leadership and the creation of political space for learning were identified as the key drivers of the process in Cambodia (Marschke \& Berkes, 2005). 
3. Adequate financial resources and budget

Pinkerton alluded to finances as enhancing the success of a co-management and in the works of Pomeroy et al (2001) (2007) they identified that sufficient sustained funding in a timely manner is critical to the success of the co-management.

4. Knowledge of a resource

Pomeroy et al (2001) highlighted the significance of communities' knowledge of the resources if communities assume responsibilities in the co-management. It is argued that communities' knowledge and perception of the resources needs to be understood (Gehab $\&$ Sarch, 2002). The likelihood for successful co-management arrangements will take place if local communities have good traditional knowledge, practices and tenure systems (White, Hale, Renard, \& Cortesi, 1994). More discussion about the forms of traditional and local knowledge in resource management is addressed later in this chapter.

\section{Individual incentive structure}

Similar to that of Ostrom's collective action theory, the motivation of individuals to participate in CPR management is important. Pomeroy and colleagues (2001) argue that the incentive structures of an individual are not just affected by the economic means but also by social and political influences. Stakeholders expectations are high so any unmet expectations can lead to an unwillingness to participate in resource management (Sverdrup-Jensen \& Nielsen, 1998). Some incentives may not drive individuals to participate in the process as McConney and colleagues (2003) findings suggested the need for individuals to have some level of personal gain from their participation (McConney, Pomeroy, \& Mahon, 2003).

\section{Summary: Co-management}

Scholarship in commons management has embraced the conclusion that there are limitations to the lessons learned from the study of local level systems because in reality, resource management systems are not static and "they go through cycles of crisis of recovery and of institutional renewal" (Berkes, 2006, p. 45).

It is argued that co-management can support those enabling institutions by creating a participatory democratic process in resource management. There are different levels of interactions between communities, government and external agencies. Pinkerton's (1989) 
pre-conditions to Pomeroy and his colleagues' work (2001) (2007) suggest conditions that complement the overall requirements for successful and durable community-based institutions in varying degrees. Nevertheless, these theories of community-based management do not guarantee that such institutions can sustain the common-pool resource.

\subsection{Concepts in community-based co-management}

This section of the review considers some of theories that have been highlighted throughout this chapter and found relevant for further elaboration for this the study.

1. Social capital (SC) theory

2. Communities as complex systems

3. Knowledge systems including Traditional Ecological Knowledge (TEK)

\subsubsection{Social capital theory}

Putnam (2001) defines social capital (SC) as "the features of social life - networks, norms, and trust - that enable participants to act together more effectively to pursue shared objectives and refers to social connections and the attendant norms and trust" (Putnam, 2001, p. 3). Key elements such as trust, shared norms, networks and neighbours are characteristics of social capital (Fukuyama, 2001). SC is also seen as the resource of networks and connections of an individual (Bourdieu, 1986; Coleman, 1990). It can act as a resource for an individual in the metaphorical sense with the concept of 'who you know' as opposed to 'what you know'(Lin, 2001). SC lies in the relations of individuals (Lin, 2001), groups and organisations (Coleman, 1988; Ostrom, 1994; Ostrom \& Ahn, 2003).

Social capital (SC) theory is of interest to this study because it has the capacity to translate community ties into collective action (Welzel, et al., 2005). Ostrom (1994) suggests that social capital can provide the universal answer to "what keeps societies together and leads individuals to act for collective goals?" (Ostrom, 1994; Welzel, et al., 2005, p. 122). Welzel and colleagues (2005) study illustrated the concept of social capital in three areas: what it needs, what it is and what it does (see Figure 7). It is useful to unpack the complexity of social capital (SC).

Figure 7 shows that SC needs to operate on having community ties as highlighted by its definition - social networks and group identities. SC also needs "translators" such as 
resources (material and intellectual) to enable a group of people to turn their ties into collective action. Norms and institutions are extrinsic values that can encourage people to use their ties for collective action (Welzel et al 2005). Welzel and colleagues' (2005) study found that value orientations such as self-expression are powerful intrinsic motivator that can stimulate people to invest their ties into collective action. The authors further conclude that SC comprises: resource-based capabilities, institution-based incentives and valuebased motivators. The product of SC is collective action in a society where frequent and widespread forms of collective actions are found. This indicates that productive features can follow from SC: transparency, reliability, accountability, responsiveness, openness and efficiency (see Figure 7) (ibid).

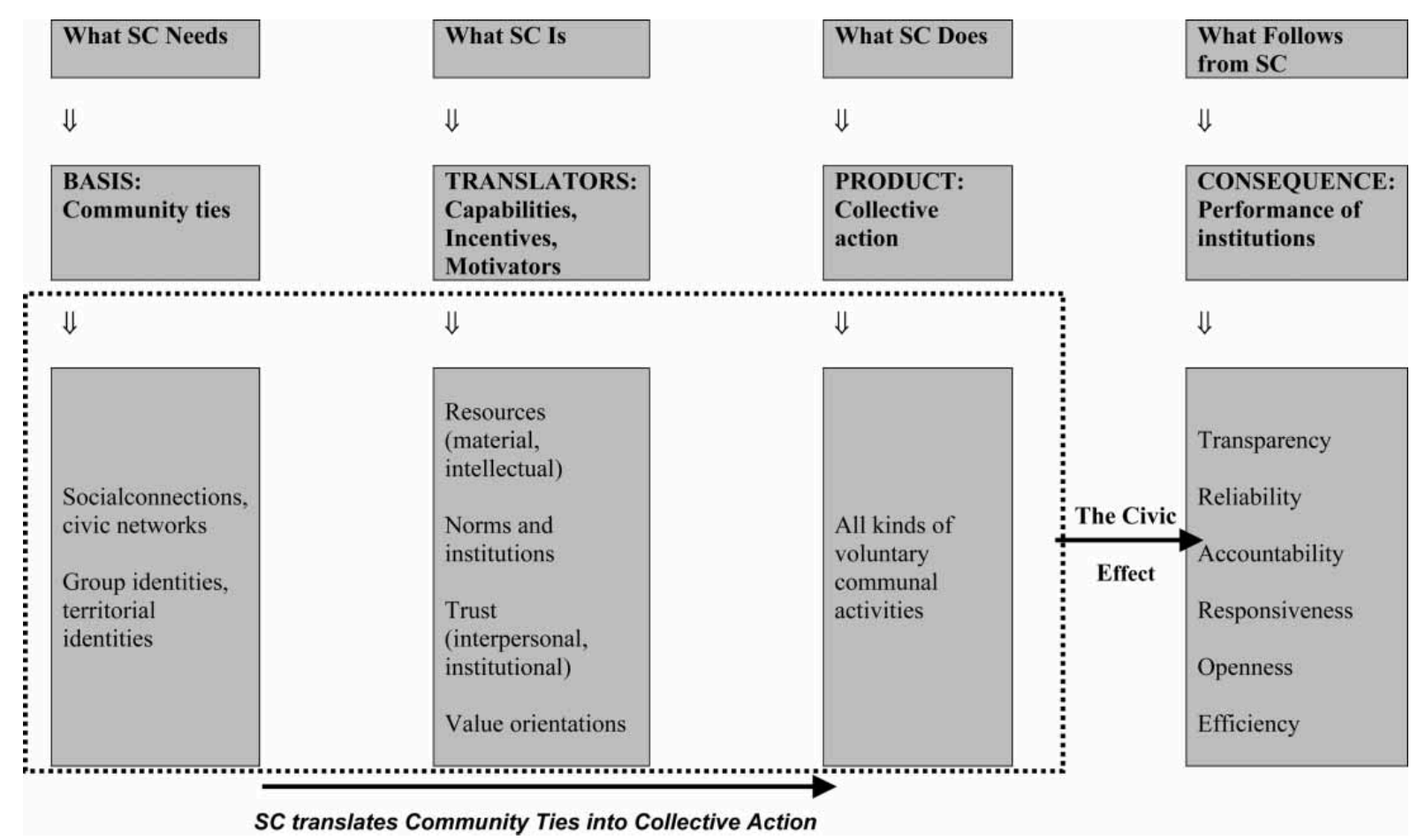

Figure 7: Distinguishing the concepts of social capital [taken from (Welzel, et al., 2005, p. 141)]

Trust has been known to better promote cooperation among people than imposed material incentives (Kahan, 2003). It is argued that various forms of trust can also lower transaction costs when using community ties to initiate collective action (Welzel et al 2005). Trust and reciprocity are critical in the link between social capital and successful collective action (Ostrom \& Ahn, 2003; Ostrom \& Walker, 2003). Developing trust in a co-management arrangement provides the opportunity for emerging roles of actors and new relationships. As Pinkerton (1989) succinctly puts it (see Appendix 2): 
- Greater trust between users and the state develops a greater sense of control by users, which in turn reduces their motivation to invest in competitiveness or free riding.

- Higher degrees of trust between users and the state improve the ability to develop and implement enforcement regimes.

- Higher degrees of trust between users and the state increase the willingness of government to allow users to self-manage.

Harkes (2006) proposed that trust, legitimacy and transparency in CPR management are the "glue" that sustains communities in natural resource management. If there is a lack of legitimate rights, equity and distribution of power among the members of the community this can affect individuals' ability to act collectively. Both Pomeroy (2007) and Pinkerton (1989) address these concerns. The former suggests enabling policies and legislation, the latter highlights that co-management arrangements should have a formal multi-year legal agreement or contract between the actors. This makes the roles of each actor transparent and legitimate in the management of natural resources between the state and user groups involved.

Pomeroy's (2007) work, as discussed earlier, embraced social capital by identifying multilevel institutions in developing those conditions for a successful co-management arrangement: from individuals to community to supra-community levels. While Agrawal (2002) and Pinkerton's (1989) work highlighted those elements of social capital based on the group characteristics such as shared norms, a cohesive social system of kinship and nested enterprises or multilevel governance as part of the social capital networks. Social capital theory provides the structures of how groups behave cooperatively and noncooperatively in community-based management. Using and understanding social capital can enhance the chance of success in community-based management.

\subsubsection{Communities as complex systems}

One of the critiques to Ostrom's design principles is the assumption that communities are seen as a coherent and cohesive group. Pomeroy's (2007) work identifies the diverse individual interests found in any given community and how this can affect their cooperative interactions in resource management. Agrawal \& Gibson (2001) warn against having such assumptions and idealistic perceptions of communities, which are:

1. Communities possess the knowledge to conserve their resources because they have lived in the area and have been dependent on the resources historically. 
2. Communities who are not involved in management or conservation are assumed to use the resources destructively, therefore should be involved in resource management and conservation projects.

It is argued that researchers often make the following assumptions about a community (Agrawal \& Gibson, 2001):

- They are small spatial units, meaning smallness in area and number of individuals who are place-based.

- They have a homogenous social structure, with the presumption there are lesser conflicting interactions within the group and greater promotion of better resource management outcomes.

- They share norms and common interests about resource use. Shared norms can also lead to environmental degradation and exploitative behaviour or resisting change.

Agrawal and Gibson (2001) further argue that research needs to take a realistic and accurate view of communities and their relationship with the natural resources. A community is:

- Made up of multiple actors with multiple interests, and actors who attend to their own interests, which can change with the changing circumstances.

- Processes through which people interrelate at the local level, and between the local level and outside agencies, including government.

- Formal and informal rules and norms that shape people's interactions with each other and nature.

Additionally, Berkes (2006) states that communities are: “Complex systems embedded in larger complex systems hence Community-based Resource Management (CBRM) systems need to deal with cross-scale governance and CBRM systems need to deal with external drivers of change, such as markets, central government policies, international economic policies ("globalization”) and donor policies" (p.16).

Agrawal and Gibson (1999) also established that a community is not an organic whole but rather a group of multiple actors with different interests. This has led to our understanding that communities are complex systems embedded in larger complex systems. The recognition that local-level systems are connected to other networks and multiple forms of 
institutions can influence and affect what happens in community-based management is critical to this study.

Social-ecological systems (SES) ${ }^{5}$ embrace different forms of knowledge and not just conventional science that can enhance the success of communities in natural resource management. Traditional Ecological Knowledge (TEK) is defined, "as a cumulative body of knowledge, practice, and belief, evolving by adaptive processes and handed down through generations by cultural transmission, about the relationship of living beings (including humans) with one another and with their environment" (Berkes, Colding, \& Folke, 2000, p. 1252). The shorter definition of TEK is " a knowledge-practice-belief complex" (Berkes, 1999). TEK is useful and significant where minimum scientific information is available about the resources or the resources are too complex to understand and where data collection is too costly. TEK could possibly help communities participate in resource monitoring and act as a capacity-building process in community-based comanagement.

It is suggested that local knowledge in resource management can strengthen collective action through shared norms and objectives (Berkes, 2002). Pinkerton (1989) identified that traditional management practices by the indigenous American Indians in the management of salmon stock were effective despite the fact conventional science was slow in response to address the changes in the resource. TEK arguably is seen as a form of knowledge that can improve resource management and enhance communities' capacity to manage their resources with the current era of environmental uncertainties (Deiye, 2010; Dowsley, 2009). Pomeroy and colleagues (2007) study also supported local knowledge to be incorporated in resource management. However, Agrawal and Gibson (2001) argue that the assumption that local people possess the knowledge to manage the resources because they have lived and use the resources for years needs to take a cautionary approach, as not all forms of local knowledge are relevant for effective resource management.

\section{Summary: Community-based co-management concepts}

A greater acceptance that there are different forms of knowledge and not only conventional science can enhance the role of communities in resource management. The growth in our understanding that ecosystems are complex systems (Capra, 1996) has led to a greater

\footnotetext{
${ }^{5}$ Social-ecological systems (SES) are integrated, coupled systems of people and environment Armitage, D., Berkes, F., \& Doubleday, N. C. (2007). Adaptive Co-Management: Collaboration, Learning and Multi-Level Governance. Vancouver: UBCPress. p. 330.
} 
appreciation in formulating management frameworks to adapt to the changes, uncertainties and newly acquired information gained in research (Olsson, Folke, \& Berkes, 2004). Recent research in the literature of adaptive community-based co-management has emerged linking social learning and social capital to embrace complex SES. The premise for linking social learning and social capital is that these concepts overlap each other and are found pertinent to environmental management frameworks (Plummer \& FitzGibbon, 2007).

\subsection{Alternative models of management}

For some cases, TEK serves an adaptive co-management (ACM) best (Berkes, Mahon, McConney, Pollnac, \& Pomeroy, 2001). ACM has been defined as flexible communitybased systems of resource management tailored to specific places and situations, supported by and working with, various organizations at different levels (Berkes, et al., 2003). To understand the key concepts of ACM, one needs to understand how an adaptive management (AM) became integrated with co-management. AM is a framework that supports a learning approach (Holling, 1978), and was developed to deal with uncertainty in resource management and seen to produce effective policies that can be found in restoration projects for endangered species (Deiye, 2010; Walters, 2007). Some of the features of AM include reflexive learning and embracing complexity and variability (Allan $\&$ Curtis, 2005; Deiye, 2010, p. 60). ACM combines both concepts of AM and comanagement (Armitage et al., 2009), where the combination of a learning framework to adapt to uncertainties in sharing the responsibilities in resource management that involves government, resource-users (harvesters) and (resource-based) communities (Charles, 2007) (Figure 8).

At the beginning of this chapter Berkes (2006) posed the critical question, "Is the longterm survival of a community-based management system a good indicator of its sustainability?" Adopting an ACM approach is perceived as the means to enhance the sustainability $^{6}$ and resilience ${ }^{7}$ of a "healthy" natural resource system (ibid). Charles (2007) identified four components of ACM:

\footnotetext{
6 "Sustainability is defined as management that promotes resource stewardship that builds or maintains system resilience over the long-term." "[sic]", p.330

7 "Resilience is the ability of a system to absorb or rebound from disturbance without shifting to another different system configuration" (ibid p.331).
} 


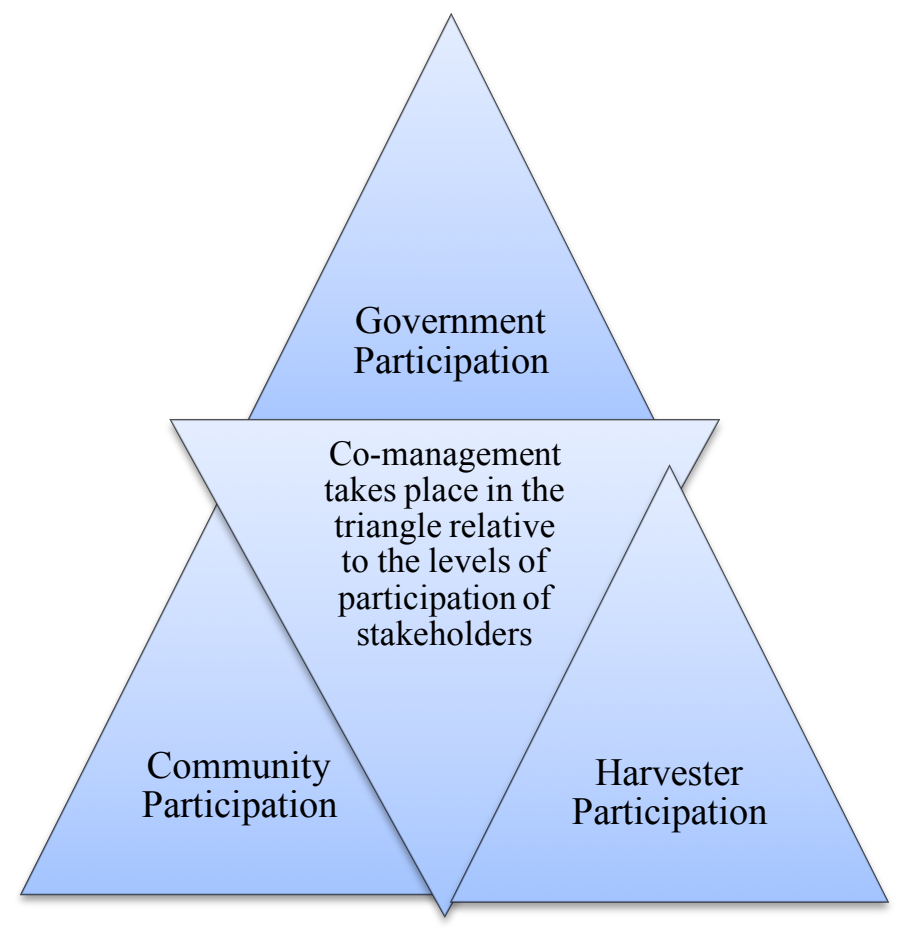

Figure 8: Co-management triangle [adapted from Charles, (2007) p.90]

1. Having a diverse "toolkit" of possible management measures and their appropriate "portfolio" for adopting the measures

The management portfolio is a set of management measures that can be either input or output controls, for example having license and permits to limit access to the resource and having catch limits in a fishery. The choice of management measures should be mutually reinforcing when selecting the right choice of tools to be used. This is crucial for successful resource management. The use of protected areas could be a part of the toolkit to protect or restrict access to the resources. The notion of a diverse toolkit enables a community to adapt, replace or supplement measures for others in order to improve the prospects to achieve sustainability and resilience of the resource system. A learning-bydoing approach should be taken with the goal of improving the future of the resource management.

\section{Pursuing a robust management}

Robust management of a resource system is designed to be able to achieve a level of performance under the given conditions (such as the status of the resources and inability to control resource exploitation) (Charles, 2001). Charles (2004) argues that there are two counter-tendencies found in resource management systems: 
i. The illusion of certainty where policy, management and practices operate with a false sense of certainty and predictability.

ii. The fallacy of controllability is the perception that if more can be known then more can be controlled.

The author suggests that for robust management, rethinking away from these tendencies and focusing on using decision-making tools such as the ones that the Food and Agriculture Organisation advocates, the precautionary (FAO, 1996) and ecosystem approach (FAO, 2003) is needed (Charles, 2004).

3.Full use of all forms of knowledge in the resource system As highlighted earlier there are diverse forms of knowledge in resource systems such as conventional science, TEK and local knowledge. These forms of knowledge should be seen as tools in the system. Charles (2007) suggests the need for a continued update of the knowledge base, which is a key element of adaptive management. The knowledge base should be maintained, regenerated and reinforced with the inclusion of communities involved in the monitoring and management. Again, both Pinkerton (1989) and Pomeroy (2007) earlier stipulated knowledge as one of their conditions to successful comanagement.

\section{Appropriate institutional reform}

Charles (2007) suggests that institutions need to be resilient to enable them "to maintain and promote resilient ecosystems in the face of intensive resource exploitation" $p .89$. One of the author's example is the need to build measures into resource management institution that move towards a self-regulatory institution (see Figure 6). Charles (2007) recommends that the participation of all stakeholders in resource management is required for conservation action. Figure 8 above illustrates his argument that resource management should be shared between government, resource-users and resource-based communities. In effect, the use of the social mechanisms may help to overcome those individuals acting against conservation and regulate compliance behaviours.

\section{Summary: Alternative co-management models}

Alternative models of resource management include AM and ACM which are both growing both in recognition and significance to address the complexities and uncertainties in environmental management. Some of the components of ACM illustrated by Charles 
(2007) suggest the fundamental need to integrate the learning process and iterative approaches in resource management models. Berkes (2007) further identified the many different faces of co-management and proposed that a resource management regime can start from one of the many facets (Berkes, 2007).

- Co-management as power sharing

- Co-management as institution building

- Co-management as trust building

- Co-management as a process

- Co-management as social learning

- Co-management as problem solving

- Co-management as governance

\subsection{Conclusion of the review}

Success for communities in resource management is two-fold. One is the community institution itself and its endurance over time. Two is the ability of the institution to sustain the resource itself. These are very two important criteria for success in communities in resource management. There are many elements for success and a set of criteria could make the community institutions successful and this chapter has provided the foundation of the basic criteria and elements required for success.

Chapter 2 has provided the context of Nauru, the government, the economic situation, its sustainable development policies, land management problems, the status of the coastal marine resources and its characteristic as a common-pool resource, the district communities as stewards of the resource and the challenges to ensure that the comanagement arrangements to manage the coastal marine resource becomes a successful one but creates an institution that also has the ability to sustain the resource.

Nauru is a single island nation that has well-defined boundaries, small in size, district communities where both individuals have the right to extract from the resource.

The following chapter will refine the criteria identified drawn from the international literature and further identify those successful elements in the Pacific region. The purpose 
of this to situate in the region of the case study as previously highlighted the context and external factors can affect the success of a co-management institution.

Chapter 2 also identified that in developing and creating Nauru's CBFM, the model is based on the Samoa model. This study should consider the different approaches and practices in community-based management found in the Pacific region to also draw and learn from their successes. 


\section{Chapter 4}

\section{Practices in the Pacific}

\subsection{Introduction}

This chapter situates the case of Nauru in the Pacific region. The purpose of this chapter is to help understand the complexities that have driven and influenced the development of coastal marine management and conservation in the Pacific region with a particular focus on the current practices of communities. It further explores expert opinions to discuss the management models and frameworks in the region to highlight the key challenges facing the region's coastal fisheries resources in the current environment. The purpose of this chapter is to evaluate Nauru's CBFM and provides the opportunity to consider other existing frameworks in the region that could improve upon the current CBFM in Nauru and ensure its success.

\subsubsection{Challenges in the Pacific region}

The Pacific Islands region, is a region that consists of 22 countries and territories found in the central and western Pacific Ocean, bounded in bold (see Figure 9), has a total land area of $550,000 \mathrm{~km}^{2}$ and a combined exclusive economic zone (EEZ) of 30 million $\mathrm{km}^{2}$ (Gillett, 2007).

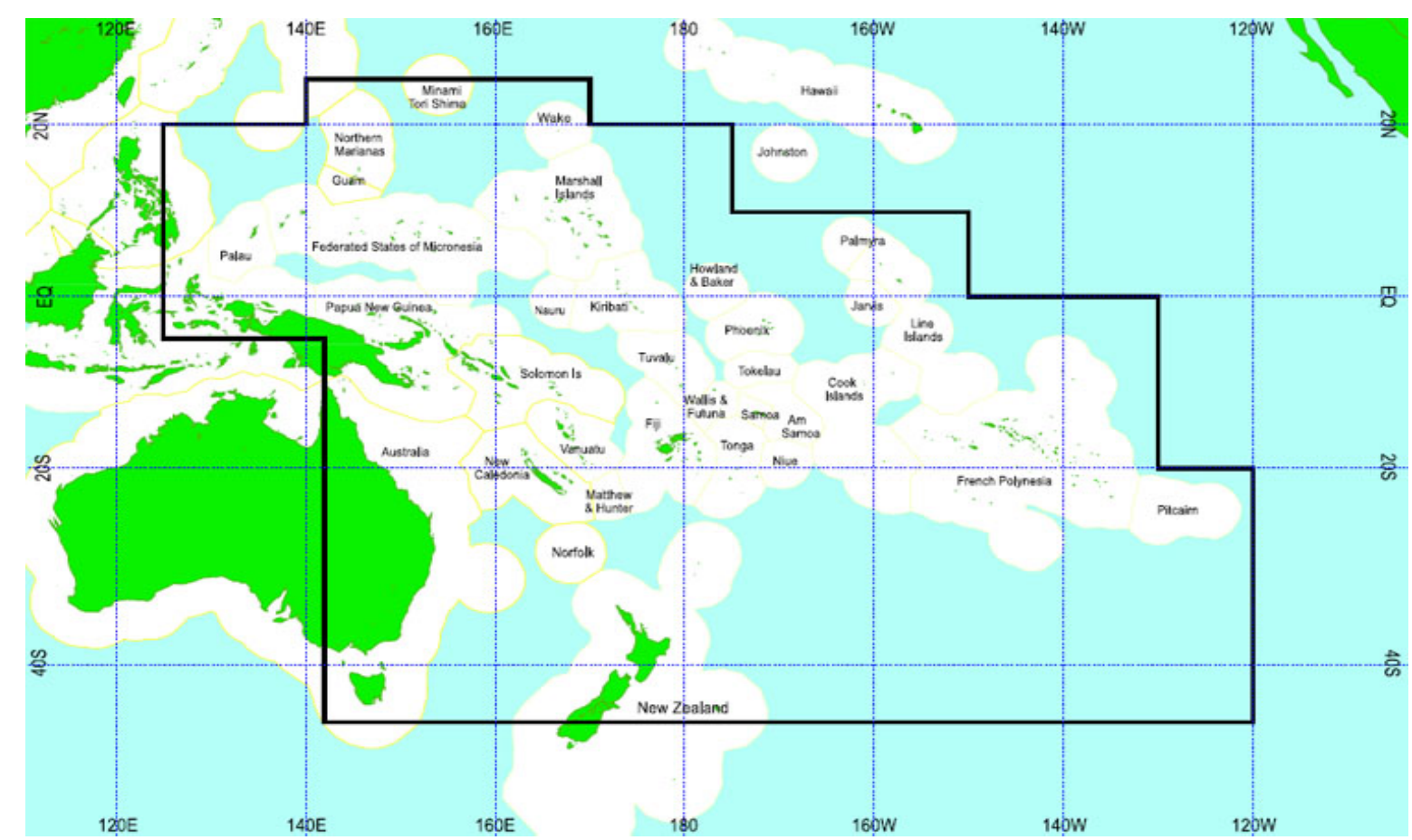

Figure 9: Pacific Islands countries and territorial region [taken from (Gillett, 2007)] 
The region's fishery resources are divided into four major categories: offshore, coastal, aquaculture and freshwater resources (Gillett \& Cartwright, 2010).

- Offshore refers to oceanic resources such as tunas, billfish and allied species. These resources are found in open-water pelagic habitats and form the basis of the region's industrial fisheries.

- Coastal refers to inshore resources and include diverse marine life from corals to finfish and invertebrates often found restricted in the shallow inshore areas that are relatively accessible to users.

- Aquaculture resources include black-lip pearl oyster, penaeid shrimp, tilapia, milkfish, giant clam and seaweed.

- Freshwater resources include fish and invertebrates.

Coastal fisheries resources are fundamental to the well being of the Pacific people as they provide food, employment, recreation and cultural value (Gillett et al., 2008). Some of the challenges are highlighted:

\section{Population and urbanisation}

The population of the Pacific is estimated to increase from 9.8 million in 2010 to 15.0 million in 2035. Melanesian countries will have the highest population growth in the region (Gillett \& Cartwright, 2010). A World Bank report (2000) stated that eight out of the twenty-two PICTs are predominantly urban and the growth of urbanisation will increase with population growth in the smaller outer islands prompting migrating into the towns. It is estimated by 2020 that more than half of the Pacific population will live in towns (WorldBank, 2000). Bell and colleagues (2009) identified that eleven out of the twenty-two Pacific countries would not be able to meet the demands of their growing population and further estimated that in 2030 an additional 115,000 tonnes of fish will be needed to maintain the traditional patterns of consumption (Bell, et al., 2009).

\section{Anthropogenic impacts}

Overfishing has been identified as a problem in coastal fisheries which is largely influenced by market pressures, population growth and urbanisation, and the improved efficient means of technology (Gillett, et al., 2008). Land-based threats from coastal development and industries of logging, mining and wastes exacerbate the impacts to the resource. These development projects often lead to competing uses of the coastal areas. 
Destructive fishing is another concern affecting the environment and its resources with the use of destructive fishing methods from fish poisons, dynamite and the use other destructive tools.

\section{Customary marine tenure (CMT) as traditional governance}

Traditional governance of marine resources exists in most parts of the region. This type of governance is based on customary marine tenure (CMT) and traditional ecological knowledge (TEK). CMT is a common practice throughout the region. CMT is where the communities own the marine resource based on customary law. The State has no ownership over the area and its resource. Nauru's CMT eroded over time and is nonexistent. Pacific scholars (Johannes, 1978; Ruddle, 1988 Aswani, 1999; Govan and colleagues, 2009) identified that customary governance systems such as CMT and TEK are the foundation for success of coastal marine resource management in the Pacific.

Gillet \& Cartwright (2010) suggested that in the future there is a higher chance that the people will lose traditional governance- CMT and TEK in the future due to resource scarcity. Govan and colleagues (2009) would disagree with this view as they have discovered that community-based governance systems in coastal marine resources have grown in number and are proliferated across the region. Moreover, the governance systems are founded upon traditional governance-CMT and TEK. The authors predicted that those countries that have poor traditional governance in place would be those who will suffer the most.

\section{Future outlook}

Gillet and Cartwright's (2010) forecasted the future economic outlook for PICTs as not good because there will be no expected future growth in coastal fisheries development. As a result unemployment rates may increase in the region. The authors suggest that having unemployed people will increase the dependency on the coastal resources for livelihoods. This in turn will lead to communities or individuals to compromise management and conservation of the resources for food security.

Agrawal's (2002) work identified the need to take into account the external factors that can affect the institution. For example, demographic issues and market demand will increase the pressures on the resource and its management. Agrawal suggests the need to buffer the system from external market forces. Moreover, he alluded to the key role of the State in 
supporting the local governance and provides the means for compensation and/or provides alternatives for the diversification of livelihoods.

\section{Climate change}

Gillet and Cartwright (2010) highlighted the challenges to the adverse impacts of climate change on coastal fisheries is expected to lessen productivity of the resources due to the potential increase of coral bleaching events, increased sea surface temperatures and turbidity of water that will degrade the marine habitats. Climate change is also a major threat to the Pacific island, in particular, the low-lying islands where displacement of people is becoming a real potential threat. At best, climate change and its impact create a great deal of uncertainty to the region's future.

\section{Section summary: challenges in the Pacific region}

This section provides the reader a snapshot of the Pacific region, the key challenges facing the people and their coastal marine resources, the highly diverse nature of the resources, and the strong historical and cultural linkages and finally a bleak future outlook (Gillet $\&$ Cartwright, 2010). The diverse nature of the coastal marine resource found in the region highlights the many challenges for management. These challenges ranged from population growth and urbanisation, anthropogenic impacts, traditional governance systems in place such as customary marine tenure and traditional ecological knowledge, the economic outlook and the potential adverse impacts of climate change can affect the successful management of marine resources. These are broad challenges and are beyond the scope of this thesis.

The purpose of this chapter is to examine communities in practice and refine the success criteria drawn from international literatures to evaluate Nauru's CBFM. The study did not conduct a desk review of literatures in the region because of the limited scope and time available. The research decided to use opinions from experts who are practitioners and managers in the field of community-based management as well coastal fisheries managers from the region to inform the evaluative framework. This approach was taken in order to draw attention to the practice and implementation process in the management and determine the implications for success. The next section introduces the management models used in coastal marine resources across the Pacific region. 


\subsection{Co-management models in the Pacific}

Chapter 3 discussed those elements for success in a co-management. Berkes and colleagues (1991) described co-management as an arrangement that involves sharing of power and responsibility between government and local resource users. Such an arrangement is fluid as illustrated in Figure 6, where a broad spectrum of possibilities in the relationships can exist in the co-management (Gavin et al, 2007).

This section discusses the role of the Secretariat of the Pacific Community (SPC) who have been instrumental to develop Nauru's CBFM provided in Chapter 2. Then considers the role of Locally-Marine Managed Area (LLMA) network and then continues to study the three models found in the region to discuss the practices.

\subsubsection{Role of Secretariat of the Pacific Community (SPC)}

The role of SPC in coastal marine management can be seen with the case of Nauru discussed in Chapter 2. As a regional agency, one of SPC's mandates is to help Pacific Island countries and territories (PICTs) manage their coastal marine resources as one way to meet the aspirations of States to achieve their international commitments. For example, the Millennium Development Goals (MDGs) (Apia Policy, 2008) where Goal 1 to eradicate extreme poverty and hunger and Goal 7 to ensure environmental sustainability are goals relevant to the Pacific coastal marine resources given its nature and functions described earlier in the chapter. Coastal fisheries and marine resources contribute to food security and through good management and conservation practices will ensure the sustainability of the resource.

SPC continues to promote the CBFM model as the regional strategy for the Pacific region (King, 2001). Recently SPC upgraded the CBFM model to a community-based ecosystem approach to fisheries management (CEAFM) model (Figure 10). The CEAFM model is defined as, "a relatively self-contained system that contain plants, animals (including humans), micro-organisms and non-living components of the environment as well as the interactions between them"(SPC, 2010).

\subsubsection{Role of LMMA Network and the FLMMA approach}

The Locally-Managed Marine Area (LMMA) network a regional initiative was established in 2000 for Southeast Asia and the South and Central Pacific. The LMMA network is a non-government organisation that plays a key role in community-based coastal management in the region. In 2002 the Fiji Locally-Managed Marine Area (FLMMA) 
network was established and operates within the wider LMMA framework. FLMMA promotes the community based adaptive management (CBAM) model also known as the FLMMA approach (Seidel, 2009). The CBAM model is based on the Learning Framework (LF) (TheLMMANetwork, 2004) and this LF is a tool used for biological, social, socioeconomic and governance monitoring and planning (Seidel, 2009). In 2004, the Fiji Fisheries Department hosted the Secretariat and adopted the FLMMA approach as its national management strategy.

CBAM is the process in which a locally managed marine area (LMMA) can be achieved and sustained. LMMA is defined as " an area of near-shore waters and coastal resources that is largely or wholly managed at a local level by the coastal communities, land-owning groups, partner organisations, and/or collaborative government representatives who reside or are based in the immediate area"(Govan, Aalbersberg, Tawake, \& Parks, 2008, p. 2).

\subsubsection{Community-based models in the Pacific region}

The section compares the CBFM, the CEAFM and the CBAM models found in the region and focuses on the CEAFM and CBAM models given that Chapter 2 has provided the example of Nauru's CBFM.

The CEAFM model takes an ecosystem-based approach where the whole coastal marine system is managed including its socio-economic and governance aspects (SPC, 2010). It has a broad support network where the network can be found within and beyond the host country. This broad-based support network is described as a multi-agency group (E-MAG) that will assist the communities in the management (Figure 10). The CEAFM process has feedback loops or an iterative process to help the communities adapt their plan if the plan is found ineffective.

Local communities still need to request assistance from the promoting agency and signal their interest to develop their management plan. The process will continue at the discretion of the promoting agency (or partner).

The processes include (3) implementation, (4) evaluation, (5) adaptation and (6) adoption of the plan similar to Nauru's CBFM the entire process takes place between the community and the promoting agencies. The CEAFM takes a similar process but has a larger network of support groups and agencies that are made available in the process and this support network can be found in and outside the host country. The shift between these two models is one of scale. 
The CBAM model, Govan and colleagues (2008) identified the four processes involved in establishing LMMAs (): 1) Initial assessment on the needs of communities and their commitment to the process is determined. 2) LMMA design and planning is a participatory learning action approach that uses a diverse tool kit. Charles (2004) recommended the need to have a diverse toolkit as an enabling the community to adapt, replace or supplement measures to sustain the resilience of the resource. Moreover, Charles (2004) suggested a learning-by-doing approach that will ensure improvement of the future management. The action-planning matrix identifies the key threats and problems and options for management. This will form the basic foundation of the community management plans. 3) Implementing the plan- this is a process of learning, increasing awareness and action. A monitoring phase by the communities who follow-up and review the management plan. 4) Iterative process - a continual and ongoing process where the community learns in new information and adapts their monitoring and continue assessing their progress to review the management plan.

Earlier in the review, Berkes (2007) identified the many different faces of co-management and as illustrated by the CBAM model it highlights co-management as a process, as social learning, as problem solving and as governance.

The promoting agency in the CBFM is the fisheries department and in the CEAFM a government or non-government organisation (NGO) or communities in the host country can be the promoting agency. The promoting agency in CBAM is the FLMMA network (see Table 3). Table 3 summarises the differences and similarities of the three models as described in this section.

Based on the promoting agency found in each model it makes it clear that communities are not the drivers of the process in the CBFM and possibly the CEAFM and FLMMA network. It is clear that the CBFM is operating in isolation from other government institutions and lacks a large support network. Pinkerton (1989) identified that available external support, as a pre-condition is required in the co-management. Ostrom (1990) and Agrawal (2002) design highlighted the need to have nested enterprises and levels of management, enforcement and government to be involved in the resource management. The FLMMA network includes partners and members who have adopted the FLMMA approach and ranges from government agencies, universities, both local and international NGOs. 
The FLMMA network partners and members have a memorandum of understanding $(\mathrm{MoU})$ and a Social Contract not legally binding but a pledge of members commitment to ensure good social relations and standing in the process (TheLMMANetwork, 2005). Pinkerton (1989) identified having agreements to be formalized, legal and multi-year as a pre-condition to successful fisheries management.

\section{Section summary of co-management models}

The models advocate that communities are central to the process through a democratic participation. Pinkerton (1989) noted that management arising from a real or imagined crisis can influence the incentives for collective action. As introduced earlier, comanagement involves the sharing of power and responsibilities between government and communities. The models identified the importance of having support networks external to the community institutions to initiate as well as enhance the management.

The steps in the models represent the different phases of the process. Once a plan is developed, the next step is its implementation and this step includes monitoring and evaluation processes followed by adapting the plan. The process is a continuous one and suggests that communities will adopt the learn-by doing approach as clearly reflected in the CBAM model (Figure 11). The differences in the models lies in its assumptions of communities where the CBFM and CEAFM assumes that communities possess the knowledge of the resource (Agrawal \& Gibson, 2001) and therefore the management depends on such information. The CBAM identified a diverse tool-kit available to practitioners or managers and the tools include helping communities learn about the resource through habitat mapping and species identification. 
Community-based Ecosystem Approach to Fisheries Management (CEAFM) Model

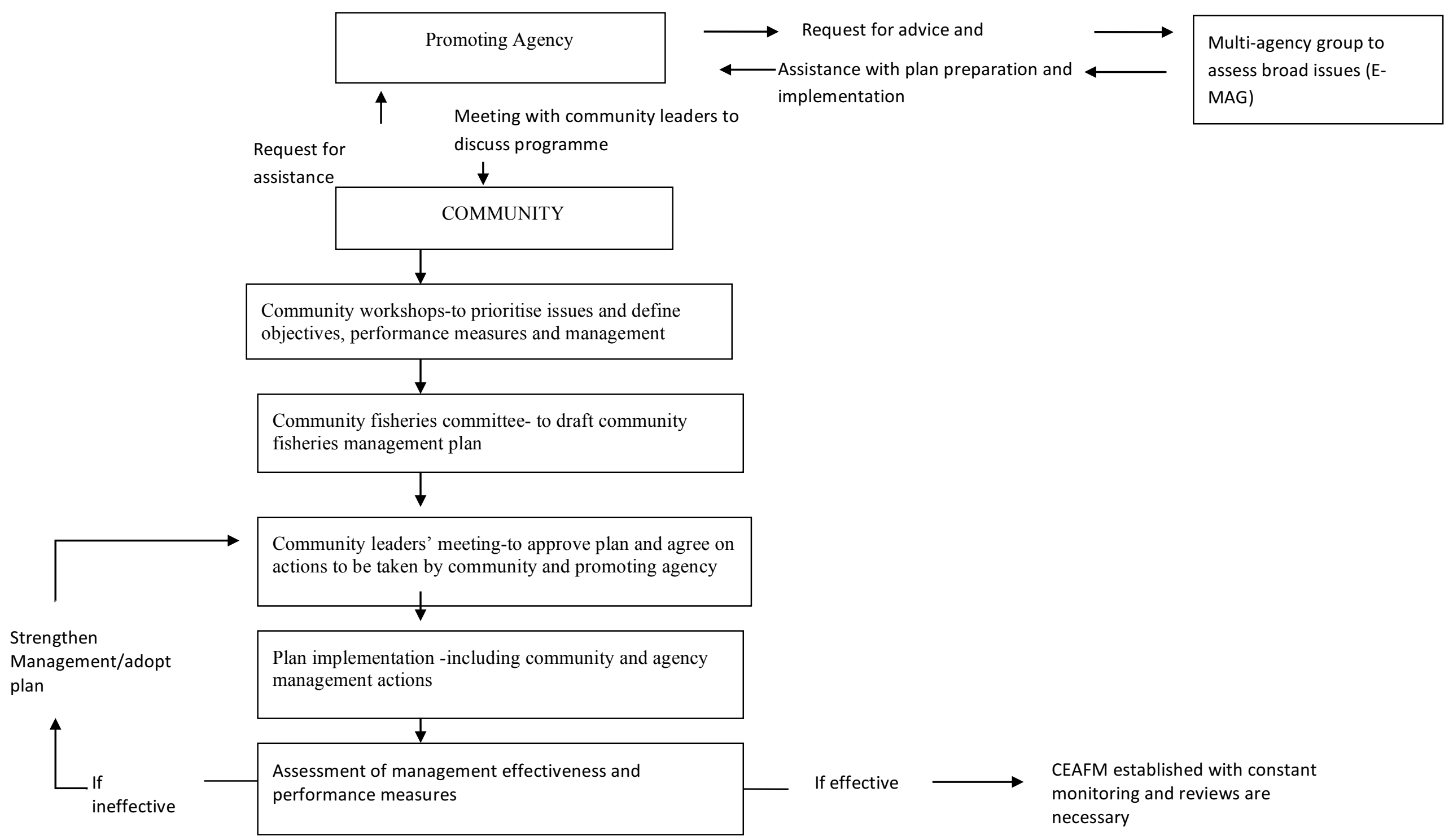

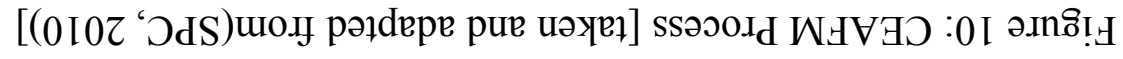


Table 3: CBFM and CEAFM model

\begin{tabular}{|c|c|c|c|}
\hline Attributes of the models & The CBFM & The CEAFM & The CBAM \\
\hline (1) Promoting agency & $\begin{array}{l}\text { Fisheries } \\
\text { Department }\end{array}$ & $\begin{array}{l}\text { Fisheries Department } \\
\text { and other } \\
\text { government agency } \\
\text { or NGO or } \\
\text { communities }\end{array}$ & $\begin{array}{l}\text { FLMMA Network } \\
(\mathrm{NGO})\end{array}$ \\
\hline (2) Community & \multicolumn{2}{|c|}{$\begin{array}{l}\text { - Requests for assistance to } \\
\text { promoting agency } \\
\text { - Workshop to determine } \\
\text { problems, causes and solutions } \\
\text { - Develop a subgroup -Fisheries } \\
\text { committee to develop plan } \\
\text { - Community leaders to approve } \\
\text { the plan }\end{array}$} & $\begin{array}{l}\text { Preliminary assessment } \\
\text { on the needs of } \\
\text { communities. } \\
\text { Participatory workshop } \\
\text { by learning and action } \\
\text { approach using a diverse } \\
\text { tool kit. } \\
\text { Learning about the } \\
\text { resource. } \\
\text { Action-plan matrix } \\
\text { identifies the key threats } \\
\text { and problems and } \\
\text { options for management. }\end{array}$ \\
\hline (3) Implementation & $\begin{array}{l}\text { Once plan is } \\
\text { approved both } \\
\text { by agency and } \\
\text { community take } \\
\text { actions }\end{array}$ & $\begin{array}{l}\text { Can request } \\
\text { assistance to E-MAG } \\
\text { (regional support } \\
\text { group of agencies, } \\
\mathrm{NGO} \text {, universities } \\
\text { and experts) }\end{array}$ & $\begin{array}{l}\text { Once plan is in place } \\
\text { monitoring phase takes } \\
\text { over by communities. }\end{array}$ \\
\hline $\begin{array}{l}\text { (4) Evaluation of } \\
\text { performance and } \\
\text { measures taken }\end{array}$ & \multicolumn{2}{|c|}{$\begin{array}{l}\text { Promoting agencies, Fisheries, NGO and } \\
\text { community evaluate performance }\end{array}$} & \multirow{2}{*}{$\begin{array}{l}\text { Iterative process - } \\
\text { learning and adapting } \\
\text { the plan with } \\
\text { communities in control. }\end{array}$} \\
\hline $\begin{array}{l}\text { (5) Adapt management } \\
\text { plan }\end{array}$ & \multicolumn{2}{|c|}{$\begin{array}{l}\text { Promoting agencies, NGO and } \\
\text { community to assist in adapting the plan }\end{array}$} & \\
\hline $\begin{array}{l}\text { (6) Adopt plan and } \\
\text { implement }\end{array}$ & \multicolumn{2}{|c|}{$\begin{array}{l}\text { Promoting agencies, } \mathrm{NGO} \text { and } \\
\text { community }\end{array}$} & Communities \\
\hline
\end{tabular}




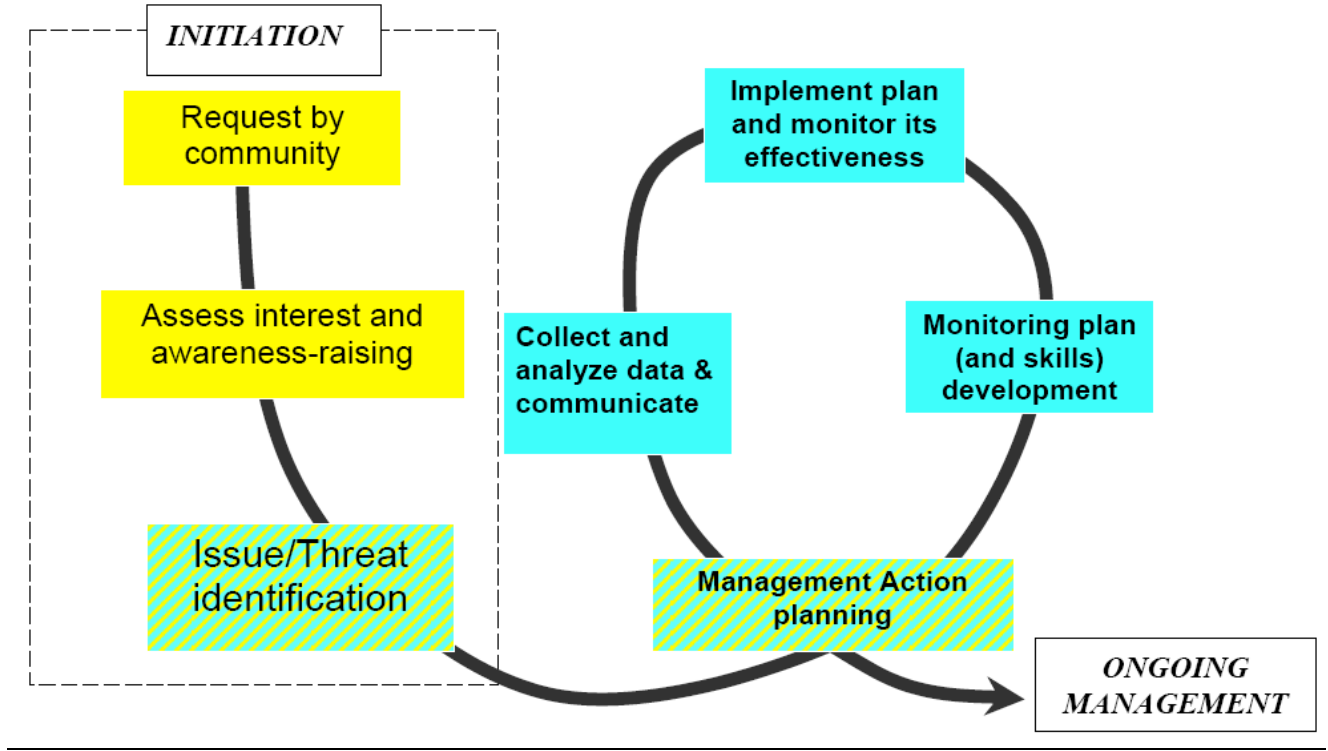

Figure 11: Adaptive management cycle [taken from (Tawake, 2007)] 


\subsection{Expert Data}

In this context, experts are defined as those 'persons' who are currently working and/or have worked in the field of community-based management as practitioners and coastal fisheries managers in the Pacific region. Four experts were interviewed for this study.

The assumptions that people doing fieldwork often hold rich sets of information based on their experiences and have been known to provide the valuable lessons learnt as well as the understanding of what works on the ground. These experts can also provide the information that cannot be gained from the desk review of the literature. The expert data is seen as an opportunity to validate the evaluative criteria drawn from the international literatures.

A qualitative approach was taken to allow for the emergence of information from different worldviews to strengthen the data gained. It is recommended that a semi-structured interview is an appropriate method when interviewing "elite members of a community" (Bernard, 2002, p. 205). A semi-structured interview was developed in advance of the interviews where the structure of the questions is based on themes.

The questions covered the thematic areas of the management process, the development and implementation phases and the follow-up phase of the co-management institutions. The points of interests are to understand how the management came about and their goals and their benefits. The factors that can affect the success of the management such as the incentives to motivate collective action, sustaining the resource, the cultural systems and the challenges facing the communities in the management and the resources.

\subsubsection{Sample Design}

A purposive and convenience sampling approach was used as the basis for selecting the experts from the region. The selection process included:

First step was to generate a list of names from those who have published work in the field of community-based marine and coastal management in the Pacific region. These people were contacted via email. As a result, the primary points of contact provided other contacts in the field. The snowball effect helped generate a second list of potential participants. Another round of communication took place via emails as well as through phone calls. Positive responses from points of contact were received from four individuals. 
The next step of the process was to consider if four experts are sufficient to the purpose of the study. Based on analysis of experts' background, profession and experiences with community-based institutions and coastal fisheries management in the region. The primary element of the selection criteria was on their years of experience in the field. Having the four experts from different backgrounds and sectors such as a regional agency, a government institution, a NGO and a consultant was an additional benefit. Experts from different worldviews were considered to be of benefit and thus sufficient to meet the purpose.

\subsubsection{Interview Data Collection}

Each expert was approached personally and via emails where an information sheet, interview schedule and a copy of the consent form were sent prior to scheduling the interviews. The interviews were conducted either face-to-face, via emails or the Internet through Skype and was recorded by the researcher using a voice recorder for the face-to face and Skype interviews. One of the participants sent an electronically recorded copy of the interview via email.

Two of the research participants signed the consent form prior to the interviews and sent the consent form back via email, while the other two experts provided their consent via emails rather than signing consent forms. The VUW Ethics Committee approved the process for those participants who gave their consent via email rather than signing the consent forms. Participation of the experts in the interviews is voluntary and quotes are attributed in codified form for confidentiality. The experts and their quotes are codified as E1, E2, E3 and E4. The researcher transcribed the recorded interviews. The researcher held copies (electronic and paper version) of all interviews. A summary of expert interviews can be found in the Appendices (see APPENDIX 3).

\subsubsection{Use of Interview Data}

Communities in practice are critical to the success of the co-management. The findings of the interviews are used to help inform the study to determine what counts in practice.

\subsection{Communities in Practice}

This particular section draws on the expert opinions in accordance to the thematic areas. The themes include; the goals for management, the implementation process, the 
participatory process, and the elements in a diverse tool-kit, marine protected areas (MPAs), markets and alternative livelihoods and the future of the institutions in the region.

\subsubsection{Primary goals for management}

Expert opinions on the primary goals of community-based coastal marine management and conservation:

"Primary goals for projects are food security and livelihoods. Climate change is not a concern for those not affected." $E 1$

"One has to take account of the broader national goals but not be driven by the aims of donors or conservation community. Locally managed marine areas (LMMA) projects focus on local community needs and food security. Communities are not concerned with biodiversity conservation at the start. Communities after seeing the recovery of numbers and sizes of invertebrates then they grow to understand the links between fish and habitats. Climate change has affected communities especially with coastal erosion - loss of coastline -so this is addressed for some communities." E3

"CEAFM is the regional approach. Climate change (CC) has always been a part of the CBFM. The issues and concerns of people are raised about the weather patterns. There is a need to build the resilience of the communities to react to the impacts of CC.

Biodiversity conservation are $\$ 50$ words invented to draw money for projects rather than help our own people." E2.

"Different places with different goals. Subsistence fishing is maintaining a sustainable but still-fishable resource may be more important. Primary goals should be determined by consultation with people concerned." E4

Food security and livelihoods are the primary goals found in community-based coastal marine management. Biodiversity conservation and addressing the adverse impacts of climate change could be secondary goals of the management if the communities learn to understand the links and for the latter communities address climate change for those who are affected. The primary goals of community management should be based on the needs of the communities.

One expert stated that communities are not concerned with biodiversity at the beginning of the process but when communities understand the links between the fish and its habitat when a stock recovers either in size or numbers from their efforts they become more engaged with biodiversity conservation. Communities need to understand the cause and effect relationship where actions can affect positive results.

Climate change is not a primary goal although it has affected some of the communities and is considered in the management. Coastal erosion is one example that some communities are experiencing with the loss of sand and coastlines. 
An expert highlighted the CEAFM model does embrace climate change as a threat and recognises the need to build the resilience of the communities to react to the adverse impacts of climate change. Further stated that the intent and goals of biodiversity conservation do not help the Pacific people. While another suggests that different places have different goals and the communities themselves should best determine these goals.

The goals of a community-based marine management institution in this regard are primarily food security and livelihoods as well as the needs of the communities themselves. As highlighted earlier, such an institution will be successful if borne out of a real or imagined crisis such as stock depletion (Pinkerton, 1989). Table 3 previously conveyed that the models used in the Pacific depict the government and/or an external agency as the promoting agency rather than the communities themselves. This type of management as illustrated in Figure 6 suggests that the relationships in the co-management is found at the lower end of the continuum such as external agents instruct communities about management rules. Agrawal (2002) argued that the goal to have enduring community institutions in place is a measure of success but Berkes (2006) highlighted it is often not its sustainability goals.

Berkes (2009) argues that for the institution to achieve the goals of sustainability and resilience it needs to embrace environmental uncertainties. It is important to understand how these institutions are able to address the challenges discussed earlier in the chapter. Climate change is a serious threat for the Pacific peoples and has the potential to increase coral bleaching events and affect sea surface temperatures that will degrade the marine habitats. This does not take into account the reality of sea-level rise for low-lying islands. These are considerable uncertainties for Pacific people whose livelihoods are dependent upon the marine resources and live around the coastline. Climate change has been identified as one of those challenges that will affect the productivity and resilience of the coastal marine resource systems (Gillet \& Cartwright, 2010).

Experts were asked how a community-based institution might help communities mitigate or adapt to the adverse impacts of climate change (CC). 
"Community-based conservation (CBC) approaches can work if you can link the effects and impacts of CC to food security and livelihoods. People are more concerned with putting food on their tables and sending their children to school." E1

"Build the resilience of communities towards the impacts of CC." E2

" $C B C$ is communities managing the projects themselves. To adapt to CC [you need to] raise their awareness and build capacities to adapt to change. Coastal erosion by replanting of mangroves." E3

"CC is an international transboundary issue rather than a local community issue. Decision-making at community level may not be appropriate. [It is] not necessary to include with the over and above existing need to act at the community-level to conserve or manage marine resources. The existing need is current and urgent and doesn't need any additional justification." E4

Addressing the adverse impacts of climate change to the resource system, one expert stated that communities would need to be able to see the links between the adverse impacts affecting their primary goals- food security and livelihoods.

Suggestions from experts for climate change adaptation are building the resilience of communities to such impacts through awareness-raising and capacity building. For example communities can protect themselves from coastal erosion through mangrovereplanting projects. While another expert does not think that community-based institutions are the appropriate level to consider a transboundary issue such as climate change.

The findings suggest mixed opinions on the issue of community-based institutions addressing adverse impacts of climate change. According to Armitage and colleagues (2009) when an adaptive co-management institution is effected this institutes a learning framework in the management to allow communities to adapt to uncertainties.

Experts were asked if the community management plans have addressed climate impacts such as sea-level rise especially for those found in the low-lying areas. Is displacement and relocation addressed for these communities in their plan? Experts' responses:

"This might be needed for communities facing flooding problems and high tides crashing in their villages." E1

\section{"These problems are mentioned in the CBFM plans." E2}

"This is not something that we have dealt with in our projects. Communities do not want to move from where they are. Strategies and actions taken by communities are completely up to them and we basically give communities advice." E3 
"Sea-level rise will not be significant in the near future. El Niño when the warm pool shifts to the east making the skipjack more available in Kiribati and Nauru is [one of the] effect of CC. Multi-species artisanal fisheries may be more resilient to CC effects on resources than commercial fishers. Nauru is one of the few PICs where artisanal fishers catch more pelagic fish than reef fish." E4

There are mixed opinions on the sea-level rise issue resulting in the displacement and relocation of coastal communities. One expert stated that the adverse impacts of climate change should be mentioned in the plan and these issues will be addressed. Two experts identified that this issue is not addressed in the current framework but may be required for those affected communities. It is clear that the decision to address potential relocation and displacement issues as a result of climate change will need to done by the communities themselves. Another expert suggested that the science does support that the sea-level rise will be significant in the near future for the Pacific and also stated that the artisanal fisheries could be more resilient to the commercial fishery sector.

Food security and livelihoods are the primary goals in the management and conservation of coastal marine areas in the Pacific. Biodiversity conservation is secondary to the primary goals. It is argued for biodiversity conservation to happen communities need to build their capacity to understand the linkages between the cause and effect. In other words, people need to understand that the impacts of their action on the resource to enjoy the benefits of biodiversity conservation.

Addressing the adverse impacts of climate change remains a challenge as clearly indicated it remains a debated issue regarding the local-level institutions can do. Adapting to climate change remains as as one of the biggest environmental uncertainties to the future of the Pacific peoples and the coastal marine resources. In Chapter 3, the literature supports that adapting to environmental uncertainties require adopting a learning framework in resource management as the best option for communities in resource management.

\subsubsection{Implementation process}

The implementation process is significant to practice and a multi-level institutional approach. For example, in the region there is the SPC approach that initially implements its work through the promoting agencies within the host countries while the FLMMA network approach operates in a similar fashion but has a broader network of partners involved in the initial processes (see Table 3). 
The implementation process occurs at the community/local-level. Chapters 2 and 3 and earlier in this chapter (see Figures 10 and 11; Table 3) highlighted the local-level implementation process. For example, Nauru's CBFM is a plan that identifies the shared responsibilities of the key stakeholders - government and communities to manage and conserve the resource.

The regional implementation process based on the approach that Nauru took to develop the CBFM programme; SPC has a mechanism in place where they engage a national counterpart from the host country to carry out the groundwork.

"SPC provides the training and capacity building with our national counterparts and these national counterparts carry out this work at the national level" E2.

The step-by-step account of this process is well articulated in the previous Chapters. The work of Michael King (2001) has been instrumental to enhancing community-based fisheries management in the Pacific. King (2001) identified the prerequisite criteria for success implementation posed as questions:

1. Is the government willing to empower communities?

2. Are communities willing to act?

3. Do communities have control over their waters?

Ropeti and Deiye's (2010) preliminary assessment report suggests that Nauru can meet all the prerequisite criteria 1, 2 and 3 and thus introduced the CBFM programme. Based on the condition those communities who are interested and willing to participate in the process. It is a demand-based process and "if communities are not interested move on to other communities" E4. This approach was further reiterated by one of the experts.

The FLMMA approach as discussed earlier in the chapter is conducted through a network of partners that include government agencies, NGOs and the community. NGOs are seen as important in the arrangement because they are often well placed in the communities. NGOs promote and advocate the implementation process of the plan and encourages community empowerment through learning and self-development process (Vunisea, 2005) as well as providing a strong support network. 
In the Pacific, it is recognised that introducing community-based management is easier if communities have some of ownership as well as existing social mechanisms in place. The following extract from experts on the implementation process;

"[When] communities have ownership [of the resource]. [We] use these existing protocols in place to implement these projects." E2

"We found that having support teams on [the] ground makes it easier to implement our projects. There are challenges with continued funding but communities are made aware of these constraints at the beginning and that they should be able to adapt and manage their projects themselves." E3

"We focus on awareness raising with the communities and provide enabling legislation and secure marine tenure and ownership." E1

The FLMMA network has developed community support teams called the "Yaubula" consisting of individuals from the village who become the drivers of the process over time. The role of this group is to implement the plan in their own village community including other community sites as part of strengthening the local network. Government agencies are also required to support the process as part of strengthening the network. The Yaubula initiative provides a good example of an energy centre as, highlighted by Pinkerton (1989) as an important driver to the success of the process.

One expert stated that the FLMMA approach, "is no[t] [a] short-term approach. We follow-through with the community management plans and we maintain our engagement with the community for 2-3 years. We work with the Ministry of Fisheries to have fish wardens in place at each site and conduct joint leadership and management." E3

Experts highlighted one of the constraints in the implementation is funding and suggests that communities need to be informed about this constraint at the beginning of the process. The implementation process needs to be seen as a long-term commitment. The FLMMA network recommends establishing a community-based management institution they would need support for about 2-3 years. This can ensure the durability of the institution in keeping the momentum going.

Pomeroy and his colleagues (2001) also identified that empowering communities, developing their capacity in the management and social preparations are necessary to the process. They also recognised the need for communities to have property rights over the resource. 


\subsubsection{Participatory process}

Community participation in the planning and decision-making process is critical to the overall process. The management models stipulate that maximum participation of stakeholders in the process is essential. There are many benefits to having a participatory process one example is tapping into the forms of knowledge in resource systems such as TEK and local knowledge. Charles (2007) argued that such forms of knowledge should be seen as tools in the system. Updating the knowledge base is a key element of adaptive management.

One expert stated, "[To] use the knowledge that communities already have [is important]." Moreover he does not think, "that monitoring is very important with communities in order for them to manage their projects. [F]or communities what's important is that they are seeing the change themselves, in any form; quantified, qualitative, perception-based or anecdotal but its highly effective." E3

One expert suggests that outputs or benefits from the management need to be evidencebased that will help build the momentum.

"We have refined our approach in conducting awareness and planning workshops. We have taken a more participatory and interactive way of teaching. I have learnt that using visuals or pictures are more effective in community planning. " E3

Moreover, the expert identified that changes have been to the approach through practice and engaging the participation of communities requires interactions where the best outcomes are delivered with the use of visual aids.

Another expert suggested the benefits of the participatory process are building awareness, engagement and capacities of communities and provides an opportunity to learn from others.

"Increased awareness of how other communities go about the same job would be a positive factor." Further recommends: "[a]n occasional national summit of fisheries management committees. A forum of learning and increasing awareness of what other communities is doing. In Fiji there are fishing right owners that sometimes have a provincial meeting to discuss measures and on occasion to set province-wide standards." E4

Having a forum to meet and discuss the management with others has been identified as important part of the practice. This allows communities to be motivated through information sharing and learn from the experiences of others. Moreover, these forum meetings could lead to the development of standardised forms of management and conservation. 
There are many benefits in the participatory process the premise of the CBAM model a democratic participatory process that maximises community participation and lead to two outcomes: (1) community empowerment and (2) ownership of the resources (Govan et al, 2008).

(1) Community empowerment is perceived significant as a motivating factor for communities to take conservation action (Govan, et al., 2008). Community empowerment increases their level of awareness, knowledge and skills through practice- monitoring and enforcement as part of the participatory process.

Community, government and stakeholder participation in the planning and decisionmaking process of resource management is significant to ensure its success. The literature supports participation can help ensure an enduring institution. Participation of all stakeholders involved in the management government, resource users and resource-based communities is required for conservation action (Charles, 2007).

Ownership of the resources (Govan, et al., 2008; Tawake, 2007) is an outcome of community participation in the management. Experts were asked how important ownership of the resource in the management.

"Ownership is important in the sense that if communities feel that they are a part of the project and the project is beneficial to them and that they are the ones reaping the benefits then they would be supportive of it. Ownership is what keeps the project going and ownership is more effective when these communities are empowered to manage the projects themselves. " $E 3$

"The ability [of communities] to control potential free riders from outside the community. Not to exclude them but to manage them and even to be able to extract a resource-rent i.e. commercial fishing permit in Fiji. "E4

Experts suggest that a sense of ownership of the resource provides many benefits for and the communities as well as the resource. Having communities participate in the process empowers them to take action over the resource and reinforces their legitimate rights to exercise control over the resources. Having the possibility to extract resource-rent from the resource system is important outcome for the communities.

As Plummer and Armitage (2007) described in Chapter 3, this type of governance can provide elements of equity; appropriate decision-making using all types of knowledge; and enhance legitimacy of community objectives and actions in resource management. The credibility of the co-management framework can transform these processes into a 
participatory democracy. Berkes (2002) identified that an adaptive co-management (ACM) framework, uses local knowledge in resource management to strengthen the collective action through shared norms and objectives.

Experts were asked if using traditional ecological knowledge (TEK) and conventional science in the management has benefits.

One expert agrees that TEK and science can further motivate communities in resource system management. Another expert suggests: "Learn[ing] about species of interests to the communities and the life cycle of species [will] enable [communities] to manage the habitats, combining scientific knowledge and community knowledge in the management." E3

One expert highlighted that "[t]raditional knowledge is far more extensive than formal knowledge but there are a lot of myths and superstitions that are floating around." This comment raises the concern about the validity and reliability of traditional knowledge and their uses in the management. One of the assumptions about communities involved in natural resource management is that they possess the knowledge because they have lived with resources over time (Agrawal and Gibson, 2001).

Experts were asked if communities are motivated towards achieving resource sustainability or stock recovery in practice.

"[Only] when communities perceive an improvement or increase of species [for example] a return of a species such as a crab. This further increases their awareness, increases the level of project awareness and this has nothing to do with actual data but simply perception." E3

"Not all CBFM decision-making processes are aimed at conservation, in some cases pulse-fisheries are sustainable over the long-term where they are usually followed by a nofishing period. But not always. In Fiji, the government should still leave it up to the local communities to decide how they wanted to treat their locally recruiting resources. [One example is to] [h] ave [the] same principle as tuna management where you need common standards e.g. FFA Minimum Terms and Conditions for Access. "E4

In short, communities in resource management need to perceive that the management and conservation efforts have improved the recovery of a species and then communities can 
appreciate resource conservation. Most often communities in resource management do not aim to conserve the resources but rather manage a stock in crisis and that communities should be allowed to make these decisions. Managing a crisis such as stock depletion is a motivating factor for communities as stipulated by Pinkerton (1989). Moreover it was suggested that having common standards for regulating coastal marine resources were done similar to that of the regional tuna management is the best way forward.

\subsubsection{Diverse toolkit}

Having a diverse "toolkit" of possible management measures and their appropriate "portfolio" for adopting the measures is a criterion that will improve the prospects to achieve sustainability and resilience of the resource system (Charles, 2004). The notion of a diverse toolkit enables a community to adapt, replace or supplement measures for others (ibid). Based on this premise the study looks at some of the current and popular control measures across the Pacific region. Some examples of such control measures (SPC, 2010):

- In Samoa, restrictions on the use of flashlights are used to control spearfishing at night and a ban on the use of SCUBA gear to catch lobsters.

- In Tuvalu, a ban on the use of net fishing in the lagoons as well as a ban on the minimum meshes sizes of nets and fish traps to reduce the catch of small fish.

- The Cook Islands have imposed size limits and catch quotas. For example, fishers are only allowed to harvest $30 \%$ of the total annual trochus stock. Once the quota is reached the fishery is closed.

Moreover, Ostrom's (1990) design principles in Table 2 of Chapter 3 showed the following principles that will ensure a successful CPR management: (2A) Appropriation rules: restriction of time, place, technology, and/or quantity of resource units should match the local conditions. (2B) The benefits gained by users in a CPR are to be determined by appropriation rules that are proportional to the amount of input required. Strongly supported principles found across 91 case studies by Cox and colleagues (2010).

Johannes' (2002) work provided a summary of the marine management measures used in coastal marine fisheries in Palau, Cook Islands, Solomon Islands, Fiji, Samoa and Vanuatu. The diverse range of measures included customary marine tenure (CMT), spearfishing restrictions, netting restrictions, a ban on destructive fishing methods, marine protected areas (MPAs), and periodic and seasonal fishing closures (Table 5). 
Table 4: Marine management measures controlled by communities in the Pacific Islands [adapted from (Johannes, 2002).]

\begin{tabular}{|c|c|c|c|c|c|c|}
\hline $\begin{array}{l}\text { Marine } \\
\text { management } \\
\text { measures } \\
(\text { MRM) } \\
\end{array}$ & Palau & $\begin{array}{l}\text { Cook } \\
\text { Islands }\end{array}$ & $\begin{array}{l}\text { Solomon } \\
\text { Islands }\end{array}$ & Fiji & Samoa & Vanuatu $^{9}$ \\
\hline $\begin{array}{l}\text { Customary } \\
\text { marine tenure } \\
(\text { CMT) }\end{array}$ & $\bullet$ & $\bullet$ & $\bullet$ & $\bullet$ & $\bullet$ & $\bullet$ \\
\hline $\begin{array}{l}\text { Spearfishing } \\
\text { restrictions }\end{array}$ & $\bullet$ & $\bullet$ & $\bullet$ & $\bullet$ & $\bullet$ & $\bullet$ \\
\hline $\begin{array}{l}\text { Netting } \\
\text { restrictions }\end{array}$ & $\infty$ & $\bullet$ & $\bullet$ & $\bullet$ & $\bullet$ & $\bullet$ \\
\hline $\begin{array}{l}\text { Destructive } \\
\text { fishing methods } \\
\text { ban }\end{array}$ & $\infty$ & $\bullet$ & $\bullet$ & $\bullet$ & $\bullet$ & $\bullet$ \\
\hline $\begin{array}{l}\text { Marine } \\
\text { protected areas }\end{array}$ & $\bullet$ & $\bullet$ & - & $\bullet$ & $\bullet$ & - \\
\hline $\begin{array}{l}\text { Periodic } \\
\text { closures-species } \\
\text { or areas }\end{array}$ & - & $\bullet$ & $\bullet$ & $\bullet$ & - & $\bullet$ \\
\hline & & \multicolumn{4}{|c|}{$\begin{array}{l}\text { - Community law } \\
\infty \text { National law- enforced by community } \\
\text { - } \quad \text { N/A }\end{array}$} & \\
\hline
\end{tabular}

The control measures found in the region (Table 4) are diverse those appropriate measures used in one place should match the local conditions and appropriate to the amount of input required. Those set of management measures that will require regulations on the types of fishing gear and method restrictions. The CMT and MPA including periodic closures are

\footnotetext{
${ }^{9}$ Johannes \& Hickey (2002) did a follow-up study of 21 villages in Vanuatu that introduced MRM measures and found from the total of 40 MRM measures operating in 1993, in which five had lapsed but 51 new ones were implemented.The promotion of voluntary village-based trochus management program in 1990 initiated by Vanuatu's Fisheries Dept. was the driver to the growth of CBMRM. Internal disputes occurred in 8 of the 21 villages studied over control of fishing ground tenure.
} 
examined more closely to understand those factors that have led to their successful implementation. The use of marine protected areas (MPA) is also addressed in this section.

According to Johannes (1978), customary marine tenure (CMT) played a critical role in securing ownership and rights of communities in the coastal marine areas across the Pacific. CMT has also influenced the development and establishment of community-based institutions in the Pacific. The 1990s saw the growth of community-based institutions as drivers of resource management because of CMT. Successful implementation of these traditional management practices can be found in Vanuatu, Samoa, Cook Islands, Fiji, Palau, Tuvalu and Hawaii. ${ }^{10}$ The findings suggest that the success of community-based marine management in the Pacific is correlated with CMT (Johannes, 2002; King, Fa'asili, \& Mulipola, 2001). According to Govan and colleagues (2009) CMT as an effective control measure in managing and conserving coastal marine resource is still debated in literature (Govan et al, 2009).

Ruddle (1988) studied Pacific sea tenure systems and found that traditional sea tenure practices reflect social organisations and power structures. In many Pacific societies traditional resource use and management are enforced by community norms that control the behaviours of its members (Ruddle, 1988). CMT and traditional practices have been the basis of coastal inshore and nearshore fisheries management for Pacific Island countries (Aswani, 1999; Govan, et al., 2009). Coastal marine resources are managed by the local communities who have marine tenure or rights of access to fishing grounds controlled by a clan, chief or family (Johannes, 2002).

During the interviews, the researcher made a comment that "community-based approaches based on CMT are all about indigenous exclusivity in the Pacific.” The responses:

"Depends how you look at it and depends on the countries national legislation. [M]ost countries [that] have national laws and legislations in place [often] lack enforcement in place. We lack the resources to have the measures enforced. One of the major assets that most communities or PIC have are their community resources. Looking to the communities to assist with the management of natural resources. Why not? Engage our own communities to assist with the management of natural resources. This is one efficient and effective way of managing coastal fisheries. Tuna fisheries are well managed in the region because governments have prioritised the management of their coastal offshore fisheries because of the money. This is not the case for coastal fisheries and where simple people

\footnotetext{
${ }^{10}$ Hawaii is illustrated as an example where CMT is used but because it is a US State it is not discussed in this review.
} 
get their food from is not a well prioritised in national governments. Ownership and empowering our own communities should be utilised well for managing fisheries." E2

"No, they're all about improving the possibility of effective management/conservation. The tendency is to capitalise on certain human tendencies such as preference for other community members over outsiders. We all accept landownership so why should sea ownership be outrageous? In Fiji- fishing rights can be bought out (hotel developments) or rented out by outsiders still. For cases where there is a huge disadvantage for outsiders that would starve without access to the sea - the [y] may need to be something built into the system to give them a say or to entrench certain rights." E4

The experts considered CMT an asset for communities to manage the coastal fisheries that can further enhance conservation. Use of existing social mechanisms in place is perceived easier for communities to manage and conserve coastal marine resources (Plummer \& Armitage, 2007). Welzel and colleagues (2005) highlighted the importance of community ties in social networks and group identities. It is an example of community ties being translated into collective action as a product of social capital. As Welzel et al (2005) states, collective action can lead to civic effects that enhance the performance of community institutions. Pinkerton's (1989) suggested that developing both the resource management and cultural systems in place at the same time is a pre-condition to success.

\subsubsection{Marine Protected Areas (MPAs)}

Marine protected areas (MPA) have been given prominence in international literature as a measure that sustains the resources. Defining MPA remains debated in international development policy including the Pacific region.

Govan and his colleagues (2009) assessed the status of locally marine managed areas (LMMAs) in the South Pacific. ${ }^{12}$ They examined the contribution of community-based marine managed areas ${ }^{13}$ (MMAs) and MPAs to the region's international and regional commitments. The following international commitments and agreements include the United Nations Conference on Environment (UNCED)- the Rio Conference (1992), the CBD, the World Summit on Sustainable Development (WSSD, 2002), the Johannesburg Programme of Implementation (JPOI), Agenda 21 and the Millennium Development Goals (MDGs, 2000). Regional commitments include the Coral Triangle Initiative (CTI) for some Pacific countries and the Micronesian Challenge for another group of Pacific

\footnotetext{
${ }^{12}$ South Pacific includes a general geographical location of Pacific countries below the equator and refers to the Melanesian and Polynesian countries.

${ }^{13}$ Marine Managed Area refers to an area of marine, estuarine, and adjacent terrestrial areas designated using federal, state, territorial, tribal, or local laws or regulations intended to protect, conserve, or otherwise manage a variety of resources and uses.
} 
countries. The report highlighted the similarity across the international and regional commitments and targets to establish MPA as a means to ensure resource sustainability.

- The CBD and WSSD (JPOI and Agenda 21) target is to "establish and implement a network of effectively managed, ecologically representative MPAs covering at least $10 \%$ of the world's seas by $2020 . "$

- The MDG goal 7 is to "Ensure environmental sustainability" and achieve poverty reduction and sustainable development.

- For CTI members the goal is for a region wide Coral Triangle MPA system in place and to be fully functional by 2020 .

- For Micronesian members the challenge is to effectively conserve at least $30 \%$ of the near-shore marine resources and $20 \%$ of the terrestrial resources across Micronesia by 2020 .

Given the significance of marine protected areas (MPA) understanding the term MPA and its relative use in the Pacific region is helpful for this study.

The CBD (1992) defined MPA as: "Marine and Coastal Protected Areas mean any defined area within or adjacent to the marine environment, together with its overlying waters and associated flora, fauna, and historical and cultural features, which has been reserved by legislation or other effective means, including customs, with the effect that its marine and/or coastal biodiversity enjoys a higher level of protection than its surroundings"'(SecretariatofCBD, 2004, p. 8).

However, the World Conservation Union (IUCN) has recently published a new definition of MPA: "A clearly defined geographical space, recognized, dedicated and managed through legal or effective means to achieve the long-term conservation of nature with associated ecosystem services and cultural values" (Govan et al, 2009 p.29).

Govan and colleagues (2009) argue that IUCN's new MPA definition creates more challenges for the Pacific countries to meet their international commitments and obligations. Moreover the authors are concerned that the efforts of the Pacific countries in establishing MPA will not be recognized and accepted by the IUCN/World Commission on Protected Areas (WCPA)-Marine (Govan et al, 2009).

To put simply understanding how the Pacific loosely uses MPA is important. The Pacific 
region uses the term Indigenous and Community Conserved Areas (ICCAs) often shortened to community-conserved areas (CCAs) are perceived to be synonymous to the definition of MPAs. The term ICCA or $\mathrm{CCA}^{14}$ was first coined by Borrini-Freyerbend and his colleagues (2004) and defines them as "specific sites, resources or species or areas voluntarily conserved through community values, practices, rules and institutions" (Govan, et al 2009 p.27). Borrini-Freyerbend and his colleagues (2004) identified three characteristics of CCAs as (ibid):

(1) Having a strong relationship between the ecosystem areas or species and the local community because of cultural or livelihood relations.

(2) The local community is the key player in the decision-making processes over the management of areas or species.

(3) Community efforts in the management and decision-making process will lead to conservation of habitats, species, ecological functions and cultural values regardless of the management objectives.

Govan and colleagues (2009) studied 500 communities from 15 different countries and territories across the Pacific and found that these communities who have CMT in place have implemented some form of CCAs or MPAs (Govan et al, 2009). The study also identified the strong correlation between communities who have CMT in place are often those who have established CCAs or MPAs.

Drawing from the Pacific literature, one assumption can be made is that the Pacific region use the terms MPAs and CCAs loosely to describe a voluntarily or legally closed area or reserve by the local community for the purpose of conservation. The second assumption is that across the Pacific region community-based institutions are successfully implementing community-conserved areas, which are considered to be marine protected areas have been attributed to the traditional governance structures (customs) along with the customary marine tenure or ownership over the coastal marine areas.

Based on these assumptions, experts were asked if establishing CCA or MPA is a measure of success for community-based institutions.

\footnotetext{
${ }^{14}$ ICCA defined as "natural and modified ecosystems including significant biodiversity, ecological and cultural values, voluntarily conserved by indigenous people and local and mobile communities through customary laws or other effective means." Borrini-Freyerbend, G., Kathari, A., \& Oviedo, G. (2004). Indigenous and Local Communities and Protected Areas: Towards Equity and Enhanced Conservation. Gland, Switzerland and Cambridge, UK: IUCN- The World Conservation Union.
} 
One expert suggested that marine reserves might work as a possible solution to overfishing problems. Another expert states that MPA is only a tool and there are other management measures that need to be in place and he simply stated that, "one can manage a fishery without [having marine] protected areas." E2

One expert states, "[It] is a fallacy of FLMMA or LMMA work. People often associate this with MPA. MPA is simply a tool [including] [c]ommunity conserved areas (CCAs). [I]t is unfair that these can be measured as an indicator of success, this is wrong. "E3

Another expert proposed that, "different resources require a different mix of strategies. Marine protected areas (MPAs) are effective but many fish are mobile. Protected areas to conserve grouper spawning aggregations would be appropriate. It's a tool. Ultimate goals of community-based approaches are to make decisions about resource use or conservation is made close as possible and gives as much say to the people most affected. Depends on the society. Where is Nauru's place along this continuum? ” E4

The expert opinions highlighted that MPA(s) or CCA(s) cannot be used as a measure of success and that these are only tools in the toolkit.

Nauru's position as articulated in Chapter 2, has lost traditional governance and customary marine tenure and as succinctly put by one expert, "Nauru is a monetised society and people who have lost traditional reliance and knowledge. Commercial fishers, government monitoring and researchers generate information." E4

Another expert suggests that Nauru looks into managing and controlling fishing and fishers' impact on the resources rather than conserving the marine resources. One suggestion for Nauru is the need to manage both extractive and non-extractive uses by limiting their access as a possibility where a regulatory framework has the strong social mechanism required to be effective.

\subsubsection{Markets and alternative livelihoods options}

Food security and livelihoods as indicated earlier in the chapter are the primary goals of communities involved in marine management and conservation in the Pacific region. Meeting the needs of communities is critical to the success of the institution and resource sustainability. Thus, the application of management and conservation measure(s) need to consider the alternative livelihood options for the communities.

The effectiveness of diversified livelihood options and income-generating strategies to achieve conservation goals is still a debated issue (Gillet et al, 2008). Gillet and colleagues work (2008) studied the use of livelihood diversification as a management tool in the 
Pacific. Their study identified four main types of livelihood diversification that being used to relieve fishing pressures in coastal near-shore areas. The types of diversification include: aquaculture, fish aggregation devices (FADs), deep reef slope fishing and alternatives outside the fisheries. They found it difficult to identify if these tools were successful. The study concluded based on the performance of the tools, they were found to be ineffective. Moreover the authors suggested that livelihood diversification, as a management tool can be a distraction from more effective forms of management. However, Kronen and colleagues' (2010) recent study on the status of coastal marine resources in the Pacific, suggested that socio-economic impacts and limited opportunities for diversified alternatives for local communities are perceived as the major causes for coastal marine resource overexploitation.

There are two different notions on the role of markets and livelihood diversification in the Pacific, first, alternatives and diversification are perceived as tools in the management and they were found not to be very effective tools as initially thought. The second notion is that when there are limited alternatives and diversification opportunities available to communities this can lead to overexploitation of the resources.

Agrawal (2002) highlighted the importance of markets and diversification because of its external or exogenous nature that are outside the control of resource users. Further Agrawal expressed the key role of the state is to support the local governance and their sanctions through means of compensation or provision of alternatives and diversification for the purpose of conservation. The work of Pomeroy and his colleagues (2001) support Agrawal based on the supra-community level category where pre-conditions for success apply to the state's responsibilities to support communities through enabling legislation and administration including the market forces.

"FLMMA has always had this challeng[e] of balancing development and conservation. Every project you give a community needs to have a thorough research with alternatives. Some projects work and some you need to keep up the momentum and engage the interests of the communities. It depends how well you establish a relationship with the communities and identify projects that are conducive to the environment and lifestyle of the communities." E1

"An alternative livelihood was to move out to offshore areas in Nauru and to alleviate the pressure from the reefs. We provide alternative livelihoods for food security and 
community livelihoods. The benefits gained will depend on how you look at it. Management alternatives you have to have them for a successful management programme" E2

“'Other organisations such as TNC and Tanya O'Gara (an external researcher) have done studies on our sites and have reported that it's improved household income and improved livelihoods in the communities. I believe that is unfair that communities need to collect data to prove to the scientific community about the benefits of their management projects. Independent researchers have conducted numerous studies for FLMMA and we have reports that state that it's working and it's not a myth. External research provides and identifies the weaknesses and we're open to recommendations for improvements and those that can better the projects we're implementing. " E3

"For some cases the development of alternative fishing livelihoods has not led to reduced pressure on resources by itself. In other cases, where the resources "left behind" are effectively protected, the development of alternative livelihoods may work. The problem with alternative livelihoods is that sometimes fisheries are the livelihood of the last resort and there is nowhere else to go. There are no viable alternatives." E4

The expert opinions are mixed with respect to the benefits of alternative livelihood options for conservation. First, there is a need to balance development and conservation goals in coastal marine management. Most experts identified that having alternative livelihood options is essential for the success of community-based management.

Research and work conducted on FLMMA projects studying household income and livelihoods income and livelihoods have shown improvements in resource sustainability. While another expert highlighted the critical point that alternatives livelihood options may work for those who have alternatives given that most Pacific countries have limited alternatives especially in the case of Nauru.

\subsubsection{Future of Community-based Institutions}

The future of community-based institutions as a vehicle to manage and conserve the coastal marine resources in the Pacific is critical to the well-being of the people and the resources. Based on Ostrom's (2004) collective-choice theory people will choose to work cooperatively under certain conditions. For example, having their expected long-term benefits of cooperating to be greater than those of the long-term costs. First, the experts were asked a range of questions regarding the effectiveness of community-based institutions as a vehicle to achieving resource and conservation goals.

Secondly the researcher is of the view that addressing the adverse impacts of climate change is a real future of the Pacific peoples based on the science and future outlook. The 
researcher solicits the views of experts on the ability of community-based institutions to address the adverse impacts of climate change.

Experts were asked on the effectiveness of the institution to manage and conserve the resource and thus 'who' benefits. The costs and benefits gained from community institutions to address alternative livelihoods, biodiversity conservation or mitigate the adverse impacts of climate change. The key question here is "who" benefits?

"For livelihoods, biodiversity conservation and climate change, the costs are borne by both the organisation and the community in terms of time, labour in workshops and meetings. Benefits are borne by the communities themselves and for the partner organisations with continued funding for successful projects. There are benefits to have a great reference for communities and in recognition of their status for partner organisations and communities. "E1

"When a community sacrifices a whole fishing area for conservation purposes what are the alternatives available to them? You implement a conservation area in Nauru where there is no social security and where do you expect the people will get their food? I hate to see most conservationists come in with ideas from developed countries who work and impose it on developing countries where we don't have the capacity. Ultimately resource management is to ensure food security and livelihoods are met. Not conservation." E2

"Not sure who benefits in those different categories. Main benefits are to make the sustainable fisheries/conservation more achievable in many developing country societies. Where people live next to the land/sea and don't rely on formal employment. The whole nation can benefit from this. Fisheries departments can benefit because conservation aims of the Fisheries Act that are more likely to be achieved." E4

The costs and benefits of community-based management based on expert opinions highlight the contextual differences. From a pragmatic standpoint, costs are borne by the implementing organisation while time and labour by the communities. Benefits from management and conservation are shared both by the communities, organisations and hopefully the resources. Another view is to dependent upon the context, the penultimate goal of the institution is to ensure food security and meet the needs of the communities. Another highlights the different areas that will benefit from such management namely, sustain the resources, sustainable food for resource-users and resource-based communities and the implementing government policies. Everyone benefits in the co-management triangle (Figure 8) as conveyed in Chapter 3 (Charles, 2009).

For the Pacific region, climate change is a reality and the future of community-based institutions is important, especially understanding the communities' ability to address the adverse impacts of climate change. The researcher asked, 
(1) "What changes (if any) should be made to include adaptation to climate change (CC) and at what scale should such changes be made?"

"CC is a real threat but to develop an approach to address $C C$ there needs to be a link made between CC and their livelihoods and food security." E1

"CEAFM is the regional approach that has changed to adapt and address the issues of $C C$. Changes in corals and spawning area, this is something beyond our capacity as PICs to deal with except build the resilience of the communities towards the impacts of CC." E2

"We have a Department that deals with CC. We work together where communities have identified threats related to CC. One project that deals with CC threats we have done is mangrove re-planting and setting up nurseries [to counter] sea-level rise. Bleaching is another issue. Integrating CC is totally dependent upon the site where these issues are happening. [T] hese changes should be made ideally. [I]t will be at the site level first but also at national level in terms of awareness and finding ways to avoid falling short of the inevitable." E3

"CC was not considered ameliorable by CBFM. The potential effects of CC are over and above [the] existing level of resource fluctuation [which is the] result of natural climate cycles. Existing capacity of fishers to cope with these fluctuations was not known then. Is it known now? For Nauru, I guess that the effects on coral from increased acidity and increased number of increase in sea temperature are over critical levels for coral bleaching. Not sure what could be done at the national levels let alone at the community levels." E4

(2) "What do you think is the future of CBCs in the Pacific given impending concerns of climate change?"

"We need to start changing the attitude and mindset of our people. We need to target the young ones and the youth to make this difference." E1

"Future of $C B$ will be resilient building and having our own people adjust to living under those conditions and being resilient to those impacts." E2

" $C B C$ will continue but there will be a need for improvements in the way we deal with $C C$ issues, needs to have more integration, more awareness, more resource material provided because the future of $C B C$ will be affected by $C C$." E3

"Is there a perception that $C B C$ will be of particular benefit in tackling $C C$ issues? If you can show a linkage it is likely to result in a lot more project money becoming available." E4

Climate change should not be an issue for the community-level as it is a global issue, however the adverse impacts of climate change happen at the local-level and addressing such challenges that affect communities is a reality. Although climate change is not a priority for most communities involved coastal marine management there is an indication that community institutions need to be flexible to adapt to the potential effects of climate 
change in the future. As one expert suggested the CEAFM is an approach that can address the adverse impacts of CC and further states that there is a need to build resilience of communities to CC. While another expert suggests the need to link the concepts in order for the communities to address CC. Another point raised if a case can be made between the adverse impacts of climate change to the coastal marine resources potential project money will be available. Clearly, improvements to the management framework will be required to better integrate $\mathrm{CC}$ including having materials for community awareness-raising.

Nauru's CBFM was recently introduced programme as indicated in Chapter 2 and understanding how communities can collectively act cooperatively is critical for this study. In such circumstances where communities do act cooperatively and how communities' grapple and tackle the greatest challenge of our time- climate change is critical for communities in the near future. Addressing adverse impacts of climate change to the coastal marine resources is a lived reality for some Pacific communities and the number of Pacific communities that will be affected will continue to increase. It is impetus to develop an effective coastal management and conservation framework taking into account the adverse impacts of climate change and that will be the biggest challenge for the Pacific region yet.

\subsection{Chapter summary}

As highlighted in the introduction, this chapter was designed to help narrow the scope of the research by focusing on the Pacific context and using those experts with vast experiences in community and coastal marine management in the region.

Some key issues have emerged both from the Pacific literature including experts' experiences and opinions with the practices of communities in coastal marine resource management across the Pacific region.

is that people and individual's perceptions play a critical role in CBCs. Individuals or communities' perceptions can work as an incentive or driver in the $\mathrm{CBC}$ process. Pomeroy et al (2001) stressed earlier the significance of an individual's incentive structure. Expert opinions were sought on the significance of people's perceptions of resource management systems: 
"This is the purpose of awareness workshops before we start management planning. "People will only look after things if they are passionate about [them]." If we don't do a good job with awareness, then people would not know about the resources and they won't care. Perception is important to understanding the level of awareness. Perception is that people are knowledgeable about their resources from their traditions and culture and they know what is going on around them. [Our] work is to get the traditional knowledge, and to get the science from the western ideas and to see how we can incorporate the two together. This further increases the awareness. Increase the level of project awareness and this has nothing to do with actual data but simply perception." E3

"This is important and is where government or outside input such as resource materials or workshops is very useful. This information flow is a two-way thing. [A] possible important role of government coastal fisheries specialists is to learn from the people what is happening on a day-to-day basis and passing on relevant information resulting from research." E4

Based on this argument, this study needs to understand Nauruan individuals' and communities' incentive structures and their willingness to manage and conserve the coastal marine systems. Understanding existing trends concerning local people's ideas, behaviour and attitudes about coastal marine systems is one knowledge gap. The use of perception- monitoring as a tool to elicit this information was found appropriate for the case, at this time. 


\section{Chapter 5}

\section{Individual perceptions}

\subsection{Introduction}

As presented in Chapter 1, this case study approach takes a sequential mixed methods format: a quantitative perception survey followed by a qualitative gender-based focus group activity. This is to ensure that the data collected is robust (valid and reliable). Due to the large amounts of data gained from the survey and the gender-based focus group, the results are presented in two consecutive chapters. The findings of the perception survey are presented in this chapter. Chapter 6 presents the results of the gender-based focus group activity.

A perception survey was used to explore the nature of individual incentive structures in Nauru. This should have been addressed prior to embarking on the community-based fisheries management (CBFM) programme in Nauru, but doing it now is still useful. It is evident that "the perception of users is a useful tool to evaluate whether a specific form of management (relying for example on a MPA) answered the needs of a recent past, and what are the expectations of the users of the resource for the future"(Hubert, 2007, p. 8).

\subsubsection{Perception monitoring}

Perception monitoring is used to determine people's willingness and capacity to participate in CBMC. Perception monitoring in surveys are used in diverse fields from user-centred attitude in businesses to evaluating regulatory reform policy (OECD, 2010); monitoring environment and health (Keune et al., 2008); and resource management projects (Bash \& Ryan, 2002). There are some advantages and disadvantages to using local perceptions in participative management of natural resources.

Some advantages of perception monitoring it is cost-effective, financially viable and can facilitate prompt management interventions in response to immediate threats to the resources. This is compared to scientific monitoring of resources where identifying changes in stock assessments often takes years, delaying adequate management interventions (Uychiaoco et al., 2005). Responsive management measures such as species enhancement and habitat protection are more diversified, realistic and arguably well 
accepted by local communities (Danielsen, Burgess, \& Balmford, 2005).

Adaptive co-management frameworks support the concept that TEK and science are integrated together in resource management, so monitoring will need to include both local knowledge and scientific monitoring to serve the framework (Berkes \& Turner, 2006; Lawrence \& Elphick, 2002). Van Rijsoort and Jinfeng (2005) argue that when resource users are directly involved in the monitoring and development of management rules, perception monitoring can be used in the decision-making process. This improves both communication between participants, and can provide transparent and democratic institutions (VanRijsoort \& Jinfeng, 2005).

Some disadvantages of perception monitoring are that they often lack objectivity (Danielsen et al., 2000). Individuals have different perspectives as well as interpretations of problems and trends. There could be communication problems during surveys. Lastly, biased opinions and generalisations about issues that are not representative may occur. Perception monitoring is best conducted using indicators to avoid biased opinions and generalisations should be carried out quantitatively (Hubert, 2007).

\subsection{Methods}

The perception survey was executed from $5^{\text {th }}$ to $30^{\text {th }}$ July 2010 by a team of NFMRA Coastal Fisheries staff with the researcher as the team leader.

\subsubsection{Objectives of the survey}

\section{Survey Objectives}

The main objectives of the perception study were to gain insight into individuals' perceptions about managing and conserving the coastal marine systems. The survey was designed to target two groups in Nauru: fishers as resource-users (extractive uses) and resource-based communities (non-extractive users) of the coastal marine system. There are three types of data collected in the survey:

a) Fishers' data included: 
- The status of fishers - their experience and knowledge about fishing, and how fishing skills are passed on (their legacy) and their fishing preferences

- TEK, beliefs or superstitions associated with fishing.

- The current types of traditional and modern fishing gear/methods used.

- The target marine species.

- The control of fishing gear and methods.

- The causal problems related to the resources compared to the 2005 ProcFISH report on the status of the resources.

- The size of catch and identifying endangered or abundant species.

- Elements involving the cost and benefits of fishing gear and methods.

- The perceived pros and cons of introducing management and conservation measures to fishing.

b) The survey of non-fishers was designed to gain:

- Information on the current and future status of the coastal marine resources and its environment.

- Identification of the major problems, causes and solutions found in the coastal marine environment through use of a ranking scale.

- People's knowledge about existing traditional or modern rules or regulations.

- Insight into people's willingness to comply with the future rules and regulations in managing and conserving coastal marine system.

- People's knowledge about managing and conserving the coastal marine system.

- Information for awareness programmes.

- Insight into existing conservation groups and people's willingness to participate in a conservation group.

- Information about introducing coastal zoning to protect and manage coastal marine systems.

c) For all survey participants the following was sought:

- Personal information - age, status of employment and the level of participation in fishing.

- Dwelling information - access to electricity and water, personal ownership of items such as fishing gear, TV, radio, and transport - in order to understand individuals' 
socio-economic backgrounds that may affect solutions and recommendations in the study.

- The value systems of individuals (analysed through a ranking scale) in order to identify the significance of coastal marine resources to their well-being.

- Information about customary marine tenure (CMT).

- Reasons for and against the introduction of marine protected areas (MPA) and the potential site(s) in Nauru.

- The level of awareness and support of the CBFM programme.

- Any general comments about the questionnaire or other relevant issues.

Overall, the information gained from the assessment of trends address the research objective: To examine based on a perception-monitoring survey the degree of willingness and capability of individuals in Nauru to act in marine and coastal co-management arrangements. This serves to inform and evaluate the CBFM programme in Nauru: to provide information about fishing gear, fishing locations and habitats, their intensity and catch; perceived coastal environmental problems; and the attitudes of the local people towards controlling actions in the CBFM. Agrawal and Gibson (2001) argue that communities are made up of multiple actors with multiple interests and a multiplicity of individual perceptions was sought in the survey.

\subsubsection{Survey format}

2. The questionnaire

This survey questionnaire (see Appendix 9) was adopted and adapted from two previous surveys, to monitor perception and to gather information. These other questionnaires were:

a) The survey on "Subsistence Fishing Activities in the Rock Islands" contracted by the Palau Conservation Society (PCS). This was designed to assess the status of noncommercial subsistence fishing activities in the Rock Islands, a protected area. The results were to be used to help finalise the Management Plan for the Rock Islands (Matthews, 2004).

b) Community perceptions of Marine Protected Area Management in Indonesia. The Nature Conservancy (TNC)-Coral Triangle Center (CTC) established marine conservation programs in Indonesia. An independent baseline study contracted by TNC to: 
(i) Assess trends in community perceptions of resource status, use and MPA management.

(ii) To provide information to managers about the attitudes, perceptions and behaviours of communities living near the resources (Halim \& Mous, 2006).

Both questionnaires mentioned above are comprehensive and were adapted into one survey for this study. The final questionnaire consisted of three parts: dwelling, non-fisher, and fisher. The questionnaire was changed after the initial rounds of pilot testing with NFMRA staff. Changes made were to eliminate repetitive questions and make others clear. The VUW Ethics Committee has approved this process.

\subsubsection{Survey design}

3. Sample design

Given the small size of Nauru, it was treated as a single study site. Initial fieldwork was designed to conduct a random selection of 10 dwellings per district totalling 150 dwellings participating in the survey and to acquire a total of 300 respondents. It was hoped to gain at least two voluntary participants at each dwelling. These had to be either a non-fisher or a fisher (detail later in this chapter). Changes have been made to the initial sample size and distribution for reasons discussed below.

The Nauru Bureau of Statistics Office provided a population sampling based on the 2006 mini-census. The recommended individual household sampling sizes are provided (see Table 6). These large sample sizes recommended by the Statistics Office were too large to be undertaken in this study.

This study targeted the dwelling ${ }^{15}$ level and not the household level. The purpose of conducting this study at the dwelling-level was:

(1) The 2002 Nauru population census found that an average of 6-8 households is found per dwelling.

(2) The higher probability of having both a fisher and non-fisher present at the dwelling level than the household level.

(3) A stratified sampling was taken to include 15 primary sampling units (PSUs) in Nauru.

\footnotetext{
${ }^{15}$ Dwelling level is where more than one family household is found living in one area or place.
} 
Table 5: Recommended sample sizes for Nauru (provided by Nauru Bureau of Statistics, 2010)

\begin{tabular}{|l|l|l|l|}
\hline Constituency/District & 2006 Population & $\begin{array}{l}\text { a) Recommended } \\
\text { household sample } \\
\text { by district } \\
\text { population }\end{array}$ & $\begin{array}{l}\text { b) Recommended } \\
\text { household sample size } \\
\text { of 1500 in proportion } \\
\text { to total and district } \\
\text { population }\end{array}$ \\
\hline Yaren & & & 109 \\
\hline Boe & 438 & 71 & 116 \\
\hline Aiwo & 494 & 80 & 143 \\
\hline Buada & 748 & 121 & 108 \\
\hline Denig & 430 & 70 & 94 \\
\hline Nibok & 322 & 52 & 85 \\
\hline Uaboe & 263 & 43 & 77 \\
\hline Baitsi & 220 & 36 & 92 \\
\hline Ewa & 313 & 51 & 80 \\
\hline Anetan & 234 & 38 & 94 \\
\hline Anabar & 326 & 53 & 87 \\
\hline Ijuw & 275 & 44 & 64 \\
\hline Anibare & 150 & 24 & 52 \\
\hline Meneng & 100 & 16 & 161 \\
\hline Location & 958 & 155 & 138 \\
\hline Total & 700 & 113 & $\mathbf{1 5 0 0}$ \\
\hline & $\mathbf{5 9 7 1}$ & $\mathbf{9 6 6}$ & \\
\hline
\end{tabular}

The changes made are reflected in Table 7; this shows the number of dwellings being surveyed at each district in Nauru. Location was the only district where the target number of dwellings was less than the initial target of 10, due to a sampling error. This sampling error was a human error. The records showed data for 10 dwellings was collected for Location but upon data entry only nine were found. As data entry was undertaken in NZ, the researcher could not salvage this loss. 
Table 6: Survey sample size based on dwelling and composition of respondents

\begin{tabular}{|c|c|c|c|c|}
\hline \multirow[t]{2}{*}{ Constituency } & \multirow{2}{*}{$\begin{array}{l}\text { Number of } \\
\text { dwellings }\end{array}$} & \multicolumn{3}{|c|}{ Composition of respondents per dwelling } \\
\hline & & $\begin{array}{l}\text { Fisher \& non- } \\
\text { fisher }\end{array}$ & Fisher only & $\begin{array}{l}\text { Non-fisher } \\
\text { only }\end{array}$ \\
\hline Anibare & 10 & 4 & 1 & 5 \\
\hline Ijuw & 13 & 4 & 3 & 6 \\
\hline Anabar & 12 & 4 & 5 & 3 \\
\hline Anetan & 11 & 4 & 3 & 4 \\
\hline Ewa & 12 & 4 & 5 & 3 \\
\hline Baitsi & 11 & 8 & 1 & 2 \\
\hline Uaboe & 13 & 5 & 1 & 7 \\
\hline Nibok & 11 & 3 & 1 & 7 \\
\hline Denig & 13 & 7 & 1 & 5 \\
\hline Location & 9 & 6 & 0 & 3 \\
\hline Aiwo & 14 & 3 & 4 & 7 \\
\hline Buada & 10 & 5 & 0 & 5 \\
\hline Boe & 17 & 10 & 1 & 6 \\
\hline Yaren & 11 & 9 & 1 & 1 \\
\hline Meneng & 16 & 11 & 1 & 4 \\
\hline TOTAL & 183 & 87 & 28 & 68 \\
\hline
\end{tabular}

Initially 150 dwellings were randomly selected. The total sample surveyed was 183 dwellings. Of these 183 dwellings, 87 dwellings had both fishers and non-fishers. Only non-fishers were found at 68 dwellings while only fishers were found at 28 dwellings. The total sample size is two hundred and seventy (270) individuals being interviewed. It was estimated to represent about $2.9 \%$ of the general population (based on the 2006 population census).

\subsubsection{Survey organisation}

The survey was carried out with assistance from the NFMRA staff using supporting funds from the Institutional Strengthening Project (ISP) -NFMRA. The researcher executed the survey with a team of staff from NFMRA-Coastal Section that consisted of 12 individuals (including the researcher). 
(a) Training

The survey team had a two-week training session prior to executing the survey. The training consisted of familiarising them with the questionnaire and ethical protocols such as asking for voluntary participation and asking the questionnaire in the local language.

(b) Pre-test

The second week of training included a pilot testing both of the team's execution skills and the questionnaire with NFMRA staff. Throughout the training, debriefing sessions and informal meetings were held to assist staff with survey matters. The team signed a confidentiality and non-disclosure commitment prior to the actual survey and met the approved VUW Ethical Standards.

(c) Fieldwork

The survey included a two-person team collecting data at each dwelling. The survey was conducted during working hours from 10 am to $5 \mathrm{pm}$ during the week. The data collection started in the district of Anibare and continued anticlockwise around the whole island. Each two-person team covered a number of dwellings per district. The team leader collected questionnaires from each team at the end of each day due to the survey's confidentiality. The team leader was also responsible for collecting team members (without transport) for data collection and making refreshments available when necessary.

(d) Survey bias

Using NFMRA staff for data collection has the potential to bias the responses gained from participants. Biased responses of survey participants can be attributed to the fact that NFMRA staff was asking the survey questions and to the time of the day. Respondents may have felt the need to either impress staff with their knowledge or not answer the questions properly because of their resistance to future management and conservation of coastal marine systems. One of the difficulties in conducting a survey given the size of the site is because people know each other on the island. The use of two-person team increases the possibility for selection-biased approach where participants can approach either family or friends in each of the districts. There is no other way to address this issue, except direct the two-person team into unfamiliar districts in Nauru, which the procedure was taken. At best, the rigour of the perception survey methods used in this survey may be questionable 
but the research was constrained by both money and time within thesis constraints. It was difficult to conduct the survey without the assistance of a team in a cost effective and timely manner. Survey times were carried out during working hours only because of the available time of the team members to assist in the data collection. There is a probability that a disproportionate number of unemployed individuals were being surveyed during these times.

(e) Data processing

Data processing began in September 2010, on return from the fieldwork. Data was entered into the Statistical Package for the Social Sciences (SPSS) a software package version also known as Predictive Analytics Software (PASW 18). Once data entry and final editing was completed, descriptive analysis and their findings were generated.

\subsubsection{Number of individuals interviewed}

Table 8 showed that $90 \%$ of the interviews were carried out when based on the initial sample target of 300 individuals bringing the total to 270 individuals. Table 9 shows the percentage of individuals interviewed based on dwelling composition. Sixty four percent of interviewees were from dwellings that had both fishers and non-fishers and about $25 \%$ from dwellings that had non-fishers only while $10 \%$ from dwellings of fishers only.

Table 7: Comparison of individuals interviewed compared to the initial target for individual interviews

\begin{tabular}{|l|l|}
\hline Interviews & Number of individuals \\
\hline Initial interviews targeted & 300 \\
\hline Actual interviews obtained & 270 \\
\hline Response rate & $90 \%$ \\
\hline
\end{tabular}

Table 8: Percentage of total interviews based on dwellings

\begin{tabular}{|l|l|l|}
\hline Interviews & Total number of individual & $\%$ \\
\hline Total number of individuals & 270 & $\mathbf{1 0 0 \%}$ \\
\hline Interviews & From dwellings that had both fisher and non-fisher & \\
\hline Actual number of individuals & 174 & $\mathbf{6 4 . 4 \%}$ \\
\hline Interviews & From dwellings that had a fisher only & \\
\hline Actual number of individuals & 28 & $\mathbf{1 0 . 4 \%}$ \\
\hline Interviews & From dwellings that had a non-fisher only & \\
\hline Actual number of individuals & 68 & $\mathbf{2 5 . 2 \%}$ \\
\hline
\end{tabular}




\subsection{Results}

\subsubsection{Characteristics of survey dwellings and participants}

This first section provides a "snapshot" of the current situation of household dwellings and demographics of participants in Nauru.

\section{$\underline{1 .}$ Dwelling characteristics}

Nauru is $100 \%$ urban and most dwellings surveyed are western style houses. Public facilities are available in all dwellings. Ninety eight percent of the dwellings have electricity. Fifty six percent of dwellings have running water, so $44 \%$ of the dwellings do not have running water. Running water in a dwelling indicates the presence of a water pump or tank. It was found that almost half of the dwellings surveyed either do not have water pumps or tanks. The reasons for this were not asked in this survey.

2. Fishing gear includes a fishing boat with outboard engine, canoe, seine and cast nets, fishing rod and traps

A total of 183 dwellings surveyed either had or did not have any fishing gear. In descending order: $27 \%$ of dwellings own one seine net while $23 \%$ have one cast net, $15 \%$ own a fishing boat with outboard motor, $11 \%$ have a fishing rod, $6.5 \%$ have a canoe and $3 \%$ have one fish trap. The percentage of dwellings of those who possess at least two of these fishing gear decreased dramatically given in descending order: $10 \%$ of dwellings possess two fish traps, $3 \%$ have two fishing rods, $2 \%$ own two cast nets. Only $0.5 \%$ of dwellings possess at least two seine nets and fishing boats with an outboard engine. Another $0.5 \%$ of dwellings owned six fish traps.

This question did not include the use of spearfishing gear, which was an oversight since these are commonly used in Nauru. This information will need to be reviewed in future research.

As described in Chapter 2, Nauruans used to enjoy high standards of living, but as clearly indicated from the dwelling characteristics, circumstances have changed. The variation of relative wealth as shown by the use of these indicators showed limited possessions of individuals based on the dwelling survey. Vunisea and colleagues' (2008) study found annual household expenditure was low and estimated this at USD 3050 per household per 
year. As Agrawal (2002) highlighted in Chapter 3, one of the critical factors related to group characteristics is to have low levels of poverty that will allow for durable institutions to develop. Any indication of high levels of poverty can affect the ability of individuals to cooperate in a collective.

\section{Demographics of research participants}

a) Age of participants

Table 9 illustrates the fishers and non-fishers being interviewed in the survey are aged 15 to 67 and 18 to 74 respectively. The calculated mean ages between the groups, 37.05 and 41.61 , does not appear to be very different. It was not determined if the difference in age groups were statistically significant.

Table 9: Survey participants' age groups

\begin{tabular}{|l|l|l|l|}
\hline Interviews & Age range & Age range & Mean age in years \\
\hline Fishers (years) & $15-67$ & & 37.05 \\
\hline Non-fishers (years) & & $18-74$ & 41.61 \\
\hline
\end{tabular}

From the calculated mean ages of both groups: a mature age group is represented in the sample. This could be attributed to the fact that these individuals were available at each dwelling when the survey was being conducted during working hours of the week.

b) Gender of participants

Table 11 showed the fisher group interviewed consisted of 100 males and 15 females and the non-fishers included 42 males and 98 females. Overall, a total of 142 males and 113 females were interviewed, with 15 individuals who did not identify their gender in the survey. The overall response rate to this question was $94.4 \%$.

Table 10: Gender of participants

\begin{tabular}{|l|l|l|l|}
\hline Interviews & Fishers & Non-fishers & Total \\
\hline Women & 15 & 98 & 113 \\
\hline Men & 100 & 42 & 142 \\
\hline Non-responses (gender unknown) & & & 15 \\
\hline Gender response rate & & $94.4 \%$ \\
\hline
\end{tabular}


Gender is a critical variable in fishing and gathering in Nauru. Offshore fishing includes the use of boat, canoe, spear fishing and SCUBA, which are male-dominated forms of fishing. Women, men and children equally participate in net fishing, rod fishing and hand gathering (gleaning) within the inshore areas (Thaman and Hassall, 1996; Jacob, 2005).

c) Employment

For the purpose of this study, employment is defined as earning income and being part of the workforce. It does not include being retired, child-raising or attending school, unless these earn income.

Table 11 showed participants interviewed, the fisher group had 69 who were recorded as employed while 44 were unemployed. Fifty-seven of non-fishers were recorded as employed while 97 were unemployed. A total of 126 participants were employed while 140 are unemployed. Four were missing data. The response rate is $98.5 \%$.

Table 11: Employment status of participants

\begin{tabular}{|l|ll|ll|l|}
\hline Interviews & \multicolumn{2}{|l|}{ Fishers } & \multicolumn{2}{|l|}{ Non-fishers } & Total \\
\hline Employed & 69 & $(55 \%)$ & 57 & $(45 \%)$ & 126 \\
\hline Unemployed & 44 & $(31 \%)$ & 96 & $(69 \%)$ & 140 \\
\hline $\begin{array}{l}\text { Non-responses } \\
\text { (status of } \\
\text { employment } \\
\text { unknown) }\end{array}$ & & & & 4 \\
\hline Employment response rate & & & & \\
\hline
\end{tabular}

Employment status is a critical variable that allows the study to understand the dynamics between the dependence of users on the resource, their attitudes and fishing habits. In this sample, employed participants constitute 55\% fishers and $45 \%$ non-fishers. For the unemployed: $31 \%$ fishers and $69 \%$ non-fishers.

Regarding employment types 
Table 12): $68 \%$ work for the public sector, $22 \%$ in the private sector, at least $8 \%$ are employed by state-owned enterprises (SOEs) and at least $\%$ are self employed.

Table 12: Employment sector (\%)

\begin{tabular}{|l|l|l|}
\hline Employment sector & No. of employed & \% of employed \\
\hline Public service & 86 & 68.3 \\
\hline Private & 28 & 22.2 \\
\hline SOEs & 10 & 7.9 \\
\hline Self & 2 & 1.6 \\
\hline TOTAL & 126 & 100.0 \\
\hline
\end{tabular}

The findings suggest in this sample that there were proportionately more non-fishers than fishers, and proportionately more unemployed than the employed being interviewed. The latter was likely a product of the time and day the survey was carried out.

With the high unemployment rate it is likely that increased dependence on the marine resources could possibly intensify fishing activities from the studies of Vunisea et al (2008) and Bell et al (2010). According to Pinkerton and Weinstein (1995) having high levels of dependence on the resource system may affect groups' cooperative behaviour to act in the CBMC because their welfare is at stake. Overall, Pinkerton (1989) suggests, this can lead to a positive outcome where management often emerges out of a real crisis. In other words, dealing with the crisis can be a good thing for people and the government because for most their welfare is at stake.

The next section presents the results of fishers and non-fishers.

\subsubsection{Fishers' results}

A fisher is defined as a person who has actively fished and harvested in the coastal marine areas within the last six months of the survey of July 2010. A total of one hundred and fifteen self-identified fishers were interviewed. The fisher questionnaire consisted of mixed closed and open-ended questions to determine fishing gear, fishing locations and habits, fishing intensity and target catch and also to determine the perceived coastal environmental problems, and fishers' attitudes to fishing actions and controls.

1. Purpose and frequency of fishing and gathering ${ }^{16}$

\footnotetext{
16 Fishing and gathering will be used as synonymously throughout this thesis and it refers to fishers' activities in coastal marine environment.
} 
Fishers were asked how often they go fishing per week. Of the 114 responses: $41 \%$ went fishing everyday, while $58 \%$ fish only when they need to which is about 3 times a week and $1 \%$ were not sure.

A multiple-choice question asked reasons for fishing and a participant could circle more than one reason. Because of this, the figures are presented as numbers rather than percentages. One hundred and twelve fishers go fishing for food. Other additional reasons for fishing include: 35 who fished as a source of their income, 22 recreationally fished, 6 fished for food specifically for their communities, and 2 fishers fished for customary reasons.

\section{$\underline{\text { 2. Fishers' experience and knowledge in fishing }}$}

A multiple-choice question was used to ask fishers how long they have been fishing. Of the 114 responses:

- $7 \%<$ a year

- $12 \%>1$ year $<5$ years

- $25 \%>5$ years $<10$ years

- $56 \%>10$ years

Fishers were asked by multiple-choice how they learnt to fish. These figures are presented in numbers rather than percentage because there could be more than one answer per person. The findings showed that 46 learned from their parents and grandparents, 42 fishers learned from relatives, 41 fishers learned from friends, whilst 40 were self-taught.

Fishers were asked by multiple-choice question whom they fish with and respondents could have more than one answer. Figures are presented as numbers. Sixty fishers identified fishing with friends, 58 stated that they could fish with either relatives or self and 30 fished with their children.

\section{$\underline{\text { 3. Fishing legacy }}$}

This open-ended question asked fishers if they passed on their skills and knowledge on how to fish. The findings showed: $55 \%$ pass on their skills practically, $34 \%$ are willing to pass on their skills but have found that their children are not interested. Four percent of 
fishers pass on their skills orally and $1 \%$ passes on their skills using both methods. At least $7 \%$ do not pass on their skills for reasons of family secrecy.

\section{Community fishing}

This question asked fishers if they were part of a group or an organisation. It is important to determine if fishers are part of an existing social network significant to the CBMC process. Collective action as a product social capital can be built upon existing local institutions.

The findings showed that most fishers are not part of any social organization. Fifteen fishers identified that they are a part of fishing organizations where 9 are members of a district fishing group, 2 were part of the district youth group, 2 are members of the Nauru Fishermen's Association (NFA) and 2 were members of a private-sector group -Capelle \& Partner (C\&P) and the Nauru Billfish Club respectively.

The following sets of questions are related to fishing patterns about fishers' preferences and their beliefs associated with fishing.

\section{Preferences for fishing}

This multiple-choice question asked fishers if they had a preference for fishing during the day, night or both and their reasons. From 104 responses: 18\% of fishers prefer to fish in the day, $10 \%$ fishers prefer to fish at night while $72 \%$ prefer to fish both.

An open-ended question asked their reasons. This was to determine the types of knowledge fishers possess about marine species. Their reasons are provided in figures below because fishers could provide more than one reason (Table 14).

There was a mixture of reasons for fishers' preferences. Their preferences are largely influenced by external variables such as time, species, the tide and gear. Fishers showed a general understanding of fish behaviours. They showed this by identifying that more fish are available and vulnerable at night. The use of noddy birds, as a fish finder mechanism is a traditional practice still used today. Also personal preferences play a significant part of fishers' decisions to fish day or night such as personal safety and taste. 
Table 13: Reasons for fishing times

\begin{tabular}{|lllll|}
\hline Reasons for fishing preferences & Day & Night & Both & Total \\
\hline After work & 1 & 1 & 0 & 2 \\
\hline More fish at night & 0 & 4 & 1 & 5 \\
\hline Safety concerns & 3 & 0 & 0 & 3 \\
\hline Depends on target catch & 1 & 0 & 46 & 47 \\
\hline Fish are easily caught & 2 & 4 & 2 & 8 \\
\hline Enjoy fishing & 0 & 0 & 4 & 4 \\
\hline Available time & 3 & 2 & 1 & 6 \\
\hline Dependent on tide and gears available & 1 & 0 & 3 & 4 \\
\hline Noddy birds used as a fish finder & 2 & 0 & 2 & 4 \\
\hline Use of flashlight is expensive & 2 & 0 & 0 & 2 \\
\hline If no fish caught during the day then fish again at night & 0 & 0 & 2 & 2 \\
\hline Fish are cleaner and tastier at night & 0 & 0 & 1 & 1 \\
\hline TOTAL & $\mathbf{1 5}$ & $\mathbf{1 1}$ & $\mathbf{6 2}$ & $\mathbf{8 8}$ \\
\hline
\end{tabular}

Overall there are many factors that can affect the fishers' choice to fish during the day and night or both which is important to understand when developing appropriate management and conservation mechanisms.

\section{Fishers belief systems}

This question is a multiple choice one. Fishers were asked if they have any traditional beliefs with respect to fishing. If fishers stated yes, then an open-ended question asked what these beliefs were. Fishers could have more than one belief. This question explores fishers' belief systems to identify any existing forms of knowledge such as superstitions, 
myths and traditional ecological knowledge (TEK). Local knowledge and TEK is important to CBMC as described in Chapters 3 and 4 . The findings were analysed and categorised according to the respondents' reasoning - superstition, common sense and TEK (Table 15).

Table 14: Fisher's beliefs

\begin{tabular}{|c|c|c|}
\hline $\begin{array}{l}\text { Beliefs associated with } \\
\text { fishing/gathering }\end{array}$ & Frequency & $\begin{array}{l}\text { Categories of belief systems } \\
\text { TEK/Superstition/Common sense/ } \\
\text { Culture }\end{array}$ \\
\hline $\begin{array}{l}\text { No fighting at home before } \\
\text { going fishing }\end{array}$ & 2 & $\begin{array}{l}\text { Superstition because it is believed that they } \\
\text { will catch no fish }\end{array}$ \\
\hline $\begin{array}{l}\text { Harvest enough to meet daily } \\
\text { needs }\end{array}$ & 1 & Part of TEK as advised by elder \\
\hline $\begin{array}{l}\text { Kamedu - a Nauruan term } \\
\text { (direct translation) means that } \\
\text { fisher cannot sleep with } \\
\text { spouse the night before any } \\
\text { big event }\end{array}$ & 10 & $\begin{array}{l}\text { Culture/superstition as this is prevalently } \\
\text { practiced also in sports and big events. The } \\
\text { idea is that one will lose their focus and as a } \\
\text { result will catch no fish. }\end{array}$ \\
\hline $\begin{array}{l}\text { If a rare fish species or not in } \\
\text { season is caught then fisher } \\
\text { has to stop fishing }\end{array}$ & 2 & $\begin{array}{l}\text { Superstition- this is a warning if fisher } \\
\text { continues to fish then it will result in serious } \\
\text { consequences }\end{array}$ \\
\hline $\begin{array}{l}\text { Not to fish on other people's } \\
\text { enge (fish aggregation } \\
\text { devices) on the reef flats }\end{array}$ & 1 & $\begin{array}{l}\text { A mixture of common sense-as this is } \\
\text { someone else's property. Superstition as a } \\
\text { result fisher will catch no fish }\end{array}$ \\
\hline $\begin{array}{l}\text { After the full moon fish are } \\
\text { easily caught }\end{array}$ & 1 & Part of TEK -informed by others \\
\hline $\begin{array}{l}\text { To catch a prized fish such as } \\
\text { a marlin. One has to abstain } \\
\text { from fishing for a month }\end{array}$ & 1 & $\begin{array}{l}\text { Superstition and TEK -informed by elder } \\
\text { and practiced }\end{array}$ \\
\hline $\begin{array}{l}\text { No fishing during half moon } \\
\text { its jellyfish season }\end{array}$ & 1 & Part of common knowledge and TEK \\
\hline $\begin{array}{l}\text { Taboo fishes are not to be } \\
\text { caught (individuals have } \\
\text { different taboo species) }\end{array}$ & 2 & $\begin{array}{l}\text { Mixture of culture and superstition - } \\
\text { informed by elder and practiced }\end{array}$ \\
\hline
\end{tabular}




\begin{tabular}{|lll|}
\hline Not to fish during rough seas & 1 & Common sense \\
\hline $\begin{array}{l}\text { Legendary shark -not to say } \\
\text { its name while fishing }\end{array}$ & 1 & $\begin{array}{l}\text { This is part of the Nauruan legend and } \\
\text { people know the story. It is surrounded with } \\
\text { myth and superstition but practiced. }\end{array}$ \\
\hline $\begin{array}{l}\text { More fish are found during } \\
\text { full moon }\end{array}$ & 1 & Part of TEK \\
\hline $\begin{array}{l}\text { Kids are not allowed to go } \\
\text { fishing }\end{array}$ & 1 & Superstition - most children fish in Nauru \\
\hline $\begin{array}{l}\text { Not to eat before fishing } \\
\text { otherwise one will not catch } \\
\text { any fish. }\end{array}$ & 2 & Superstition but practiced \\
\hline TOTAL & 27 & \\
\hline
\end{tabular}

Fisheries are often surrounded by superstition and myths that are passed down from generations as described by one expert in Chapter 4. Some beliefs are well known while others are personal ones. Caution is needed in interpreting the results here, as these are based on the people's perceptions, and those categorised as TEK need further verification.

This section focuses on fishing gear: the types of gear used the use traditional versus modern gear, efficiency of gear and their control measures.

\section{$\underline{\text { 8. Traditional and modern fishing gear and methods }}$}

This question asked fishers about their use of traditional and modern gear. The findings from 115 fishers showed: 97\% use modern fishing gear and 3\% claimed to use only traditional fishing gear. Out of the $97 \%$ who use modern fishing gear: $54 \%$ also use traditional fishing gear. Fishers were asked to identify the traditional fishing gear used (see Appendix 4: Table 40). The findings are summarised below:

- Etangat ${ }^{17}$ used in bottom or deep-sea fishing

- Deganke $e^{18}$ a tool used for catching octopus

\footnotetext{
${ }^{17}$ Nauruan name of a highly efficient gear which looks similar to a Christmas tree line with hooks at every end.

${ }^{18}$ Nauruan name of a gear that has a long staff with a hook at the end-usually composed of modern materials (e.g. coat hanger).
} 
- Traditional fish traps for eel and lobster

- Koro a hand-line method for deep-sea fishing

- Use of moon cycles and phases to indicate fishing seasons

- Baits to target specific species

- Hammer, knife and net used in gleaning

Traditional gear and methods identified by fishers are made out of modern materials and not local materials as they were formerly. Despite this fact, fishers have maintained traditional concepts of the gear over time.

Fishers were also asked if modern gear and methods have increased or decreased their catches. From 71 recorded responses: $63 \%$ of fishers agreed that traditional gear increased their catch, $24 \%$ fishers stated no difference between their catches using both gear and $13 \%$ fishers do not use traditional gear.

\section{Efficiency of gear and having control measures}

This question asked fishers to list the fishing gear they considered efficient ${ }^{19}$ and which gear should be controlled. Missing data or non-responses were found in this question. Fishers' responses are tabulated (Table 15). A number of fishers identified the type of fishing gear as efficient or inefficient and what gear needed control.

Table 15: Efficiency and control of fishing gear and methods

\begin{tabular}{|l|l|l|l|l|l|l|l|}
\hline $\begin{array}{l}\text { Type of fishing } \\
\text { gear }\end{array}$ & \multicolumn{3}{|l|}{ (i) Gear efficiency } & \multicolumn{3}{l|}{ (ii) Control gear } \\
\hline $\begin{array}{l}\text { Fisher } \\
\text { responses }\end{array}$ & Efficient & $\begin{array}{l}\text { Not } \\
\text { efficient }\end{array}$ & $\begin{array}{l}\text { Not } \\
\text { sure }\end{array}$ & Agree & $\begin{array}{l}\text { Not } \\
\text { agree }\end{array}$ & $\begin{array}{l}\text { Not } \\
\text { sure }\end{array}$ & $\begin{array}{l}\text { No } \\
\text { comment }\end{array}$ \\
\hline Spear gun & 64 & 39 & 3 & 31 & 0 & 1 & 32 \\
\hline SCUBA & 61 & 36 & 6 & 52 & 2 & 2 & 5 \\
\hline Night fishing & 67 & 35 & 3 & 23 & 2 & 1 & 41 \\
\hline Cast net & 68 & 36 & 6 & 39 & 2 & 1 & 26 \\
\hline Seine net & 66 & 38 & 4 & 46 & 2 & 1 & 17 \\
\hline Spearfishing & 66 & 36 & 2 & 32 & 1 & 1 & 32 \\
\hline
\end{tabular}

\footnotetext{
${ }^{19}$ Efficient was defined in its simplest form as less cost/effort/time spent fishing but with more catch.
} 


\begin{tabular}{|l|l|l|l|l|l|l|l|}
\hline (fork) & & & & & & & \\
\hline Rod fishing & 62 & 40 & 4 & 12 & 3 & 1 & 46 \\
\hline Canoes & 63 & 40 & 4 & 12 & 3 & 1 & 47 \\
\hline $\begin{array}{l}\text { Fishing } \\
\text { boats/skiffs }\end{array}$ & 62 & 39 & 5 & 26 & 2 & 1 & 33 \\
\hline Gleaning & 56 & 44 & 5 & 37 & 1 & 1 & 27 \\
\hline
\end{tabular}

(i) The findings showed that most (68 to 66) fishers stated that the following types of gear were efficient, given in descending order: cast nets, night fishing, seine nets and spearfishing (fork). About 35-44 fishers disagreed that any gear is efficient. About 2-6 fishers were unsure.

(ii) The findings also showed that the number of fishers who agreed to have control measures on different types of gear ranged from 12 to 52. Most fishers wanted control (given in descending order) on SCUBA, seine net, gleaning and spearfishing (fork and gun). At least 3 fishers disagreed with having any control measures and one person was unsure. There was no response from about 47 fishers to this question.

The high level of non-responses to the second question could be interpreted as indicating fishers' unwillingness to see control measures introduced on their fishing gear. This is a significant finding for this study because the CBMC process relies on individuals' incentive structures (Pomeroy, 2007), especially for extractive users of the resource. In other words, the willingness of fishers to participate in the CBMC bears upon their willingness to comply with and adopt control measures to regulate their own activities in the resource system.

Based on the result, this data was further analysed to estimate the percentage of fishers who agreed, disagreed or were unsure about gear efficiency and their controls. These findings are given in Figures 12 and 13. 


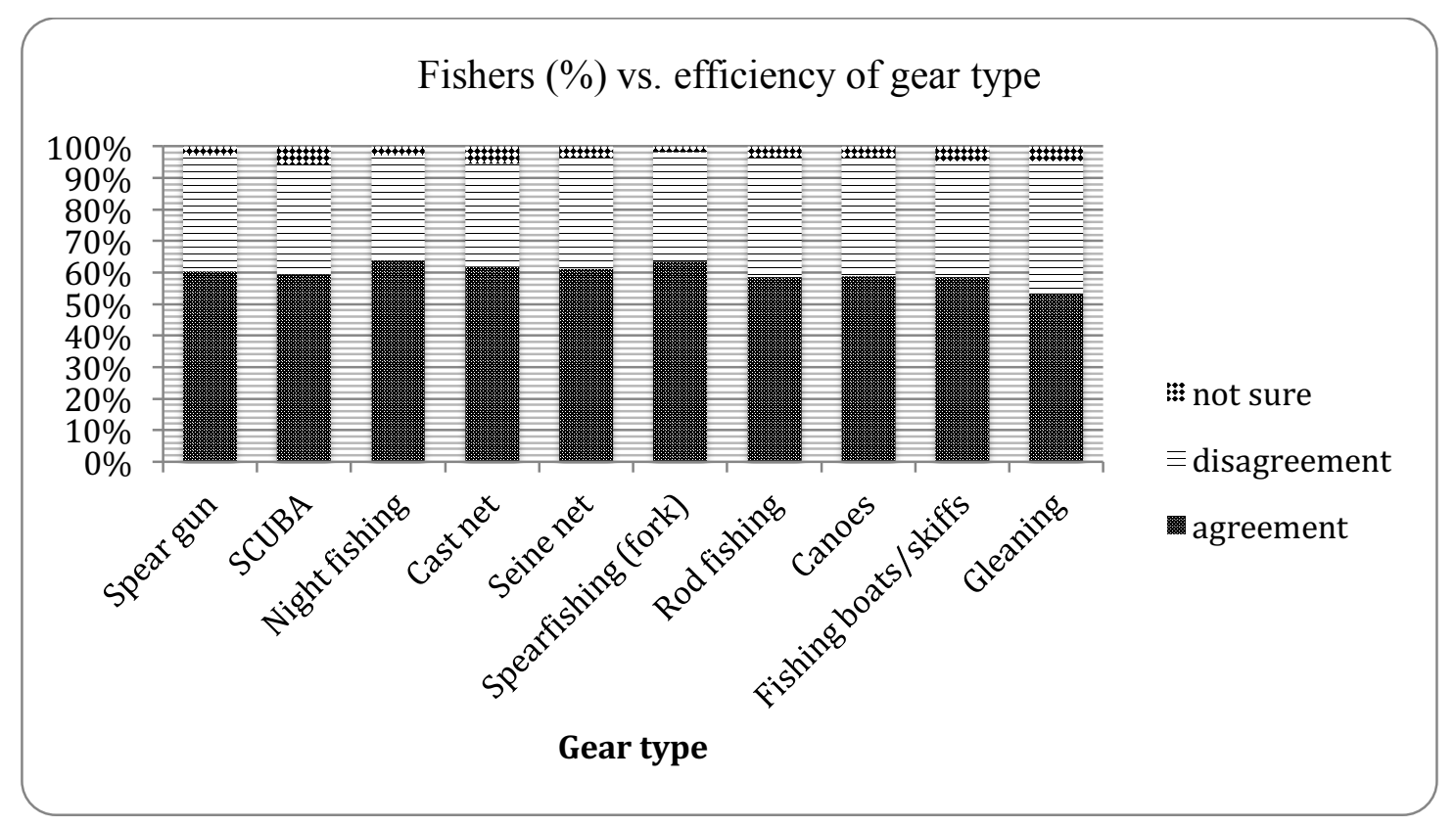

Figure 12: Fishers (\%) perceived efficiency of fishing gear

(i) About $60 \%$ of fishers identified all type of fishing gear as efficient. About $40 \%$ disagreed and fewer than $5 \%$ of fishers were unsure (

Figure 12).

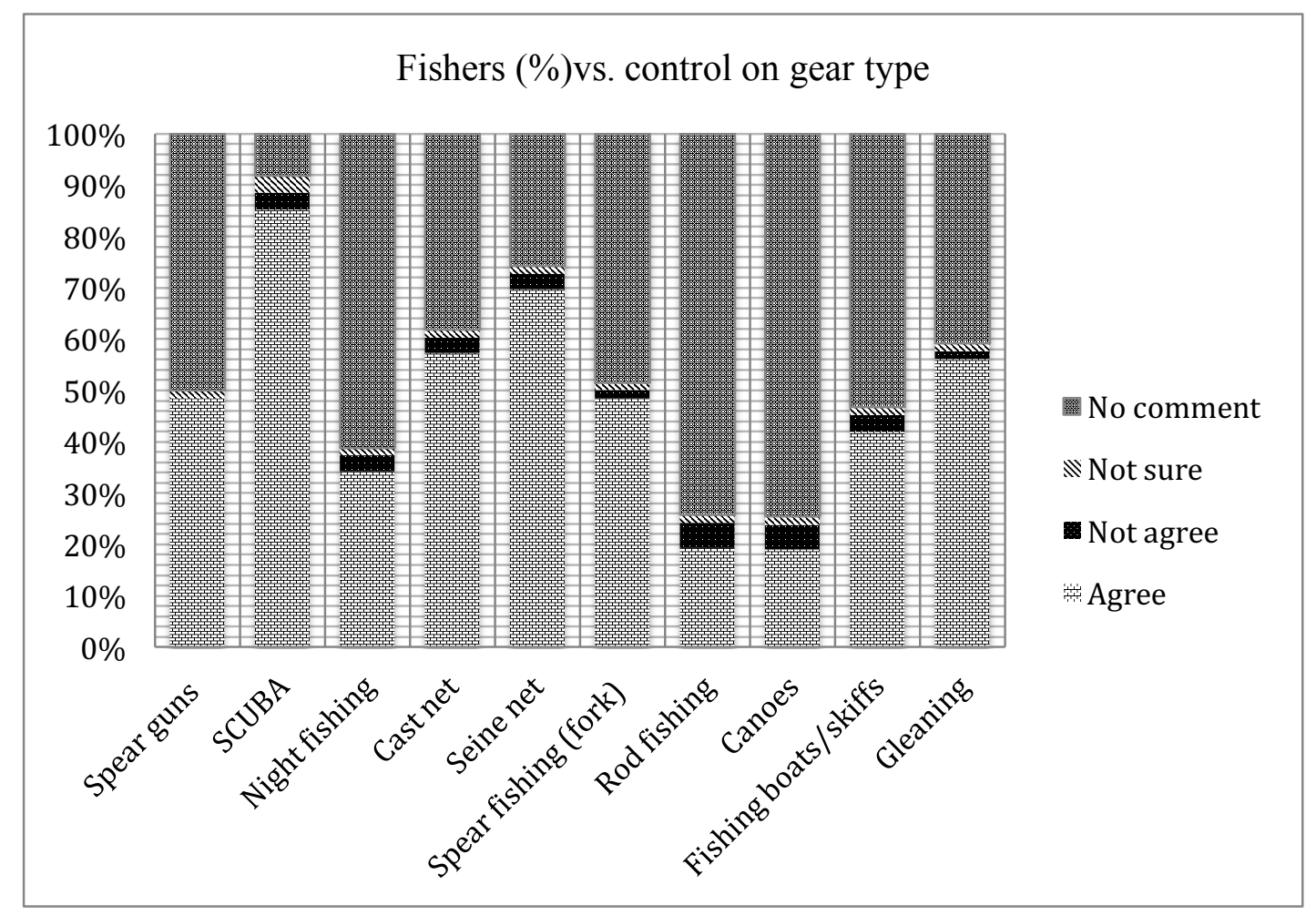

Figure 13: Fishers' (\%) response to control gear type 
(ii) Fishers were asked about taking action or control against each gear type. The findings display a pattern of gear types that most fishers agreed should be controlled or managed. Given in descending order, these are: (82\%) SCUBA, (70\%) seine nets, (58\%) cast nets, $(56 \%)$ gleaning. Gear types that were identified by about $50 \%$ of fishers or less less include: spearfishing, boat fishing (with outboard motor), night fishing, use of rods and canoe.

(iii) Figure 13 also presents the percentage of fishers who did not respond to this question, disagreed or were not sure about introducing gear control opposite to the given descending order above (ii). Fishers showed their agreement to action but were not as willing to take such action themselves. Festinger's (1957) theory of cognitive dissonance is used to explain the contradictory behaviour of fishers (more detail on this in the discussion section of this chapter).

\section{Target species}

Fishers were asked using a multiple choice question if they target specific species. To validate these responses, a second question asked fishers to name specific species being targeted and the types of gear and methods used to catch them. The respondents provided local common names of target species and the researcher provided both the scientific and common-name for each species mentioned.

Of a total of 115 respondents: $73 \%$ fishers stated that they do target specific species using specific gears and methods. The findings are presented in a matrix to indicate the target species identified by the respondents including the types of gear and methods used. This table is available in the appendices (see Appendix 4-Table 41). Figure 3 provides a crosssection of the coastal areas; the reef flat, sheltered reefs and passages (offshore and deeper areas) and the findings indicate that in each area, fishers target various species using the different gear and methods in Table 44. The majority of the fishers use spearfishing gear (SCUBA, spearguns, forks and group fishing) to target most coastal marine species.

Canoes and boats with outboard motor target larger pelagic and deep-sea fishery.

It is argued that Nauruan fishers' are generalists in their fishing behaviours and they have reported collecting all invertebrates and reef finfish species they come across, and are consuming and harvesting species not harvested before (Vunisea, 2007). Generalists have 
the tendency to be opportunistic rather than selective, especially when the resources are overexploited (Vunisea, 1997).

There are noted discrepancies regarding the researcher's findings compared to Vunisea's (2007) findings regarding the fishing behaviours of the fishers. It should be articulated that the methodology of these two researches are different. The researcher conducted dwelling interviews while Vunisea's (2007) method included ad-hoc fieldwork and verified fishers' catches in the field. The findings are highlights the credibility of the fishers' who identified themselves as selective for this study.

\section{Status of the coastal marine resources and its environment}

Fishers were asked to identify the key problems the coastal marine environment faces, their causes, and potential solutions for these. These questions are multiple-choice and open-ended. Fishers could identify up to five site(s) as having current problems and could suggest possible strategies to address these problems.

For ease of comparison these results are generated from the recorded responses of fishers and are presented in tabular format (see Appendix 4: Table 42). A total of 227 responses were recorded. The findings are summarised under each theme, with a brief explanation. Respondents could have more than one answer.

a) Problems with coastal development

1. Sand erosion is a problem for all coastal districts except for Anetan, Uaboe, Nibok and Denig.

2. Sewage problems found in Aiwo and Denig because of the national sewage drainage pipes emptying out to sea. Sewage problems found in Anibare and Ewa could be from people using the beaches as toilet facilities. As highlighted earlier, nearly half of the dwellings do not have running water, which could be one explanation of this issue.

3. Change of ocean currents is perceived as a problem, as it creates uncertainty among fishers generating navigational concerns and difficulties in finding fish.

4. Waste oils from Utilities ${ }^{20}$ because they directly discharge into the coastal marine areas of Boe.

\footnotetext{
${ }^{20}$ Utilities is a state-owned entity that generates national power and distributes potable water to the country. Utilities operate generators and processes potable water from the desalination plants.
} 
5. Problems of man-made and land reclamation infrastructures in Aiwo and Boe. In Aiwo, the land-fill ${ }^{21}$ on the reef and in Boe, the rocks ${ }^{22}$ were set in the boat channel to stop sand erosion.

b) Problems found in the coastal marine habitats

1. Algal growth is a problem found in Anibare, Ijuw, Anabar, Anetan, Baitsi, Boe and Meneng. Algal growth on coral reefs is an ecological indicator of human impacts; the combination of high nutrients such as sewage pollution or runoffs and low herbivorous stocks that predate on algae (ReefCheck, 2010).

2. Rubbish was identified as a problem all around Nauru except for the districts of Anetan and Nibok.

3. Damaged reefs, which fishers recognised as a threat to their livelihoods. Meneng district was frequently mentioned as having this problem. Then Boe, Yaren, Anibare, Baitsi, Uaboe, Aiwo and Nibok.

4. Change in the reef colour in Ewa, Baitsi and Uaboe. Fishers regarded this as indicating a reef health problem.

5. Fishers identified these districts as overfished: Anibare, Meneng, Ewa, Baitsi, Denig, Aiwo and Yaren.

c) Problems with the marine resources

1. Fewer fish are found in all coastal districts except for Boe and Location ${ }^{23}$.

2. There are too many sea urchins found in the districts of Anibare, Boe, Yaren and Meneng.

3. Loss of hermit crabs in the districts of Anibare, Anabar and Yaren.

4. Fish is becoming harder to find or found only in deeper waters especially in the areas of Anibare, Ijuw, Anetan, Ewa, Baitsi, Uaboe, and Yaren.

5. Some fish species have disappeared in Ewa and Baitsi.

\footnotetext{
${ }^{21}$ The land-fill was constructed to allow the phosphate to be loaded on ships when the shipping dock was unavailable due to rough seas and where there was a lack of shipping buoys to hold the ship in place for the loading.

${ }^{22}$ The purpose NFMRA placed rocks in the channel was for fishers' fishing boats to use it, as a point of entry and exit (launch site) safely.

${ }^{23}$ Interpreting this finding could also mean that fishers do not frequent these two coastal districts but fewer fish are found by fishers.
} 
6. Too many sharks ${ }^{24}$ are a problem found in all coastal districts except for Ewa, Uaboe, Location and Boe. Ijuw and Yaren were identified as shark areas.

7. Too many dolphins are a problem ${ }^{25}$ especially in Anabar. The coastal areas of Anibare, Ijuw, Ewa, Denig and Boe are not included. Dolphins are not eaten in Nauru like in some Pacific Island countries. This is why local fishers resent them and call them pests ${ }^{26}$. There are no records of dolphins caught in Nauru.

d) Problems with resource-users

1. There are too many fishers. As illustrated in Chapter 2, overcrowding is bound to be a problem ${ }^{27}$.

2. There are too many net fishers in Ijuw and Ewa. Same problem as above.

3. Frigate-bird owners ${ }^{28}$ from Meneng are a problem because they use destructive fishing gear (cyanide) to catch their fish. Perceived as competing with other fishers in order to feed their frigate birds and not families.

Some fishers provided possible strategies to the problems above. A total of 44 responses were coded and a summary is presented below (see Appendix 4: Table 43):

- Clean-up rubbish, sewage and overfished areas.

- Introduce regulatory measures or laws to control the number of fishers and stop damage to reefs.

- A ban on the use of SCUBA gear as some fishers suggest that SCUBA fishers are responsible for fish moving into deeper waters (as fish are difficult to find).

- Some were not sure of any solutions to address algal growth, fewer fish in the sea, too many sea urchins and overfished areas.

\footnotetext{
${ }^{24}$ Fishers compete with sharks. Despite this problem, there are no recorded shark attacks in Nauru.

${ }^{25}$ These compete with the tuna fishers' catch.

${ }^{26}$ Dolphins can eat tunas caught on a fisher's line and will leave the head of the tuna on the hook intact with no body.

${ }^{27}$ Recap of some of the challenges; a high population density, decreased standards of living, open-access nature of the resource system and people reverting to fish for their livelihoods. No strong regulatory measures are in place yet.

${ }^{28}$ Frigate-bird ownership is a culturally revered occupation among frigate-bird owning community in Nauru. The majority of frigate-bird owners in Nauru feed their frigates tunas and not reef finfish because they are revered and thus well-cared for.
} 
Not one of the fishers had included community-based measures as a suggestion or a solution to the problems. The probability is that fishers are not aware or are unfamiliar with the NFMRA CBFM programme, which could explain the lack of inclusion.

The response rate to this question was low and this could be interpreted as indicating fishers' lack of knowledge and information about what needs to be done. It could also indicate their resistance to or avoidance of making any suggestions for management measures that may affect them personally in the future.

\section{Perception on endangered or abundant species}

Fishers were asked using an open-ended question to identify any marine species perceived as 'disappeared' (of concern) or seemingly in abundance within the last five years. .

Fishers highlighted the loss of hermit crabs (in previous question). This question is to find links between the problems of specific species. The results are tabulated with the species of concern on the left hand side and species found in abundance on the right hand side (

\section{Table 16).}

Table 16: Species of concern and abundance

\begin{tabular}{|llll|}
\hline Species of concern & Frequency & Species found in abundance & Frequency \\
\hline Large trevally (eapwe) & 8 & Skipjack tuna & 2 \\
\hline Octopus & 4 & Leather jacket fish family & 4 \\
\hline Eaborbor (banded surgeon fish) & 4 & Ename (sea perch) & 2 \\
\hline Snappers & 4 & Surgeon fish family & 7 \\
\hline Big eye tuna & 1 & Dedawud (porcupine fish) & 1 \\
\hline Small trevally (ereb) & 7 & Iudud (cod) & 1 \\
\hline Iwiji (leather jacket family) & 3 & Large trevally (eapwe) & 1 \\
\hline Eweo (convict surgeon fish) & 3 & & \\
\hline Mullet & 4 & & \\
\hline Iwuro (cod) & 2 & \\
\hline Soldierfish & 2 & & \\
\hline Ijibawo (drummer fish) & 3 & & \\
\hline
\end{tabular}




\begin{tabular}{|lc|}
\hline Dabugbug (seargent fish) & 1 \\
\hline Dogtooth tuna & 2 \\
\hline Turban snails (emari) & 7 \\
\hline Goat fish & 1 \\
\hline Cods & 2 \\
\hline TOTAL & $\mathbf{5 8}$ \\
\hline
\end{tabular}

The top five species of most concern include: trevally species - adult and juvenile, turban snail (invertebrates), octopus, surgeon fish, snappers, and mullet. The top five species found in abundance include: fish of the surgeon family (Acanthuridae), leather jacket fish family (Balistidae), skipjack tuna, sea perch and surgeon fish. Some species, such adult silver trevally, banded surgeon fish and convict fish (Acanthuridae) were identified as both of concern and in abundance. This data does not provide substantive information about species of concern. These findings will be compared to the ProcFISH project report in the key point discussion.

\section{Simple analysis on cost and benefits of fishing}

This question asked fishers the amount they spend to go fishing using various gear and methods. Some fishers answered this question by providing the initial costs of their gear for each specific methods and another group of fishers provided the weekly costs of fishing after gear has been purchased. The results are presented in two forms, a) the initial cost of the gear and b) the average weekly costs of fishing based on gear and methods.

\section{a) Initial cost of fishing gear}

A total of 29 fishers provided an estimated cost of their gear and methods. In order to understand the cost of gear to method, a tabulation of costs to gear is presented in summary form (see APPENDIX: Table 45). Costs presented are an estimated range of costs rather than a specific unit of cost to acknowledge the fact that the price of gear does fluctuate over time. All prices and costs indicated are in Australian Dollars (AUD) based on Nauru's currency.

For example if a person was to enter fishery as a spearfishing free-diver then initial costs of gear would range between $\$ 200-\$ 500$, while for SCUBA the cost of gear can range 
between $\$ 500-\$ 1000$. Net fishing using a cast net or seine net costs range from $\$ 150-\$ 200$. For rod fishers the cost will range from $\$ 200-\$ 500$ and sometimes even more dependent upon their quality. Gleaners' fishing gear cost range from $\$ 20-\$ 50$. For fishers who use boats with a motor, costs were based on these three methods; trolling for tunas, bottomfishing for deep sea fishes and scoop net for flying fish. The costs reflect estimated costs of gear (engine, winches, fuel, hooks, and lines) excluding the boat. Fishing gear can cost these fishers from $\$ 100$ to $>\$ 1000$. In general most fishers participate in more than one of these fishing methods and this is largely dependent upon the target species.

b) Weekly costs

The costs of fishing on a weekly basis after gear were procured. The costs of using different fishing methods are indicative of fuel costs and maintenance:

An average weekly cost of gleaning is $\$ 0-\$ 5$, but other fishers stated that it can cost them up to $\$ 20-\$ 50$ when gleaning at night. Weekly costs for free divers are $\$ 0$ - $\$ 20$ but costs can increase when spearfishing at night. SCUBA divers' average cost is $\$ 20-\$ 50$, indicative of the costs of refilling compressed air for their cylinder tanks. Cast and seine net fishers spend on average $\$ 0-\$ 5$ to fish. Rod fishers find weekly fishing expenses are about \$20-\$50. Boat fishers who troll and bottom fish, spend on average from \$50- \$200 per week mainly for fuel costs. Boat fishers fishing for flying fish can spend an average of $\$ 0$-\$5 per week, while fishers who use a canoe can spend about $\$ 0$ - $\$ 50$ per week, at the higher end if they fished both day and night.

Initial entry into the fishery for gear can cost fishers from $\$ 100$ to $>\$ 1000$ for all gear and methods used except for gleaning which costs almost next to nothing.

\section{Who covers the costs of fishing?}

Fishers were asked a multiple-choice question about who covers the costs of fishing including both the start-up costs and weekly fishing activities. Respondents could circle all those that apply to their situation. This question helps to understand how fishers have adapted to changes in circumstance. The findings showed:

- A total of $80 \%$ of fishers pay their own fishing expenses and $17 \%$ of these fishers also share the costs of fishing.

- A total of $14 \%$ of fishers share their costs of fishing. 
- A total of $6 \%$ of fishers use other means.

Some examples include stealing and asking for money from their constituent representatives or community leaders (i.e. Member of Parliament).

\section{Costs of fishing compared to 5 years ago}

Fishers were asked using a multiple-choice question if they perceive any change with the current costs of fishing today compared to five years ago (2005), and if fishing costs more than buying food from the shops.

One hundred and thirteen responses out of a total of 115 respondents:

- $78 \%$ stated that fishing costs more today while $6 \%$ stated that fishing costs less, another $4 \%$ stated that fishing costs are the same today compared to five years ago while $12 \%$ were not sure.

- $40 \%$ stated that it does cost them more to fish than buy food from shops, $56 \%$ stated that it is cheaper for them to fish compared to buying food, $4 \%$ stated that the costs are the same.

This is an important question for this study, as it helps to understand the level of fishing intensity. Although fishing costs more today compared to five years ago, most fishers find that fishing is cheaper than buying food from shops.

\section{Catch given away}

Fishers were asked if they give away their catch and if they do how much. A total of 83 respondents stated yes they still practice this tradition of giving away a portion of their catch to others (usually relatives and friends). These respondents stated that it is entirely dependent upon the quantity and species of their catch (Table 18). 
Table 17: Average catch given away

\begin{tabular}{|ll|}
\hline Average quantity of catch & Number of fishers \\
\hline $1 / 4$ of catch & 20 \\
\hline $1 / 2$ of catch & 44 \\
\hline $3 / 4$ of catch & 15 \\
\hline All of catch & 4 \\
\hline TOTAL & $\mathbf{8 3}$ \\
\hline
\end{tabular}

\section{Benefits from fishing}

Fishers were asked if they benefit from fishing in the coastal marine areas and if yes, what the benefits are. This is an open-ended question and the responses were coded and recorded in the matrix.

Out of 100 responses, only one fisher stated that fishing has cost him more or he has lost more money compared to the benefits gained from fishing. Ninety-nine fishers stated that they do benefit from fishing but improvements need to be made. The benefits from fishing include: food, saving and earning money.

A total of 55 fishers benefit from the resources for their food security, 23 fishers stated that fishing saves money and 30 fishers benefit by earning money.

a) Improvements made to increase benefits

This open-ended question was coded to help summarise the key points that fishers identified as needing improvements to gain more benefits from fishing. These include:

- Introduce regulations in the coastal marine areas.

- Ban the use of SCUBA gears.

- Introduce species-specific limits on catch.

- Stop rubbish in the marine environment.

- Stop fishing of brood stocks.

- Introduce management of reefs.

- Introduce awareness programmes on reefs and resources. 
- Introduce seasonal closure of areas.

- Introduce mesh net size limits.

- Have more information about fishing gears and their impacts.

- Reduce cost of fishing- subsidised costs of fuel and gears.

- Stronger commitment of the government to manage marine resources.

- Introduce alternative-livelihoods to fishing.

- Revive the fish market.

- Ensure safety at sea gears is available.

- Introduce fishing regulations in the boat harbour areas.

- Increase the number of fish aggregating devices (FADs).

- Introduce marine reserves to farm clams.

Fifty four fishers suggested a reduction on the costs of fishing such as the introduction of government subsidies on the costs of fuel and gear to improve their livelihoods. Fishers in lesser numbers identified other improvements that include introducing management measures such as controls on gear, methods and catches, introduction of alternatives to fishing, implementation of marine reserves specifically for culturing clams ${ }^{29}$, and having FADs in place.

\section{Conserving the coastal resources and areas}

Fishers were asked using a multiple-choice question if they thought that conserving and protecting the coastal marine resources and its areas would be beneficial to them and their livelihoods. Out of 115 fishers, only 95\% (109) of fishers' responses were recorded: 91\% of fishers stated that they will benefit from the introduction of protection and conservation measures for the coastal marine areas, $1 \%$ stated no, $8 \%$ were unsure.

\footnotetext{
${ }^{29}$ The idea of establishing marine reserves to culture clam is perceived as increasing the value of the reserve by being productive. For example, a marine 'no-take zone' while at the same time productively ensuring food security needs are met.
} 


\subsubsection{Non-fishers' results}

Non-fishers were defined for the purpose of this study as those not actively fishing in coastal marine areas within the period of six months before the fieldwork took place in July 2010. There are fishers who may not have participated in answering the fishers' questionnaire due to the strict time constraint of this questionnaire. The total number of non-fishers who answered the questionnaire was 155 . The questionnaire had a mixture of closed, multiple-choice and open-ended questions.

$\underline{1 .}$ Non-fishers' perceptions about the present and future status of the marine environment

Non-fishers were asked what they thought of the current status of the marine environment using a multiple-choice question. Some respondents provided their reasons (see Table 19):

Of a total of 155 non-fishers, only 140 responses were recorded. Twenty two percent stated that the current status of the marine environment was either very good or good, $46 \%$ stated the contrary, and 35\% were not sure. As to the future status of the marine environment, at least $6 \%$ expected that the status would improve, $9 \%$ thought that it would remain the same, $35 \%$ seemed to think the status of the marine environment would get worse over time and $51 \%$ were not sure.

Table 18: Non-fishers perceptions on the status of the coastal marine environment

\begin{tabular}{|lllllr|}
\hline $\begin{array}{l}\text { Current } \\
\text { status }\end{array}$ & $\begin{array}{l}\text { Number of } \\
\text { responses }\end{array}$ & $\%$ & Future status & $\begin{array}{l}\text { Number of } \\
\text { responses }\end{array}$ & $\%$ \\
\hline Very good & 6 & 4 & Better & 8 & 6 \\
\hline Good & 25 & 18 & $\begin{array}{l}\text { Remain the } \\
\text { same }\end{array}$ & 12 & 35 \\
\hline Bad & 49 & 35 & Worse & 49 & 0 \\
\hline Very bad & 15 & & & 0 & 51 \\
\hline Not sure & 45 & 11 & Very bad & 0 & 71 \\
& & & & Not sure & \\
\hline
\end{tabular}


Sixty-eight non-fishers provided reasons for their views. The responses were coded to provide a summary of their answers, because recorded responses were not limited to those who stated that the status was either very good or good as instructed in the questionnaire (Table 20).

Table 19: Non-fishers' reasons of their perceptions regarding the status of the marine environment

\begin{tabular}{|llllllc|}
\hline Reasons for their assessment & $\begin{array}{l}\text { Very } \\
\text { good }\end{array}$ & Good & Bad & $\begin{array}{l}\text { Very } \\
\text { bad }\end{array}$ & $\begin{array}{l}\text { Not } \\
\text { sure }\end{array}$ & Total \\
\hline Plenty of fish & 6 & 7 & 0 & 0 & 0 & 13 \\
\hline Little change in environment & 3 & 3 & 0 & 0 & 0 & 6 \\
\hline Fish still available & 0 & 4 & 4 & 0 & 0 & 8 \\
\hline No marine life on reefs & 0 & 0 & 8 & 0 & 0 & 8 \\
\hline Big changes in the environment & 0 & 0 & 2 & 1 & 0 & 3 \\
\hline Impacts of destructive fishing & 0 & 0 & 6 & 3 & 0 & 9 \\
\hline Impacts of land developments & 0 & 0 & 1 & 0 & 0 & 1 \\
\hline $\begin{array}{l}\text { Impacts of coastal (sand) } \\
\text { erosion }\end{array}$ & 0 & 1 & 4 & 1 & 1 & 7 \\
\hline Sea-level rise & & & & & & 1 \\
\hline Rubbish & 0 & 0 & 1 & 0 & 0 & 1 \\
\hline Not interested & 0 & 0 & 10 & 1 & 0 & 1 \\
\hline
\end{tabular}

The reasons non-fishers answered either very good or good was based on the justification that they perceived that there are plenty of fish, and there has been little change in the environment and they believe that plenty of fish are still available. Of those who said the status of the marine environment was bad had identified rubbish as their reason. Others suggested there was no marine life to be found on the reefs due to destructive fishing, and coastal erosion. These individuals also stated that they have noticed big changes in the marine environment from land-based development and sea level rise. 


\section{Non-fishers ranking of problems found in the coastal marine environment}

This is a sequential question. It asked respondents to rank which impacts and activities were causing major problems in the coastal marine environment. The ranking scale was 1 to 5 , where $1=$ low and $5=$ high or major problem. Next was to identify 'who' was responsible for these detrimental impacts or activities. Then they were asked to provide some solutions to address the major problems they identified.

a) The findings are based on the total aggregated mean scores (see Appendix 4: Table 46). For example, a mean score of 1.69 is of low concern while a mean score of 4.78 is seen as indicating a major problem affecting the coastal marine environment.

Based on the aggregated mean scores, non-fishers identified those impacts and activities as problems in the coastal marine environment as (in descending order): rubbish, land-based development, pollution, sewage, land-based run-offs, cyanide fishers, crowbar fishers, coral and sand mining, overfishing, phosphate mining, SCUBA fishers, group fishers "akida," seine net fishers, cast net fishers, free divers, reef FAD fishers, night fishers, trolling and trap fishers. Port development ${ }^{30}$ was identified as having detrimental impacts on the coastal marine environment.

Overall non-fishers ranked rubbish as number one. Other detrimental impacts include landbased development, pollution, sewage and land-based run-offs. Of all the forms of fishing activity, non-fishers ranked the use of destructive methods such as crowbars and cyanide as having the most detrimental impact.

b) Non-fishers identified 'who' was responsible for causing these detrimental impacts. The findings here are based on 'major' impacts that gained an aggregated mean score of $\geq 4.05$ in the previous question.

\footnotetext{
${ }^{30}$ One person identified this as having a major impact to the coastal marine environment and scored it a ' 4 '. Caution is required when interpreting this as a major impact problem because this is not an 'aggregated' mean score.
} 
Table 20: Non-fishers identified the major causers of detrimental impacts and activities found in the coastal marine environment

\begin{tabular}{|c|c|c|c|c|c|c|}
\hline $\begin{array}{l}\text { Detrimental impacts and } \\
\text { activities to the coastal } \\
\text { marine environment and } \\
\text { their 'causers' }\end{array}$ & Locals & Chinese & Government & Other & $\begin{array}{l}\text { Not } \\
\text { sure }\end{array}$ & Total \\
\hline Rubbish & 122 & 0 & 1 & 1 & 1 & 124 \\
\hline Sewage & 60 & 0 & 38 & 1 & 1 & 100 \\
\hline Pollution & 87 & 0 & 17 & 2 & 2 & 108 \\
\hline Land-based run-offs & 65 & 0 & 1 & 1 & & 67 \\
\hline Use of cyanide in fishing & 67 & 11 & 0 & 9 & 9 & 96 \\
\hline $\begin{array}{l}\text { Use of crowbar/hammer in } \\
\text { fishing }\end{array}$ & 81 & 3 & 0 & 4 & 3 & 91 \\
\hline Coral mining & 83 & 0 & 4 & 1 & 2 & 90 \\
\hline Sand mining & 83 & 0 & 3 & 1 & 1 & 88 \\
\hline Overfishing & 84 & 1 & 0 & 2 & 1 & 88 \\
\hline Phosphate mining & 19 & 0 & 33 & 0 & 4 & 56 \\
\hline
\end{tabular}

The findings showed the 'causers' as mostly local people. Some identified Chinese fishers as those using cyanide, crowbars and hammers in their fishing. The government plays a role in the problems of sewage and pollution. For phosphate mining, the government is perceived to take the lead responsibility for any detrimental impacts affecting the marine environment.

c) Non-fishers identified how these problems can be addressed and their potential solutions. The popular solution to the identified problems was to have rules and regulations put in place to address rubbish, sewage, pollution, coral and sand mining, and land-based run offs. Regulatory measures were recommended for the use of cyanide, and crowbars and hammers in fishing. The local community, NFMRA, as well as the national government were identified as the institutions responsible for addressing these problems (Table 22). 
Table 21: Non-fishers identified those that should be responsible

\begin{tabular}{|llllllc|}
\hline $\begin{array}{l}\text { Major problems \& } \\
\text { 'who' should be } \\
\text { responsible }\end{array}$ & $\begin{array}{l}\text { Local } \\
\text { community }\end{array}$ & NFMRA & $\begin{array}{l}\text { Have } \\
\text { rules in } \\
\text { place }\end{array}$ & Government & $\begin{array}{l}\text { Not } \\
\text { sure }\end{array}$ & Total \\
\hline Rubbish & 37 & 17 & 46 & 13 & 3 & 124 \\
\hline Sewage & 8 & 17 & 39 & 28 & 1 & 93 \\
\hline Pollution & 17 & 15 & 42 & 27 & 4 & 105 \\
\hline Land-based run-offs & 14 & 13 & 32 & 22 & 4 & 85 \\
\hline $\begin{array}{l}\text { Use of cyanide in } \\
\text { fishing }\end{array}$ & 20 & 22 & 33 & 10 & 3 & 88 \\
\hline $\begin{array}{l}\text { Use of } \\
\text { crowbar/hammer in } \\
\text { fishing }\end{array}$ & 19 & 20 & 36 & 7 & 3 & 85 \\
\hline Coral mining & 14 & 16 & 38 & 14 & 1 & 83 \\
\hline $\begin{array}{l}\text { Sand mining } \\
\text { Overfishing }\end{array}$ & 15 & 17 & 37 & 14 & 2 & 85 \\
\hline $\begin{array}{l}\text { Impacts of phosphate } \\
\text { mining }\end{array}$ & 3 & 23 & 28 & 9 & 4 & 85 \\
\hline
\end{tabular}

As described in Chapter 2, Nauru has regulations that prohibit people from littering in the coastal marine environment under the Littering Act 1983, and under the NFMRA Act of 1998 use of destructive fishing methods is banned. These need to be strengthened and enforced as part of the CBFM programme.

3. Non-fishers' awareness of existing rules and regulations in Nauru's coastal marine $\underline{\text { environment }}$

Using a multiple-choice question, non-fishers were asked if they were aware of any rules or regulations, either traditional or national, concerning coastal marine systems. If respondents stated yes, then they were asked what these rules were. From 154 responses, only $27(18 \%)$ of respondents stated yes and $127(83 \%)$ stated that no, they were not aware of any existing rules. 
For those who were aware, were further asked the type of rules they knew of and whether these were traditional or national. Only 24 responses (Table 23): Thirteen respondents were aware of traditional rules while 11 were aware of the existing national regulations.

Table 22: Non-fishers identified a) Traditional rules and b) National rules and regulation

\begin{tabular}{|llll|}
\hline $\begin{array}{l}\text { (a) Known traditional } \\
\text { rules }\end{array}$ & Frequency & $\begin{array}{l}\text { Compliance action } \\
\text { through self } \\
\text { regulation }\end{array}$ & $\begin{array}{l}\text { Compliance action } \\
\text { by informing others }\end{array}$ \\
\hline $\begin{array}{l}\text { Seasonal harvesting of } \\
\text { marine resources }\end{array}$ & 4 & 3 & 1 \\
\hline $\begin{array}{l}\text { Turban snail shells need to } \\
\text { be recycled (placed back on } \\
\text { the beach) }\end{array}$ & 2 & 1 & 0 \\
\hline $\begin{array}{l}\text { Expatriates or foreigners are } \\
\text { not allowed to fish }\end{array}$ & 1 & 0 & 0 \\
\hline $\begin{array}{l}\text { Leaders inform people of } \\
\text { the times to harvest }\end{array}$ & 1 & 0 & 1 \\
\hline $\begin{array}{l}\text { Seine nets are not to be } \\
\text { extended or lengthened }\end{array}$ & 2 & 2 & 0 \\
\hline (b) National rules & Frequency & $\begin{array}{l}\text { Compliance action } \\
\text { through self } \\
\text { regulation }\end{array}$ & $\begin{array}{l}\text { Compliance action } \\
\text { by informing others }\end{array}$ \\
\hline $\begin{array}{l}\text { No rubbishing on the beach } \\
\text { and the marine environment }\end{array}$ & 2 & 2 & 0 \\
\hline $\begin{array}{l}\text { Ban on destructive fishing } \\
\text { methods }\end{array}$ & 4 & 4 & 0 \\
\hline
\end{tabular}

At least 6 people are aware of the existing national regulations in place, 10 suggested traditional rules and most stated seasonal harvesting of marine resources. Some of the findings concerning former traditional rules, such as seasonal harvesting, are of interest to this study. These 'rules' could easily be developed into management tools and be a part of the 'diverse resource toolkit'.

This group were asked if they currently comply with the rules, and if so, how they comply. A total of 13 respondents said they do comply through self-regulation and by informing others. Three said they do not comply with the existing rules. Overall the level of 
awareness of existing traditional and national regulations regarding the coastal marine environment was limited to $18 \%$ of non-fishers in this sample. Compliance actions were very weak and limited to self-regulation and word of mouth.

$\underline{4 .}$ Non-fishers' perception regarding the introduction of rules and regulations in the coastal $\underline{\text { marine environment }}$

The first question was multiple-choice and asked whether non-fishers saw a need to introduce rules and regulations that aim to protect, restore and manage the coastal marine environment. Then they were asked whether they would be willing to comply to any rules or regulations if they were introduced. If respondents said yes or no, they were asked for their reasons.

The findings showed that from 152 responses recorded to the first question, 144 (95\%) stated yes, while $5(3 \%)$ stated no and $3(2 \%)$ were not sure. In terms of their willingness to comply in the future, from a total of 169 recorded responses, $160(95 \%)$ respondents stated yes while $9(5 \%)$ stated no. The reasons for their willingness and non-compliance in the future are tabulated (Table 24).

Table 23: Non-fishers reasons for compliance and non-compliance

\begin{tabular}{|c|c|c|c|}
\hline Reasons & $\begin{array}{l}\text { Willingness to } \\
\text { comply }\end{array}$ & $\begin{array}{l}\text { Not willing to } \\
\text { comply }\end{array}$ & $\begin{array}{l}\text { Total number of } \\
\text { responses }\end{array}$ \\
\hline Stop damage to our reefs & 15 & 1 & 16 \\
\hline Restore our fish stocks & 20 & 1 & 21 \\
\hline Protect our food resource & 19 & 1 & 20 \\
\hline For our future generations & 28 & & 28 \\
\hline Self-obligation and regulation & 6 & 1 & 7 \\
\hline Ensure a healthy environment & 48 & 0 & 48 \\
\hline Sustain our resources & 20 & 0 & 20 \\
\hline $\begin{array}{l}\text { Need an effective programme } \\
\text { in place }\end{array}$ & 1 & 0 & 1 \\
\hline Not used to having rules & 1 & 5 & 6 \\
\hline No comment & 2 & 0 & 2 \\
\hline TOTAL & 160 & 9 & 169 \\
\hline
\end{tabular}


The findings showed that non-fishers were willing to comply with future rules that ensured a healthy marine environment and conserved the resource for their future generations. Other reasons include: restoring fish stocks, sustaining the resource and preventing further damage to the reefs. Six respondents were willing to comply through self-regulation. One respondent suggested the need for an effective management programme in place before compliance can take place. Another reason that respondents cited was that they were not used to having rules but will comply. Five out of nine are not willing to comply based on not being used to having rules in place, and the rest gave reasons that contradict their unwillingness to act.

As Charles (2007) highlighted resource-communities are non-extractive users but still need to participate in the CBMC. Thus, this question is important for this study, because it assists in understanding the level of compliance among resource-communities. For those who are not willing to comply in the future, this could be a recognised phenomenon in environmental psychology (as highlighted earlier in this chapter) known as Festinger's (1957) theory of cognitive dissonance (more discussion concerning how to tackle this behaviour is found in the key point section of this chapter).

$\underline{\text { 5. Non-fishers' level of knowledge and information about marine management and }}$ conservation

This question asked about levels of knowledge and sources of information about coastal marine environment. They were asked if they would like to receive more information about coastal marine environment and what types of information they would prefer.

a) Level of knowledge about the coastal marine environment and their resources

From 154 responses recorded: 28 (18\%) stated that they had sufficient knowledge to manage and conserve the marine environment. Most, $126(82 \%)$ respondents stated that they lack this type of knowledge and information.

Those 28 respondents who have sufficient knowledge and information were asked to validate the source of this knowledge and information. Respondents were asked to identify their source(s). The findings showed that the forms of knowledge and information are: 
tradition through legends, elders, own experiences, school, and interest groups and from the media (Table 25).

Table 24: Non-fishers identified their sources of knowledge and information regarding coastal marine conservation

\begin{tabular}{|ll|}
\hline Sources of knowledge/information & Number of responses \\
\hline Traditional from legends & 12 \\
\hline From elders & 18 \\
\hline Own experience & 14 \\
\hline School (formal education) & 8 \\
\hline Interest groups & 8 \\
\hline Media & 5 \\
\hline
\end{tabular}

b) Non-fishers identified the source and types of information required

All were asked if they need more information and if so what type of information they want to receive and how they would like to receive this information. From a total 154 recorded responses: One hundred and thirty six (88\%) wanted more information about coral reef and marine environment management and conservation. Nine $(6 \%)$ did not want any information and 9(6\%) were unsure.

The types of information requested were coded and are presented in summary form (Table 26).

Table 25: Non-fishers identified the types of information they would like to receive

\begin{tabular}{|ll|}
\hline Types of information & No of responses \\
\hline Reef management & 103 \\
\hline Fishing gear/methods and news & 9 \\
\hline Status of resources & 18 \\
\hline Human impact on resources & 24 \\
\hline Breeding cycles of important food fishes & 11 \\
\hline All types of information & 29 \\
\hline
\end{tabular}


The most popular type of information wanted by non-fishers in descending order: reef management, all types of information, human impacts on the resources, the status of the marine resources, biological information about important food fishes and about fishing gear and methods.

In terms of preferred means of information dissemination, (Table 27) the findings show that most prefer to receive this information through: TV, newsletters, radio, workshops, email and phone calls. The questionnaire had included "other" as an option but most respondents stated workshop under this category. Adult literacy rate is $95 \%$ (Nauru, 2009). It was found that at least 1 in 3 Nauruans $\left(30.7 \%\right.$ ) have not completed their $3^{\text {rd }}$ year of secondary education and there is a low enrolment ratio of school-aged children although school is compulsory and free in Nauru (Nauru \& SPC, 2002). Brochures and posters may also be effective mediums.

Table 26: Non-fishers' responses to the type of medium best for awareness

\begin{tabular}{|ll|}
\hline Medium & No of responses \\
\hline TV & 84 \\
\hline Radio & 48 \\
\hline Email & 18 \\
\hline Newsletter & 61 \\
\hline Phone & 6 \\
\hline Workshop & 46 \\
\hline
\end{tabular}

\section{$\underline{\text { 6. Non-fishers' awareness of a marine conservation group and if one such group is }}$} established their willingness to join

The last series of questions asked participants if they are aware of any social groups that were currently involved in any forms of protection and conservation of the coastal marine environment. They were asked whether think there should be such a group and whether they would like to be a part of it. These questions were in a multiple-choice format. 
Of 151-recorded responses (Table 28), only 24 (16\%) stated that that they were aware that a marine conservation group does exist, with 127 (84\%) being unaware of any group. The 24 respondents who claimed that such a group exists were asked to name the conservation group(s). The groups involved in conservation activities are NFMRA, district communities and youth groups.

Table 27: Non-fishers identified current known marine conservation groups

\begin{tabular}{|ll|}
\hline Groups & No of responses \\
\hline NFMRA & 15 \\
\hline District community & 7 \\
\hline Youth (within district community) & 1 \\
\hline
\end{tabular}

One hundred and forty two recorded responses to the two following questions, 137 (97\%) said yes, there should be a marine conservation group. Only 83 (58\%) said that they would like to be a part of this group and 59 (42\%) said no.

7. Non-fishers' responses regarding introducing coastal zoning for protection of marine environment and who should be responsible for such a management

The last two questions were multiple-choice format, asking participants if they believe that introducing zoning in coastal areas for management and conservation purposes was a good idea, and if not, why not. The second part of the question asked who should be responsible for managing these zoned areas.

The findings showed that from the 153 recorded responses, one hundred and thirty-one $(86 \%)$ agreed to the introduction of coastal zoning for the purposes of marine protection, 9 (5\%) disagreed and $13(7 \%)$ were unsure. Those respondents who disagreed or were unsure were asked their reasons. Each respondent could have more than one reason. The findings were coded and tabulated (Table 29). 
Table 28: Non-fishers against coastal zoning as a means of marine conservation

\begin{tabular}{|ll|}
\hline Reasons for their disagreement & \multicolumn{1}{l|}{$\begin{array}{l}\text { No. of } \\
\text { responses }\end{array}$} \\
\hline Coastal marine environment is for food security & 6 \\
\hline $\begin{array}{l}\text { Coastal marine areas in Nauru are too small for any zoning to be put in } \\
\text { place }\end{array}$ & 1 \\
\hline This will create and cause conflict among the local people & 7 \\
\hline Some value the resources or their fishing grounds for zoning & 1 \\
\hline $\begin{array}{l}\text { Need more information and evidence about the benefits of coastal } \\
\text { zoning }\end{array}$ & 2 \\
\hline
\end{tabular}

The last question was what party/parties should be responsible for leading and managing coastal zoned areas. This was cross-tabbed against those who answered the first part of this question by identifying which key government agencies should share these responsibilities.

From the findings (Table 30), twenty-one suggested that the government should be responsible for the management. Nineteen thought that the community should be responsible and 95 stated that the government and communities should share responsibilities to manage the zoned areas. Two claimed they were willing to self-manage the zoned areas but 3 were unsure.

Table 29: Non-fishers identified those responsible to manage coastal zoning

\begin{tabular}{|lllllll|}
\hline $\begin{array}{l}\text { Coastal zoning and } \\
\text { who should be } \\
\text { responsible for } \\
\text { their management }\end{array}$ & Government & Community & $\begin{array}{l}\text { Government } \\
\&\end{array}$ & Self & $\begin{array}{l}\text { Not } \\
\text { sure }\end{array}$ & Total \\
\hline Agreed & 21 & 19 & 95 & 2 & 3 & 140 \\
\hline
\end{tabular}

Those respondents who wanted government to be responsible went further to identify the key agencies: Ten said NFMRA should be responsible for the management of coastal zones. Eleven stated that NFMRA with the Department of Justice should share the responsibilities. 


\subsubsection{Fisher \& non-fisher results}

Both fishers and non-fishers (nf) answered the following part of the questionnaire. The presentation of the results provided identified the two groups separately reflecting the dataentry process in the SPSS.

\section{$\underline{1 . \text { Participants value systems }}$}

The question asked all participants about their value of the coastal marine systems. This question was used to determine individual's perceived well-being received from the coastal marine systems based on a set of variables. Value systems are important to this study to determine the extractive and non-extractive users of coastal marine systems and their active-use and passive-use values (Pearce, 1990).

A ranking scale was used to indicate an individual's value sets against these variables: (1) food, (2) income (3) cultural identity (4) recreational (5) legacy or future generations (6) aesthetic (7) biodiversity and (8) climate change. The value system asked participants to rank these on a scale of 1 to 5 , where $1=$ not important, $2=$ slightly important, $3=$ moderately important, $4=$ very important and 5= extremely important (Figure 14).

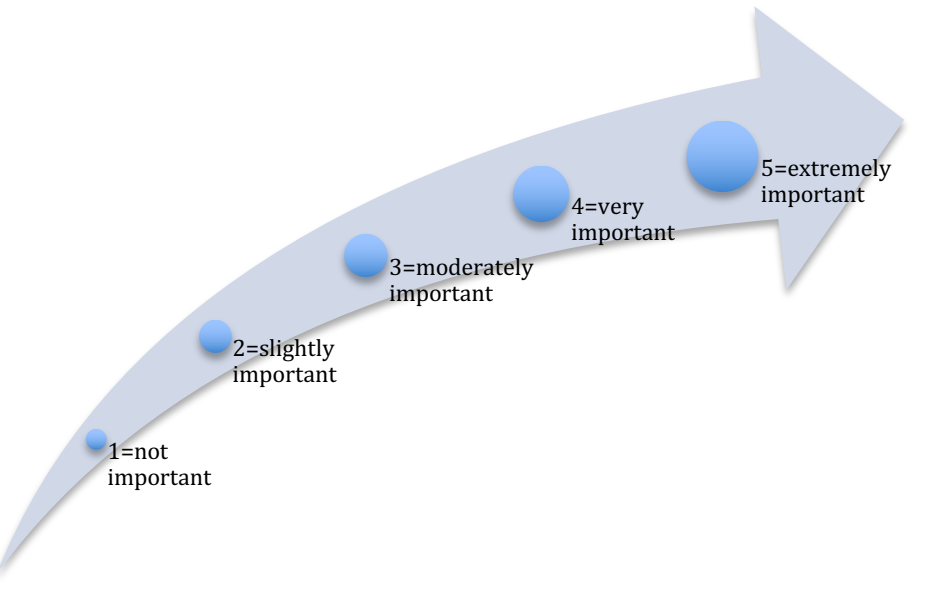

Figure 14: Ranking individuals values to a set of variables

The findings are based on aggregated mean scores for fishers and non-fishers (nf). The findings of each group are presented individual and then comparatively. The findings show explicitly how resource-users (fishers) and resource-communities (non-fishers) define the significance of each variable based on the benefits gained or to be gained (well-being) from marine resources and its environment. Additional details are found in the survey field notes (see Appendix 7). 
(i) Fishers' value systems (Table 30)

The mean score for food is 4.93 , which is the highest ranked mean score compared to all other variables by fishers. In descending order of value for each variable: food (4.93), biodiversity (4.57), legacy (4.53), aesthetics (4.17), recreational (3.95), climate change (3.92), income (3.75), and cultural identity (3.70).

(ii) Non-fishers' value systems (Table 30)

Non-fishers (abbreviated nf) showed that the value of food obtained the highest mean score out of all the variables at 4.74. In descending order, biodiversity was scored the next highest at 4.45 just above legacy value at 4.44 . Climate change is valued higher than aesthetic value. These scored at 4.26 and 4.23 respectively. Recreational value scored at 3.78 gaining a higher value than cultural identity (3.51) and income (3.09).

Comparing the two groups, both fishers and non-fishers highest value is food with mean scores at 4.93 and 4.74 respectively. Ranking second to food is biodiversity, then legacy. Overall, aesthetic value is scored high for both groups although non-fishers scored impacts of climate change higher than aesthetic value. Those variables scored as being less in value were income and cultural identity.

Table 30: Ranking order of the significance of the marine environment of each variable as indicated by fishers and non-fishers

\begin{tabular}{|l|l|l|l|}
\hline Fishers results & No of responses & Mean & Std. Deviation \\
\hline Food & 112 & $\mathbf{4 . 9 3}$ & 0.373 \\
\hline Biological diversity & 107 & $\mathbf{4 . 5 7}$ & 0.912 \\
\hline Bequest (legacy) & 109 & $\mathbf{4 . 5 3}$ & 1.093 \\
\hline Aesthetic & 107 & $\mathbf{4 . 1 7}$ & 1.377 \\
\hline Recreational & 111 & $\mathbf{3 . 9 5}$ & 1.513 \\
\hline Climate change & 102 & $\mathbf{3 . 9 2}$ & 1.565 \\
\hline Income & 111 & $\mathbf{3 . 7 5}$ & 1.604 \\
\hline Cultural identity & 109 & $\mathbf{3 . 7}$ & 1.664 \\
\hline Non-fishers results & No of responses & Mean & Std. Deviation \\
\hline
\end{tabular}




\begin{tabular}{|l|l|l|l|}
\hline Food (nf) & 152 & $\mathbf{4 . 7 4}$ & 0.874 \\
\hline Biological diversity (nf) & 146 & $\mathbf{4 . 4 5}$ & 1.157 \\
\hline Bequest (legacy) (nf) & 147 & $\mathbf{4 . 4 4}$ & 1.25 \\
\hline Climate change (nf) & 129 & $\mathbf{4 . 2 6}$ & 1.388 \\
\hline Aesthetic (nf) & 142 & $\mathbf{4 . 2 3}$ & 1.307 \\
\hline Recreational (nf) & 151 & $\mathbf{3 . 7 8}$ & 1.514 \\
\hline Cultural identity (nf) & 149 & $\mathbf{3 . 5 1}$ & 1.769 \\
\hline Income (nf) & 145 & $\mathbf{3 . 0 9}$ & 1.852 \\
\hline
\end{tabular}

The differences in mean value scores may indicate how CBMC may appeal to the different groups. These differences suggest strategies such as ensuring that food security is met through conserving biodiversity, highlighting benefits for future generations, and building community resilience regarding the aesthetic value of the marine environment is important to fishers while addressing impacts of climate change for non-fishers.

\section{Existence of Customary Marine Tenure (CMT)}

This multiple-choice question asked participants about their awareness of any customary marine tenure (CMT) in the coastal marine areas of Nauru. Once a respondent stated, "yes" to this question, they were asked to elaborate on the forms of CMT.

The findings show from the 114-recorded fishers' responses, forty (35\%) stated that yes, they were aware of CMT, $52(46 \%)$ stated no and $22(19 \%)$ were unsure. From a total of 153 non-fisher responses, 42 (32\%) stated yes, 77 (50\%) stated no and 27 (18\%) were unsure. The findings show that most participants were unaware of any existing CMT. Only a minority recognised the existence of CMT.

For this minority group, they were asked about what types of CMT they knew of. This information is used to generate an understanding and justification of their claims. These responses were coded and tabulated ( 
Table 31).

Table 31: Types of customary marine tenure systems in Nauru

\begin{tabular}{|l|l|l|l|}
\hline Customary marine tenure areas & Fishers & Non-fishers & Total \\
\hline Beachside & 3 & 2 & 5 \\
\hline Beach to reef flat & 4 & 8 & 12 \\
\hline Enge (man-made FAD on reef flat) & 27 & 22 & 49 \\
\hline Reef flat & 2 & 6 & 8 \\
\hline Reef flat to slope & 1 & 1 & 2 \\
\hline Reclaimed marine areas & 0 & 1 & 1 \\
\hline TOTAL & 37 & 40 & 77 \\
\hline
\end{tabular}

The findings show that both groups agreed that CMT are limited to the enge owned by those who made them. Twelve people identified that CMT extends from the beach to the reef flat. All other forms of CMT such as adjacent beachside, reef flats, from the reef flat to slopes and reclaimed marine areas received $<10$ responses across both groups. Some non-fishers stated that the loss of CMT was the fault of the government for not recording and recognising CMTs. There is a clear disparity of viewpoints among respondents about the existence of CMT and also the boundaries of these. As discussed in Chapter 4, CMT have played a critical role in securing ownership and rights of communities in the Pacific and have paved the way for the development and establishment of CBCs (Johannes, 1978). It is vital to this study to understand individuals' level of awareness about any forms of CMTs in existence in Nauru.

\section{Introducing Marine Protected Area(s) (MPAs)}

MPA covers many different types of protection (IUCN, 2010), so to avoid any confusion, this question refers to no-take marine reserves. ${ }^{31}$ As discussed in Chapter 4, the use of

\footnotetext{
${ }^{31}$ Marine reserve is a 'no take' reserve, which is an area of the sea in which all consumptive or extractive uses, including fishing, are effectively prohibited and other human interference is minimised to the extent
} 
community conserved areas (CCAs) is popular in the Pacific region and defining the type of MPA to meet the needs of Nauru could well be part of any future research based on this work.

This multiple-choice question asked participants if introducing marine reserve(s) could help improve the status of the coral reefs, fisheries and the marine environment. Those participants who stated yes were asked where marine reserve(s) should be and to give their reasons. They were also asked who should manage the marine reserve(s). Those respondents who do not agree to have marine reserve(s) were also asked to give their reasons why.

a) The findings showed that of 114 fishers: One hundred and three $(90 \%)$ agreed to the introduction of marine reserves, $9(8 \%)$ said no, and $2(2 \%)$ were unsure. For non-fishers, from 151 responses, one hundred and thirty-eight (92\%) said yes, $8(5 \%)$ said no and 5 (3\%) were unsure. An overwhelming number of participants say they support the introduction of marine reserves to help protect and conserve the marine resources. In the literature, there are cases of people who have been known to agree with marine reserves but not agree with them in their locality. This issue has not been addressed adequately in this research but needs more consideration in future work.

b) In order to gain a better understanding of the reliability of participants' choices for marine reserve(s), those respondents who stated yes were asked which site was the best for marine reserve(s) and to provide their reasons. This is an open-ended question that was coded, summarised and tabulated.

Of a total of 263 recorded responses: sixty-three were unsure, 43 identified Anibare district, 21 equally suggested Meneng and the isolated area between Anabar and Ijuw respectively, 18 said Baitsi and 16 suggested all districts should have their own marine reserve. Other sites had $<13$ responses suggesting them (see Appendix 4: Table 47).

The findings show that 72 participants consisting of 35 fishers and 37 non-fishers agreed to have a marine reserve in their own districts. A total of 191 participants agreed to have marine reserves only in other districts. These were 83 fishers and 108 non-fishers 
respectively. More participants were opposed to having marine reserves in their own district than those who agreed.

c) An open-ended question asked participants their reasons for selecting these particular sites as marine reserve(s). The most popular sites selected for a marine reserve was crosstabbed against the reasons given. An open coding was applied in order to tabulate the findings (Appendix 4: Table 48). This is to allow the study to generate an understanding of the motives behind the participants' selection criteria. The most popular reasons $(>10$ responses) for selecting a marine reserve site are:

1. Fewer people living in the area.

2. Isolated areas where no or few people live adjacent to the coast.

3. Areas are identified as being overexploited in short known as overfished areas.

4. Areas where fish stocks have disappeared and need to be restored and revived.

5. Areas where species breeding grounds are found.

In addition to the site-selection reasons participants also included their reasons for why they believe marine reserves are necessary in Nauru. These responses were received from 37 fishers and 40 non-fishers and have been added to the findings (Table 33).

d) Participants were also asked who should manage the marine reserve(s). This was an open-ended question and the findings are presented in summary form. If participants responded to this question by identifying government as the manager (other than NFMRA) then 'government' includes other departments such as the Commerce, Industry \& Environment Department (CIE), the Nauru Police Force and Justice Department (Table 34).

Table 32: Purpose for a marine reserve

\begin{tabular}{|l|l|l|}
\hline $\begin{array}{l}\text { Reasons for the need for marine } \\
\text { reserve or MPA }\end{array}$ & $\begin{array}{l}\text { No. of fishers } \\
\text { responses }\end{array}$ & $\begin{array}{l}\text { No. of non-fishers } \\
\text { responses }\end{array}$ \\
\hline Food & 1 & 4 \\
\hline Alternative post-phosphate resource & 0 & 1 \\
\hline Restore fisheries & 31 & 10 \\
\hline Save the marine environment & 2 & 13 \\
\hline Have fish farms & 3 & 10 \\
\hline
\end{tabular}




\begin{tabular}{|l|l|l|}
\hline Need to control SCUBA fishers & 0 & 2 \\
\hline Total & 37 & 40 \\
\hline
\end{tabular}

Table 33: Coastal resource management and responsibilities

\begin{tabular}{|l|l|l|l|}
\hline Who to manage MPA & $\begin{array}{l}\text { No. of fishers } \\
\text { responses }\end{array}$ & $\begin{array}{l}\text { No. of non-fishers } \\
\text { responses }\end{array}$ & Total \\
\hline Community & 21 & 22 & 43 \\
\hline NFMRA & 32 & 37 & 69 \\
\hline Government (Govt) & 8 & 11 & 19 \\
\hline Community + NFMRA + Govt & 10 & 13 & 23 \\
\hline NFMRA+ Community & 11 & 12 & 23 \\
\hline NFMRA + Govt & 4 & 5 & 3 \\
\hline Community + Govt & 1 & 3 & 1 \\
\hline $\begin{array}{l}\text { Non-governmental organisation } \\
\text { (NGO) }\end{array}$ & 1 & 0 & 3 \\
\hline Not sure & 2 & 1 & 193 \\
\hline TOTAL & 89 & 104 & \\
\hline
\end{tabular}

There is no wrong or right answer but the findings do convey participants' level of awareness and understanding of the role of NFMRA in relation to coastal marine management. When participants identify government this means the institution as a whole, rather than separate agencies. As previously highlighted earlier in the methods section, the survey team were NFMRA staff. Participants were aware of this, and it may have influenced their responses.

4. Those against having marine reserve(s) 
Those participants who were against having marine reserves were asked to provide a brief explanation as to why. To recap, of 114 fishers, $9(8 \%)$ said no with only $2(2 \%)$ fishers unsure. Of the non-fishers from 151 responses: Eight (5\%) stated no and $5(3 \%)$ were unsure. From this one may conclude that a total of 11 fishers and 13 non-fishers do not agree with the introduction of marine reserve(s). The reasons for their disagreement are coded and presented in tabular format (Table 35). Each participant can have more than one reason for his or her disagreement.

Table 34: Reasons against marine reserves

\begin{tabular}{|c|c|c|c|}
\hline Reasons against introducing marine reserves & $\begin{array}{l}\text { No. of fishers } \\
\text { responses }\end{array}$ & $\begin{array}{l}\text { No. of non- } \\
\text { fishers } \\
\text { responses }\end{array}$ & TOTAL \\
\hline Marine reserve(s) is not a solution & 1 & 2 & 3 \\
\hline Marine reserve(s) will not restore the fisheries & 1 & 0 & 1 \\
\hline $\begin{array}{l}\text { Marine reserve(s) is not acceptable when there are } \\
\text { limited alternatives for food }\end{array}$ & 3 & 0 & 3 \\
\hline $\begin{array}{l}\text { Marine reserve(s) will create conflict with } \\
\text { customary owners }\end{array}$ & 2 & 0 & 2 \\
\hline Enjoy the freedom of fishing/gathering & 1 & 1 & 2 \\
\hline $\begin{array}{l}\text { Marine reserve(s) cannot address the problem of } \\
\text { overfishing }\end{array}$ & 1 & 0 & 1 \\
\hline $\begin{array}{l}\text { Marine reserve(s) is not necessary; we need to do } \\
\text { other activities such as clean-up of the rubbish } \\
\text { and pollution }\end{array}$ & 1 & 0 & 1 \\
\hline $\begin{array}{l}\text { Marine reserve(s) will need to involve everyone } \\
\text { in the process and this is difficult }\end{array}$ & 0 & 1 & 1 \\
\hline Doubt that marine reserve(s) will work & 0 & 2 & 2 \\
\hline Marine reserve(s) will deny access to seafood & 0 & 2 & 2 \\
\hline Do not see the purpose. & 0 & 1 & 1 \\
\hline TOTAL & 10 & 9 & 19 \\
\hline
\end{tabular}

\section{The CBFM process}


As described earlier in Chapter 2, community-based fisheries management plans (CBFM) are part of NFMRA's national project. The CBFM project attempts to develop coastal marine management plans for all the district communities, which total 14 in Nauru. The challenges of this are illustrated in Chapter 2.

a) A multiple-choice question asked participants if they had ever heard about the CBFM programme and the second part asked where and whom they heard it from.

The findings showed that for fishers, from 114 responses, only $36(32 \%)$ have heard about the CBFM while 78 (68\%) have not. Of the 52 non-fishers recorded responses, only 44 (29\%) have heard about the CBFM while 108 (71\%) have not. Overall the findings showed a poor level of awareness about the CBFM programme.

b) The second question is an open-ended one that asked participants where they had heard about the CBFM, if they had. These responses are presented in summary form (Table 36). The findings show 30 participants have heard about the CBFM programme from NFMRA, 21 heard it from their district communities and 14 heard from others (through word of mouth).

Table 35: Awareness of the CBFM programme in Nauru

\begin{tabular}{|l|l|l|l|}
\hline Heard about the CBFM from who/where? & Fishers & Non-fishers & TOTAL \\
\hline NFMRA (Fisheries) & 11 & 19 & 30 \\
\hline District community & 10 & 11 & 21 \\
\hline Other & 5 & 9 & 14 \\
\hline TOTAL & 26 & 39 & 65 \\
\hline
\end{tabular}

The next question is dealt with in two parts. The first question seeks the participants' views as to whether the CBFM approach is a good idea and if it could work for Nauru. This was followed by an open-ended question that asked participants if they thought that the CBFM approach could work, would they support the initiative. These questions were developed based on the assumptions that the research participants understood the CBFM concepts as explained by the surveyors. The basic information shared to research participants regarding the CBFM approach was that 1) people or communities themselves 
would need to take a more proactive role in the decision-making process and to share the responsibilities with NFMRA in managing the coastal marine resources.

c) A multiple-choice and an open-ended question asked participants if they agree that the CBFM approach could work for Nauru and to give their reasons for their responses.

The findings showed that of 97 responses from fishers, 57 (59\%) stated that it could work, 3 (3\%) stated that it couldn't and 37 (38\%) were unsure. For the non-fishers, out of 137 responses, $80(58 \%)$ stated that CBFM could work while $12(9 \%)$ stated that the CBFM will not work and $45(33 \%)$ were not sure. Overall the findings indicate that participants were supportive of the CBFM approach but some participants were sceptical.

To generate an overview of participants' reasons to their answers, an open-coding was applied to the respondents' answers and results are presented in summary: (i) reasons for the support for the CBFM approach and (ii) reasons for their scepticism or doubt. The summarised findings are tabulated in (Table 37) and (Table 38), based on aggregated figures from both groups rather than percentages. This is because a respondent can have more than one reason, thus the use of percentage can be misleading. Overall there was no right or wrong answer, but it gives a better understanding of the general perception about the CBFM approach and its potential to work in Nauru.

Table 36: Reasons for support of the CBFM programme

\begin{tabular}{|l|l|l|l|}
\hline Reasons for their support of the CBFM & Fishers & $\begin{array}{l}\text { Non- } \\
\text { fishers }\end{array}$ & TOTAL \\
\hline $\begin{array}{l}\text { Locals can work together, they understand the issues and } \\
\text { can find solutions }\end{array}$ & 12 & 63 & 75 \\
\hline Compliance issues & 2 & 2 & 4 \\
\hline Give people ownership of the resources & 6 & 11 & 17 \\
\hline Can work but needs more awareness campaigns & 20 & 9 & 29 \\
\hline Management has never been done before but can work & 0 & 3 & 3 \\
\hline People need to be involved for this to work & 8 & 9 & 17 \\
\hline People will avoid losing the resources & 0 & 1 & 1 \\
\hline People will need incentives to manage & 2 & 3 & 5 \\
\hline Need to ensure that the people's needs are met for this to & 6 & 3 & 9 \\
\hline
\end{tabular}




\begin{tabular}{|l|l|l|l|}
\hline work & & & \\
\hline Limited food resources - so management can work & 1 & 2 & 3 \\
\hline Lack the power to enforce rules & 0 & 1 & 1 \\
\hline Corrupt community leaders & 0 & 1 & 1 \\
\hline Need government and community commitment & 17 & 0 & 17 \\
\hline Faith that it can work & 1 & 0 & 1 \\
\hline Not sure - but may work & 2 & 3 & 5 \\
\hline TOTAL & $\mathbf{7 7}$ & $\mathbf{1 1 1}$ & $\mathbf{1 8 8}$ \\
\hline
\end{tabular}

This part of analysis includes reasons why participants do not think the CBFM approach can work or are sceptical. The number of respondents who are both sceptical or in nonagreement with the CBFM approach is fewer than the supporters (Table 38).

Table 37: Reasons for the lack of support of the CBFM programme

\begin{tabular}{|l|l|l|l|}
\hline $\begin{array}{l}\text { Reasons for participants' lack of support and } \\
\text { scepticism about the CBFM }\end{array}$ & Fishers & $\begin{array}{l}\text { Non- } \\
\text { fishers }\end{array}$ & TOTAL \\
\hline Compliance will be difficult & 2 & 3 & 5 \\
\hline Sceptical about ownership of coastal areas & 0 & 1 & 1 \\
\hline Locals do not understand the issues & 1 & 1 & 2 \\
\hline Need more awareness & 2 & 1 & 3 \\
\hline Need more information about the programme & 0 & 5 & 5 \\
\hline Prefer open access & 0 & 1 & 1 \\
\hline Never been done before & 2 & 0 & 2 \\
\hline Ensure that people's needs are met & 1 & 2 & 3 \\
\hline Corrupt community leaders & 0 & 4 & 4 \\
\hline Limited food resource & 1 & 3 & 4 \\
\hline Lack of power to enforce rules & 4 & 0 & 4 \\
\hline $\begin{array}{l}\text { Difficult to gain local and government commitment to } \\
\text { the approach }\end{array}$ & 3 & 0 & 3 \\
\hline
\end{tabular}




\begin{tabular}{|l|l|l|l|}
\hline Not sure if it can work & 2 & 6 & 8 \\
\hline TOTAL & $\mathbf{1 8}$ & $\mathbf{2 7}$ & $\mathbf{4 5}$ \\
\hline
\end{tabular}

Overall the reasons for the doubt and scepticism about the CBFM approach can be attributed to lack of knowledge and information about the programme itself. Some doubt their community leaders will lead them in the right direction and one prefers the status quo. There is no doubt that these participants are doubtful of the CBFM programme. However, both the findings of these interrelated questions are inconclusive at this time and will need to be revisited in the future for a more comprehensive review of these particular questions.

The last question in the survey asked participants to add any general comments about the questionnaire. Because these comments take up some space, a summary of these comments can be found (in Appendix 4: Table 49), but are not analysed as part of the results. These commentaries are kept for the purpose of improving upon future research in Nauru.

\subsection{Key findings}

The purpose of this section is to draw together results that may shed light on factors that hinder or advance the management and conservation of coastal marine resources in Nauru. This chapter explored the perception of fishers (resource-users) and non-fishers (resourcebased communities). It highlights some of the constraints that may prohibit them from participating or engaging in the national CBFM programme. The broad coverage of issues in this survey does not allow discussion of every issue in detail but it will cover those issues that are most prominent in the responses and relevant to the research aim: to discover individuals' willingness and capacity to act in a CBMC.

\section{$\underline{\text { CBFM process to manage and conserve Nauru's coastal marine systems }}$}

At least seven district communities have been inducted into the CBFM programme since its introduction in 2007, as discussed in Chapter 2. The study results showed an overwhelming number of individuals were unaware of the CBFM programme. This shows 
the weakness of the awareness and implementation process of the CBFM programme to date. The use of district communities as drivers of the CBFM process is still an evolving concept for both the government and communities. The question of individuals' willingness and ability to become "stewards" of the coastal marine systems is the focus of this research. Based on the survey results, participants are doubtful of the approach and process because of the poor level of information received about the CBFM programme itself.

The findings draw attention to other dimensions that may affect individuals' incentives structures, to willingly participate in the CBFM process, such as economic, political and social factors. Incentive structures can affect both individuals' and communities' engagement in the process, as has been highlighted by Ostrom (1990) and Pomeroy et al (2001) in Chapter 3. The results suggest that people will not comply with the rules if they will go hungry or do not perceive any gain from their participation (Marshe and Berkes, 2005); McConney et al, 2003) in the process. Most participants identified that the local community can work together in the CBFM process, because they understand the situation and can find the solutions. Experts in Chapter 4 identified that local knowledge is important in CBCs, but this concept is debated in the literature. Agrawal and Gibson (1999) suggest that communities in resource management are often assumed to possess the knowledge to conserve their resources.

The findings indicate a need to empower communities with knowledge, information and awareness of the resource management system in order to become 'stewards' of the resources, as was recommended by the experts in Chapter 4. NFMRA should continue to provide those enabling policies and legislation that recognises 'communities' as legitimate partners in the sharing of management responsibilities in the CBFM.

Problems in coastal marine environment

Knowledge of the problems identified in coastal marine areas by both groups is required to understand what needs to be done. Both groups suggested many problems they found in the coastal marine environment. The fishers' main suggestion to tackle these problems was to organize clean-ups. Non-fishers suggested introducing regulatory measures to address these problems. Fishers did not identify the cause of the problems; rather their focus is on problems that they found while fishing and did not mention who was responsible for addressing the problems. Non-fishers identified both the parties responsible for causing the 
problems and solving them. Based on the survey findings, the author has summarised the key problems identified by both groups together in tabulated form and chose to not distinguish between the two groups because this is the results section of this chapter (see Table 39).

Table 38: Summary of problems found in coastal marine environment

\begin{tabular}{|c|c|c|c|}
\hline $\begin{array}{l}\text { Type of } \\
\text { problem }\end{array}$ & Issues & $\begin{array}{l}\text { Identified } \\
\text { solutions }\end{array}$ & Responsibilities \\
\hline $\begin{array}{l}\text { Coastal } \\
\text { development }\end{array}$ & $\begin{array}{l}\text { sand erosion, sewage, change of } \\
\text { currents, oil discharge and land } \\
\text { reclamation }\end{array}$ & Clean up & $\begin{array}{l}\text { local communities, } \\
\text { NFMRA } \\
\text { (government) }\end{array}$ \\
\hline $\begin{array}{l}\text { Coastal } \\
\text { habitats }\end{array}$ & $\begin{array}{l}\text { rubbish, algal growth on coral } \\
\text { reefs, damaged reefs, colour } \\
\text { changes in reefs and overfished } \\
\text { areas }\end{array}$ & $\begin{array}{l}\text { Clean up } \\
\text { Introduce } \\
\text { regulatory } \\
\text { measures }\end{array}$ & $\begin{array}{l}\text { local communities, } \\
\text { NFMRA } \\
\text { (government) }\end{array}$ \\
\hline $\begin{array}{l}\text { Marine } \\
\text { resources }\end{array}$ & $\begin{array}{l}\text { fewer fish, too many sea urchins, } \\
\text { loss of hermit crabs, fish being } \\
\text { difficult to find, some fish species } \\
\text { have disappeared and too many } \\
\text { dolphins }\end{array}$ & $\begin{array}{l}\text { Introduce } \\
\text { regulatory } \\
\text { measures }\end{array}$ & $\begin{array}{l}\text { local communities, } \\
\text { NFMRA } \\
\text { (government) }\end{array}$ \\
\hline $\begin{array}{l}\text { Resource- } \\
\text { users }\end{array}$ & $\begin{array}{l}\text { too many fishers, fishers using } \\
\text { destructive fishing methods, } \\
\text { overfishing }\end{array}$ & $\begin{array}{l}\text { Introduce } \\
\text { regulatory } \\
\text { measures }\end{array}$ & $\begin{array}{l}\text { local communities, } \\
\text { NFMRA } \\
\text { (government) }\end{array}$ \\
\hline $\begin{array}{l}\text { Resource } \\
\text { communities }\end{array}$ & coral and sand mining & $\begin{array}{l}\text { Introduce } \\
\text { regulatory } \\
\text { measures }\end{array}$ & $\begin{array}{l}\text { local communities, } \\
\text { NFMRA } \\
\text { (government) }\end{array}$ \\
\hline Government & $\begin{array}{l}\text { Sewage and land-based } \\
\text { development }\end{array}$ & Clean up & government \\
\hline
\end{tabular}


Non-fishers were also quick to point out the need for a partnership of community and government to address the problems. This increases the chance of the CBFM programme working in Nauru. A regulatory framework does already exist for controlling rubbish and destructive fishing gear and methods in the coastal marine environment.

- A prohibition under The Littering Act of 1983 is that no one is to litter or rubbish in the coastal marine areas, and the agency responsible for enforcing this is the Police.

- A ban of destructive fishing gear and methods under NFMRA Act of 1998 prohibits the use of destructive fishing gear and methods in coastal marine areas, and the agency responsible for enforcing this is the Police.

Only $18 \%$ of non-fishers were aware of these existing regulations. Most participants are not aware of these existing regulations. Awareness, enforcement and strengthening of these regulations are required. Given in table 39 are other regulatory measures that were mentioned by participants to address other problems, since having regulatory measures is a critical suggestion in the survey. One such management tool is putting MPAs or marine reserve(s) in place.

\section{Introduce MPA(s), marine reserve(s) or CCAs?}

There was overwhelming support from the individuals for marine reserve(s). As defined earlier, marine reserves are equivalent to "no-take" areas. The survey found that the concept of marine reserves or MPAs is not well understood by participants, as revealed by the response of one respondent, who suggested having a marine reserve to culture clams. More awareness of the functions of MPA(s) is required. Some of the participants also requested more information about MPAs. There is a clear need for more discussion about the types and uses of MPAs, as both local people and government need to find a common ground of understanding to implement such measures. As discussed in Chapter 3, because of the NBSAP (2010) strategy, under which Nauru has committed itself to having protected areas in place by 2020, discussions may be held soon.

MPA(s) have many definitions depending on their classifications and purposes. In Chapter 4 Govan and colleagues (2009) IUCN and CBD definition of a protected area was put 
forward. The IUCN's notion of a protected area is essentially used for biodiversity conservation (Borrini-Freyerbend, et al., 2004). The IUCN has six protected areas management strategies which have gradual increases of human intervention from Category Ia to VI (ibid). As was also discussed by Govan and colleagues (2009) in Chapter 4, there has been a growth in community conserved areas (CCAs) ${ }^{32}$ across the Pacific region. The difference between IUCN protected areas and CCAs is that the latter is declared and run by local communities themselves (Borrini-Freyerbend, et al., 2004). CCAs could be an option for Nauru in the future. The experts suggest that MPA(s) should ultimately be perceived as a tool and not as a measure of the performance of $\mathrm{CBC}$. Based on the findings, individuals are supportive of MPAs in Nauru.

\section{$\underline{\text { Potential use of value systems }}$}

Another method that could be used in nurturing individual or community interests in the CBMC process is forming an understanding of individuals' and communities' value systems. As explored in Chapter 3, extractive and non-extractive users can hold active-use and passive-use values about the coastal marine systems. Value systems can play a critical role in ensuring the success of the CBMC. Based on the results, both groups highly ranked food and biodiversity as significant. In third position, fishers and non-fishers ranked bequest (legacy) and non-fishers valued avoiding the impacts of climate change. However, the field-notes (see Appendix 7) showed that most of participants were not familiar with the terms biodiversity, climate change and cultural values. This is a further indication of people's lack of knowledge and information systems concerning some environmental issues. This finding again provides another starting point to develop awareness programmes, incentives and small achievable targets that benefit individuals engaging in the CBFM process. As described by some experts in Chapter 4, people need to see the link between food security and biodiversity conservation in order to understand basic conservation concepts. Habitat protection enhances recruitment of spawning stocks and may improve stock abundance in the future. This can be used to link the goals of food security and biodiversity conservation.

The study sought to understand the factors that can affect various groups' willingness to participate in the process, such as developing an effective regulatory framework to control

\footnotetext{
${ }^{32}$ CCAs represent "specific sites, resources or species or areas voluntarily conserved through community values, practices, rules and institutions" (Govan, et al 2009 p.27).
} 
fishers and their activities. As highlighted in Chapter 4, current practices range from imposing regulations on catch sizes, catch limits, fishing gear, fishing times to limiting access to the resource. The results suggest that challenges abound with:

i. Imposing rules on fishing times, since fishers surveyed prefer to fish at night due to personal reasons, such as their personal availability and the belief that fish are found more easily and are tastier at night. In Samoa a ban is in place on the use of flashlights for night spear fishing because reef fisheries are vulnerable at night (Johannes, 2002).

ii. Fishers' belief systems are surrounded with more superstition than traditional ecological knowledge (TEK), making it difficult to incorporate local knowledge into a management strategy that has worked in other parts of the Pacific region. The combination of local knowledge and science is not an easy task. From the indigenous knowledge perspective this form of knowledge can come from different worldviews, starting points, assumptions and rules (Berkes, 2008). Based on fishers' knowledge about species, those potentially of concern include finfish families of Acanthuridae and Balistidae, which were found far in excess of other families in 2005 (Vunisea et al 2008). For fishers to list these as being of concern could mean that overexploitation has occurred within a short period of time. More research is required on this issue.

iii. Commonly used regulatory measures in coastal fishery includes control of fishing gear and methods and imposition of size and catch limits as a means of protecting marine resources (King \& Lambeth, 2000). The results showed that there were a high number of non-responses from fishers when asked about the introduction of control measures on gear despite the fact that they perceived their gear and methods as over efficient and will lead to overexploitation. It shows that fishers are unlikely to be willing participants in the CBFM process. As highlighted in the chapter, Festinger's (1957) theory of cognitive ${ }^{33}$ dissonance can help explain fishers' failure to agree with gear control. The state of cognitive dissonance is when a person's beliefs and knowledge are inconsistent with each other (Cooper, 2007; Festinger, 1957). Festinger's (1957) theory is based on two hypotheses:

\footnotetext{
${ }^{33}$ Cognition is, "a piece of knowledge that a person has" this can be knowledge of one's behaviour or attitude and views Cooper, J. (2007). Cognitive Dissonance: Fifty years of a Classic Theory. Los Angeles: SAGE Publications..
} 
a) The existence of dissonance will motivate a person to reduce the inconsistencies to achieve consonance.

b) When dissonance is present, the person will try to reduce it, by avoiding the situation and information that would increase inconsistencies. (p.3)

Fishers were asked which fishing gear or methods need to be controlled because of its efficiency. According to this theory, there are two ways a person will react, either to reduce or to avoid this situation. One can hypothesise that the fishers' reactions in this context was to avoid dissonance and not respond to the question because it was inconsistent with their beliefs and opinions. According to Festinger (1957), if gear regulations were introduced, this may force fishers to change their attitudes about the efficiency of their gear and not change their behaviours about overexploitation in order to reduce the dissonance. One suggestion to tackle this issue is to spread the information through "word of mouth." For example, if a fisher respects a person and they are consistently in contact with them, and such a person suggests the idea that catching undersized fish can affect stock recruitment then the fisher, after consistently receiving this type of information, may change their behaviour in time.

iv. Most fishers do not perceive themselves to be members of any social fishing groups or organisations, despite the fact that they fish with friends and members of their own family. This is problematic because having high social capital can also enhance compliance without the need for graduated sanctions to be introduced to the management and conservation of coastal marine systems.

v. Use of any tool that breaks the reef, such as a hammer or crowbar, is banned in most PICTs (Johannes, 2002) including Nauru (Ropeti \& Deiye, 2006). Based on the results, it is clear fishers still practice destructive fishing in Nauru. For example, gleaners (hand collectors) stated their traditional fishing gear as a hammer or a knife with a net. The need for awareness raising and information made available to communities on the types of destructive (traditional or modern) fishing gear that are banned in Nauru.

\section{$\underline{\text { Other issues }}$}

According to Ostrom's (1990) collective action theory, for an individual to participate in a collective the benefits gained from participating in the collective or management process should outweigh the costs involved. The results of the survey indicate that for fishers 
found at the minimum cost end of the spectrum, such as spear fishers (free divers), net fishers, fish trappers and gleaners, creative use of incentives would be required to encourage them to participate in the CBFM process. Some of these incentives have been highlighted earlier. Fishers suggested a diverse range of improvements to help their own situations in fishing. In general, most fishers suggested improvements to increase their fishing capacity rather than for management and conservation purposes. As described in Chapter 2, communities, especially fishers, still look to their own interests rather than realizing that the $\mathrm{CBFM}$ is promoting sustainable use and practice.

In terms of species management, Pinkerton (1989) identified from her work that the two most significant conditions to engage users' participation in co-management were (i) stock enhancement planning and (ii) habitat protection. These ensured its success. Based on the responses from fishers, which species are of concern and which are in abundance was unclear. There is a need for more substantive research to identify species of interest and concern in the future. An expert in Chapter 4 stated that addressing species of interest to the communities is one appropriate way of introducing protection and control measures.

Fishers have indeed adapted to economic circumstances. Previously individuals could finance their own fishing activities but now sharing expenses has becoming prevalent as a cost-effectiveness measure. Stealing was mentioned as a result of these circumstances, thus adding to the list of social problems due to poverty.

One of the arguments of CBFM is that it empowers communities to take ownership and management of the resources (Govan, et al., 2008). As discussed in Chapter 4, CMTs have been instrumental to advancing CBCs in the Pacific. The key question then is whether customary marine tenure (CMTs) can be reinstated in Nauru. For Nauru, since the advent of the NFMRA Act of 1998, one could state that CMTs have been lost. The loss of CMT as suggested by respondents may have indeed have eventuated from both the government's and owners' lack of maintenance of ownership records system, which occurred for the many reasons discussed in Chapter 2. This issue can be a contentious one. One district community has identified the loss of CMT as a problem in their CBFM plan and wants NFMRA to assure them that this can be rectified in the future as part of the process (MenengDEC \& NFMRA, 2006).

Local communities need to be informed about the current status of their resources and the urgent need for management. It has been due to the lack of traditional and conventional 
management and the lack of enforcement of existing rules that has resulted in the exploitation of resources under the current open-access regime. The goals of the CBFM need to be well-defined and articulated to the local people. The goals of CBFM are about meeting the needs of local communities for their food security and livelihoods, as discussed in Chapter 4. There is a greater need to manage and conserve coastal marine systems.

Some solutions to these problems have been highlighted by Thaman and Hassall (1996) in Chapter 2. These also have been addressed throughout the theory and practices of CBC in Chapter 4. One solution is to develop a learning environment where information and knowledge flow throughout the process. This is one of the components of the adaptive comanagement framework described in Chapter 3. Based on the survey results that $82 \%$ of non-fishers lack both the knowledge and information about managing and conserving coastal marine systems, it is clear that resource-users' knowledge is surrounded by superstitions rather than TEK. This raises the issue of what materials are required to help bridge the significant gap in information. The findings suggested these types of information are of interest to the people:

- Spawning aggregation of species of interest.

- Biology and life cycles of species of interest.

- Management tools such as regulatory measures (size and catch limits, gear restrictions).

- $\quad$ MPAs and marine reserve(s).

- Examples from other countries of $\mathrm{CBC}$ processes and their activities.

- The national CBFM programme and its purpose.

The types of information media respondents preferred to receive this information are through TV, newsletter, radio, workshops, email and phone. From the dwelling survey, only $72 \%$ have a TV while $14 \%$ do not have a TV, and $65 \%$ have a radio and $19 \%$ do not have access to a radio. The results suggest that the whole population will still not be covered. The need for alternative forms of media to disseminate both information and awareness is necessary. These could be things such as newsletters and public outreach programmes in each district to ensure that everyone can access the information. One of the expert states that using visuals in community planning and workshops is the most effective tool. 
According to Berkes (2009) there is a need to generate new knowledge or to make sense of the knowledge from different sources and build upon it, described by Davidson-Hunt and O'Flaherty (2007) as the co-production of knowledge (Davidson-Hunt \& O'Flaherty, 2007).“Knowledge is a dynamic process - contingent upon being formed, validated and adapted to changing circumstances" (Berkes, 2009, p. 1659).

There is a need for individual and social learning to take place through information sharing in Nauru. Awareness-raising needs to take place to actually realise the potential of both the local community and the government to willingly participate and act in the CBFM programme as a route towards a CBMC. At this stage, based on the perception-monitoring results, Nauru is only at the beginning of this process. Much investment is required to develop a social learning framework for collective action to manage and conserve the coastal marine systems.

\subsection{Brief discussion}

There are advantages and disadvantages to using a perception survey, as highlighted early in this chapter. Using a perception survey was relevant to the context because of the poor information available about people's understanding and ideas about coastal marine management and conservation in Nauru. Since this is the first-ever type of study that focuses on individuals' perceptions about the coastal marine systems, this study will serve as a baseline study.

There are limitations on the rigour of the methods used, as identified earlier in the chapter. The sample was smaller than the ideal on account of the limited resources and time. The researcher engaged the assistance of a survey team that could have biased the data. The results are based on the interpretations of individuals who come from different worldviews and experiences, another variability to consider with perception surveys. It is difficult when the survey site is a small country and where everyone knows each other to be objective. The researcher is also a part of the local community.

This study provides a "snapshot" view of what the local communities understand about their marine environment. This study can be used to identify those existing gaps of information for future research in Nauru. Based on this, the use of a perception survey and 
its broad-based approach to the context is relevant. As highlighted throughout the research there are many complex issues involved in community-based co-management institutions. Understanding knowledge limits was an opportunity for the study to cover broad issues with the limited time and funds available.

Improvements that can be made to the study:

- Find resources for a larger and more representative study;

- Focus on one issue at a time, now that this study has covered much of the broadbased issues in CBCs for this case. For example, understanding how effective the awareness campaigns and its effect on the local people are.

- Avoid using terms that people do not understand, especially when conducting an ethnographic survey, and avoid having too many questions, as people get easily bored.

- Future questionnaires should be short, and more concise.

- Surveys needs to be conducted at varied times of the day and not only during standard working hours.

- Avoid the use of surveyors from a government agency. 


\section{Chapter 6}

\section{Group perceptions}

\subsection{Introduction}

This chapter presents the findings of two gender-based focus groups conducted in Nauru. Creswell's (2009) mixed methods design suggests that qualitative focus group research can complement survey data. Qualitative research is used to explore those underlying barriers and incentives that may allow individuals to willingly participate and act in the CBFM process.

A focus group is defined as, "a group of individuals selected and assembled by the researcher to discuss and comment on, from personal experience, the topic that is the subject of the research" (Pickard, 2007). The purpose of using gender-based groups is to provide different perspectives on CBFM from the community-level. Fishing activities, as described in Chapter 5, are gender-oriented depending on the type of fishing gear used. Gender grouping allows for the discussion of issues that are common to each group, as well as their activities.

\subsection{Methods}

\subsubsection{Objectives}

The main objectives of the focus group research are to:

- Investigate the group's perceptions about the community-based fisheries management (CBFM) programme.

- Gain insight into the local context concerning the community-based approach, specifically on the issues of 'boundaries' and 'governance.'

- Understand the people's concerns that may affect their willingness to participate and act in CBMC.

- Identify some of the obstacles faced by communities who have been inducted into the CBFM process.

- Gain some perspective from the local people that may improve the CBFM to a CBMC. 


\subsubsection{Selection of participants}

A purposive sampling method was taken to select focus group members from the general population. Participants may have participated in the survey but this was not a prerequisite for their selection. A mature cast of participants was selected because these participants were approached and were willing to voluntarily participate in the research. The characteristics of group participants included active members from top governmental positions, leaders or members of the district executive committees (DEC). Some are experienced fishers, some non-fishers. There was at least one staff member from NFMRA. The selection process tried to include participants from different district communities who were willing to participate.

\section{a) Selection-biased sampling}

The researcher is Nauruan and this may have biased the selection process. The researcher's awareness of the social protocols within the society may have influenced the selection process by encouraging her to enlist a mature cast of participants. Nauru has been earlier identified by one of the experts as an urban, monetised and modern society where all traditional forms of knowledge have been lost (Thaman \& Hassall, 1996). This is true in a sense, but in being a member of the society, there is an innate understanding of social structures and status. For example, if one looks across most PICTs decision-making processes in communal societies: they are most often done by chiefs, elders or leaders, but not by young people. This is the practice in Nauru. Even with the loss of traditional chiefly structures, decision-making is done at the family and household levels. Selecting a mature cast of participants was largely influenced by this social convention.

b) Sample size

The recommended sample size for a focus group is 6-8 participants per group (Chapman, 2009). Each focus group had seven participants (see group composition). This small number is manageable and allows individuals to participate equally in the process. Qualitative research often uses a small sample sizes and data generated are not used for wider inferences. For this study the data is used to complement the survey results. 
c) Group composition

Focus group I (FG I)

Focus group I consisted of seven female participants. Only one invited participant was absent, as the participant could not get leave from work for the session. The facilitator added an extra participant from NFMRA to provide a robust discussion about the CBFM process.

Focus group II (FG II)

Focus group II consisted of seven male participants, and again one participant could not attend on the day and the facilitator added one NFMRA male staff member to the group (for reasons stated above).

\subsubsection{Group interview questions}

The gender-based focus groups ran on the $10^{\text {th }}$ and $12^{\text {th }}$ of August 2010. The facilitator had prepared semi-structured questions (in the form of a handout) to guide each session (Appendix 8). The participants were given information sheets and invites prior to the sessions. The facilitator collected those who had no transport and were willing to participate in the session. The VUW Ethics Committee approved the focus group research.

Open-ended questions were used to generate discussion that was designed to reflect the survey questionnaire. These discussions were used to capture dynamics not captured by the survey. For example, participants were asked, "if CBFM using district communities was the most appropriate way to manage and conserve the coastal marine systems in Nauru?" and "if they think the approach can work and their reasons?" Probes focused on whether participants agreed to district communities as drivers of the CBFM process. This helped to identify their willingness to participate in the CBFM process or whether they thought government should be responsible for managing the coastal marine resources: questions that probed perceptions of dependency and control.

\subsubsection{Procedure}

The focus groups were conducted by the researcher/facilitator $(\mathrm{F})$ who engaged the assistance of an assistant moderator (AM) and a co-facilitator (CF) to manage the recording. Both sessions were recorded and the AM took field notes. The purpose of the study was explained to all participants. The facilitator was aware that not all participants had the same level of awareness about the CBFM programme in Nauru, as NFMRA had 
not inducted all district communities into the programme. Several ice-breaking questions were used to create a comfortable environment for discussion, and small refreshments were made available. The facilitator informed the participants that all opinions were helpful to the discussion. They were also told that all responses will remain confidential as stipulated in the consent forms and that participants' views are important to the research. The focus group sessions were conducted at the NFMRA office building on different days (Tuesday and Thursday) and times (morning and afternoon). Both focus groups lasted for at least 2 hours. Focus group sessions were conducted in Nauruan. All comments were recorded and transcribed into English. Due to the confidentiality of focus groups, participants have been codified based on the seating arrangements (Appendix 8).

\subsubsection{Data process}

A tape-based analysis was taken. The researcher translated the data from Nauruan to English. Field notes written by the AM were used to complement the analysis. Data that emerged from the analysis were coded firstly into categories under each theme. A comparative analysis of the themes (Silverman, 1993) was conducted for each group but not across the groups. The findings could not be generalised across each group because of the non-probability of the purposive sampling techniques does not allow the data to be merged because of the gender groupings (Beyea \& Nicoll, 2000).

\subsection{Results}

An overview

As previously explained, not all participants in the focus groups are at the same level with their knowledge of CBFM plans and process. For those participants already participating in the CBFM programme, they had an advantage over those who have not experienced the CBFM process. The facilitator was aware of this relative variation among the participants in each of the group.

Results are presented under these three broad themes that were developed prior to the focus group to guide the process:

1. Boundaries - community and resources

2. Community governance issues and challenges

3. Management and conservation tools and options 
Each focus group is represented as FG I for the first group and FG II for the second group in the results section. The facilitator will be identified as (F); assistant moderator (AM) and all group members will be numbered according to their seating arrangement for reasons of confidentiality. For example, Participant 1 is identified as $\mathrm{P} 1$. The seating arrangements are provided in (Appendix 8).

\section{Boundaries of community and resources}

These questions were discussed by the focus groups to determine whether district-based approach is best for Nauru for the CBFM based on Ostrom's (1990) design principles in Chapter 2 suggested well-defined boundaries to successful CPR management. Cox and colleagues (2010) study revised this to suggest these two concepts:

- 1A. Individuals or households have rights to extract resource units from the CPR.

- 1B. CPR boundaries are well-defined.

a) Can a community-based fisheries management programme work in Nauru using districts as drivers of the approach? Why or why not?

Neither of the focus groups (FG I and II) found it easy to focus on this question and the facilitator $(\mathrm{F})$ had to reiterate this question to the group throughout the session.

FG I preferred to discuss more about the status of the CBFM programme, its progress and the experiences of the group members with the programme. FG II jumped right into the discussion of coastal resource management options and tools especially marine reserve(s) at the introduction of its session. The facilitator attempted to redirect both groups to discuss their concerns with the issue of boundaries. Both focus groups preferred to highlight problems and challenges about coastal marine management and the use of control measures and management tools. The groups seemed to accept the underlying assumption that the community-based approach is the best way to get people involved in managing and conserving coastal marine systems in Nauru.

The interpretation that "what was unsaid within the group" (Krueger, 1998) is in fact the support of districts as the boundaries of communities and resources for both groups. Some of the quotes are illustrated below to show the groups' support of the CBFM programme based on their discussion. 


\section{FG I responses:}

"Through this [CBFM] programme, NFMRA finds it easier to coordinate and support the districts to access funds for their projects." P2

"Communities in the districts we have conducted the workshop with, are more than willing to participate in the [CBFM] programme." $\mathrm{P} 4$

"Communities are willing to do something about the problems they are facing. People have many ideas and input to what needs to be conserved and managed in their area." P2

\section{FG I field report}

The facilitator posed the question to the FG I where a consensus agreement was provided by the nodding of the participants' heads.

\section{FG II responses:}

"Yes but you need to start with "something," that has to be strong and the district communities will be able to then learn from it and adapt the rules and regulations over time working with the experiences from the use of such rules. It will somewhat trigger an automatic reaction but it will evolve and become part of the district communities' responsibilities. But it will then be dependent upon these district communities of how to address the concerns of their people and other people coming in to fish in their areas." P3 FGII

Participant 3 in reference to "something" (above) refers to the management measures, however this comment also supports district communities' involvement in the CBFM and their responsibility in addressing the rest of community members' concerns about managing and conserving the coastal marine systems.

"I agree with this [community-based] approach, as it will cause less conflict among the people, as they will be aware of their boundaries and responsibilities [it is] clearer and much better that way." P1

"With the community-based programme I think district communities are already monitoring their resources - for example in Meneng if you're a fisher from other districts going into Meneng, these people tend to flatten the tyres of motorbikes and it seems they have rules there." P4

One participant suggested another approach, which was not clarified when asked to explain but raised at point for discussion:

"Another approach where everyone agrees and are all involved in the management [of coastal marine systems].” P3

Based on the context of the discussion, P3 referred to developing a national coastal marine management system. This is one of scale. The idea is to include everyone from all district 
communities in managing and conserving the coastal marine systems rather than individual district communities.

Buada is different to other districts in Nauru because it does not have access to adjacent coastal marine areas. It is found in the centre of the island with a lagoon (Figure 15). There are currently no plans to develop a CBFM plan for this district community. Rather Buada community's interest is in reviving its milkfish (Chanos chanos) culture in their lagoon as described in Chapter 1. NFMRA is also responsible for aquaculture development in Nauru.

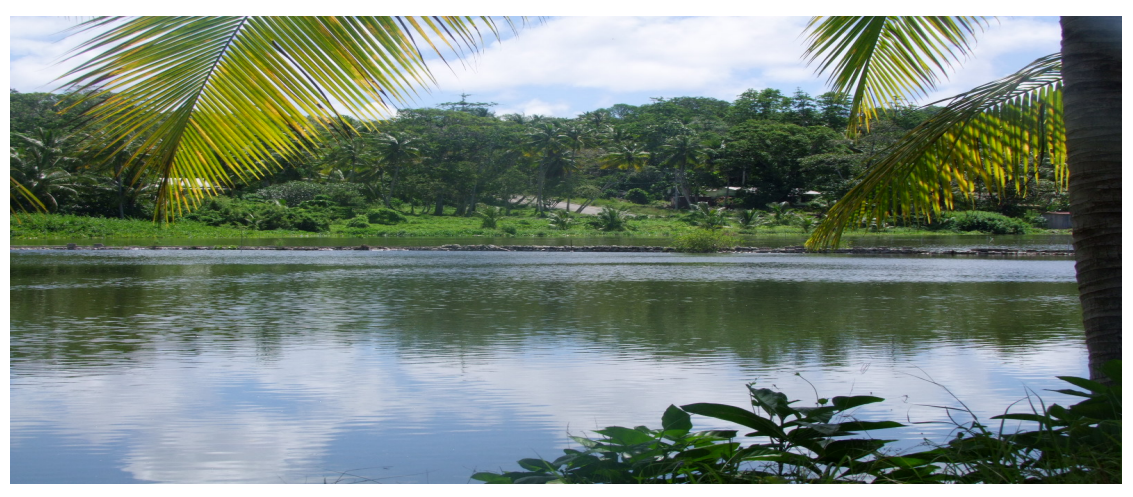

Figure 15: Photo of Buada district with its lagoon

The Buada community would be required to comply with other coastal districts community-based fisheries management (CBFM) plans. Due to Buada community's unique situation, the implications for the success of the CBFM programme in Nauru will also be dependent upon the community's willingness to comply with other coastal districts' management plans. Focus group members were interested on how this issue will be tackled. The facilitator raised the issue in both sessions and some of these discussions are illustrated:

\section{FG I responses:}

"If the coastal district communities in Nauru are managing [their] coastal marine areas, is this is agreeable with you?" $F$

"Of course, we can observe and monitor how well coastal communities are managing the coastal [marine] resources and areas. " P4

"Our community would not be against the Buada community or any other communities from harvesting resources from our coastal areas but we would like them to take better care and conduct sustainable fishing practices when harvesting [from] the [marine] resources." P7

\section{FG II responses:}


"What about the people in Buada who don't live next to the coast? What happens to us?" $P 2$

"I guess you will have follow the district management plans, depends where you are fishing." $F$

"I mean in reality everyone will just be expected to respect the regulations set up in each district community. I don't think the plan is to keep people out. The purpose behind the concept of setting up rules in the first place is to make sure that we fish sustainably to sustain our resources. " $P 2$

"Yes I agree on this point that "outsiders" should not be ruled against but rather just follow the rules for each district." P3

District boundaries in Nauru are well defined and are clearly delineated by physical markers (see

Figure 2). These boundaries can be used to mark the adjacent coastal marine areas in each district.

b) Can the CBFM approach work in Nauru? Why or why not?

As discussed earlier, some of the focus group members do not have the same level of awareness about the national CBFM programme. One of the emergent issues from the focus group discussions was the role of NFMRA and communities in the CBFM process. Focus group responses are presented and tabulated (see Appendix 8: Table 50).

Based on the group discussions about the roles of NFMRA and community in the CBFM process:

The role of NFMRA could include:

1. Completing the seven district CBFM plans to develop the legislative framework for the CBFM process and legitimising the responsibilities of communities in the managing and conserving the coastal marine systems.

2. Implementing the CBFM plans for those district communities inducted into the CBFM programme.

3. Providing livelihood alternatives for communities who participate in the CBFM process such as FADs and canoe-building projects.

4. Being responsible for the communities who participate in the CBFM process. 
5. Having the ability to put interim measures in place while the CBFM programme is being developed. For example, stopping other government agencies issuing fishing licenses and permits. This will help to avoid any future conflicts.

One focus group member asked if NFMRA's role is to support the development of community rules and regulations in the CBFM plans and whether it will act in the interests of community and represent the communities' concerns at the national level. Based on the concepts of co-management, NFMRA is in partnership with district communities to manage and conserve Nauru's coastal marine systems.

The role of communities in the CBFM process according to the group discussions need to recognise that communities:

1. Want to participate in developing awareness campaigns within their schools.

2. Want to voluntarily participate in the CBFM process and to take part in managing and conserving their coastal marine resources.

3. Want to participate in the decision-making processes.

4. Develop their own rules and regulations in the CBFM plan.

5. Monitor and enforce the rules of the CBFM plan.

6. Have district representatives or wardens in place as part of the awareness-raising process.

7. Are partners in the CBFM process.

As described in Chapter 2, Meneng district community was the first district for which NFMRA developed its CBFM plans, in 2007. A member from the Meneng community participated in FG I. When faced with the above question (above), asking whether the community-based approach can work, Meneng's experience based on the account of this focus group member highlights the challenges that other communities have not yet faced in the implementing phase of the CBFM process. This is presented in Box 1. Issues raised are contextual but relevant to the question. 
Box 1: Quotes from FG member's experience of the CBFM process

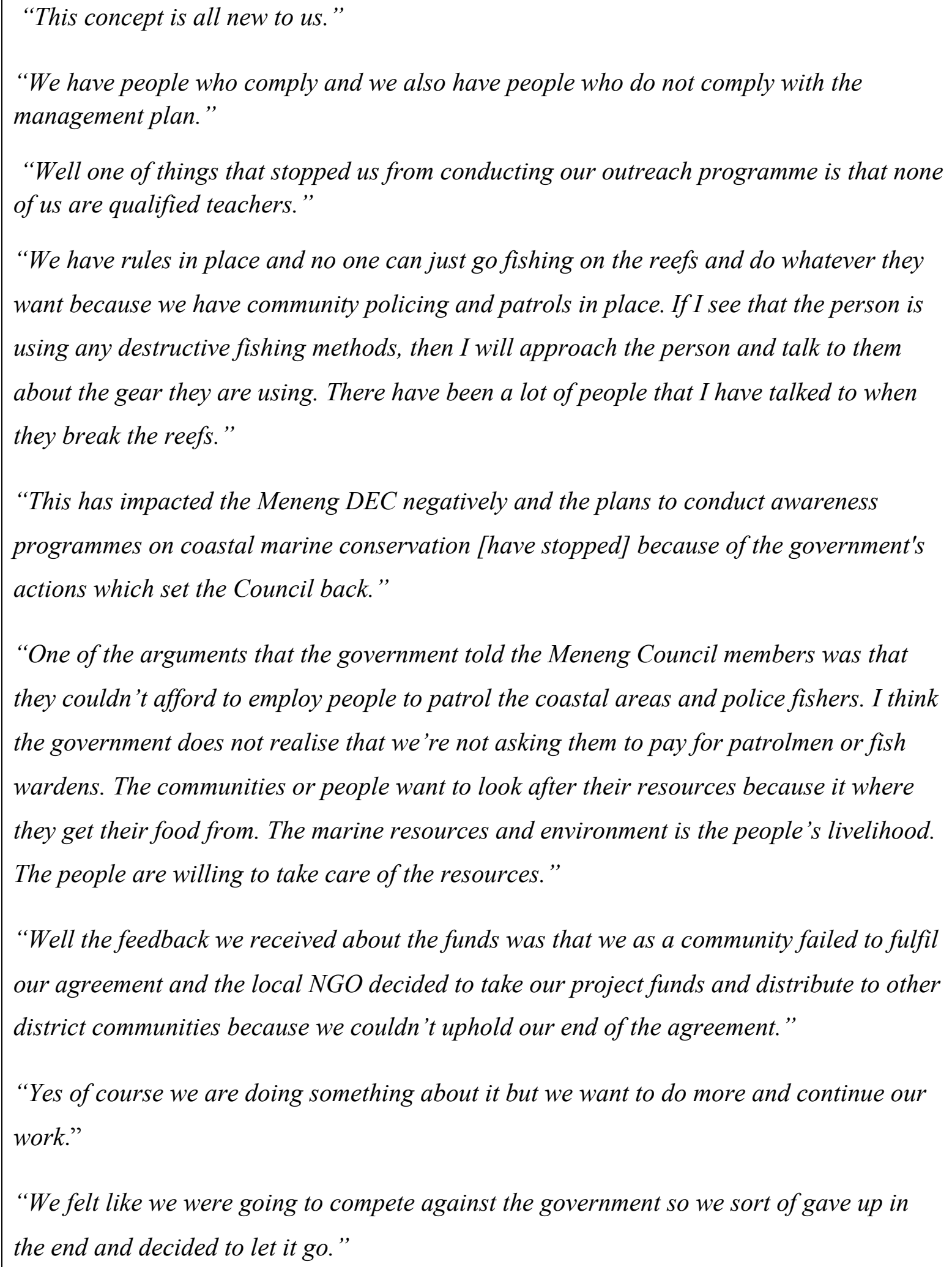


Two incidents happened in Meneng that have affected the community's willingness to continue their efforts in the CBFM process.

(1) Foreign fishers have been harvesting the sea-cucumbers (beche-der-mere) for export without the knowledge of Meneng District Executive Committee/Council (DEC) and the members. These foreign fishers had permits issued by the government. Members of the DEC discussed their concerns of this incident with their Member of Parliament (MP). This leader informed the DEC that community monitoring and enforcement of coastal marine areas is not a solution because government cannot afford to pay to have monitors in place. One outcome of this incident is that communities were set back in developing their awareness campaigns and as commented by one member in the FG I, "The government defeated their own project with their [own] actions. " P3

(2) As described in Chapter 2, the Meneng community project proposal was successful. The GEF-SGP community funds are managed and coordinated by the local NGO in Nauru. Meneng community's project did not progress as observed in June 2010 on my return to conduct my fieldwork. Based on the group member's account, this lack of progress was the result of miscommunication between the Meneng DEC the NGO. The NGO informed the community that they failed to uphold their end of the agreement to conduct the awareness campaign of the CBFM in their own district.

\section{Community governance issues and challenges}

This section tackles those issues and challenges relevant to the $\mathrm{CBC}$ practices.

\section{FG I responses:}

I. Awareness-raising, campaigns and programs of district community rules and regulations

"I think with the Meneng community they need a lot of awareness campaigning within their own district that they haven't done. [NFMRA] had to talk to them about their actions because they act just from hearing about having rules and regulations. Through hearsay these people are taking action. Like hitting fishers on the head who use a crowbar on the reefs." P4

"Right now we focus [our awareness] in our households and children as I said earlier. Before when you [go] swimming, you would frequently come across disposed nappies and 
sanitary items that float past you as you're swimming but now things have changed. The chance of swimming and seeing disposed nappies in the water is scarce now. " P7

"[This is] similar to the case of the communities from Ijuw who actually approached the police to complain about the fishers harvesting the sea cucumbers and the police not doing anything about it. This incident has made the communities realise that they were powerless in stopping the fishers and anyone else who exploits their resources. The government [is] not supportive of their community rules." AM

II. To have strong monitoring and enforcement mechanisms in place

\section{FG II responses:}

"[We] should have one national body [be] doing [the monitoring and enforcement]". P4

"And the responsibilities should be driven at the community-level?" $F$

"Yes [we] need to have one way of organising this [monitoring and enforcement] approach". P3

"It seems like Meneng community have taken upon themselves to monitor the coastal areas. There are so many rumours going around about the [community's] hostile behaviour with outside fishers. " P4

\section{Livelihood diversification options}

As described earlier, NFMRA's role is to provide the community with alternatives that aim to alleviate the intensity of fishing on the coastal marine systems for those communities willing to participate in the CBFM programme. Some of these options that have been carried out in Nauru:

- Development and deployment of fish aggregation devices (FADs) for fishers to fish in offshore marine areas.

- Canoe building projects to build canoes for fishers to fish in offshore areas (e.g. around FADs).

- Aquaculture with the culturing of milkfish (Chanos chanos) for individuals and communities who have access to ponds or a lagoon on their land or district.

Given below are some group responses about these options. 
"I mean some district communities would not need to go fishing offshore, instead [they could] culture and farm their own fish. This could be applied to people who own ponds and bombed ${ }^{34}$ areas on their land." P7- FG I

"I was not aware that Fisheries is willing to support and provide alternatives to the people such as fishing in the offshore areas and aquaculture projects. I mean that is what we need to know, as we can always say yes to have a marine reserve but we're not aware of the consequences of this decision. If we go ahead with a marine reserve and we need food from the resources - we will look to [NFMRA] to help us in anyway and if you cannot help us, then people will start fishing again in the marine reserve. People will not comply if they are hungry- if [NFMRA] doesn't commit to what they say will do." P7 -FG II

"Even fishponds such as aquaculture, people will have to construct these ponds - there is a lot of work involved. The "yes" answer is easily stated but if people are made aware of what they are willing to give up or sacrifice such as fishing ground or even fish speciesno one gets to eat a convict fish for a year." P7 FG II

IV. Communication is perceived as the key for a successful to the CBFM process

\section{FG I responses:}

One emerging theme that was discussed by this particular group was communication. The members highlighted the need to have effective means and forms of communication about the CBFM process that will ensure its success in Nauru.

"So I believe that communication is the key concept to the success of this programme-we need to communicate to whoever is involved-stakeholders which is practically everyone in Nauru. We will need to inform other districts what is happening in each district and [what] management plans [are] in place." P2

This example is illustrated from one member's personal experience in talking to local people who were harvesting the felsic rocks off the beach in her district.

"I begged them not to take them and tried to persuade them of the reasons why we need to start taking care of our country and its resources. The problem with harvesting these rocks is that most of the land area in our district seems to be eroding and our foundation is shaky. After the group of people left, I thought to myself, "Oh no, I will be people's number 1 enemy from now on." P6

"I know some people who don't know how to talk or approach people in this situation and could have had a very different result from yours. I mean that is one avenue we could spread this information about managing and caring for the marine resources. If we get so many people on board who talks to other people about this (organic-word of mouth) then we may get great results. " $P 2$

\footnotetext{
34 'Bombed' areas literally mean areas where World War II bombs struck and have created a water hole on people's land.
} 
"So we could say that communication is the key concept to our success with this programme." $\mathrm{P} 5$

"This is evident of the people's lack of ecological knowledge - that the coral rocks in Ijuw hold together the porous land there." P1

\section{Management and conservation tools and options}

Questions about management and conservation tools and options were asked in several ways in the survey. For example, questions were asked about the introduction of (a) coastal zoning and (b) (i) marine reserve(s) and the (ii) site-selection process. These issues were addressed by the focus groups in different order, a) (i) marine reserve(s) and (ii) siteselection, b) coastal zoning and c) license and permits (an additional issue that emerged from FG II).

a) (i) Marine reserve(s) as a management tool

The results of the group discussions are presented separately for each group.

\section{FG I responses:}

The comments reflected the group's lack of understanding about marine reserves, their concerns for food security, and their scepticism in their effectiveness as a management tool but they were still supportive for its introduction. This is illustrated below:

"If one area becomes a marine protected area, is this area going to be closed for conservation purposes or would there be times when people will be allowed to fish in the area?" P5

"To have a marine reserve what is the difference to having a national one as [compared] to a community one?" P4

"The idea that if we open a marine reserve after a couple of years, I believe I will want to fish as much as I can at once." P4

"People will go hungry if the whole area is closed." P7

Group discussion about the benefits of marine reserve(s):

Reef fish species are overexploited. Some examples were highlighted throughout the discussions about the problems with introducing size limits on turban snails (Turbo sp.) and limiting harvest sizes to mature sizes. Fishers who harvested the mature turban snails 
contributed to their overexploitation because for a couple of years, there were no turban snails in Nauru.

Based on this thread of discussion, the species that seems to have disappeared today is the octopus; "we're having problems finding them on the reef even though it is octopus season" P1 FG I. "Divers cannot find octopus in the reef slopes." AM FG I. That is because the "octopus' habitats have been destroyed" P4 FG I.

A probe from the facilitator asked, "From these experiences and examples does everyone here think that Nauru should have a marine reserve(s)?"

\section{FG I Field report}

Participants looked at each other and some nodded their heads while two stated yes. It is a good idea to have a marine reserve(s) for Nauru.

The facilitator probed NFMRA staff in this group, if communities have highlighted marine reserve(s) in their CBFM plans. The discussions were as follows:

"From your community-based management plans that you have developed how many communities have suggested a marine reserve in these plans?" $F$

"I don't think that because you have seven management plans then you need to have seven marine reserves." $P 1$

"There are some communities who prefer to manage only specific species without having a full-scale marine reserve. For example, Ijuw community would like to protect the clamshells (dagoygoy) found on the beach." AM

"Communities suggest other areas should have a marine reserve but not in their own districts.” AM

The assistant moderator (AM) suggested that Nauru should have only two marine reserve(s) because if there are too many reserves people will be hungry. Another member supported this.

"Especially for people like me who are unemployed and dependent upon the marine resources for food." P1

The facilitator again probed the FG members about the implementing marine reserve(s) without people's consent:

"Do you think that people need to agree or do you think we can just go ahead and have the less populated areas as a reserve?" $F$

After a moment of silence... 
"I think people should agree to it and I think it should be the communities themselves." P5 "I think communities because it will affect them the most plus they need to be strong too." P7

\section{FG II responses:}

Introducing marine reserve(s) was a contentious issue for the members of this group.

While the facilitator was introducing the core discussion topics one participant wanted to understand how people could say yes to a marine reserve at this time. Some of his points are illustrated:

"My point here is when all these people agree with having marine reserves are they aware of the consequences of saying 'yes'?" P7

"I mean [marine reserves] have to be clearly defined. You need to be specific like closed for 1 year or so and I mean with clear accurate goals such as within the one-year perioda spawning has passed and all the fish eggs have hatched something like that." P7

"Fishers don't want permanent fishing grounds closed." P7

“...for what purpose, I mean these other district communities having raised the need to have marine reserves?" P7

"One of the problems with marine reserves is that we are currently just surviving off the marine resources and if there are plans to start closing areas to protect the stocks. You know at this time this is a very hard thing to do.... It has to be very clear as to the purpose of what these management actions are for, because I don't think people will respect them if they are not sure why such measures are in place and rather than just cutting off the rest of the population from specific areas, then everyone should be informed." P7

One member suggested the option of having seasonal closures rather than a marine reserve:

"People have suggested having seasonal closures. They meant specific rotational closures for example one area is closed (indicates on map) for the year and then the following year the area is opened but another area is closed and so on. If marine reserve(s) are in place, people will still need to be able to fish in their district too. I mean there might be times when they may have no transport and they cannot fish in other districts and if their district area is closed-they will have a problem with that. They would still need to get their food; I mean especially for those who have specific fishing grounds in their district." P6

Other members provided their views:

"As I said this should be left entirely up to district communities if specific fisheries are closed at specific times. For example, mullet-no fishing for mullet at this time but they can still have the option of having marine reserves in place where people are not allowed to fish. Eventually people will agree on specific rules and over time develop effectively but I think it should start now. I mean the district communities can work on these rules and regulations over time but I think this should start now." P3 
"The idea about future generations needs to be strongly instilled in the people that they are sacrificing their fishing grounds because of our future generations but on the otherhand it is true that we need to strengthen the alternatives that Fisheries can provide for these people. If we start the marine reserve option, then it is best to start providing offshore fishing as an alternative and strengthen this ahead of implementing marine reserves." $P 2$

The facilitator probed the group members, "Ok let us ask [the] question when most of you in this group stated yes to marine reserves what were your reasons?"

"To take care of the fish- there is no more fish." P3

"To take care of the marine resources." P2

"For our future generations so that they can enjoy the same resources we are enjoying now." AM

\section{FG II Field report}

Based on the field notes, FG II began the discussion with marine reserve(s). P7 dominated the discussion. P7 was a former DEC leader in his district and still plays a critical leadership role within his district community in the youth programs. This member finds introducing marine reserve(s) a contentious issue with the current economic climate in Nauru. He was confident and outspoken, and some group members seemed to agree with him.

(ii) Each group discussed the site selection of marine reserve(s). Again the results are presented separately.

\section{FG I responses:}

"I think having marine reserves is all and well but I believe that there should be research done on the best area(s) to have them for Nauru." P4

"I agree that we shouldn't just decide and select an area for the reserve but also [the people should] know what the purpose for having one is in the first place." P5

"To find the best area for a marine reserve in Nauru. We were informed that we should have a reserve where spawning occurs because of the spill-over effects. Closing the area will make no difference as to having the place open because the fish larvae will move to other areas following the tidal currents." P1

"The potential site for a marine reserve is in Anabar/Ijuw area where historically the ponds in that area used to have an open passage to the sea but with the road development this area is closed. I am thinking we should reopen the passage again. I believe that this is potentially a good thing because if the passage is reopened then the area could potentially become a fish nursery again as this area has mangroves. My father told me that this place used to have an open passage to the ocean and that the area was a nursery for all fish and 
invertebrate species. I am thinking if we can reconsider opening the passage and develop a nursery area. Then this area can become one of the marine reserves in Nauru. Is this possible?" AM

The Meneng community did select a site for a marine reserve in their district. This is based upon P7's account of their selection criteria:

- "Less populated area and a well-known area for its fishing ground." P1

- "The area needs protection and it seems more manageable" P7

- "We know that fish spawns in that area" P7

- "[We] plan to [have] zoned areas within this reserve from March to April. We would be allowed to fish on one side of the reserve [during these months]. [This is] for the people [to get their food]. That is why we incorporated this seasonal rule in place. We [also] wanted to [identify] the spawning seasons or times of the fish [in this area]." P7

Other group members did not have the opportunity to discuss a marine reserve site in their district communities. Rather than have marine reserve(s), some district communities have identified other management measures in their CBFM plans, as previously highlighted.

\section{FG II responses:}

It was interesting that P7 questioned the area and the size of marine reserve(s) as important factors in the site-selection process. Then he highlighted that the Ewa community (of which he was a member) wants to put in place a species protection program. This changed his scepticism about the site-selection process, suggesting mapping as a tool that will help with the protection of marine species and areas.

"How then do you know that those areas are right ones for fish spawning that will have a spill over effect?" P7 FG II

"My point is, it really depends on how large an area you close, as it will affect where people go to target specific fisheries and who will suffer from this closure. So if you have a clear idea on how big these closures will be, you have to make it very clear to the people giving up these areas. People will have to fish further offshore and you have to be mindful that not everyone owns fishing boats to do this or can afford to use boats to fish offshore." P7

"[Having] maps of closed areas and reserves in specific districts but [maybe] not a species map. Ok for example, Ewa district wants to protect our two Groupers species (kowodo). [I]f we mark this on the map and everyone is aware of this. [It] will [help] protect our residential groupers. There is a need for having good awareness programme, but it will depend on the media and how they present this stuff or how awareness is being communicated. [In order] to avoid people fishing in these [closed] areas or the protected species." P7 
"For example in one district if there is a protection of the clamshells on the beach then you should have this in the map. [NFMRA] needs to update [the map] as you implement district management plans. [The map needs to] include other management or conservation measures in place that could be updated every year. For example, what communities want to manage should be on maps so everyone becomes aware of activities taking place." P7

The facilitator asked a question to probe responses from the group members, "if we are to have habitat mapping of marine resources and mark specific-species and areas under protection, is there a chance that people will go out and target these species when a map is available?

"Depends if people value being famous and having their photos on the Capelle \& Partner wall of fame and wanting to be known about their catch-unique species" P5

FG II identified the need to have maps of protected areas and species. Other members did not disagree with the idea but when probed further about the usefulness of maps, one member suggested that this was dependent upon the people's attitude and value. In Nauru, fishing is highly competitive among fishers. One can become well known based on his catch. A photo of the fisher and his catch can be displayed at the only sports fishing shop in Nauru, Capelle \& Partner. Interpretation from this group discussion about mapping of protected species requires caution because there is great uncertainty how fishers will react to such a map.

b) Coastal zoning

In FG I, the Meneng community planned to use zoning within its marine reserve as previously highlighted (above). The zoning is within the marine reserve to delineate a "notake" area and an open season area during March and April.

In FG II, some members identified the constraints of zoning in Nauru because of its small coastal areas. For example, if net fishers are zoned and limited to one or two coastal reefflat and slopes (Figure 3), this can increase the intensity of fishing within the areas as well as elsewhere. This can also lead to overcrowding of fishers in the zoned areas.

"It doesn't sound like a realistic thing, if you put it that way so we should not zone [specific resource-users to specific sites and areas]. " AM

Although coastal zoning was discussed more in FG II than FG I, most members in the former group did not contribute much to the discussion about zoning. It was probably difficult for the members to grapple with the concept of resource-use zoning because, again, it is a new concept to them. 
c) Use of permits and licenses option was raised by FG II but not FG I.

\section{FG II responses:}

"The fee means that the cost of fish will need to increase amidst the increasing fuel price. If we could get the license free and then we will all agree to getting registered or having a license." P3

"It is difficult to have people pay fees if government benefits but the community will suffer from another increased cost of living. The costs of fish will increase for the local people if you implement licenses and permits." $P 7$

"I mean one idea with license fees is that it should be recirculated back to the community in the form of community funds. This then allows communities to access these funds for their projects in the CBFM. [The government could] use these funds to support alternatives provided back to the communities-aquaculture and canoe-building programmes. " $F$

"I am against licenses and I do not agree. But it could be used as an option to control fishers and their impacts on the inshore areas and on the reefs. I think with this licensing you can control the number of fishers in the inshore areas. I mean everyone just tramples on everything and anything out there nowadays and the number of people fishing in the areas is increasing. When you go to the reefs the evidence of destructive fishing and trampling on marine species can be seen - with trampled sea urchins." P3

\subsection{Some key findings}

This particular section is to link the focus group findings to the perception survey (in Chapter 5). Based on the focus group results there are a number of crossover issues.

\section{District communities as drivers of the CBFM process in Nauru}

Both focus groups accepted that district communities should be the drivers of the CBFM process. As highlighted in Chapter 2, district communities have formed the basis of a democratic electorate and they represent socio-political units in Nauru (Thaman and Hassall, 1996). With the current economic situation, these district communities have gained recognition and their District Executive Council (DEC) are becoming resourceful to source funds and distribute goods to members within their community. District communities are seen as a cohesive social unit that has well-defined boundaries of both resources and communities. Participants from the central district of Buada also accepted that district communities as drivers of the CBFM process. The location of this district does 
not allow this community to have a CBFM plan but they will need to comply with other districts' CBFM plans.

By comparison, the perception survey findings showed that the participants were doubtful of the CBFM approach and process because of their lack of information about the CBFM programme. The focus groups had an advantage over survey participants because the discussions were focused towards the CBFM programme and process.

The focus groups also stated whether the CBFM approach could work in Nauru. Again, most survey participants were sceptical about the approach. Discussions in the focus groups were about the roles and objectives of NFMRA and communities in the process. Based on these results, some issues were highlighted that supported the notion that the CBFM approach can work in Nauru.

- NFMRA finds it easier for district communities to drive the CBFM process because NFMRA can coordinate its efforts to support and monitor the progress of district communities in the CBFM programme.

- NFMRA found that in working with district communities through their national workshops, the local people are willing to participate and have a lot to contribute to their own CBFM plans.

- One member believes that district communities will learn to adapt to the situation and the new approach. District communities have the ability to be responsible for managing the coastal marine areas. They can develop their own rules and also address the concerns of their own community members about the rules and adapt them accordingly. For communities to learn and understand the process, a very strong or powerful measure should be introduced right at the very beginning ${ }^{35}$ of the process.

- One member suggested that the district-based approach is best and clearest. It will avoid any conflicts among communities and they will learn about their boundaries and responsibilities in the CBFM process.

- Another member highlighted that one district has already developed a community monitoring process that is in place, but the rest of the population is not being informed.

\footnotetext{
${ }^{35}$ This member was not probed to clarify why a "strong" measure needs to be implemented at the beginning of the CBFM process was necessary.
} 
- Both groups identified Buada community's unique situation and suggested that district CBFM plans should not exclude outside fishers from fishing in the coastal marine areas.

- All resource-users should respect and comply with district rules and regulations in the CBFM plans.

Based on the results, NFMRA did not provide the legitimate rights for its partners (the communities) to exercise authority in the CBFM process. NFMRA did not coordinate with other government agencies over the CBFM programme. District communities want to develop their own rules, participate in the decision-making processes, monitor and enforce their own rules, have wardens in place and have a volunteer group that conducts awareness programmes with schools. That the central role of the community was identified in the discussions strongly suggests the willingness of these groups to engage in the CBFM process.

One of Ostrom's (1990) design principles is the formulation of 'nested enterprises' to allow "governance activities [to be] organized in multiple layers" (p.90.). There is the need for NFMRA to clarify its role in the CBFM process if it wants the CBFM programme to succeed. The roles of NFMRA and communities in the CBFM process as based on the focus groups' responses may be a reflection of their expectations. As Sverdrup-Jensen and Nielsen (1998) notes, communities' expectations are often high.

An example is the experience of the Meneng community based on the account of one member. The CBFM process is still a new idea to the community with mixed levels of compliance levels. Monitoring of resource-users takes place but is still very weak as it is carried out individually. Self-regulation is meant that one directly approaches users when seen offending and informing them about rules. After two incidents (see results section), the community gave up trying to continue with the CBFM process. The challenge highlighted from the Meneng community's experience is their lack of power to control management over their own waters. The DEC failed to develop good relations with other partner organisations an NGO. As Pinkerton (1989) suggests in Chapter 3, forming relationships in the CBFM process is one of the keys to its success. 


\section{Challenges and opportunities of the CBC process}

Four issues emerged from the group discussions that are significant to both the process and practice of CBC. These included: awareness raising, campaigns and programs of district community rules and regulations;

As highlighted in Chapter 4, awareness-raising is a significant part of CBC practices. Based on the implementation processes of the FLMMA approach, is that they have created a "Yaubula" group at the community level in Fiji. This group is effectively raises the awareness of communities about their resources but also drives the process. According to an expert (E3), the use of such a group has made it easier to implement the CBC process. As highlighted earlier the perception survey indicated that there are an overwhelming number of survey participants who are unaware of the CBFM programme and its purpose in Nauru. Based on the focus group discussions, this small sample of people were unaware of the CBFM programme, let alone the Meneng community's CBFM plans (rules and regulations). The Police are not even aware that district communities are being empowered to manage and conserve their coastal marine reserves.

- Monitoring and enforcement mechanisms in place

It was discussed in the group that the community should participate in the resource monitoring and enforcement of their rules and regulations (see above). The group discussion was inconclusive about the level of monitoring and enforcement that should take place and whether it should take place on a community or national level. Some members were aware that the Meneng community was already conducting weak but illegal monitoring and policing of their coastal marine areas. Based on Ostrom's (1990) design principles, monitors are essential. Monitors need to check the conditions of the resource and the appropriate behaviours of users. The monitors need to be accountable to the appropriators (community) to ensure the effectiveness of the management.

- Livelihood diversification options

Based on the group results, a member suggested milkfish culturing as an alternative and others were not aware that NFMRA offered such options. NFMRA offers communities in the CBFM programme these alternatives as part of alleviating fishing pressures from the coastal marine areas as highlighted in Chapter 2. The use of livelihood diversification options is part of the $\mathrm{CBC}$ practices in the Pacific region as discussed in Chapter 4. It was 
mentioned that the performance of these livelihood diversification tools were not to be found as effective as initially thought (Gillett, et al., 2008). A recent study suggests that socio-economic impacts and limited opportunities for diversified alternatives for local communities are the major causes of coastal marine resource exploitation (Kronen, et al., 2010). As an expert (E1) highlighted in Chapter 4, there is a need to balance both development and conservation in resource management, which has remained a challenge in practice.

- Communication is perceived as the key to the success of the CBFM process

One group highlighted that communication is a key to the success of the programme in Nauru. As experts suggested in Chapter 4, understanding the perceptions of the communities can help the CBC process succeed.

\section{Management and conservation tools and options}

There was overwhelming support from the perception survey for the introduction of marine reserves in Nauru. Some of the group dynamics in discussing marine reserves cannot be seen from the survey and the findings are summarised to help this study understand community perceptions about marine reserves. The survey results about why participants selected a particular site to have a marine reserve did overlap with some of the focus groups criteria. Both groups refrained from identifying specific districts and sites.

(i) Based on both group discussions, introducing marine reserve(s) produced mixed responses among the members. There are still a lot of questions about marine reserve(s): Is it a no-take area? What is the difference between having a national reserve compared to a community conserved area? What is the purpose of it? The difficulties of implementing a marine reserve with the current economic climate were raised. There is a preference for seasonal closures rather than a marine reserve. Some district communities prefer to have species protection in place to a marine reserve. There was a suggestion for a cap on the number of national marine reserves was mooted, with two being suggested for Nauru. It was argued that people might starve from having too many reserves in place. Another suggestion was that communities should make these decisions for themselves so they can learn from the process. One view is to have marine reserves as a legacy, while NFMRA strengthens the options for alternative livelihoods. Focus group I suggested that 
communities' consent is required, including, their participation in the decision-making process to implementing marine reserve(s).

(ii) The discussion of the site-selection process for marine reserves by each gender-based group highlighted different criteria. In FG I (females), one wanted research to identify the best site for a reserve and another suggested that the purpose of the reserve should be decided first. One member highlighted that protecting spawning areas where tidal conditions are favourable can increase the spill-over effect. Another member wanted to redevelop a former fish nursery as a reserve. One member's informed the group her community's criteria for a reserve should include: where fewer people live, having a manageable reserve size, a fish spawning area and to have specific no-take zones within the reserve. In FG II (males), the question of the 'right' area and size of the reserve was perceived as significant to the site-selection process. Marine reserves or protected species should be mapped as part of the awareness campaign. It was highlighted in the discussion that mapping of protected species can have its advantages and disadvantages such as people knowing where protected species and areas are located and also people may exploit the protected species as they are marked on a map.

Another option discussed is coastal zoning. One member considered zoning unrealistic after making the claim that zoning fishers in specific areas may lead to overexploitation due to fishing intensity and overcrowding. There was a high level of support for coastal zoning from the survey results. Thaman and Hassall (1996) recommended that Nauru should introduce integrated coastal zone management (ICZM). More research is required for this option.

There was resistance among the members of Focus group II to the introduction of license and permit as a preferred management option, even though the facilitator tried to suggest the benefits from the fees, to fund potential community projects. As Pinkerton (1989) highlighted in Chapter 3, there is a need to have funds recirculating back to the local community in community-based co-management arrangements to enhance their chance of success.

Some issues to improve the CBFM process in Nauru:

- District communities are perceived as the best way to drive the CBFM process, but the CBFM programme is still not well understood by the communities. 
- The roles and objectives of NFMRA and communities as partners in the CBFM process are not well-defined and not clearly understood by the participants.

- The lack of nested enterprises was identified as a constraint on the CBFM process. For example, NFMRA needs to communicate with communities and other government agencies about the CBFM programme, to form good working relationships with government and local NGOs.

- More information about marine reserve types and their purposes should be made available. This is important if Nauru is to meet its national and international agreements (NBSAP (2010) strategy and its CBD commitments).

- There is a need to hold more discussions about managing and conserving the coastal marine systems in small groups in the future. This would promote awareness, information sharing and knowledge about the CBFM programme, process and practice.

Improvements that can be made to this study:

- Improve the participants' selection-process. Include a more representative sample from the general population, for example have more young people participate in the discussions.

- Have more than one gender-based focus group to allow for a comparative analysis.

- Have a mixed group session rather than only gender-based groups.

\subsection{Brief discussion}

\section{Focus group methods}

This is the researcher's first focus group activity and future research may strengthen, deepen and test the results. The researcher's inexperience in moderating a focus group may have biased the responses, but the researcher had developed guiding questions to avoid this form of bias. The researcher had to facilitate and moderate the focus group sessions because of the limited skills of other individuals on site. Both the ability to facilitate the process and to understand the research topic was needed. The issue of maintaining objectivity in the process for the researcher was difficult, especially in such a small country where people know each other. The researcher's position in the community as a 
NFMRA Officer may have influenced the participants' responses in the discussions and interactions within the group.

Regarding translation of the focus group discussion data, the researcher did this. A crosscomparison was done with the field notes. There are terms in the Nauruan vernacular that could not be directly translated into English. Due to limited time, the researcher had to rely upon the tape and field notes. Overall, these issues may have diminished the rigour of the methods and quality of the findings.

Other difficulties were found in each of the group sessions. In focus group I, there was one dominant group member who had the tendency to lead the group discussions. This may have influenced some of findings in this group. In focus group II, there were two group members who dominated the discussion as highlighted in the results. Another found it difficult to participate in the process even when the researcher specifically tried to engage the member with questions throughout the session. This member's responses were restrictive. It was made clear to the researcher that this member may not have been comfortable within the group dynamics. However, this is difficult for the researcher to ascertain because focus group discussions are rarely conducted in Nauru and people are not familiar with the process. People are accustomed to workshops or training programs where someone is always teaching and leading the process. This time the focus group session was about the participants' discussions and opinions, which may have been uncomfortable for some members. For such a small place, opinions are not given freely; especially when there is a suspicion everyone else will find out the next day. To mitigate this problem, and in accordance with good research practice, confidentiality and nondisclosure forms were signed by each participant prior to the sessions. 


\section{Chapter 7}

\section{Discussion and conclusions}

\subsection{Introduction}

This chapter aims to provide recommendations for policy, practices and institutions that may advance community-based marine conservation (CBMC) in Nauru, and to indicate future research needs. It begins with a discussion of what the investigation revealed based on the research objectives and how each was achieved or not achieved. It follows with some recommendations for policy, practice and institutions for Nauru. It then provides suggestions for future research work in Nauru. Finally, the contribution of this thesis to the intellectual knowledge-base is considered.

\subsection{Research objectives}

\subsubsection{Objective 1}

The challenges for Nauru in managing and conserving its coastal marine resources are highlighted throughout Chapter 2. The overexploitation and degradation of its coastal marine resource systems are attributed to problems of population pressures and economic decline. Other challenges for Nauru include its obligations to the MDG goals and commitments to the CBD. Nauru has been well-advised of the urgent need to develop an effective coastal marine regime if it wants to ensure food security needs of its people are met especially in the future. With the introduction of the community-based fisheries management regime in Nauru in 2007, new and complex challenges have been emerging. Problems have been identified over the government's and local institutions' ability to form good working relationships and partnerships. Based on these issues, the next chapter sought to explore theories of community-based management institutions that will help foster a better working relationship among resource stakeholders in Nauru.

\subsubsection{Objective 2}

The community-based institutions in resource management are very complex in nature, as described in Chapter 3, particularly in coastal and marine management. The interdisciplinary nature of the theoretical framework makes it difficult for this study to 
address one aspect of these broad issues, especially because of the existing gaps in information in Nauru. The scope of this review was limited to exploring success factors from local-level and governmental-level institutions, but the study was aware that are multiple institutional levels in resource management. Commons research has been instrumental to develop the theories of successful local-level institutions but limits itself to addressing contextual and external factors such as population pressures, markets and new technology. This study had to draw upon empirical work of scholars from commons research and co-management frameworks to gain a better understanding of how collective action theories work at multiple institutional levels. The interdisciplinary nature of the literature did not allow the study to explicitly explore the nature of community-based comanagement institutions but has highlighted those factors relevant to the case study at this time. Thus, the review was limited to identifying those co-management frameworks that seek to help improve upon community-based institutions in their management and conservation of coastal marine systems. What is important to this study is that the success of community-based co-management is not just about enduring institutions that enable collective action to take place; they need to achieve resource sustainability goals. Resource management regimes and their institutions should have an adaptive capacity to be resilient. This ensures the management regime's ability to address changing environments and circumstances, and include newly acquired information.

\subsubsection{Objective 3}

A problem identified in the literature review is that commons research has failed to embrace contextual and external factors affecting community-based institutions. This study explored the current practices of community-based conservation in the Pacific region. Nauru is based in this region and its CBFM model was adapted from Samoa and now serves as a blueprint for the region. Chapter 4 looked at two CBC models and interviewed experts about the practices in the region. Of these two regional approaches, one takes an ecosystems approach to fisheries management and the other an adaptive learning process. The primary goals are similar between these two models: to ensure sustainable practice and use for food security purposes, while biodiversity conservation remains a secondary goal. Climate change is still an emerging challenge for the region as well as the CBC frameworks and is addressed on a "need to" basis. It is recognised that more work is required to address this issue in the future. Based on expert opinion, the approach with climate change mitigation is to build the resilience of the local people 
through awareness raising and providing relevant information and resources. This study looked at the current $\mathrm{CBC}$ practices in the region and the many processes involved: the implementation process, democratic participation, the diverse management toolkit, customary marine tenure (CMT), marine protected areas (MPAs) and alternative livelihood options.

In chapters 3 and 4, this study was able to explore and examine both the theory and practice of community-based co-management institutions. As a result, it helped to identify gaps of information relevant to the case of Nauru. It was identified from the expert interviews that understanding the local context and peoples' perceptions about their coastal marine resources is significant to ensuring the success of the CBC. It was recommended that this should have been done before embarking on the $\mathrm{CBC}$, but is still found useful now.

\subsubsection{Objective 4}

The perception study was still found useful for the case study. In the following chapters of 5 and 6, the study took a broad-base examination of resource-users (fishers) and resourcebased communities (non-fishers) in Nauru. It aimed to identify the willingness and capacity of individuals to act in community-based co-management arrangements by looking across the levels awareness, knowledge, attitudes and behaviours about coastal marine management and conservation. This snapshot view can only serve as a baseline study at this time because of its broad outlook. This information has helped in our understanding about why there are many challenges and issues with for individuals as well the local institutions to be drivers of the community-based management process in Nauru.

Some of the constraints include: lack of supporting and enabling institutions in place, the lack of awareness, information materials and knowledge of individuals to engage in the CBC process, limited alternative livelihood options and of course, and the current economic climate in Nauru. These factors can affect the willingness of individuals as well as communities to participate in the $\mathrm{CBC}$ process. Some suggestions for awareness raising and dissemination of resource materials are necessary, as is developing an energy centre to drive the process. Institutional building also needs to take place, from reviewing the current legislation frameworks to empowering the local-level institutions to share this responsibility. A learning framework should be included in the CBFM model. 
There was overwhelming support for the introduction of marine reserves based on the survey results. The level of understanding over what marine reserves are is still limited. Based on the focus group the benefits of having marine reserves are understood but the 'best' types and number of marine reserves to be implemented is still unknown at this time. Species protection management is well-accepted by the focus groups but there is a general lack of information as to species lifecycle and how best to protect them. The loss of traditional ecological knowledge about the marine resources does not help this situation.

Some of the communities' needs were identified throughout these two chapters. More information about the types of marine protected areas (MPAs) should be made available to individuals and communities. As highlighted in Chapter 5, discussing MPA options needs to be part of the learning framework in Nauru. More information is needed about marine species of interest to communities in order to help them understand about these species and enable them to manage and conserve the stocks. Again, the need for more awarenessraising and available information about the current national community-based fisheries management $(\mathrm{CBFM})$ programme is essential. Based on the survey there is a poor level of awareness of the programme and most participants suggested that this approach would not work in Nauru. In focus group sessions, participants agreed that communities should play a role in managing and conserving the coastal marine resources and its surrounding environment. District communities were also seen as the best way to drive the process. There are conflicting results here but considering the focus groups had time to discuss the purpose of the CBFM programme, it would seem that they had more information than the survey participants.

The various roles of government and communities in the co-management arrangement are still unclear to all research participants even though NFMRA is currently implementing the CBFM programme. The government has been slow to respond to the drafted coastal law that recognises communities as 'stewards' of the marine resources. It reflects the government's lack of interest in prioritising the development of the CBFM programme. Some individuals are still conflicted over the loss and recognition of CMT in Nauru. To date the coastal marine resources and areas have suffered from the 'tragedy of the commons' because of the current open-access regime under state ownership where areas have been left to resource-users' own devices. 
The research did gain some insight as to why fishers are resistant to the introduction of fishing gear and methods regulation based on cognitive dissonance theory (Festinger, 1957). But the research did not succeed in finding out what incentives may help fishers engage and act in the CBFM process at this time. The study did however reveal how survey participants value the coastal marine systems to their well-being based on a set of variables. This information is important as it can be used to appeal to the masses in explaining why Nauru needs to protect and conserve its coastal marine resources in the future.

\subsection{Research Recommendations}

This section will discuss the last objective of this study. Provide some recommendations for policy, practice and institutions to ensure that the current CBFM programme succeeds and can move on route towards a community-based marine conservation (CBMC) regime. In Chapter 2, Thaman and Hassall (1996) did provide recommendations and action plans for Nauru as part of its national sustainable development plan. This research does not attempt to duplicate their recommendations but these may overlap based on the findings of this study (see Chapters $5 \& 6$ ).

\subsubsection{Policy}

1. Strengthen and develop enabling policies and legislation that legitimises communities as 'stewards' and partners in the CBFM process.

2. Develop a national coastal plan to address the problems of sand erosion, sewage, pollution and waste, coastal land reclamation and infrastructure development.

3. Strengthen national environmental and marine education to include sustainable marine use and practices.

4. Promote national awareness of climate change and biodiversity conservation strategies, goals and targets.

5. Mainstream the National Biodiversity Strategy and Action plan (2010) to complement the current work of NFMRA. This will allow the co-ordination of marine management and conservation activities carried out at the community level.

6. The biodiversity strategy should also support relevant community-based projects that foster the link between food security and resource sustainability. 
7. Develop a national policy on marine protected area(s) and/or community conserved areas (CCAs) as part of its commitment to the Biodiversity strategy and CBFM programme.

8. Develop a national policy on the monitoring and enforcement of community-based rules and regulations. For example, monitoring and enforcement of fishery regulations should recognise the powers of community wardens. Both Fisheries and Police Officers could support the community's role in resource management. Enable the right to penalise offenders when a community member reports the offender subject.

9. In the mean time, NFMRA should implement some interim measures while the CBFM programme is in the process of being implemented so that both government and communities are aware of the national programme. This will avoid future conflict of interest between government agencies and communities on account of the Meneng community's experience with the CBFM process.

\subsubsection{Practice}

The recommendations from the findings on $\mathrm{CBC}$ practices

1. It is recommended that communities are part of the decision-making processes in developing, managing and conserving coastal marine systems.

2. It is recommended by the focus group that communities need to hold more discussion forums about the CBFM programme, and the process and the roles of NFMRA and of communities, as part of the awareness campaigns.

3. Because of Buada's unique situation, it was suggested that individuals from outside coastal communities are not to be excluded from fishing in districts but should be required to uphold and respect the district community's rules and regulations. This is similar for other district communities. Even Buada's unique situation is unlikely to negatively affect the CBFM process if people understand its goals.

4. Regulatory measures on fishing activities and their impacts such as catch and size limits and fishing gear controls should be identified by the communities but national standard protocols would need to be developed to support these regulations. 
5. The use of MPAs should have specific goals such as protecting spawning aggregations. This will require seasonal closures and protection of marine habitats. Coastal zoning can be used to support marine reserve(s) or seasonal closures.

6. The use of licensing and permits and the use of mapping as tools should remain as options in the CBFM, but they require further discussion.

7. Awareness-raising and access to information about coastal marine management and conservation should be made available to communities as required.

\subsubsection{Institutions}

Institutions play a significant role in the success of $\mathrm{CBC}$, so some of the recommendations are highlighted based on the findings.

1. District communities including the Location community are perceived as the best way to drive the $\mathrm{CBC}$ process with the support of government.

2. NFMRA should strengthen its diversified livelihood options and make them available to communities who participate in the CBFM process.

3. NFMRA as the lead government agency in the CBFM programme should develop nested enterprises of networks and partnerships with government agencies, the community and other organisations as part of the process. In Fiji, the Fisheries Department coordinated its FLMMA approach by hosting a Secretariat that focuses on community development of marine conservation. This model could be established within the NFMRA.

\subsection{Future research}

As highlighted throughout this thesis, there are gaps in information with respect to understanding people's perceptions about the coastal marine systems that require more research work. This investigation is only a first step, which attempted to understand some of the underlying perceptions of individuals about the management and conservation of coastal marine systems in Nauru. In order to help ensure that a successful CBMC is achieved, future research needs to apply a more focused spotlight on the elements of the $\mathrm{CBC}$ process. 
Specific research areas include:

- Identifying what incentives individuals have to act and participate in the CBFM process.

- Identifying species of concern and interest to communities that require enhancement and protection.

- Validating the reliability of TEK and local knowledge. As highlighted in this study, such knowledge may enhance the CBFM process.

- Investigating marine protected area(s) and their purposes. Research is needed to select the type that is applicable for use in Nauru. Various forms of MPA(s) could be introduced as a pilot project and experimented on a trial-and-error basis.

- Introduce regulatory measures identified by communities in their CBFM plans as part of an adaptive management strategy.

Broad-scale research includes:

- Developing social learning mechanisms where a social group or organisation is formed to help and encourage communities in the CBFM process.

- Adopting a learning framework for the current CBFM model that allows for acquired information such as new research, biodiversity conservation or environmental changes (climate change) to be adapted into it.

- Develop partnerships with regional or international NGOs to share new information about resource management systems and to keep up with new and relevant developments in this area. This could include the regional University of the South Pacific. These links could identify future research applicable to Nauru.

To conclude, this thesis set out to reveal individuals' willingness and capacity to participate and act in the CBFM programme. As it turned out, more information and research are required, but the research has provided considerable insight into the current situation and its people. The level of knowledge and the capacity of individuals and communities in Nauru to manage and conserve the coastal marine systems are influenced by other dimensions - political, economic, social and cultural. All these dimensions may 
act as obstacles or opportunities in the face of the current challenges but the urgency to act remains, as social-ecological systems are not static and the need to do so is pressing.

Developing a successful CBFM or CBMC, considerable investment and effort is required, from developing the people's capacity and knowledge systems, to putting mechanisms in place that include institutional reforms and institutional building. There is still a long way to go, but let this thesis be a contribution to that journey.

\subsection{Contribution to intellectual knowledge}

This research began from the personal experience and frustrations of the author with the community-based fisheries management programme in Nauru. The research was set out to help identify the failings of both the government and communities in committing to and progressing the CBFM process in Nauru.

This study has not only provided some insights into Nauru's current situation with the CBFM process and its needs; it has also contributed to the debate over community-based co-management institutions' effectiveness in resource and environmental management. This study also has found that the 'communities in practice' paradigm supports interdisciplinary social research in a way that is flexible, pragmatic and meet the needs of the research problem. 


\section{References}

Agrawal, A. (2002). Common resources and Institutional Sustainability in The drama of the commons (pp. 41-86). E. Ostrom, T. Dietz, N. Dolsak, P. C. Stern, S. Stonich \& E. U. Weber (Eds.), Washington: National Academy Press.

Agrawal, A., \& Gibson, C. C. (1999). Enchantment and disenchantment: The role of communities in natural resource conservation. World Development, 27(4), 629-649.

Agrawal, A., \& Gibson, C. C. (2001). The Role of Community in Natural Resource Conservation. In A. Agrawal \& C. C. Gibson (Eds.), Communities and the Environment: Enthnicity, Gender and the State in Community-based Conservation. New Jersey, New Brunswick: Rutgers University Press.

Allan, C., \& Curtis, A. (2005). Nipped in the Bud: Why Regional Scale Adaptive Management is Blooming. Environmental Management, 36(3), 414-425.

Armitage, D., Berkes, F., \& Doubleday, N. C. (2007). Adaptive Co-Management: Collaboration, Learning and Multi-Level Governance. Vancouver: UBCPress.

Armitage, D., Plummer, R., Berkes, F., Arthur, R. I., Charles, A. T., Davidson-Hunt, I. J., et al. (2009). Adaptive co-management for social-ecological complexity. Frontiers in Ecology and the Environment, 7(2), 95-102.

Aswani, S. (1999). Common property models of sea tenure: A case study from the Roviana and Vonavona Lagoons, New Georgia, Solomon Islands. Human Ecology, $27(3), 417-453$.

Baland, J. M., \& Platteau, J. P. (1996). Halting Degradation of Natural Resources: Is there a Role for Rural Communities? Rome: Food and Agriculture Organization of the United Nations, FAO.

Bardhan, P. (2000). Irrigation and cooperation: an empirical analysis of 48 irrigation communities in South India. Economic Development and Cultural Change, 48(4), 847-865.

Bash, J. S., \& Ryan, C. M. (2002). Stream Restoration and Enhancement Projects: Is Anyone Monitoring?. Earth and Environmental Science, 29(6), 877-885.

Bell, J. D., Kronen, M., Vunisea, A., Nash, W. J., Keeble, G., Demmke, A., Pontifex, S., and Andrefouet, S. (2009). Planning the use of fish for food security in the Pacific. Marine Policy, 33(1), 64-76. 
Berkes, F. (1999). Sacred ecology: Traditional ecological knowledge and resource management. London: Taylor and Francis.

Berkes, F. (2002). Cross-scale institutional linkages: Perspectives from the bottom up in The drama of the commons. E. Ostrom, T. Dietz, N. Dolsak, P. C. Stern, S. Stonich \& E. U. Weber (Eds.), Washington, D.C.: National Academy Press.

Berkes, F. (2006). From Community-Based Resource Management to Complex Systems: The Scale Issue and Marine Commons. Ecology and Society, 11(1:45).

Berkes, F. (2007). Adaptive Co-management and Complexity: Exploring the Many Faces of Co-management in Adaptive Co-Management: Collaboration, Learning and Multi-Level Governance. D. Armitage, F. Berkes \& N. C. Doubleday (Eds.), Vancouver: UBC Press.

Berkes, F. (2008). Sacred Ecology: Second Edition. New York: Routeledge.

Berkes, F. (2009). Evolution of co-management: Role of knowledge generation, bridging organizations and social learning. Journal of Environmental Management (90), 1692-1702.

Berkes, F., Colding, J., \& Folke, C. (2000). Rediscovery of Traditional Ecological Knowledge as Adaptive Management. Ecological Applications, 10(5), 1251-1262.

Berkes, F., Colding, J., \& Folke, C. (2003). Introduction in Navigating Social-Ecological Systems: Building resilience for Complexity and Change (pp. 1-30). F. Berkes, J. Colding \& C. Folke (Eds.), Cambridge, UK: Cambridge University Press.

Berkes, F., George, P., \& Preston, R. J. (1991). Co-Management: The Evolution of the Theory and Practice of Joint Administration of Living Resources. Paper presented at the Second Annual Meeting of IASCP. Retrieved from http://dlc.dlib.indiana.edu/dlc/bitstream/handle/10535/1506/CoManagement_The_Evolution_in_Theory_and_Practice_of_the_Joint_Administration_of Living_Resources.pdf?sequence $=1$

Berkes, F., Mahon, R., McConney, P., Pollnac, R., \& Pomeroy, R. (2001). Managing small-scale Fisheries: Alternative Directions and Methods. Ottawa: International Development Research Centre.

Berkes, F., \& Turner, N. J. (2006). Knowledge, learning and the evolution of conservation practice for social-ecological system resilience. Human Ecology, 34(4), 479-494. 
Bernard, H. R. (2002). Interviewing: Unstructured and Semistructured Research Methods in Anthropology: Qualitative and Quantitative Methods (pp. 203-212). Walnut Creek, CA.: Alta Mira Press.

Beyea, S. C., \& Nicoll, L. H. (2000). Collecting, analyzing and interpreting focus group data- Statistical Data Included. AORN Journal(June, 2000).

Borrini-Freyerbend, G., Kathari, A., \& Oviedo, G. (2004). Indigenous and Local Communities and Protected Areas: Towards Equity and Enhanced Conservation. Gland, Switzerland and Cambridge, UK: IUCN- The World Conservation Union. Bourdieu, P. (1986). The forms of capital Handbook of Theory and Research for Sociology Education (pp. 241-258). New York: Greenwood Press.

Capra, F. (1996). The web of life: A new scientific understanding of living systems. New York: Doubleday.

Chapman, R. (2009). Presentation of research proposal of M. Deiye, Wellington.

Charles, A. (2001). Sustainable fishery systems. Halifax: Blackwell Science.

Charles, A. (2004). Sustainability and resilience in natural resource systems: Policy directions and management institutions in Encyclopaedia of Life Support Systems (EOLSS). Y.-K. Ng \& I. Wills (Eds.), Oxford: Oxford EOLSS Publishers.

Charles, A. (2007). Adaptive Co-Management for Resilient Resource Systems: Some Ingredients and the Implications of Their Absence in Adaptive Co-management: Collaboration, Learning and Multi-Level Governance. D. Armitage, F. Berkes \& N. C. Doubleday (Eds.), Vancouver: UBC Press.

CIA. (2008). The World Factbook. Retrieved from https://http://www.cia.gov/library/publications/the-world-factbook/geos/nr.html

Cohen, F. (1986). Treaties on Trial: The Continuing Controversy over Northwest Indian Fishing Rights. Seattle: University of Washington Press.

Coleman, J. S. (1988). Social capital in the creation of human capital. American Journal of Sociology(94), 95-121.

Coleman, J. S. (1990). Foundations of Social Theory. Cambridge: MA: Harvard University Press.

Constanza, R., d'Arge, R., de Groot, R., Farber, S., Grasso, M., Hannon, B., et al. (1987). The Value of the World's Ecosystem Services and Natural Capital. 387, 253-260. Retrieved from http://www.ecy.wa.gov/PROGRAMS/wr/hq/pdf/naturepaper.pdf 
Cooper, J. (2007). Cognitive Dissonance: Fifty years of a Classic Theory. Los Angeles: SAGE Publications.

Corvalan, C., Hales, S., \& McMichael, A. (2005). Ecosystems and Human Well-Being: Health Synthesis: a report of the Millennium Ecosystem Assessment. France: WHO.

Cox, M., Arnold, G., \& Tomas, S. V. (2010). A Review of Design Principles for Community-based Natural Resource Management. Ecology and Society, 15(4), -.

Creswell, J. W. (2009). Research Design: Qualitative, Quantitative and Mixed Methods Approach. California: SAGE Publications, Inc.

Creswell, J. W., Shope, R., Clark, P., \& Green, D. (2006). How Interpretative Qualitative Research Extends Mixed Methods Research. Research in the Schools, 13(1), 1-11.

Dalzell, P., \& Debao, A. (1994). Coastal Fisheries Production on Nauru. Noumea: South Pacific Commission.

Danielsen, F., Balete, D. S., Poussen, M. K., Enghoff, M., Nozawa, C. M., \& Jensen, A. E. (2000). A simple system for monitoring biodiversity in protected areas of a developing country. Biodiversity and Conservation(9), 1671-1705.

Danielsen, F., Burgess, N. D., \& Balmford, D. (2005). Monitoring matters: Examining the potential of locally-based approaches. Biodiversity and Conservation(14), 25072542.

Davidson-Hunt, I. J., \& O'Flaherty, R. M. (2007). Researchers, indigenous peoples, and place-based learning communities. Society \& Natural Resources, 20(4), 291-305.

Deiye, M. (2004). Nauru. In R. Sulu (Ed.), Status of coral reefs in the Southwest Pacific: 2004. Suva: IPS Publications.

Deiye, M. (2010). Alternative management frameworks: Exploring the conceptual framework of co-management and adaptive management to natural resource management. Unpublished ENVI527 Assignment. Victoria University of Wellington.

Deiye, M., \& Tsiode, E. (2007). The Draft Community-based Fisheries Management Model for Nauru's Coastal Fisheries Management Programme. Nauru: Nauru Fisheries \& Marine Resources Authority.

Descombe, M. (2008). Communities of Practice: A research paradigm for the mixed methods approach. Journal of Mixed Methods Research, 2(3), 270-283. 
Dowsley, M. (2009). Community clusters in wildlife and environmental management: using TEK and community involvement to improve co-management in an era of rapid environmental change. Polar Research(28), 43-59.

FAO. (1996). Precautionary approach to capture fisheries and species introductions.

Rome: Food and Agriculture of the United Nations (FAO).

FAO. (2003). The ecosystem approach to fisheries. Rome: Food and Agriculture Organisation of the United Nations.

Festinger, L. (1957). A theory of cognitive dissonance. California: Stanford University Press.

FinancialStandardsFoundation. (2009). Country Brief: NAURU. Retrieved from http://www.estandardsforum.org/system/briefs/289/original/briefNauru.pdf?1254987855

FreedomHouse. ( 2008). Freedom in the World 2008-Nauru. Retrieved from http://www.unhcr.org/refworld/docid/487ca22d82.htm

Fukuyama, F. (2001). Social capital, civil society and development. Third World Quarterly, 22(1).

Gardner, R., Ostrom, E., \& Walker, J. (1990). The Nature of Common-Pool Resource Problems. Rationality and Society(2), 335-358.

Gavin, M. C., Wali, A., \& Vasquez, M. (2007). Working towards and beyond collaborative resource management. In S. Kindon, R. Pain \& M. Kesby (Eds.), Participatory Action Research Approaches and Methods: Connectivng People, Participation and Place (pp. 60-70). London and New York: Routledge.

Gehab, K., \& Sarch, M.-T. (2002). Africa's Inland fisheries: The management challenge. Kamapala, Uganda: Fountain Publishers.

Gillett, R. (2007). A short history of industrial fishing in the Pacific Islands. Bangkok: Asia Pacific Fishery Commission Regional Office for Asia and the Pacific.

Gillett, R., \& Cartwright, I. (2010). The future of Pacific Island fisheries. Noumea: Gillett, Preston and Associates and Thalassa Consulting.

Gillett, R., Preston, G., Nash, W., Govan, H., Adams, T., \& and Lam, T. (2008). Livelihood Diversification as a Marine Resource Management Tool in the Pacific Islands: Lessons Learned. SPC Fisheries Newsletter(No.125).

Google images. (2012). Map of Nauru. Retrieved from vidiani.com on $22^{\text {nd }}$ October 2012 Govan, H., Aalbersberg, W., Tawake, A., \& Parks, J. (2008). Locally-Managed Marine Areas: A guide to supporting Community-Based Adaptive Management. Suva. 
Govan, H., Tawake, A., Tabunakawai, K., Jenkins, A., Lasgorceix, A., Techera, E., et al. (2009). Community Conserved Areas: A review of status and needs in Melanesia and Polynesia.

Halim, A., \& Mous, P. (2006). Community Perceptions of Marine Protected Area Management. Bali: The Nature Conservancy- Coral Triangle Center.

Harkes, I. (2006). Fisheries co-management, the role of local institutions and decentralisation in Southeast Asia: with specific reference to marine sasi in Central Maluku, Indonesia. Unpublished PhD Dissertation, Leiden University The Netherlands.

Hauck, M., \& Sowman, M. (2003). Waves of change: Coastal and fisheries comanagement in Southern Africa. Landsdowne, South Africa: University of Cape Town Press.

Holling, C. S. (1978). Adaptive environmental assessment and management. New York: John Wiley and Sons.

Hubert, A. (2007). Use of fishermen perception in participative resources management: Case study in Navakavu (Fiji). Suva: University of the South Pacific.

IUCN. (2010). Marine Protected Areas - Why have them? Fact sheet. Retrieved 29 April 2011, 2011, from http://www.iucn.org/about/work/programmes/pa/pa_what/?4646/Marine-ProtectedAreas--Why-have-them

Jacob, P. (2005). Coastal fisheries profile for Nauru. Nauru: Nauru Fisheries \& Marine Resources Authority.

Johannes, R. E. (1978). Traditional marine conservation methods in Oceania and their demise. Annual Review Ecology and Systematics(9), 349-364.

Johannes, R. E. (2002). The Renaissance of community-based marine resource management in Oceania. Annual Review Ecological System(33), 317-340.

Kahan, D. M. (2003). The Logic of Reciprocity: Trust, Collective Action, and Law. Michigan Law Review, 102(1), 71-103.

Keune, H., Loots, I., Bruckers, L., Bilau, M., Koppen, G., Larebeke, N., et al. (2008). Monitoring environment, health and perception. An experimental survey on health and environment in Flanders, Belgium. International Journal of Global Environmental Issues, 8(1-2), 90-111.

King, M. (2001). Session 16 including 18 (problem/solution tree) Community-based fisheries management: Secretariat of Pacific Community. 
King, M., Fa'asili, U., \& Mulipola, A. (2001). Community-based management of subsistence fisheries in Samoa. . Paper presented at the Environmental Awareness and Community Participation, Hawaii.

King, M., \& Lambeth, L. (2000). Fisheries management by communities: a manual on promoting the management of subsisten fisheries by Pacific Island communities. Noumea.

Klooster, D. (2000). Institutional choice, community and struggle: a case study of forest co-management in Mexico. World Development, 28(1), 1-20.

Kronen, M., Vunisea, A., Magron, F., \& McArdle, B. (2010). Socio-economic drivers and indicators for artisanal coastal fisheries in Pacific island countries and territories and their use for fisheries management strategies. Marine Policy, 34(6), 11351143.

Krueger, R. (1998). Analyzing \& Reporting Focus Group Results. Thousand Oaks, California: Sage Publications.

Lawrence, A., \& Elphick, M. (2002). Policy implications of participatory biodiversity assessment: summary report. Oxford, UK: Environmental Change Institute.

Leathers, A. (2008). Common property resource management in Vanuatu: perspective from the community. Victoria University of Wellington, Wellington.

Lin, N. (2001). Social Capital: A Theory of Social Structure and Action. Cambridge: Cambridge University Press.

Marschke, M., \& Berkes, F. (2005). Local level sustainability planning for livelihoods: A Cambodian experience. International Journal of Sustainable Development and World Ecology, 12(1), 21-33.

Matthews, E. (2004). Subsistence Fishing Activities in the Rock Islands: PCS Report No.2004-01: Palau Conservation Society.

McConney, P. R., Pomeroy, \& Mahon, R. (2003). Guidelines for coastal resource comanagement in the Carribean: Communicating the concepts and conditions that favor success. Barbados: Carribean Conservation Association.

McKean, M. (1992). Management of traditional common lands (Iriaichi) in Japan. In D.

W. Bromley (Ed.), Making the Commons Work: Theory, Practice and Policy (pp. 63-98). San Francisco: ICS Press.

MenengDEC, \& NFMRA. (2006). Coastal Fisheries Management for the District of Meneng. Nauru: MenengDEC. 
Nauru. (2004). Nauru social impact assessment.

Nauru. (2005a). Nauru: National Sustainable Development Strategy 2005-2025.

Nauru. (2005b). A situation Analysis of Children, Women and Youth. Retrieved from http://www.uncief.org.

Nauru. (2009). Republic of Nauru:National Sustainable Development Strategy-Revised 2009.

Nauru Bureau of Statistics (Nauru) and the Secretariat of the Pacific Community (SPC). (2002). 2002 Nauru Census Main Report and Demographic Profile of the Republic of Nauru, 1992-2002.

Nauru, SPC, \& MACROInternational. (2009). 2007 Demographic and Health Survey (DHS): Final report and Factsheet.

NFMRA. (2009). NFMRA Corporate Plan 2009-2012.

OECD. (2010). The Use of Perception Surveys in OECD Countries. Directorate for Public Governance and Territorial Development Retrieved 21 April, 2011, from http://www.oecd.org/regreform/perceptions

Olsson, P., Folke, C., \& Berkes, F. (2004). Adaptive comanagement for building resilience in social-ecological systems. Environmental Management, 34(1), 75-90.

Olsson, P., Folke, C., \& Hahn, T. (2004). Social-ecological transformation for ecosystem management: the development of adaptive co-management of a wetland lansdscape in souther Sweden. Ecology and Society, 9(4), 2.

Onorio, K., \& Deiye, T. (2010). Nauru's Biodiversity Strategy and Action Plan.

Ostrom, E. (1990). Governing the Commons: The Evolution of Institutions for Collective Action. Cambridge: Cambridge University Press.

Ostrom, E. (1994). Constituting Social Capital and Collective Action. Journal of Theoretical Politics, 6(4), 527-562.

Ostrom, E., \& Ahn, T. K. (2003). Introduction. In E. Ostrom \& T. K. Ahn (Eds.), Foundations of Social Capital (pp. xi-xxxix). Northampton: MA: Edward Elgar.

Ostrom, E., \& Walker, J. (2003). Introduction. In E. Ostrom \& J. Walker (Eds.), Trust and reciprocity (pp. 1-18). New York: Russell Sage, Foundation.

Pearce, D. (1990). Environmentalism and the Green Economy. Environment and Planning A, 22(7), 852-854.

Pickard, A. J. (2007). Research methods in information. London: Facet Publishing. 
Pinkerton, E. (1989). Co-Operative Management of Local Fisheries: New Directions for Improved Management and Community Development. Vancouver: University of Bristish Colomiba Press.

Pinkerton, E., \& Weinstein, M. (1995). Fisheries that work: Sustainability through community-based management. Vancouver: The David Suzuki Foundation.

Plummer, R., \& Armitage, D. (2007). Crossing Boundaries, Crossing Scales: The Evolution of Environment and Resource Co-Management. Geography Compass, 1(4), 834-849.

Plummer, R., \& FitzGibbon, J. (2007). Connecting Adaptive Co-management, Social Learning, and Social Capital through Theory and Practice In D. Armitage, Berkes, F and Doubleday, N (Ed.), Adaptive Co-management: Collaboration, Learning and Multi-Level Governance (pp. 37-61). Vancouver: UBC Press.

Pomeroy, R. S. (2007). Conditions for Successful Fisheries and Coastal Resources CoManagement: Lessons Learned in Asia, Africa and the Wider Caribbean. In D. Armitage, F. Berkes \& N. C. Doubleday (Eds.), Adaptive Co-Management: Collaboration, Learning and Multi-Level Governance. Vancouver: UBC Press.

Pomeroy, R. S., Katon, B. M., \& Harkes, I. (2001). Conditions affecting the success of fisheries co-management: lessons from Asia. Marine Policy, 25(3), 197-208.

Preston, G. (2009). The Ecosystem Approach to Coastal Fisheries and Aquaculture in Pacific Island Countries and Territories. In P. a. A. Gillett (Eds.)

Putnam, R. D. (2001). Bowling alone: the collapse and revival of American community. New York: Touchstone.

Quanchi, M. (2009). Pacific Ways: Government and Politics in the Pacific Islands. In S. I. Levine (Ed.), (pp. 121-129). Wellington: Victoria University Press.

ReefCheck. (2010). Technical question of the month: Why are turf algae not counted in reef checks? Retrieved 25 April, 2011, from http://www.reefcheck.org/news/print.php?id=590

Ropeti, E. M., \& Deiye, M. (2006). Preliminary assessment for the development of Nauru's Community-based Fisheries Management Programme: Field report 2006. Noumea.

Ruddle, K. (1988). Social principles underlying traditional inshore fishery management systems in the Pacific Basin. Marine Resource Economics, 5, 351-363. 
Secretariat of CBD. (2004). Protected areas and biodiversity: An overview of key issues. Montreal and Cambridge: SCBD and UNEP World Conservation Monitoring Centre.

Seidel, H. (2009). Evaluating the role of science in Community Based Adaptive Management of coastal resources in Fiji. University of Bremen, Bremen.

Sen, S., \& Nielsen, J. R. (1996). Fisheries co-management: A comparative analysis. Marine Policy, 20(5), 405-418.

Silverman, D. (1993). Interpreting Qualitative Data: Methods for Analysing Talk, Text and Interaction. London: SAGE Publications.

Sobel, J., \& Dahlgren, C. (2004). Marine Reserves: A guide to Science, Design and Use. Washington: Island Press.

SPC. (2010). A Community-Based Ecosystem Approach to Fisheries Management: Guidelines for Pacific Island Countries. Noumea.

Sverdrup-Jensen, S., \& Nielsen, J. R. (1998). Co-management in small-scale fisheries: A synthesis of Southern and West African experiences. Hirtshals, Denmark: Institute for Fisheries Management and Coastal Community Development.

Swallow, B. M., \& Bromley, D. W. (1994). Co-management or No-management: The Prospects for Internal Governance of Common Property Regimes through Dynamic Contracts. Oxford Agrarian Studies, 22(1), 3-16.

Tawake, A. (2007). Scaling-Up Networks of Locally Managed Marine Areas (LMMAs) to Island wide Ecosystem Management while Decentralising the Effort of Fiji LMMA Network and its Implementation from National to Provincial Levels. Suva: IASUSP.

Thaman, R., \& Hassall, D. (1996). Republic of Nauru: National Environmental Management Strategy and National Environmental Action Plan. Apia: SPREP.

The LMMA Network. (2004). Learning Framework for the Locally-Managed Area Network. Suva: LMMA Network.

TheLMMANetwork. (2005). The Locally-Managed Marine Area Network. Retrieved 10/05/2011: http://www.Immanetwork.org.

UNCCD. (2003). First National Report to the United Nations Convention to Combat Desertification (UNCCD). Nauru: Department of Economic Development and Environment. 
Uychiaoco, A., Arceo, H., Green, S., De la Cruz, M., Gaite, P., \& Alino, P. (2005). Monitoring and Evaluation of Reef Protected Areas by Local Fishers in the Philippines: Tightening the Adaptive Management Cycle. Biodiversity and Conservation (14), 2775-2794.

VanRijsoort, J., \& Jinfeng, Z. (2005). Participatory Resource Monitoring as a Means for Promoting Social Change in Yunnan, China. Biodiversity and Conservation(14), 2543-2573.

Vatn, A. (2007). Resource regimes and cooperation. Science Direct(24), 624-632.

Viviani, N. (1970). Nauru: Phosphate and political progress. Canberra: Australian National University Press.

Vunisea, A. (1997). Women as managers of resources. SPC Women-in-FIsheries Information, (1), 7

Vunisea, A. (2005). Session 19: Community experiences in Coastal fisheries management work in Pacific Island countries. Paper presented at the SPC/WPRFMC/FAO Workshop on Fisheries Legislation and Community-based Fisheries Management, Hawaii, USA.

Vunisea, A. (2007). Fishing to sustain livelihoods in Nauru. SPC Women in Fisheries Information Bulletin No.16, 22-23.

Vunisea, A., Pinca, S., Friedman, K., Chapman, L., Magron, F., Sauni, S., et al. (2008). Nauru Country Report: Profile and results from in-country survey work. Noumea: Secretariat of the Pacific Community.

Wade, R. (1988). Village Republics: Economic Conditions for Collective Action in South India. San Francisco: ICS Press.

Walters, C. J. (2007). Is Adaptive Management helping to solve Fisheries problems $>$. Ambio, 36(4), 304-307.

Welzel, C., Inglehart, R., \& Deutsch, F. (2005). Social Capital, Voluntary Associations and Collective Action: Which Aspects of Social Capital Have the Greatest 'Civic' Payoff? Journal of Civil Society, 1(2), 121-146.

Wenger, E. (2000). Communities of Practice and Social Learning Systems. Organization $7(2), 225-246$.

White, A. T., Hale, L. Z., Renard, Y., \& Cortesi, L. (1994). Collaborative and communitybased management of coral reefs. West Hartford, CT.: Kumarian Press.

WorldBank. (2000). Year 2000 Regional Economic Report for the Pacific Islands. 


\section{Appendices:}

Appendix 1: Critical enabling conditions for sustainability on the commons (Agrawal,

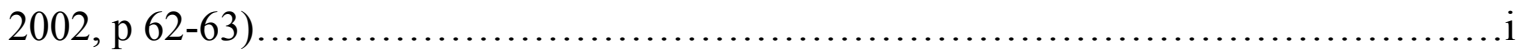

Appendix 2: Pinkerton's (1989) conditions to successful co-management arrangements...ii

Appendix 3: Summary of expert interviews V

Appendix 4: Fisher survey result xix

Appendix 5: Non-fishers survey results $\operatorname{xxx}$

Appendix 6: Fishers \& Non-fishers survey results. xxxi

Appendix 7: Survey field notes. xxxvvi

Appendix 8: Focus group information \& results xxxvvii

Appendix 9: Survey questionnaire. xxxviii 
Table 39: NEMS recommendations and plan of actions for Nauru

\begin{tabular}{|c|c|c|}
\hline $\begin{array}{l}\text { NEMS report } \\
\text { recommendations }\end{array}$ & $\begin{array}{l}\text { Suggested plan of actions } \\
\text { (POAs) }\end{array}$ & Relevance to this study \\
\hline $\begin{array}{l}\text { 1. Control population and urban } \\
\text { growth }\end{array}$ & $\begin{array}{l}\text { (i) Proposal for an effective } \\
\text { family planning program to be } \\
\text { developed. } \\
\text { (ii) Suggests the development for } \\
\text { new residential and agricultural } \\
\text { areas as part of the rehabilitation } \\
\text { scheme. } \\
\text { (iii) Strengthening of } \\
\text { immigration policies to keep the } \\
\text { inflow of migrants within } \\
\text { Nauru's carrying capacity. }\end{array}$ & $\begin{array}{l}\text { Addresses the problems of the } \\
\text { rapidly growing population and } \\
\text { its increasing pressures on } \\
\text { marine resources. }\end{array}$ \\
\hline $\begin{array}{l}\text { 2. Strengthen environmental } \\
\text { education }\end{array}$ & $\begin{array}{l}\text { (i) Review of the formal } \\
\text { education curriculum. } \\
\text { (ii) Awareness-raising programs } \\
\text { such as informal education for } \\
\text { the general public through } \\
\text { workshops, dissemination of } \\
\text { information and the application } \\
\text { of traditional management } \\
\text { systems. }\end{array}$ & $\begin{array}{l}\text { Awareness-raising for the people } \\
\text { on environmental management. }\end{array}$ \\
\hline $\begin{array}{l}\text { 3. Strengthen environmental } \\
\text { institutions and legislation }\end{array}$ & $\begin{array}{l}\text { (i) Develop a land use planning } \\
\text { system especially with respect to } \\
\text { the reform of land tenure } \\
\text { systems (addressed in detail later } \\
\text { in the chapter). } \\
\text { (ii) Conduct environmental } \\
\text { baseline studies for inshore } \\
\text { fishery given their significance } \\
\text { to the well-being of the people. } \\
\text { Marine areas require urgent } \\
\text { attention for baseline studies and } \\
\text { monitoring. } \\
\text { (iii) Establish an information } \\
\text { system for single species } \\
\text { recovery and management. } \\
\text { (iv) A review of existing } \\
\text { legislation given they lack } \\
\text { enforcement. } \\
\text { (v) Identification of the existing } \\
\text { gaps for development and } \\
\text { enactment of new environmental } \\
\text { legislations. } \\
\text { (vi) Fostering of cooperation, }\end{array}$ & $\begin{array}{l}\text { Thaman and Hassall (1996) } \\
\text { perceived that environmental } \\
\text { institutions and legislation is a } \\
\text { prerequisite to the successful } \\
\text { implementation of } \\
\text { environmental action in Nauru. } \\
\text { The authors proposed that } \\
\text { environmental legislations are to } \\
\text { be clearly advertised through } \\
\text { awareness campaigns. The best } \\
\text { way to disseminate legislative } \\
\text { information is to educate and } \\
\text { empower people across the } \\
\text { government agencies and non- } \\
\text { government organisations } \\
\text { (NGOs). }\end{array}$ \\
\hline
\end{tabular}




\begin{tabular}{|c|c|c|}
\hline & $\begin{array}{l}\text { coordination and shared } \\
\text { responsibility in environmental } \\
\text { management rather than } \\
\text { centralising the responsibility on } \\
\text { a single agency. }\end{array}$ & \\
\hline $\begin{array}{l}\text { 4. Conservation of biological } \\
\text { diversity (biodiversity) }\end{array}$ & $\begin{array}{l}\text { (i) The entire Anibare Bay to be } \\
\text { established as a marine reserve } \\
\text { where spearfishing, net fishing } \\
\text { and reef gleaning are prohibited } \\
\text { within } 100 \text { m of the mean low } \\
\text { tide. } \\
\text { (ii) Ijuw-Anabar mangrove and } \\
\text { wetland area to be conserved for } \\
\text { its unique ecological and scenic } \\
\text { beauty. } \\
\text { (iii) The coastal littoral zone } \\
\text { where all mature coastal trees } \\
\text { within } 50 \mathrm{~m} \text { of the high tide line } \\
\text { to be protected for their useful } \\
\text { salt-tolerant mechanisms. } \\
\text { (iv) Protect portions of the forest } \\
\text { around the Buada Lagoon area } \\
\text { because of its unique landlocked } \\
\text { freshwater and brackish lagoon. } \\
\text { (v) Protect endangered species } \\
\text { that includes both land and } \\
\text { marine species. }\end{array}$ & $\begin{array}{l}\text { Thaman and Hassall (1996) } \\
\text { recommended that one of the } \\
\text { most effective ways to reverse } \\
\text { the loss of coastal marine } \\
\text { biodiversity is to survey and } \\
\text { select priority conservation } \\
\text { areas, establish pilot } \\
\text { conservation areas, and protect } \\
\text { and restore endangered plants } \\
\text { and animals in Nauru. }\end{array}$ \\
\hline $\begin{array}{l}\text { 5. Promote the sustainable use of } \\
\text { marine resources }\end{array}$ & $\begin{array}{l}\text { (i) Establishment of marine } \\
\text { reserves. } \\
\text { (ii) Improvement of the fisheries } \\
\text { database. } \\
\text { (iii) Control of marine resource } \\
\text { overexploitation. } \\
\text { (iv) Improvement of the } \\
\text { exploitation of pelagic and deep- }\end{array}$ & $\begin{array}{l}\text { Thaman and Hassall (1996) } \\
\text { perceived sustainable use of } \\
\text { marine resources as one of the } \\
\text { most important challenges for } \\
\text { Nauru. }\end{array}$ \\
\hline
\end{tabular}

${ }^{36}$ Biodiversity is defined as: "the variety of life forms, the different plants, animals and microorganisms, the genes they contain, found in different kinds of ecosystems (terrestrial, freshwater and marine) and found at three levels; genetic diversity, species diversity, and ecosystem diversity. "Osorio

Biodiversity also includes: "the richness of knowledge, uses, beliefs and language for societies who live and depend for their survival on the natural environment" Thaman, R., \& Hassall, D. (1996). Republic of Nauru: National Environmental Management Strategy and National Environmental Action Plan. Apia: SPREP. 


\begin{tabular}{|c|c|c|}
\hline & $\begin{array}{l}\text { water marine resources. } \\
\text { (v) Reinstitute traditional marine } \\
\text { management strategies. } \\
\text { (vi) Rehabilitate aquaculture in } \\
\text { Buada Lagoon. }\end{array}$ & \\
\hline $\begin{array}{l}6 . \text { Pollution and waste } \\
\text { management }\end{array}$ & $\begin{array}{l}\text { (i) Establish a sewage treatment } \\
\text { system in Nauru. }\end{array}$ & $\begin{array}{l}\text { To avoid contamination of the } \\
\text { groundwater system and direct } \\
\text { discharge into the marine waters } \\
\text { (Thaman \& Hassall, 1996). } \\
\text { According to Jacob (2005), } \\
\text { sewage discharge is a minimal } \\
\text { problem but pollutants such as } \\
\text { oil spills from barges; ballast } \\
\text { water discharges from ships and } \\
\text { disposal of people's rubbish on } \\
\text { beaches and marine areas pose } \\
\text { more serious problems. There is } \\
\text { no sewage treatment system in } \\
\text { place. }\end{array}$ \\
\hline $\begin{array}{l}\text { 7. Prepare for climate change } \\
\text { impacts and their effects }\end{array}$ & $\begin{array}{l}\text { (i) Develop an Integrated Coastal } \\
\text { Zone Management Plan (ICZM) } \\
\text { based on the needs of the } \\
\text { community and the natural } \\
\text { attributes of the different coastal } \\
\text { sites and environments. } \\
\text { (ii) Develop a protection plan for } \\
\text { coastal forest protection and } \\
\text { reforestation. } \\
\text { (iii) Develop awareness and } \\
\text { education programs for public } \\
\text { awareness about coastal } \\
\text { problems and in replanting } \\
\text { coastal littoral trees and plants. }\end{array}$ & $\begin{array}{l}\text { Thaman and Hassall (1996) } \\
\text { highlighted the uncertainty with } \\
\text { impacts of climate change such } \\
\text { as sea level rising and their } \\
\text { effects. Nauru's current problem } \\
\text { with coastal erosion damages } \\
\text { vegetation, reefs, seawalls and } \\
\text { other structures during extreme } \\
\text { events such as storms, high tides } \\
\text { and salt spray. The authors } \\
\text { suggest protection rather than } \\
\text { replanting schemes based on } \\
\text { experience. Jacob (2005) } \\
\text { highlights that } 20 \% \text { of Nauru is } \\
\text { low-lying and the rise of sea } \\
\text { level may inundate these areas, } \\
\text { relocation to higher ground } \\
\text { maybe necessary but } \\
\text { rehabilitation of the mined fields } \\
\text { should be the first option. }\end{array}$ \\
\hline
\end{tabular}


APPENDIX 1: Critical enabling conditions for sustainability on the commons (Agrawal, 2002, p 62-63)

\begin{tabular}{|c|c|c|}
\hline \multirow[t]{6}{*}{$\begin{array}{l}\text { (1) Resource system } \\
\text { characteristics }\end{array}$} & & $\begin{array}{l}\text { Works of } \\
\text { authors }^{37}\end{array}$ \\
\hline & Small size & RW \\
\hline & Well-defined boundaries & $\mathrm{RW}$;EO \\
\hline & Low levels of mobility & \\
\hline & Possibilities of storage of benefits from the resource & \\
\hline & Predictability & \\
\hline \multirow[t]{8}{*}{ (2) Group characteristics } & Small size & RW: B\&P \\
\hline & Clearly defined boundaries & RW:EO \\
\hline & Shared norms & $\mathrm{B} \& \mathrm{P}$ \\
\hline & Past successful experiences-social capital & RW: $B \& P$ \\
\hline & Appropriate leadership-young familiar with changing environment or connected to local traditional elite & $\mathrm{B} \& \mathrm{P}$ \\
\hline & Interdependence among group members & RW: B\&P \\
\hline & Heterogeneity of endowments, homogeneity of identities and interests & $\mathrm{B} \& \mathrm{P}$ \\
\hline & Low levels of poverty & \\
\hline \multirow{3}{*}{$\begin{array}{l}\text { Relationship between (1) resource } \\
\text { system characteristics \& (2) group } \\
\text { characteristics }\end{array}$} & Overlap between user-group both from residential and resource location & RW: B\&P \\
\hline & High levels of dependence by group members on resource system & RW \\
\hline & Fairness in allocation of benefits from common resources & $\mathrm{B} \& \mathrm{P}$ \\
\hline
\end{tabular}

\footnotetext{
${ }^{37}$ Wade, R. (1988). Village Republics: Economic Conditions for Collective Action in South India. San Francisco: ICS Press.-RW Ostrom (1990)-EO

Baland and Platteau (1996)-B\&P
} 


\begin{tabular}{|c|c|c|}
\hline & Low levels of user demand & \\
\hline & Gradual change in levels of demand & \\
\hline \multirow[t]{6}{*}{ (3) Institutional arrangements } & Rules are simple and easy to understand & $\mathrm{B} \& \mathrm{P}$ \\
\hline & Locally devised access and management rules & RW: B\&P: EO \\
\hline & Ease in enforcement of rules & RW: B\&P: EO \\
\hline & Graduated sanctions & RW;EO \\
\hline & Availability of low-cost adjudication & EO \\
\hline & Accountability of monitors and other officials to users & EO:B\&P \\
\hline $\begin{array}{l}\text { Relationship between (1) resource } \\
\text { system and (3) institutional } \\
\text { arrangements }\end{array}$ & Match restrictions on harvests to regeneration of resources & RW;EO \\
\hline \multirow[t]{4}{*}{ (4) External environment } & $\begin{array}{l}\text { Technology } \\
\text { a) Low-cost exclusion technology } \\
\text { b) Time for adaptation to new technologies related to the commons }\end{array}$ & RW \\
\hline & Low levels of articulation with external markets & \\
\hline & Gradual change in articulation with external markets & \\
\hline & $\begin{array}{l}\text { State } \\
\text { a) Central government should not undermine local authority } \\
\text { b) Supportive external sanctioning institutions } \\
\text { c) Appropriate levels of external aid to compensate local users for conservation activities } \\
\text { d) Nested levels of appropriation, provision, enforcement, governance }\end{array}$ & $\begin{array}{l}\text { RW;EO } \\
\text { B\&P } \\
\text { B\&P } \\
\text { EO }\end{array}$ \\
\hline
\end{tabular}


APPENDIX 2: Pinkerton's (1989) conditions to successful co-management arrangements

\begin{tabular}{|c|c|c|c|}
\hline $\begin{array}{l}\text { Management functions } \\
\text { and their purpose }\end{array}$ & $\begin{array}{l}\text { Preconditions favourable to } \\
\text { successful co-management }\end{array}$ & $\begin{array}{l}\text { Groups pre-adapted to co-management } \\
\text { arrangements }\end{array}$ & $\begin{array}{l}\text { Proposed relationships and roles that emerge of } \\
\text { actors in successful co-management }\end{array}$ \\
\hline $\begin{array}{l}\text { 1. Data gathering and } \\
\text { analysis to understand } \\
\text { the resource }\end{array}$ & $\begin{array}{l}\text { 1. Management is developed out of a } \\
\text { real or imagined crisis such as stock } \\
\text { depletion }\end{array}$ & $\begin{array}{l}\text { 1. A group already has a cohesive social system } \\
\text { based on kinship, ethnicity and homogenous gear } \\
\text { type }\end{array}$ & $\begin{array}{l}\text { 1. Creates co-operation among individual fisher groups } \\
\text { in planning and improving local fish stocks }\end{array}$ \\
\hline $\begin{array}{l}\text { 2. Logbook- harvest } \\
\text { decisions such as } \\
\text { licence, timing and } \\
\text { location }\end{array}$ & $\begin{array}{l}\text { 2. When a fisher shows their } \\
\text { willingness to contribute financially } \\
\text { or by recruiting others for support to } \\
\text { the management }\end{array}$ & $\begin{array}{l}\text { 2. A group or community can define its } \\
\text { boundaries where membership is clear and } \\
\text { allocation and regulations can be applied }\end{array}$ & $\begin{array}{l}\text { 2. Creates commitment among local fishers to share both } \\
\text { the costs and benefits of their efforts }\end{array}$ \\
\hline $\begin{array}{l}\text { 3. Harvest allocation } \\
\text { decisions }\end{array}$ & $\begin{array}{l}\text { 3. An opportunity exists for a } \\
\text { negotiation process }\end{array}$ & $\begin{array}{l}\text { 3. Fishers are involved as members of the } \\
\text { managing body }\end{array}$ & $\begin{array}{l}\text { 3. Success in allocating harvest decisions is the drive to } \\
\text { resolve conflict and increase the motivation to negotiate } \\
\text { sharing of access }\end{array}$ \\
\hline $\begin{array}{l}\text { 5. Enforcement of } \\
\text { regulations }\end{array}$ & $\begin{array}{l}\text { 5. A mechanism exist where wealth } \\
\text { generation is recirculated back into } \\
\text { some communities }\end{array}$ & $\begin{array}{l}\text { 5. Government officials have direct experience of } \\
\text { the industry and willing to have a direct hands-on } \\
\text { relationship with fishers }\end{array}$ & $\begin{array}{l}\text { 5. Creates a higher degree of organisation and mutual } \\
\text { commitment among fishers }\end{array}$ \\
\hline 6. Enhancement and & 6. A mechanism exists for conserving & 6. Where more than one stakeholder is involved & 6. Creates a willingness among fishers and government \\
\hline
\end{tabular}




\begin{tabular}{|c|c|c|c|}
\hline long-term planning & $\begin{array}{l}\text { and enhancing a fishery while at the } \\
\text { same time enhance the operation of a } \\
\text { cultural system }\end{array}$ & $\begin{array}{l}\text { in technical issues of stock health separate from } \\
\text { harvest allocations }\end{array}$ & $\begin{array}{l}\text { to share data about the resources and reaching a } \\
\text { collective understanding }\end{array}$ \\
\hline \multirow[t]{4}{*}{$\begin{array}{l}\text { 7. Broad policy } \\
\text { decision-making }\end{array}$} & $\begin{array}{l}\text { 7. Operates best where external } \\
\text { support is available such as } \\
\text { universities and scientists }\end{array}$ & $\begin{array}{l}\text { 7. Where more than one stakeholder is involved } \\
\text { in the opportunity to have creative and informal } \\
\text { problem-solving tasks among stakeholders }\end{array}$ & $\begin{array}{l}\text { 7. Creates a willingness among fishers and government } \\
\text { to explore options for regulation and reduce } \\
\text { inefficiencies for fishers }\end{array}$ \\
\hline & $\begin{array}{l}\text { 8. Operates best where the area is not } \\
\text { too large and the benefits can be } \\
\text { linked to watersheds or local waters }\end{array}$ & $\begin{array}{l}\text { 8. If one large group is involved then co- } \\
\text { management operates best if decisions about } \\
\text { harvest levels, regulations and allocations are } \\
\text { made on the same level which the information is } \\
\text { collected }\end{array}$ & $\begin{array}{l}\text { 8. Successful co-management of regulations creates } \\
\text { greater trust between fishers and government that further } \\
\text { develops a greater sense of control of fishers in turn } \\
\text { reduces their motivation to invest in competitive gear for } \\
\text { capture }\end{array}$ \\
\hline & $\begin{array}{l}\text { 9. The number of communities or } \\
\text { fishers is not too large for effective } \\
\text { communication }\end{array}$ & $\begin{array}{l}\text { 9. A culturally cohesive group practices self- } \\
\text { regulation }\end{array}$ & $\begin{array}{l}\text { 9. Creates a higher degree of trust between fishers and } \\
\text { government and improves their ability to develop and } \\
\text { implement enforcement regimes }\end{array}$ \\
\hline & $\begin{array}{l}\text { 10. The size of government } \\
\text { bureaucracy is small and local }\end{array}$ & $\begin{array}{l}\text { Develop an energy centre such as a dedicated } \\
\text { person or core groups who consistently apply } \\
\text { pressure in the arrangement }\end{array}$ & $\begin{array}{l}\text { 10. Creates a higher degree of trust between fishers and } \\
\text { government and greater willingness of government to } \\
\text { allow fishers to self-manage }\end{array}$ \\
\hline
\end{tabular}




\section{APPENDIX 3: Summary of expert interviews}

\begin{tabular}{|c|c|c|}
\hline THEME 1 & Questions & Summary of Interviews \\
\hline \multirow{3}{*}{ 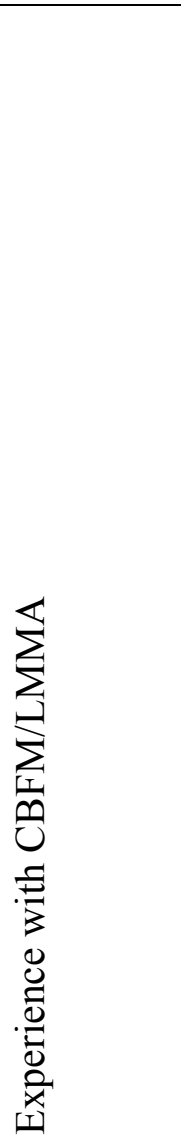 } & $\begin{array}{l}\text { How many community-based } \\
\text { conservation }(\mathrm{CBC}) \text { projects } \\
\text { have you been involved with? }\end{array}$ & $\begin{array}{l}\text { 1. Many, part of the Fiji Locally Marine Managed Area (FLMMA) Network. } \\
\text { 2. Many, I have lost count about } 30 \text { at the national level in Samoa and now as part of Secretariat of the Pacific } \\
\text { Community (SPC)'s regional work. } \\
\text { 3. I am responsible for } 49 \text { sites with the IAS/FLMMA. I am the site-liaison officer (SLO). } \\
\text { 4. None or a lot it depends on how you look at it. I have worked in the policy development for fisheries } \\
\text { management in Fiji for a couple of years then I moved and worked in the regional organisation where there has } \\
\text { been a lot of development in this area since. I have been working in areas that provide supporting policies and } \\
\text { institutions in place to help build on this community-based framework. I have supported CBC development for } \\
\text { sustainable artisanal fisheries. }\end{array}$ \\
\hline & $\begin{array}{l}\text { How many of these community- } \\
\text { based projects you were } \\
\text { involved in that have } \\
\text { established one or more } \\
\text { community conserved area or a } \\
\text { reserve or a protected area? }\end{array}$ & $\begin{array}{l}\text { 1. About 100. The FLMMA Secretariat is partner organization } \\
\text { 2. } 50 \% \text { of the site but one cannot measure the achievement of community-based projects to the number of } \\
\text { reserves, because these are community-driven. } \\
\text { 3. There are } 23 \text { sites out of } 49 \text { who have marine reserves. But other sites have focused on managing other threats } \\
\text { and do not have marine reserves. } \\
\text { 4. None or several depend on how you look at it. The support is different for each site and dependent upon their } \\
\text { purpose. }\end{array}$ \\
\hline & $\begin{array}{l}\text { What was your role in these } \\
\text { CBC projects? A: For example, } \\
\text { were you part of a } \\
\text { team/organization? }\end{array}$ & $\begin{array}{l}\text { 1. FLMMA Secretariat is the link between partner organization and we evaluate the progress of projects } \\
\text { 2. National programmes in Samoa and now following the SPC mandate conduct and develop CBFM in the region } \\
\text { 3. Team leader-in charge of the community awareness and management planning and workshops. } \\
\text { 4. Various roles training conduct baseline studies and drafting enabling legislations for national governments }\end{array}$ \\
\hline
\end{tabular}




\begin{tabular}{|c|c|}
\hline $\begin{array}{l}\text { I am aware that projects are } \\
\text { often short-term so when you go } \\
\text { to community site, and what } \\
\text { strategies if any do you use (if } \\
\text { any) to overcome these short- } \\
\text { term projects? }\end{array}$ & $\begin{array}{l}\text { 1. We follow-through with the management plans and review the plans every } 2 \text { years. } \\
\text { 2. Dependent on national counterparts SPC provides the training and capacity building with our national } \\
\text { counterparts and these national counterparts carry out this work at the national level. } \\
\text { 3. There is no short-term approach. We follow-through with the community management plans and we maintain } \\
\text { our engagement with community for } 2-3 \text { year. We work with the Ministry of Fisheries to have fish wardens in } \\
\text { place at each site and conduct joint leadership and management workshops. } \\
\text { 4. If project seems to be successful then gaining funds for on-going continuous projects. }\end{array}$ \\
\hline $\begin{array}{l}\text { Do you think implementing } \\
\text { such projects gets easier or more } \\
\text { challenging today? }\end{array}$ & $\begin{array}{l}\text { 1. We focus on awareness raising with the communities and provide enabling legislation and secure marine tenure } \\
\text { and ownership } \\
\text { 2. Communities having some form of ownership so our work we use these existing protocols in place to } \\
\text { implement these projects. } \\
\text { 3. We found that having support teams on ground makes it easier to implement our projects. There are challenges } \\
\text { with continued funding but communities are made aware of these constraints at the beginning and that they } \\
\text { should be able to adapt and manage their projects themselves. } \\
\text { 4. If communities are not interested move on to other communities. }\end{array}$ \\
\hline
\end{tabular}




\begin{tabular}{|c|c|c|}
\hline THEME 2 & Question & Summary of responses \\
\hline 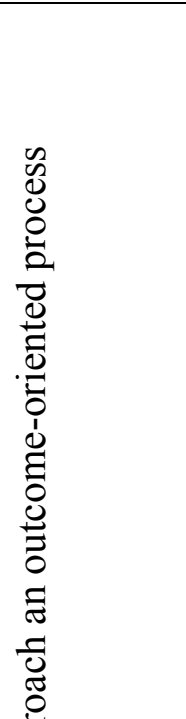 & $\begin{array}{l}\text { What do you think is your } \\
\text { primary goal(s) for these } \\
\text { projects? Livelihoods- food } \\
\text { security, biodiversity } \\
\text { conservation and what about } \\
\text { climate change (CC)? }\end{array}$ & $\begin{array}{l}\text { 1. Primary goals for projects are food security and livelihoods. Climate change is not a concern for those not } \\
\text { affected. } \\
\text { 2. CEAFM is the regional approach. CC has always been a part of the CBFM. The issues and concerns of people } \\
\text { are raised about the weather patterns. There is a need to build the resilience of the communities to react to the } \\
\text { impacts of CC. Biodiversity conservation are } \$ 50 \text { words invented to draw money for projects rather than help our } \\
\text { own people. } \\
\text { 3. One has to take account of the broader national goals but not be driven by the aims of donors or conservation } \\
\text { community. LMMA projects focus on local community needs and for food security. Communities are not } \\
\text { concerned with biodiversity conservation at the start. Communities after seeing the recovery of numbers and sizes } \\
\text { of invertebrates. They grow to understand the links between fish and habitats. Climate change has affected } \\
\text { communities especially with coastal erosion - loss of coastline -so this is addressed for some communities. } \\
\text { 4. Different places with different goals. Subsistence fishing is maintaining a sustainable but still-fishable resource } \\
\text { may be more important. Primary goals should be determined by consultation with people concerned. }\end{array}$ \\
\hline$\sum_{\substack{\infty \\
\infty}}^{\sum_{0}^{\infty}}$ & $\begin{array}{l}\text { How would community- } \\
\text { based approaches help } \\
\text { communities to mitigate or } \\
\text { adapt to climate change in } \\
\text { Pacific Island countries }\end{array}$ & $\begin{array}{l}\text { 1. CBC approaches can work if you can link the effects and impacts of CC to food security and livelihoods. } \\
\text { People are more concerned with putting food on their tables and sending their children to school. } \\
\text { 2. Build the resilience of communities towards the impacts of CC. } \\
\text { 3. } \mathrm{CBC} \text { is communities managing the projects themselves. To adapt to CC -raise their awareness and build } \\
\text { capacities to adapt to change. Coastal erosion replanting of mangroves. }\end{array}$ \\
\hline
\end{tabular}




\begin{tabular}{|c|c|}
\hline (PICs)? & $\begin{array}{l}\text { 4. CC is an international transboundary issue than a local community issue. Decision-making at community level } \\
\text { may not be appropriate. Not necessary to include with the over and above existing need to act at the community- } \\
\text { level to conserve or manage marine resources. The existing need is current and urgent and doesn't need any } \\
\text { additional justification. }\end{array}$ \\
\hline $\begin{array}{l}\text { Do you need to convince } \\
\text { people that by managing the } \\
\text { marine resources are the best } \\
\text { option when facing concerns } \\
\text { of sea level rise and other } \\
\text { non-fisheries impact? }\end{array}$ & $\begin{array}{l}\text { 1. Need to link the two - impacts of CC and non-fisheries having on the marine resources and you can get people } \\
\text { on board. } \\
\text { 2. CEAFM addresses the issues to address CC. The issues of non-fisheries and CC impacts are part of the CBFM. } \\
\text { 3. Management plans are developed by communities to address the threats that communities are facing and we } \\
\text { encourage that management plans are made according to these threats. } \\
\text { 4. Managing the causes of non-fisheries impacts is important. Other impacts on community resources and the } \\
\text { community should have a say in how other impacts are managed. }\end{array}$ \\
\hline $\begin{array}{l}\text { Would part of the planning } \\
\text { and coping strategies for } \\
\text { communities include } \\
\text { displacement and relocation } \\
\text { of communities in low-lying } \\
\text { areas be relevant in the near } \\
\text { future? }\end{array}$ & $\begin{array}{l}\text { 1. This might be needed for communities facing flooding problems and high tides crashing in their villages. } \\
\text { 2. These problems are mentioned in the CBFM plans. } \\
\text { 3. This is not something that we have dealt with in our projects. Communities do not want to move from where } \\
\text { they are. Strategies and actions taken by communities is completely up to them and we basically give } \\
\text { communities advice. } \\
\text { 4. Sea-level rise will not be significant in the near future. El Niño when the warm pool shifts to the east making } \\
\text { the skipjack more available in Kiribati and Nauru- effect of CC. Multi-species artisanal fisheries may be more } \\
\text { resilient to CC effects on resources than commercial fishers. Nauru is one of the few PICs where artisanal fishers } \\
\text { catch more pelagic fish than reef fish. }\end{array}$ \\
\hline
\end{tabular}




\begin{tabular}{|c|c|c|}
\hline THEME 3 & Question & Summary of responses \\
\hline 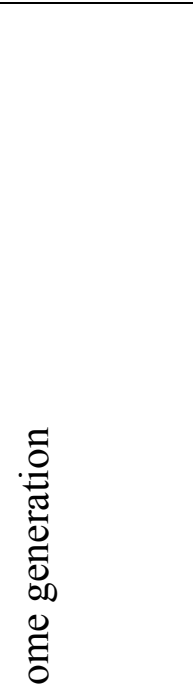 & $\begin{array}{l}\text { Are community-based } \\
\text { approaches used to control } \\
\text { commercial fisheries and } \\
\text { species of coastal resources? }\end{array}$ & $\begin{array}{l}\text { 1. To an extent for Fiji's case yes. Limiting licenses and permits for others to commercially fish in I-qoliqolis } \\
\text { (customary owned marine areas). } \\
\text { 2. Yes depends on the species. For example, communities as the resource-owners control the sea cucumber fishery in } \\
\text { Vanuatu and in the Cook Islands the trochus fishery, communities control harvest. } \\
\text { 3. Sometimes the communities identify loss of commercial fishes with issuing license to commercial fishers to fish } \\
\text { in their fishing grounds. Try to reduce amount of fishing licenses that's being given out and or increase price of } \\
\text { licenses to reduce the effort. } \\
\text { 4. There is a difficulty of separating "commercial" from subsistence in most PICs. There is not much point in making } \\
\text { a sharp distinction between commercial and others. Some CB approaches are hybrid community-government } \\
\text { approaches. In Fiji's example, government maintains I-qoliqolis registration systems and sets the broad framework of } \\
\text { passive resource such as size limits, mesh sizes and destructive fishing bans. Registered fishing rights owners make } \\
\text { the decision of who shall fish commercially or subsistence and sets conditions of fishing, which can be more } \\
\text { restrictive using closed areas, seasons, smaller size limits before issuing the permit that enables government to issue } \\
\text { the license. }\end{array}$ \\
\hline 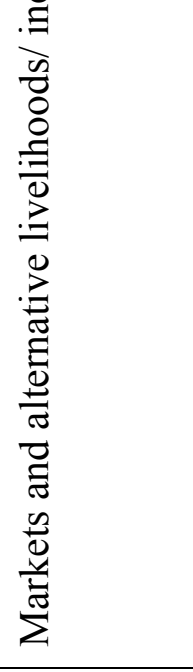 & $\begin{array}{l}\text { If so, how well have } \\
\text { community-based } \\
\text { approaches integrate with } \\
\text { markets? For example, } \\
\text { ornamental and live rock } \\
\text { trade and marine culture } \\
\text { such as (trochus) species. } \\
\text { Reference to any cases, } \\
\text { would be helpful. }\end{array}$ & $\begin{array}{l}\text { 1. There have been successes and failures to do with these projects. Live rock trade, live coral harvesting, beche-de- } \\
\text { mer trade and live fish trade. Communities often make a quick buck take advantage of these opportunities without } \\
\text { anticipating the impacts. Trades have very good markets in Suva and where communities have had to ban } \\
\text { companies. } \\
\text { 2. See previous answer. } \\
\text { 3. Most of the communities that we deal with do not have ornamental fish or live rock trade and a few have trochus } \\
\text { species. Most of our communities ban the harvest of triton (conch) shell now because this feeds on COTs that } \\
\text { threaten coral reefs. For communities who manage their fishing grounds licenses are issued for fishers to fish in the } \\
\text { fishing grounds. The community has the right to indicate on the license the areas that the fisher can enter or not - } \\
\text { MPAs and the types of fishing gears allowed through the Ministry for Fisheries. Communities either advise the } \\
\text { Ministry of their rules and regulations and the Ministry provides technical advice to the communities. } \\
\text { 4. This is a complicated issue. If there is money to be made out of the resources, then there may be more incentive to } \\
\text { get together and make sure individuals do not unduly benefit at the expense of the community- but there are different } \\
\text { attitudes in different places. One of the original main drivers behind development of government and formal fisheries }\end{array}$ \\
\hline
\end{tabular}




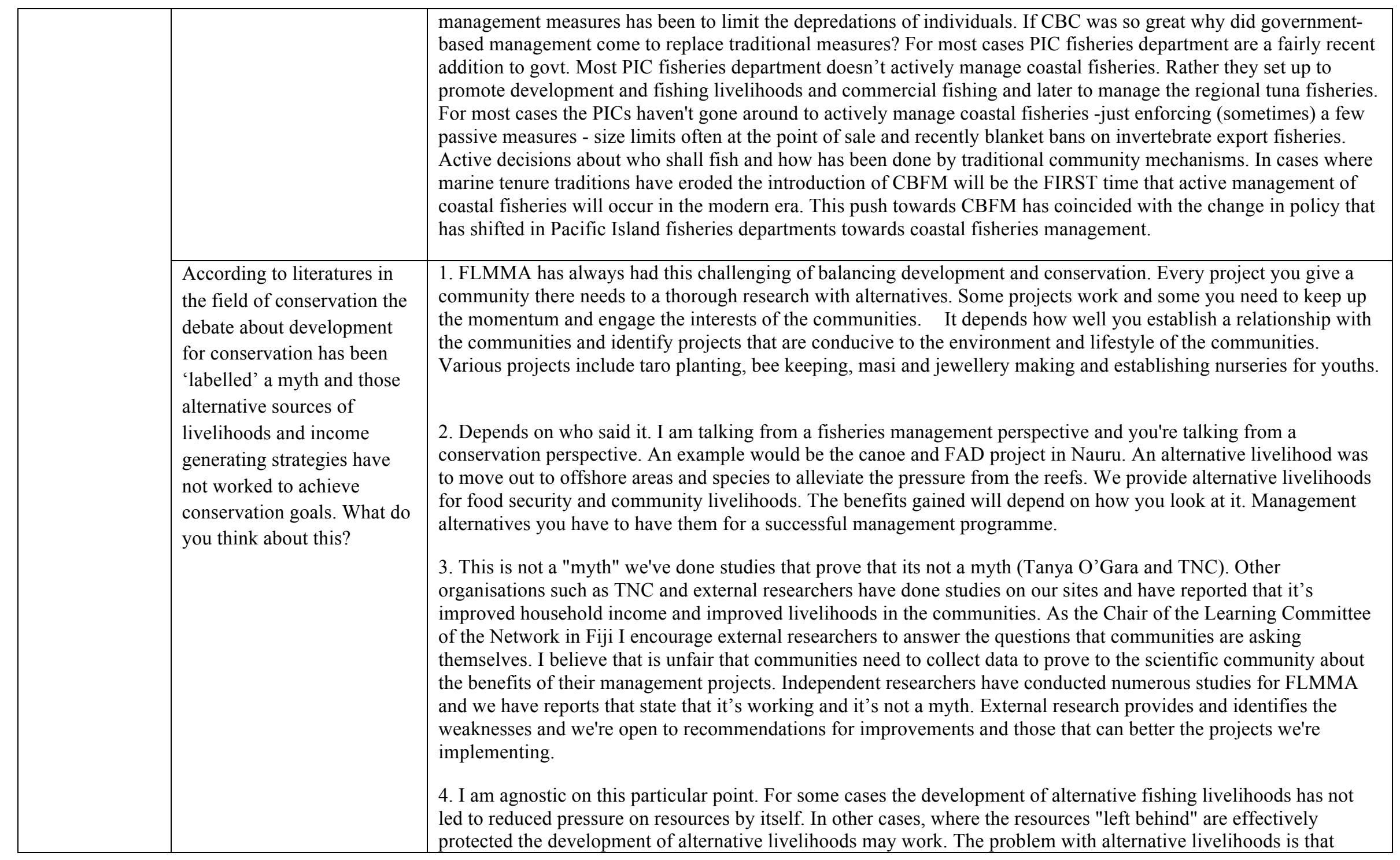


sometimes fisheries are the livelihood of the last resort and there is nowhere else to go. There are no viable alternatives. 


\begin{tabular}{|c|c|c|}
\hline THEME 4 & Question & Summary of responses \\
\hline 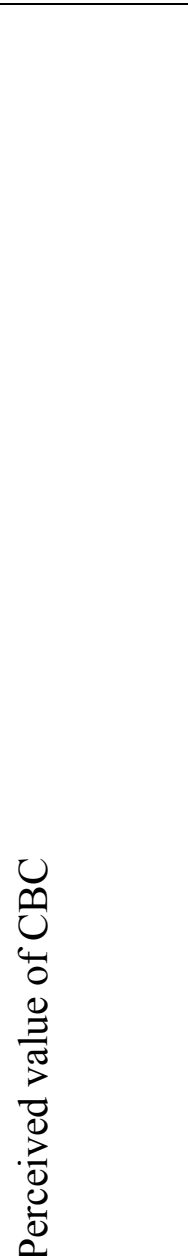 & $\begin{array}{l}\text { Any comments on the costs } \\
\text { and benefits gained from } \\
\text { implementing CBCs for } \\
\text { each of the following? The } \\
\text { key question here is "who" } \\
\text { benefits? } \\
\text { - Livelihoods: } \\
\text { - Biodiversity } \\
\text { - Climate change }\end{array}$ & $\begin{array}{l}\text { 1. For livelihoods, biodiversity conservation and climate change. The costs are borne by both the organisation and } \\
\text { the community in terms of time, labour in workshops and meetings. Benefits are borne by the communities } \\
\text { themselves and for the partner organisations with continued funding for successful projects. There are benefits to } \\
\text { have a great reference for communities and in recognition of their status for partner organisations and } \\
\text { communities. } \\
\text { 2. When a community sacrifices a whole fishing area for conservation purposes what are the alternatives available } \\
\text { to them? You implement a conservation area in Nauru where there is no social security and where do expect the } \\
\text { people will get their food? I hate to see most conservationists come in with ideas from developed work and } \\
\text { impose it on developing countries where we don't have the capacity. Ultimately resource management is to ensure } \\
\text { food security and livelihoods are met. Not conservation. } \\
\text { 3. There are reports done by Hugh Govan and Tewake (members of FLMMA) in costs and benefits of the work } \\
\text { we've done at sites. Other organisations include Community Conservation International Forum (CCIF) based in } \\
\text { Bali \& Indonesia that assists with cost and benefits work at the sites Conservation International within FLMMA } \\
\text { that have their programme. Marine Managed Area Science Programme and they're all looking at the impacts of } \\
\text { this project on livelihoods; cultural values on ecological change reports are in press right now. } \\
\text { 4. Not sure who benefits in those different categories. Main benefits are to make the sustainable } \\
\text { fisheries/conservation more achievable in many developing country societies. Where people live next to the } \\
\text { land/sea and don't rely on formal employment. The whole nation can benefit from this. Fisheries departments can } \\
\text { benefit because conservation aims of the Fisheries Act that are more likely to be achieved. }\end{array}$ \\
\hline
\end{tabular}




\begin{tabular}{|c|c|c|c|}
\hline THEME 5 & Question & Motivating factors & Summary of responses \\
\hline \multirow[b]{3}{*}{ 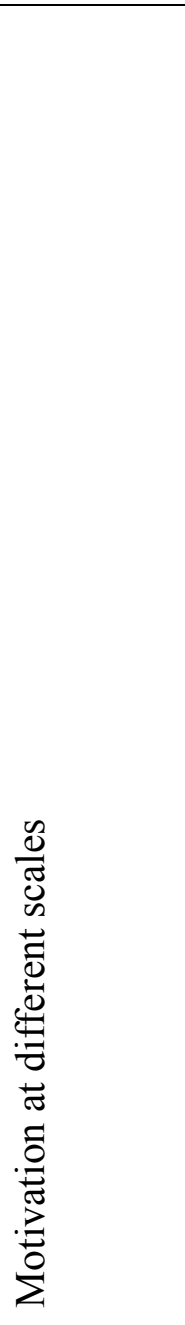 } & \multirow{3}{*}{$\begin{array}{l}\text { I surmised } \\
\text { from the } \\
\text { literatures } \\
\text { some key } \\
\text { motivating } \\
\text { factors in } \\
\text { successful } \\
\text { CBCs found } \\
\text { in the } \\
\text { Pacific. Can } \\
\text { you add to } \\
\text { this list or } \\
\text { comment/ } \\
\text { verify any of } \\
\text { these } \\
\text { factors? } \\
\text { What } \\
\text { motivates } \\
\text { you or your } \\
\text { organization? }\end{array}$} & $\begin{array}{l}\text { 1. Security of ownership for } \\
\text { indigenous groups }\end{array}$ & $\begin{array}{l}\text { 1. Agrees } \\
\text { 2. Agrees and adds that "empowering" is a significant motivating factor. } \\
\text { 3. Ownership is important in the sense that if communities feel that they are a part of the } \\
\text { project and the project is beneficial to them and that they are the ones reaping the benefits } \\
\text { then they would be supportive of it. Ownership is what keeps the project going and } \\
\text { ownership is more effective when these communities are empowered to manage the } \\
\text { projects themselves. } \\
\text { 4. The ability to control potential free riders from outside the community. Not to exclude } \\
\text { them but to manage them and even to be able to extract a resource-rent i.e. commercial } \\
\text { fishing permit in Fiji. }\end{array}$ \\
\hline & & 2. High levels of social capital & $\begin{array}{l}\text { 1. Agrees } \\
\text { 4. Not sure what high social capital means -an interlinked and cohesive communities or a } \\
\text { community with a high proportion of skilled/experienced /educated people in it? }\end{array}$ \\
\hline & & $\begin{array}{l}\text { 3. Perceptions of people and their } \\
\text { understanding }\end{array}$ & $\begin{array}{l}\text { 1. Agrees } \\
\text { 3. This is the purpose of awareness workshops before we start management planning. } \\
\text { "People will only look after things if they are passionate about." If we don't do a good job } \\
\text { with awareness, then people would not know about the resources and they won't care. } \\
\text { Perception is important to understanding the level of awareness. Perception is that people } \\
\text { are knowledgeable about their resources from their traditions and culture and they know } \\
\text { what is going on around them. The work of FLMMA and LMMA is to get the traditional } \\
\text { knowledge, and to get the science from the western ideas and see how we can incorporate } \\
\text { the two together. This further increases the awareness, increase the level of project } \\
\text { awareness and this has nothing to do with actual data but simply perception. } \\
\text { 4. This is important and is where government or outside input such as resource materials or }\end{array}$ \\
\hline
\end{tabular}




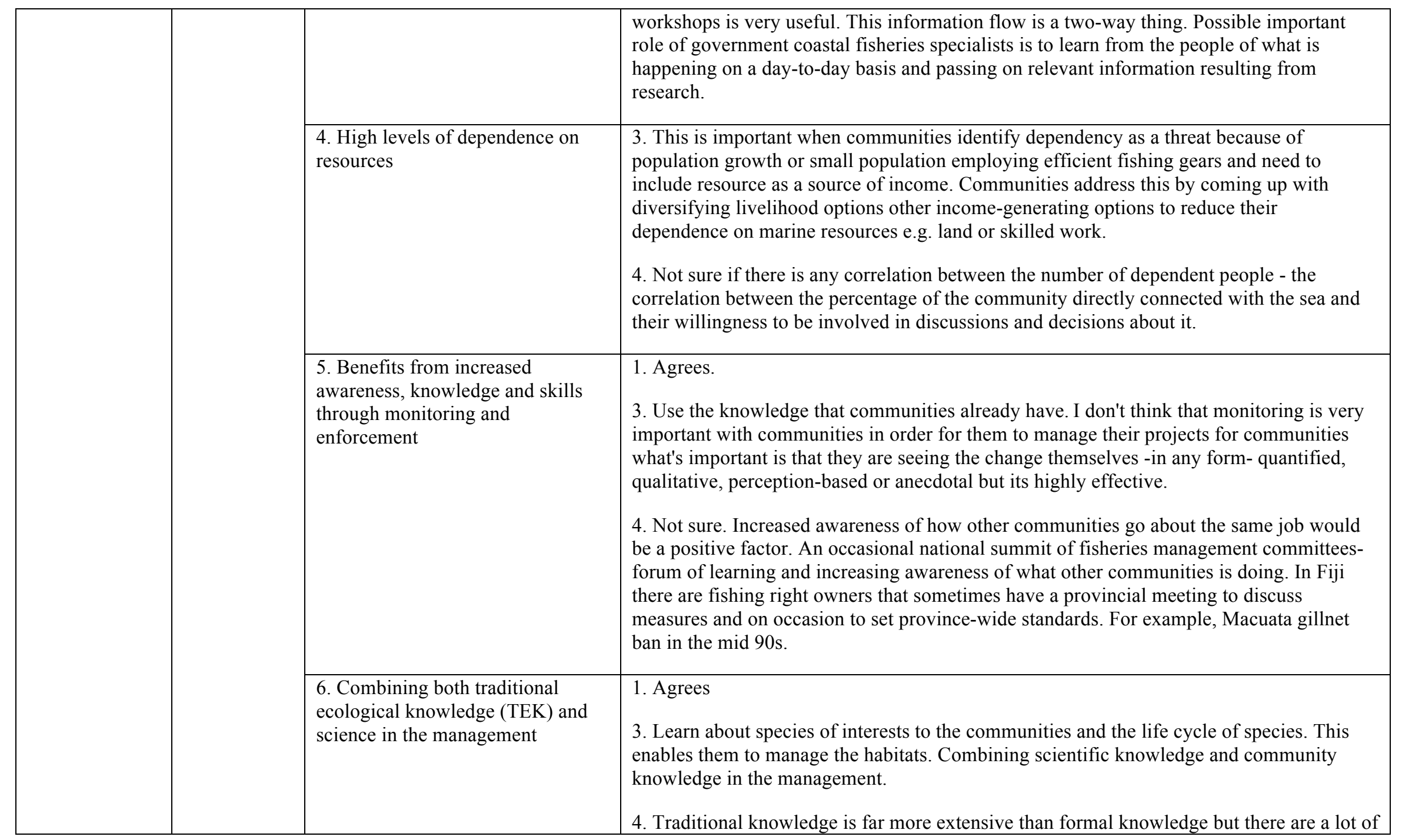




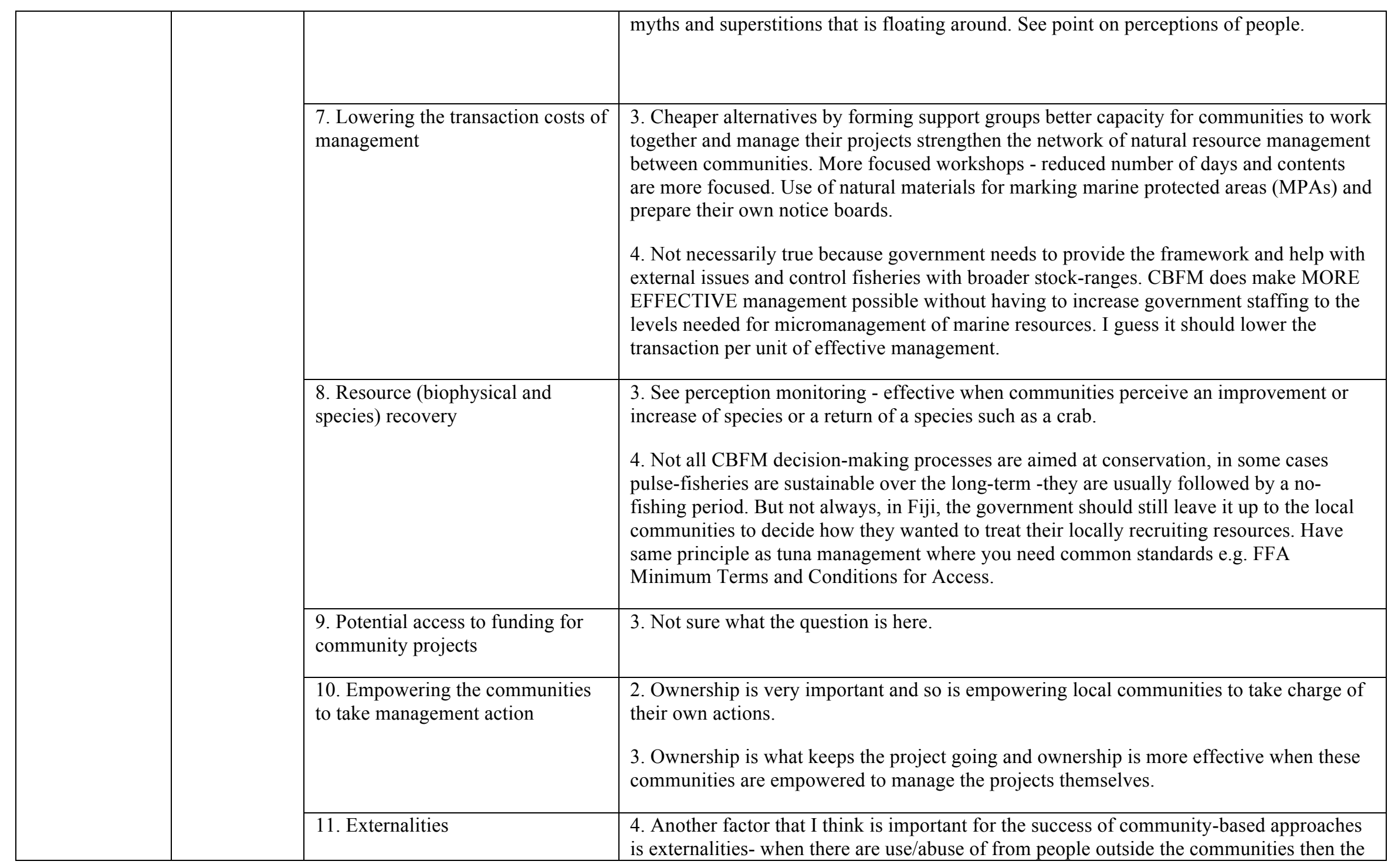




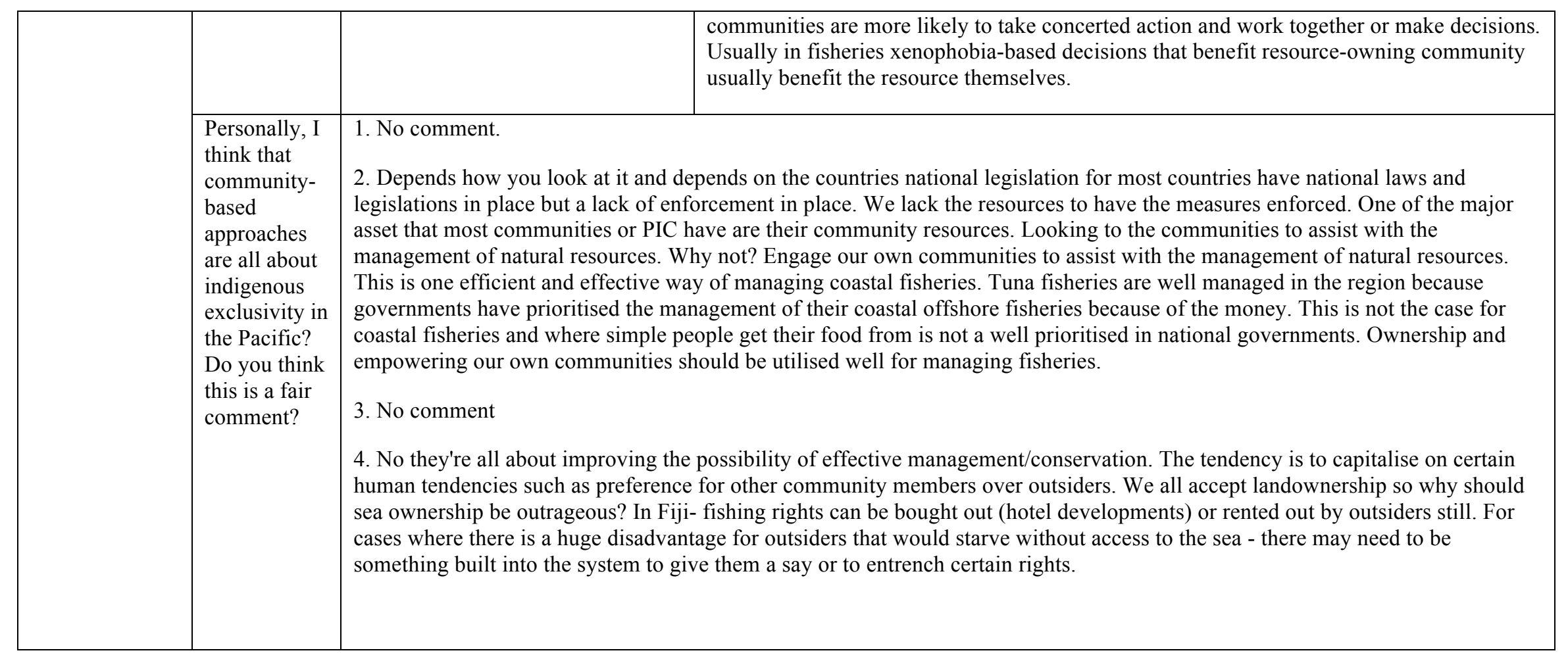




\begin{tabular}{|c|c|c|}
\hline THEME 6 & Question & Summary of responses \\
\hline 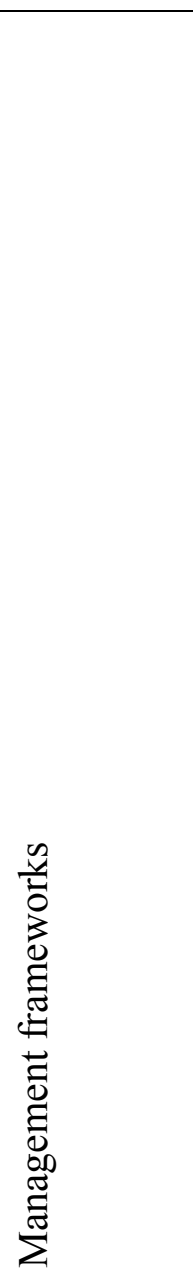 & $\begin{array}{l}\text { The management framework } \\
\text { that have been used in your } \\
\text { projects - community-based } \\
\text { adaptive management } \\
\text { (CBAM) or community } \\
\text { ecosystem approach to } \\
\text { fisheries management } \\
\text { (CEAFM), what changes (if } \\
\text { any) to include adapting to } \\
\text { climate change? And at what } \\
\text { scale such changes should be } \\
\text { made? }\end{array}$ & $\begin{array}{l}\text { 1. CC is a real threat but to develop an approach to address CC there needs to be a link made between CC and } \\
\text { their livelihoods and food security. Communities are culturally structured and it will be difficult to take them } \\
\text { away from something that they know and their lifestyle. } \\
\text { 2. The community-based ecosystem approach to fisheries management (CEAFM) is the regional approach that } \\
\text { has changed to adapt and address the issues of CC. CC is an issue and in the entire CBFM programme that I have } \\
\text { been involved with there has always been issues of weather changes in patterns. Changes in corals and spawning } \\
\text { area, this is something beyond our capacity as PICs to deal with except build the resilience of the communities } \\
\text { towards the impacts of CC. } \\
\text { 3. We have a Department that deals with CC. We work together where communities have identified threats } \\
\text { related to CC. One project that deals with CC threats we have done is mangrove re-planting and setting up } \\
\text { nurseries - sea- level rise. Bleaching is another issue. Integrating CC is totally dependent upon the site where } \\
\text { these issues are happening. For other sites we do not exclude them but we can start advising them so its clear that } \\
\text { these changes should be made but ideally it will be at the site level first but also at national level in terms of } \\
\text { awareness and finding ways to avoid falling short of the inevitable. } \\
\text { 4. No comment. CC was not considered ameliorable by CBFM. The potential effects of CC are over and above } \\
\text { existing level of resource fluctuation result of natural climate cycles. Existing capacity of fishers to cope with } \\
\text { these fluctuations was not known then is it known now? For Nauru, I guess that the effects on coral from } \\
\text { increased acidity and increased number of increase in sea temperature are over critical levels for coral bleaching. } \\
\text { Not sure what could be done at the national levels let alone at the community levels. }\end{array}$ \\
\hline
\end{tabular}




\begin{tabular}{|l|l|l|}
\hline $\begin{array}{l}\text { What do you think is the } \\
\text { future of CBCs in the Pacific } \\
\text { with impending concerns of } \\
\text { climate change? }\end{array}$ & $\begin{array}{l}1 . \text { There is a lot of potential for CBC in the Pacific but we need to address these threats the Pacific Way and the } \\
\text { way we know best for our people. Not to rely heavily on the western influences and lifestyle - this influence is } \\
\text { spreading rapidly and makes an impact on every aspect of our lives socially, politically, economically, culturally } \\
\text { etc....CC is a real threat and it's happening. We need to start changing the attitude and mindset of our people. We } \\
\text { need to target the young ones and the youth to make this difference. }\end{array}$ \\
$\begin{array}{l}\text { 2. I think the future would be working with our own people to build the resilience to the impacts of CC. Although } \\
\text { we contribute to CC to point of a fraction we are the first one to be hit on the CC theory. But I think that working } \\
\text { with communities is and to advise them. Building community resilience to the impacts of CC is the best way out. } \\
\text { Future of CB will be resilient building and having our own people adjust to living under those conditions and } \\
\text { being resilient to those impacts. }\end{array}$ \\
$\begin{array}{l}3 . \text { CBC will continue but there will be a need for improvements in the way we deal with CC issues, needs to have } \\
\text { more integration, more awareness, and more resource material provided because the future of CBC will be } \\
\text { affected by CC. } \\
4 . \text { There is a lot of mention of CC in this interview. Is there a perception that CBC will be of particular benefit in } \\
\text { tackling CC issues? If you can show a linkage it is likely to result in a lot more project money becoming } \\
\text { available. }\end{array}$
\end{tabular}




\section{APPENDIX 4: Fisher survey results}

Table 40: Traditional fishing gear

\begin{tabular}{|lll|}
\hline Traditional gear/methods & $\begin{array}{l}\text { Number of fishers who use } \\
\text { these gear/methods }\end{array}$ & Target species \\
\hline Etangat (see above) & 21 & Bottom fishes or deep-sea fishes \\
\hline $\begin{array}{l}\text { Fishing tools - hammer or } \\
\text { knife and a net }\end{array}$ & 6 & $\begin{array}{l}\text { Reef fishes and shellfishes on reef } \\
\text { flats gleaning }\end{array}$ \\
\hline Deganke (see above) & 4 & Octopus \\
\hline $\begin{array}{l}\text { Traps -use modern } \\
\text { materials }\end{array}$ & 1 & Usually eels or lobsters \\
\hline Hand-lining (koro) & 1 & $\begin{array}{l}\text { Mainly deep/bottom-sea fishes but } \\
\text { can target pelagic species }\end{array}$ \\
\hline Moon cycle & & $\begin{array}{l}\text { Variety of targets dependent upon the } \\
\text { phase of the moon }\end{array}$ \\
\hline Bait & 1 & Not specified \\
\hline
\end{tabular}

Table 41: Target species by gear/methods

\begin{tabular}{|c|c|c|c|c|c|c|c|c|c|c|}
\hline $\begin{array}{l}\text { Gears/ } \\
\text { methods }\end{array}$ & Scientific name & $\begin{array}{l}\text { Gleaning } \\
\text { (erom) }\end{array}$ & $\begin{array}{l}\text { Spearfishing } \\
\text { (SCUBA, } \\
\text { speargun and } \\
\text { fork) }\end{array}$ & $\begin{array}{l}\text { Cast- } \\
\text { net }\end{array}$ & $\begin{array}{l}\text { Seine } \\
\text {-net }\end{array}$ & $\begin{array}{l}\text { Akida } \\
\text { (group } \\
\text { of } \\
\text { divers- } \\
\text { bottom } \\
\text { fishing) }\end{array}$ & Rod & $\begin{array}{l}\text { Scoop } \\
\text { net \& } \\
\text { light }\end{array}$ & Troll & $\begin{array}{l}\text { Bottom } \\
\text { fishing }\end{array}$ \\
\hline \multicolumn{11}{|c|}{$\begin{array}{l}\text { Invertebrates found on reef flat or } \\
\text { top }\end{array}$} \\
\hline $\begin{array}{l}\text { Sea urchin } \\
\text { (enor) }\end{array}$ & $\begin{array}{l}\text { Tripneustes } \\
\text { gratilla }\end{array}$ & $\checkmark$ & & & & & & & & \\
\hline $\begin{array}{l}\text { Octopus } \\
\text { (dagiga) }\end{array}$ & Octopus sp. & $\checkmark$ & $\checkmark$ & & & & & & & \\
\hline Eared horse & Actinopyga & $\checkmark$ & & & & & & & & \\
\hline
\end{tabular}




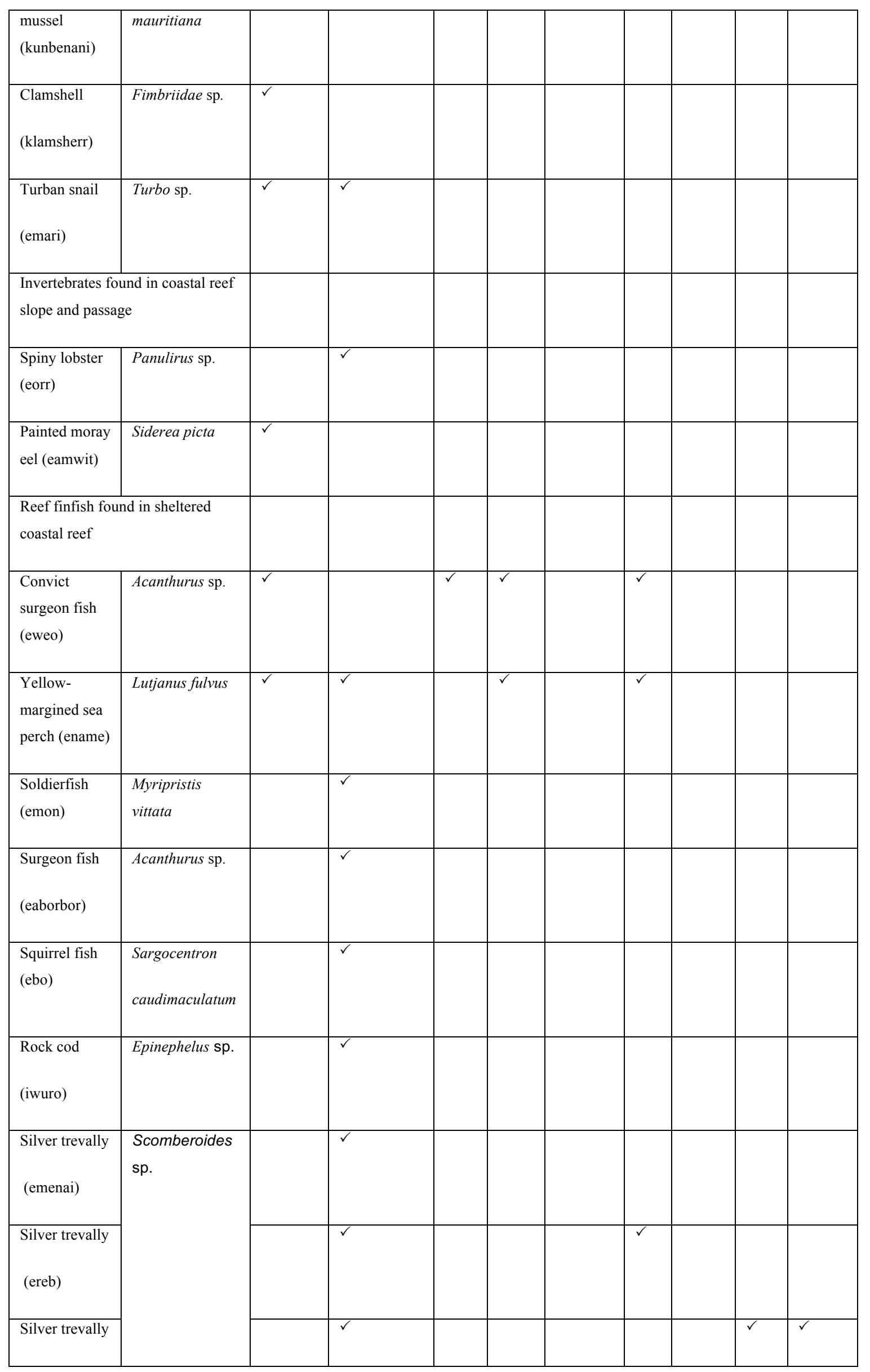




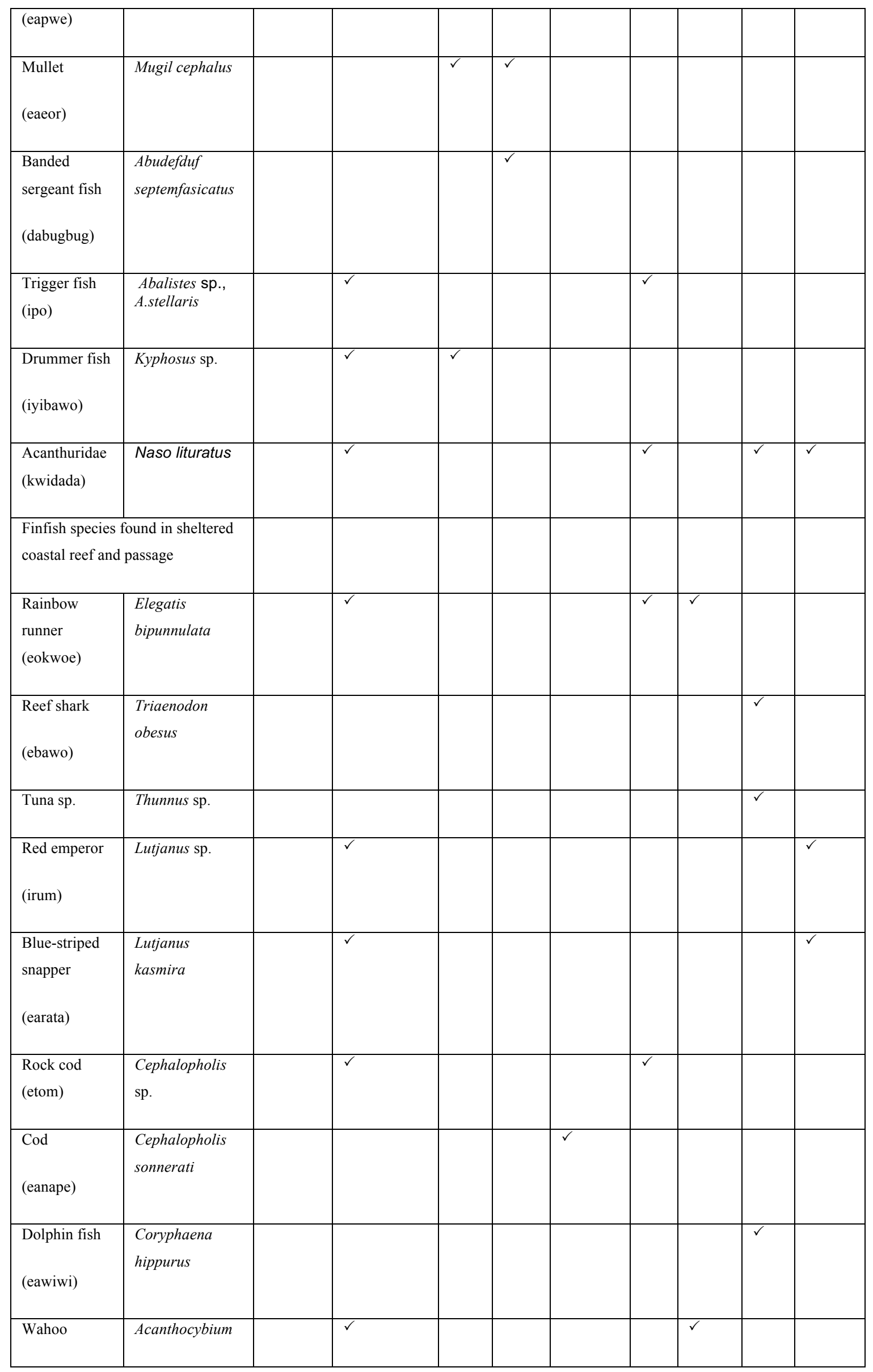




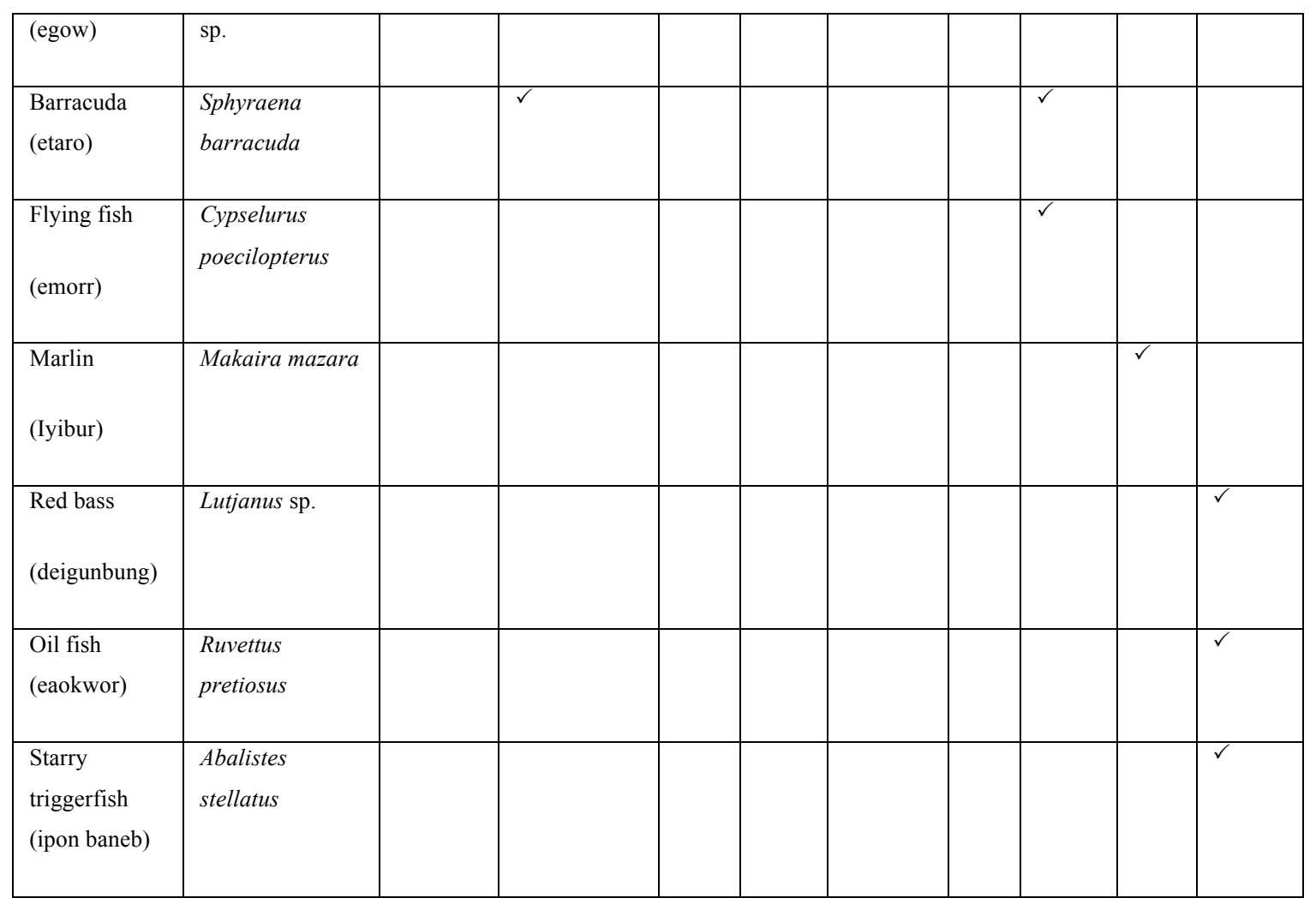

Table 42: Problems of sites and areas identified by fishers

\begin{tabular}{|c|c|c|c|c|c|c|c|c|c|c|c|c|c|c|c|c|}
\hline $\begin{array}{l}\text { Site/ } \\
\text { Proble } \\
\text { ms }\end{array}$ & $\begin{array}{l}\text { Anib } \\
\text { are }\end{array}$ & $\begin{array}{l}\mathbf{I j} \\
\mathbf{u} \\
\mathbf{w}\end{array}$ & $\begin{array}{l}\text { Ana } \\
\text { bar }\end{array}$ & $\begin{array}{l}\text { Ane } \\
\text { tan }\end{array}$ & $\begin{array}{l}\mathbf{E} \\
\mathbf{w} \\
\mathbf{a}\end{array}$ & $\begin{array}{l}\text { Bai } \\
\text { tsi }\end{array}$ & $\begin{array}{l}\text { Ua } \\
\text { boe }\end{array}$ & $\begin{array}{l}\text { Nib } \\
\text { ok }\end{array}$ & $\begin{array}{l}\text { De } \\
\text { nig }\end{array}$ & $\begin{array}{l}\text { Loca } \\
\text { tion }\end{array}$ & $\begin{array}{l}\text { Ai } \\
\text { wo }\end{array}$ & $\begin{array}{l}\text { B } \\
\text { oe }\end{array}$ & $\begin{array}{l}\text { Ya } \\
\text { ren }\end{array}$ & $\begin{array}{l}\text { Men } \\
\text { eng }\end{array}$ & $\begin{array}{l}\text { B/har } \\
\text { bours }\end{array}$ & $\begin{array}{l}\text { TOT } \\
\text { AL }\end{array}$ \\
\hline $\begin{array}{l}\text { Algal } \\
\text { growth }\end{array}$ & 2 & 1 & 1 & 1 & 0 & 1 & 0 & 0 & 0 & 0 & 0 & 1 & 0 & 2 & 0 & 9 \\
\hline $\begin{array}{l}\text { Few } \\
\text { fish }\end{array}$ & 2 & 5 & 3 & 2 & 4 & 1 & 1 & 3 & 2 & 0 & 3 & 0 & 7 & 3 & 0 & 36 \\
\hline $\begin{array}{l}\text { Rubbis } \\
\mathrm{h}\end{array}$ & 2 & 1 & 1 & 0 & 3 & 2 & 1 & 0 & 1 & 2 & 3 & 1 & 1 & 2 & 2 & 22 \\
\hline $\begin{array}{l}\text { Sand } \\
\text { erosio } \\
\mathrm{n}\end{array}$ & 1 & 1 & 1 & 0 & 3 & 2 & 0 & 0 & 0 & 2 & 6 & 1 & 8 & 2 & 2 & 29 \\
\hline
\end{tabular}




\begin{tabular}{|c|c|c|c|c|c|c|c|c|c|c|c|c|c|c|c|c|}
\hline $\begin{array}{l}\text { Too } \\
\text { many } \\
\text { fishers }\end{array}$ & 2 & 1 & 2 & 1 & 0 & 1 & 1 & 0 & 0 & 0 & 1 & 2 & 2 & 1 & 0 & 14 \\
\hline $\begin{array}{l}\text { Loss } \\
\text { of } \\
\text { hermit } \\
\text { crabs }\end{array}$ & 1 & 0 & 1 & 0 & 0 & 0 & 0 & 0 & 0 & 0 & 0 & 0 & 1 & 0 & 0 & 3 \\
\hline $\begin{array}{l}\text { Sewag } \\
\text { e }\end{array}$ & 2 & 0 & 0 & 0 & 1 & 0 & 0 & 0 & 1 & 0 & 2 & 0 & 1 & 0 & 0 & 7 \\
\hline $\begin{array}{l}\text { Damag } \\
\text { ed } \\
\text { reefs }\end{array}$ & 3 & 1 & 0 & 0 & 2 & 2 & 1 & 0 & 0 & 0 & 2 & 5 & 4 & 6 & 0 & 26 \\
\hline $\begin{array}{l}\text { Fish } \\
\text { hard to } \\
\text { find }\end{array}$ & 1 & 1 & 0 & 1 & 1 & 1 & 1 & 0 & 0 & 0 & 0 & 0 & 1 & 0 & 0 & 7 \\
\hline $\begin{array}{l}\text { Too } \\
\text { many } \\
\text { sharks }\end{array}$ & 1 & 3 & 2 & 1 & 0 & 1 & 0 & 2 & 2 & 0 & 1 & 0 & 3 & 2 & 0 & 18 \\
\hline $\begin{array}{l}\text { Overfi } \\
\text { shed } \\
\text { areas }\end{array}$ & 2 & 0 & 0 & 0 & 1 & 1 & 0 & 0 & 1 & 0 & 1 & 0 & 1 & 2 & 0 & 9 \\
\hline $\begin{array}{l}\text { Fish } \\
\text { species } \\
\text { have } \\
\text { disapp } \\
\text { eared }\end{array}$ & 0 & 0 & 0 & 0 & 1 & 1 & 0 & 0 & 0 & 0 & 0 & 0 & 0 & 0 & 0 & 2 \\
\hline $\begin{array}{l}\text { Chang } \\
\text { e of } \\
\text { ocean } \\
\text { current } \\
\text { s }\end{array}$ & 0 & 1 & 0 & 1 & 0 & 1 & 0 & 0 & 0 & 0 & 1 & 0 & 0 & 1 & 0 & 5 \\
\hline $\begin{array}{l}\text { Too } \\
\text { many } \\
\text { net } \\
\text { fishers }\end{array}$ & 0 & 1 & 0 & 0 & 1 & 0 & 0 & 0 & 0 & 0 & 0 & 0 & 0 & 0 & 0 & 2 \\
\hline $\begin{array}{l}\text { Too } \\
\text { many } \\
\text { dolphi } \\
\text { ns }\end{array}$ & 0 & 0 & 4 & 1 & 0 & 1 & 1 & 1 & 0 & 1 & 1 & 0 & 1 & 0 & 0 & 11 \\
\hline $\begin{array}{l}\text { Colour } \\
\text { change } \\
\text { of }\end{array}$ & 0 & 0 & 0 & 0 & 1 & 1 & 1 & 0 & 0 & 0 & 0 & 0 & 0 & 0 & 0 & 3 \\
\hline
\end{tabular}




\begin{tabular}{|l|l|l|l|l|l|l|l|l|l|l|l|l|l|l|l|l|}
\hline reefs & & & & & & & & & & & & & & & & \\
\hline $\begin{array}{l}\text { Waste } \\
\text { oils }\end{array}$ & 0 & 0 & 0 & 0 & 0 & 0 & 0 & 0 & 0 & 0 & 0 & 1 & 0 & 0 & 0 & 1 \\
\hline $\begin{array}{l}\text { Frigate } \\
\text { bird } \\
\text { owner }\end{array}$ & 0 & 0 & 0 & 0 & 0 & 0 & 0 & 0 & 0 & 0 & 0 & 0 & 0 & 1 & 0 & 1 \\
\hline $\begin{array}{l}\text { Rocks } \\
\text { at site }\end{array}$ & 0 & 0 & 0 & 0 & 0 & 0 & 0 & 0 & 0 & 0 & 1 & 1 & 0 & 0 & 0 & 2 \\
\hline $\begin{array}{l}\text { No } \\
\text { change }\end{array}$ & 3 & 3 & 2 & 0 & 0 & 0 & 0 & 0 & 0 & 1 & 3 & & 3 & 1 & 0 & 16 \\
\hline $\begin{array}{l}\text { TOTA } \\
\text { L }\end{array}$ & 23 & 19 & 17 & 8 & 18 & 16 & 7 & 6 & 7 & 6 & 25 & 1 & 34 & 24 & 4 & 227 \\
\hline
\end{tabular}


Table 43: Possible solutions to problems identified by fishers

\begin{tabular}{|l|l|l|l|l|l|l|l|l|l|}
\hline $\begin{array}{l}\text { Problems } \\
\text { \& their } \\
\text { solutions }\end{array}$ & $\begin{array}{l}\text { Algal } \\
\text { growth }\end{array}$ & $\begin{array}{l}\text { Less } \\
\text { fish }\end{array}$ & Rubbish & $\begin{array}{l}\text { Too } \\
\text { many } \\
\text { fishers }\end{array}$ & $\begin{array}{l}\text { Too } \\
\text { many } \\
\text { sea } \\
\text { urchins }\end{array}$ & Sewage & $\begin{array}{l}\text { Damaged } \\
\text { reefs }\end{array}$ & $\begin{array}{l}\text { Fish } \\
\text { harder } \\
\text { to find } \\
\text { or } \\
\text { found } \\
\text { deeper }\end{array}$ & $\begin{array}{l}\text { Overfished } \\
\text { areas }\end{array}$ \\
\hline Clean-up & & & $\checkmark$ & & & $\checkmark$ & & & $\checkmark$ \\
\hline $\begin{array}{l}\text { Introduce } \\
\text { laws and } \\
\text { regulatory } \\
\text { measures }\end{array}$ & & & & $\checkmark$ & & & $\checkmark$ & & \\
\hline $\begin{array}{l}\text { Ban } \\
\text { SCUBA } \\
\text { fishers }\end{array}$ & & & & $\checkmark$ & & & & & \\
\hline Not sure & $\checkmark$ & $\checkmark$ & & $\checkmark$ & $\checkmark$ & & & & $\checkmark$ \\
\hline None & & $\checkmark$ & & $\checkmark$ & & & $\checkmark$ & & \\
\hline
\end{tabular}

Table

44:

Benefit s and

loss from fishing versus improvements

\begin{tabular}{|c|c|c|c|c|c|c|}
\hline $\begin{array}{l}\text { Gains \& losses from } \\
\text { fishing and their } \\
\text { improvements }\end{array}$ & $\begin{array}{l}\text { Food } \\
\text { for } \\
\text { family }\end{array}$ & $\begin{array}{l}\text { Help } \\
\text { feed } \\
\text { others }\end{array}$ & $\begin{array}{l}\text { Convenient with } \\
\text { less time/effort to } \\
\text { get food }\end{array}$ & $\begin{array}{l}\text { Save } \\
\text { money }\end{array}$ & $\begin{array}{l}\text { Earn } \\
\text { money }\end{array}$ & $\begin{array}{l}\text { Loss of } \\
\text { money }\end{array}$ \\
\hline Introduce regulations & 2 & 1 & 1 & 0 & 0 & 0 \\
\hline Ban SCUBA gears & 2 & 0 & 0 & 2 & 0 & 0 \\
\hline $\begin{array}{l}\text { Introduce species-specific } \\
\text { limits on catch }\end{array}$ & 1 & 0 & 1 & 2 & 0 & 0 \\
\hline $\begin{array}{l}\text { Stop rubbish in marine } \\
\text { environment }\end{array}$ & 2 & 0 & 3 & 2 & 1 & 0 \\
\hline Stop fishing brood stocks & 1 & 0 & 0 & 0 & 0 & 0 \\
\hline Manage the reefs & 4 & 0 & 0 & 2 & 3 & 0 \\
\hline $\begin{array}{l}\text { Awareness programmes } \\
\text { for management }\end{array}$ & 2 & 0 & 0 & 0 & 0 & 0 \\
\hline $\begin{array}{l}\text { Introduce seasonal } \\
\text { closure of areas }\end{array}$ & 1 & 0 & 0 & 1 & 0 & 0 \\
\hline $\begin{array}{l}\text { Introduce mesh net size } \\
\text { limits }\end{array}$ & 0 & 0 & 0 & 1 & 0 & 0 \\
\hline $\begin{array}{l}\text { More information about } \\
\text { fishing gears and their }\end{array}$ & 3 & 0 & 0 & 1 & 0 & 0 \\
\hline
\end{tabular}




\begin{tabular}{|c|c|c|c|c|c|c|}
\hline impacts & & & & & & \\
\hline $\begin{array}{l}\text { Reduce cost of fishing- } \\
\text { subsidised costs of fuel } \\
\text { and gears }\end{array}$ & 21 & 1 & 1 & 3 & 17 & 1 \\
\hline $\begin{array}{l}\text { Stronger commitment by } \\
\text { government to manage } \\
\text { marine resources }\end{array}$ & 0 & 0 & 0 & 1 & 0 & 0 \\
\hline $\begin{array}{l}\text { Introduce alternative to } \\
\text { fishing }\end{array}$ & 1 & 0 & 0 & 1 & 0 & 0 \\
\hline Revive the fish market & 1 & 0 & 0 & 0 & 1 & 0 \\
\hline $\begin{array}{l}\text { Ensure safety at sea gears } \\
\text { are available }\end{array}$ & 1 & 0 & 0 & 1 & 1 & 0 \\
\hline $\begin{array}{l}\text { Introduce fishing } \\
\text { regulations in the boat } \\
\text { harbours }\end{array}$ & 1 & 0 & 0 & 0 & 0 & 0 \\
\hline $\begin{array}{l}\text { Have more fish } \\
\text { aggregation devices } \\
\text { (FADs) }\end{array}$ & 0 & 0 & 0 & 1 & 3 & 0 \\
\hline $\begin{array}{l}\text { Implement marine } \\
\text { reserves to farm clams }\end{array}$ & 0 & 0 & 0 & 1 & 0 & 0 \\
\hline Not sure & 4 & 1 & 0 & 4 & 3 & 0 \\
\hline
\end{tabular}


Table 45: Estimated cost of fishing gear in Nauru

\begin{tabular}{|l|l|l|l|l|l|l|}
\hline $\begin{array}{l}\text { Estimated average start-up costs of } \\
\text { fishing gears/methods }\end{array}$ & $\begin{array}{l}\mathbf{\$ 2 0 -} \\
\mathbf{\$ 5 0}\end{array}$ & $\begin{array}{l}\mathbf{\$ 1 0 0 -} \\
\mathbf{\$ 1 5 0}\end{array}$ & $\begin{array}{l}\mathbf{\$ 1 5 0} \\
\mathbf{\$ 2 0 0}\end{array}$ & $\begin{array}{l}\mathbf{\$ 2 0 0 -} \\
\mathbf{\$ 5 0 0}\end{array}$ & $\begin{array}{l}\mathbf{\$ 5 0 0}- \\
\mathbf{\$ 1 0 0 0}\end{array}$ & $\mathbf{> \$ 1 0 0 0}$ \\
\hline $\begin{array}{l}\text { Spearfishing } \\
\text { (i) free-divers } \\
\text { (ii) SCUBA }\end{array}$ & & & & $\checkmark$ & & \\
\hline & & & & & $\checkmark$ & \\
\hline $\begin{array}{l}\text { Net fishing } \\
\text { (i) Cast net } \\
\text { (ii) Seine net }\end{array}$ & & & $\checkmark$ & & & \\
\hline Rod fishing & & & $\checkmark$ & & & \\
\hline Gleaning & & & & $\checkmark$ & & \\
\hline Boat fishing & & & & & \\
(i) Troll fishing & & & & & & \\
\hline
\end{tabular}

APPENDIX 5: Non-fishers survey results

Table 46: Ranking 'causers' of major problems based on mean scores

\begin{tabular}{|llcl|}
\hline $\begin{array}{l}\text { Major causers of "problems" to coastal marine } \\
\text { environment }\end{array}$ & $\begin{array}{l}\text { Number of } \\
\text { respondents }\end{array}$ & Mean & $\begin{array}{l}\text { Std. } \\
\text { Deviation }\end{array}$ \\
\hline Trap fishers & 121 & $\mathbf{1 . 6 9}$ & 1.224 \\
\hline Troll fishers & 125 & $\mathbf{1 . 6 9}$ & 1.253 \\
\hline Night fishers & 122 & $\mathbf{1 . 7 4}$ & 1.252 \\
\hline Reef fad (enge) fishers & 120 & $\mathbf{1 . 7 5}$ & 1.349 \\
\hline Free divers (spearfishers) & 122 & $\mathbf{1 . 8}$ & 1.311 \\
\hline Cast net fishers & 127 & $\mathbf{1 . 8 6}$ & 1.314 \\
\hline
\end{tabular}




\begin{tabular}{|c|c|c|c|}
\hline Seine net fishers & 127 & 1.96 & 1.365 \\
\hline Group fishers -"akida" & 116 & 2.37 & 1.655 \\
\hline SCUBA fishers & 121 & 3.1 & 1.744 \\
\hline Phosphate mining & 96 & 3.71 & 1.66 \\
\hline Overfishing & 127 & 3.97 & 1.506 \\
\hline Port development & 1 & 4 & \\
\hline Sand mining & 127 & 4.07 & 1.432 \\
\hline Coral mining & 125 & 4.13 & 1.442 \\
\hline Use of crowbar in fishing & 126 & 4.17 & 1.401 \\
\hline Use of cyanide in fishing & 124 & 4.18 & 1.504 \\
\hline Land run-offs & 3 & 4.22 & 1.411 \\
\hline Sewage & 128 & 4.51 & 1.136 \\
\hline Pollution & 131 & 4.53 & 1.105 \\
\hline Land-based development & 121 & 4.67 & 0.577 \\
\hline Rubbish & 138 & 4.78 & 0.732 \\
\hline
\end{tabular}

APPENDIX 6: Fishers \& Non-fishers survey results

Table 47: Site-selection for marine reserve(s) in Nauru 


\begin{tabular}{|c|c|c|c|}
\hline Anabar & 4 & 1 & 5 \\
\hline Ewa & 5 & 4 & 9 \\
\hline Aiwo & 6 & 7 & 13 \\
\hline $\begin{array}{l}\text { Isolated area } \mathrm{b} / \mathrm{w} \text { Anabar and } \\
\text { Ijuw }\end{array}$ & 6 & 15 & 21 \\
\hline Anetan & 3 & 5 & 8 \\
\hline Baitsi & 13 & 5 & 18 \\
\hline Ijuw & 7 & 0 & 7 \\
\hline Nibok & 1 & 1 & 2 \\
\hline Yaren & 2 & 3 & 5 \\
\hline Boe & 5 & 5 & 10 \\
\hline Denig & 4 & 1 & 5 \\
\hline Uaboe & 0 & 1 & 1 \\
\hline All districts & 8 & 8 & 16 \\
\hline Boat harbours & 4 & 1 & 5 \\
\hline Offshore area & 0 & 1 & 1 \\
\hline Any & 2 & 8 & 10 \\
\hline Not sure & 19 & 44 & 63 \\
\hline TOTAL & 118 & 145 & 263 \\
\hline
\end{tabular}


Table 48: Participants reasons for selecting specific sites to host a marine reserve

\begin{tabular}{|c|c|c|c|c|c|c|}
\hline Sites/reasons & Anibare & Meneng & Anabar/Ijuw & Baitsi & $\begin{array}{l}\text { All } \\
\text { districts }\end{array}$ & TOTAL \\
\hline $\begin{array}{l}\text { Marine areas and habitats that } \\
\text { are 'unique' }\end{array}$ & 1 & 0 & 1 & 1 & 1 & 4 \\
\hline Fewer people living in the area & 16 & 4 & 8 & 0 & 0 & 28 \\
\hline $\begin{array}{l}\text { Areas are identified as being } \\
\text { overexploited in short overfished }\end{array}$ & 4 & 3 & 1 & 1 & 3 & 12 \\
\hline $\begin{array}{l}\text { District or community is a strong } \\
\text { social unit }\end{array}$ & 1 & 1 & 3 & 0 & 0 & 5 \\
\hline Areas have plenty of fish & 4 & 2 & 1 & 1 & 0 & 8 \\
\hline $\begin{array}{l}\text { Isolated areas where no or few } \\
\text { people live adjacent to the coast. }\end{array}$ & 9 & 1 & 10 & 0 & 1 & 21 \\
\hline $\begin{array}{l}\text { Research is required to find the } \\
\text { appropriate site(s) }\end{array}$ & 0 & 0 & 1 & 1 & 0 & 2 \\
\hline $\begin{array}{l}\text { Government-owned areas such } \\
\text { as boat harbours }\end{array}$ & 1 & 0 & 0 & 0 & 0 & 1 \\
\hline Highly polluted coastal areas & 1 & 0 & 0 & 0 & 0 & 1 \\
\hline $\begin{array}{l}\text { Areas where fish have } \\
\text { disappeared and need to be } \\
\text { restored and revived }\end{array}$ & 4 & 1 & 1 & 0 & 5 & 11 \\
\hline $\begin{array}{l}\text { Areas where marine reserves are } \\
\text { used to develop fish farms }\end{array}$ & 0 & 1 & 0 & 0 & 0 & 1 \\
\hline $\begin{array}{l}\text { Areas where species breeding } \\
\text { grounds are known }\end{array}$ & 8 & 1 & 0 & 1 & 0 & 10 \\
\hline $\begin{array}{l}\text { Areas that are close proximity to } \\
\text { home }\end{array}$ & 0 & 1 & 0 & 1 & 1 & 3 \\
\hline $\begin{array}{l}\text { Areas where protection is needed } \\
\text { for their aesthetic reasons }\end{array}$ & 1 & 0 & 0 & 0 & 6 & 7 \\
\hline $\begin{array}{l}\text { Areas where spill-over effect of } \\
\text { marine reserves can occur based } \\
\text { on ocean currents }\end{array}$ & 1 & 0 & 1 & 1 & 0 & 3 \\
\hline $\begin{array}{l}\text { Areas that harbour "unique" } \\
\text { marine species }\end{array}$ & 0 & 1 & 0 & 0 & 1 & 2 \\
\hline
\end{tabular}


Table 49: Comments on questionnaire

\begin{tabular}{|c|c|}
\hline ISSUES & COMMENTS \\
\hline Questionnaire itself & $\begin{array}{l}\text { Some terms were difficult to understand } \\
\text { Confusing } \\
\text { Ok }\end{array}$ \\
\hline CBFM approach & $\begin{array}{l}\text { Need an action plan before implementation and this should be a } 20-50 \text { year plan } \\
\text { Programme to part of the school curriculum } \\
\text { NFMRA project development fund (PDF) should finance community monitoring } \\
\text { and enforcement of management rules }\end{array}$ \\
\hline Attitudes & $\begin{array}{l}\text { Locals are highly dependent on resources potential difficulties to comply with } \\
\text { future rules and regulations } \\
\text { Locals believe that management is unnecessary } \\
\text { Locals need to protect resources without the government }\end{array}$ \\
\hline Action plan & $\begin{array}{l}\text { Majority of participants want action now! } \\
\text { Keep our beach clean } \\
\text { Have rotational closures in place } \\
\text { Introduce subsidised cost to fishing gear } \\
\text { Put in place inshore fish aggregation devices in Baitsi } \\
\text { Protect the boat harbour areas during seasonal breeding } \\
\text { Government to encourage people to look after the resources } \\
\text { Government to stop land-based development in coastal areas } \\
\text { Frigate fishers to be banned from fishing }\end{array}$ \\
\hline $\begin{array}{l}\text { Information } \\
\text { management }\end{array}$ & $\begin{array}{l}\text { Need more information about the CBFM } \\
\text { More information required about controlling dolphin problems and their adverse } \\
\text { impacts to fishers } \\
\text { Learn about the impacts of climate change on sea temperatures } \\
\text { Learn about the impacts of sand erosion on the marine resources and the overall } \\
\text { environment } \\
\text { Learn about how ownership of reclaimed coastal areas }\end{array}$ \\
\hline $\begin{array}{l}\text { Changes identified } \\
\text { to resources }\end{array}$ & Coral reefs are changing in colour \\
\hline Cultural activities & $\begin{array}{l}\text { Frigate birds are family -these birds formerly and still held by some with cultural } \\
\text { status and legacy therefore have the right to be fed fish (locals assume that frigate } \\
\text { birds are in competition with human consumption). }\end{array}$ \\
\hline
\end{tabular}




\section{APPENDIX 7: Survey field notes}

\section{$\underline{\text { Value ranking systems }}$}

The team provided participants a brief translation of each of the terms biodiversity and cultural identity. The question was posed in local language for simplicity. For example the biodiversity question was asked as, "How important to your well-being to have "many kinds of fish and other marine species" in the marine environment? Rank on a scale of 1 to 5." While for cultural identity the question was, "How important to your well-being is it be a Nauruan to access and use the marine resources? Rank on a scale of 1 to 5." The term climate change was difficult to define but the survey team used examples such as the impacts of climate change that include sea-level rise, warming of the seas and ocean acidification bringing about potential threats.

Participants understood the basic concepts of biodiversity and the impacts of climate change but wanted more information. It was not within the scope of the study but important that biodiversity and climate change, especially their effects on coastal marine resources in Nauru. Cultural identity was a variable that was difficult to explain and not many participants were familiar with this term. Despite these terms being unfamiliar, the value ranking of biodiversity and avoiding climate change was high compared to other variables. 


\section{APPENDIX 8: Focus group information \& results}

Focus group activity to be conducted in Nauru based with gender groups of about 6-8 participants, where the focus group participants are selected from the wide population and to consist of key informants and representatives of interest groups in the Nauruan community.

The purpose of this focus group activity is to allow an in-depth discussion of pertinent issues about how and what are the 'boundaries' for community-based approach will work in Nauru

Focus group activities and discussion are conducted in Nauruan, but all information will be written in English.

Time: $11 / 2-2$ hours

\section{Focus group Themes}

\section{Part 1: Boundaries -Territorial Use-Rights in Fisheries (TURFs)}

Social mapping based on the maps from conducted in the survey of problem sites, target areas and habitats is used to provide the focus for discussion on the strengths, weaknesses, opportunities and threats of community-based approaches to alleviate these problems.

a) Opportunities and obstacles for community-based management relating to spatial 'boundaries' ( $1 / 2$ hour).

b) Discussion of spatial mapping of community conserved area(s) or marine reserve or marine protected area(s) (1/2 hour).

\section{Part 2: Local governance}

Before any measure is selected for group discussion, I will explain each measure and you can start by "agreeing or disagreeing" with each measure. [Please tick -agree $(\sqrt{ })$ and a cross $(X)$ - disagree to all that apply in Table 1]. Table 1 (below) has a list of potential rules and regulations, which can be used to protect the coral reefs and marine environment. You can add any measure (s) to the list. Think about these measures that you have agreed and disagreed and let discuss each briefly and select at least one or two measures (group consensus) to discuss the following questions:

a) Why have you agreed or disagreed with such measure? (1/2 hour)

b) Identify either person(s) or group(s) that you know of or yourself that would be affected these measures (specify which measure) and your concerns with respect to implementation (if any) $(1 / 2$ hour).

c) What and how groups can be motivated to adopt this measure(s)? Or which existing social organization or group best address issues of governance ( $1 / 2$ hour). 
Table 1: Rules and regulations for coastal and marine environment

\begin{tabular}{|c|c|c|c|c|c|}
\hline $\begin{array}{l}\text { Rules and } \\
\text { regulations to } \\
\text { fishing /gathering }\end{array}$ & $\begin{array}{l}\text { Agree/Not } \\
\text { agree }\end{array}$ & $\begin{array}{l}\text { Perceived } \\
\text { problems with } \\
\text { each measure } \\
\text { and for which } \\
\text { group(s) }\end{array}$ & $\begin{array}{l}\text { Reasons } \\
\text { for such } \\
\text { problems }\end{array}$ & $\begin{array}{l}\text { What and how } \\
\text { groups can be } \\
\text { motivated or } \\
\text { buy-in with } \\
\text { these measures }\end{array}$ & $\begin{array}{l}\text { Best approach } \\
\text { through current } \\
\text { social organization } \\
\text { e.g. church, youth } \\
\text { groups }\end{array}$ \\
\hline $\begin{array}{l}\text { Have fishing areas } \\
\text { zoning }\end{array}$ & & & & & \\
\hline $\begin{array}{l}\text { Size limits for } \\
\text { catches }\end{array}$ & & & & & \\
\hline $\begin{array}{l}\text { Have fishing } \\
\text { seasons }\end{array}$ & & & & & \\
\hline $\begin{array}{l}\text { Catch limits or } \\
\text { quotas }\end{array}$ & & & & & \\
\hline $\begin{array}{l}\text { Protecting certain } \\
\text { species }\end{array}$ & & & & & \\
\hline $\begin{array}{l}\text { Community } \\
\text { conserved } \\
\text { areas/marine } \\
\text { reserves/MPAs }\end{array}$ & & & & & \\
\hline $\begin{array}{l}\text { Impacts of climate } \\
\text { change } \\
\text {-sea level rise } \\
\text {-coastal erosion }\end{array}$ & & & & & \\
\hline $\begin{array}{l}\text { Other } \quad \text { (please } \\
\text { specify) }\end{array}$ & & & & & \\
\hline
\end{tabular}


a) Nauru Gender-based focus group 1 -Women

Date: $10^{\text {th }}$ August 2010

Time: $10.00-12.00 \mathrm{pm}$

Venue: NFMRA complex -Anibare - new building

All participants are seated on "flattened" cardboards as mats in the room

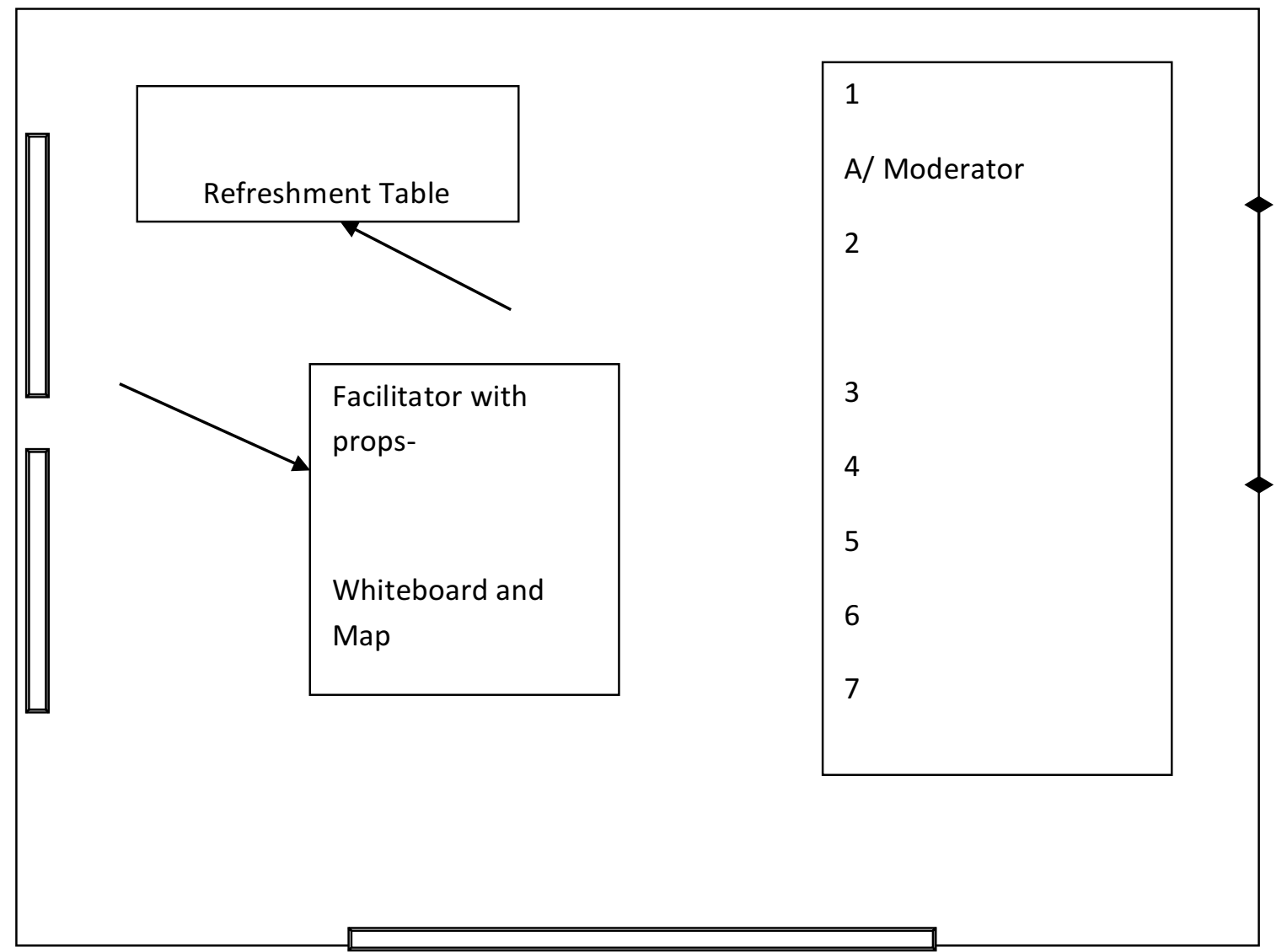

Figure 16: Focus group I: seating arrangement

Symbol Meaning

$\longrightarrow \quad$ Marks the location of Facilitator and key items in room

Windows in the room

$\longmapsto$ Doorway

1-7 Seating arrangements -number of participants 
Nauru Gender-based focus group 2 -Men

Date: $13^{\text {th }}$ August 2010

Time: $2.00-4.00 \mathrm{pm}$

Venue: NFMRA complex -Anibare - new building

All participants are seated on "flattened" cardboards as mats in the room.

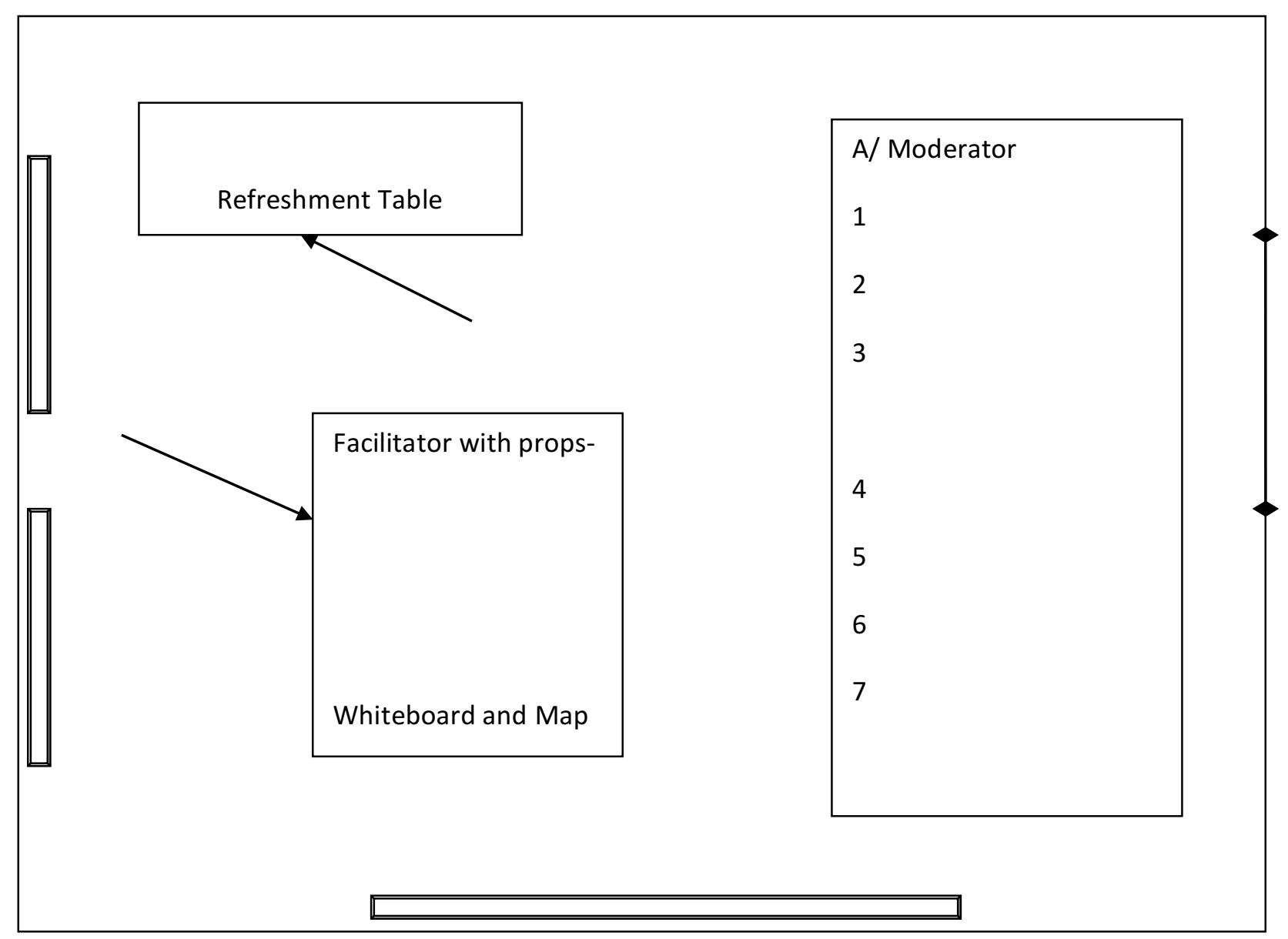

Figure 17: Focus group II: seating arrangements

Symbol Meaning

Marks the location of Facilitator and key items in room

Windows in the room

Doorway

1-7 Seating arrangements -number of participants 
Table 50: Role and objectives of NFMRA and the community in the CBFM process

\begin{tabular}{|c|c|c|}
\hline $\begin{array}{l}\text { Emergent } \\
\text { issues }\end{array}$ & Quotes & $\begin{array}{l}\text { FG } \\
\text { Groups }\end{array}$ \\
\hline \multirow[t]{2}{*}{$\begin{array}{l}\text { Role and } \\
\text { objectives of } \\
\text { NFMRA }\end{array}$} & $\begin{array}{l}\text { "Our aim is to complete } 7 \text { districts CBFM plans so we [can] gain the } \\
\text { support from the government to develop the supporting legislation." AM } \\
\text { "NFMRA haven't even reached the point of implementation and these } \\
\text { districts have not yet implemented these regulations because of the lack of } \\
\text { formal support from government." P2 } \\
\text { "Key alternative projects include-fish aggregation devices (FADs) and } \\
\text { canoe-building projects to help [district] communities realise that we are } \\
\text { committed in our agreement." AM } \\
\text { "This falls under the responsibilities of Fisheries to find out more about } \\
\text { this so-called business license that gives foreigners permits to fish in the } \\
\text { coastal waters. Fisheries need to raise their concerns with the government } \\
\text { on this very issue that the communities already have developed } \\
\text { community-based management plans. The government should be excluded } \\
\text { from issuing licenses and permits because these are the requests of the } \\
\text { communities you are working with."P5 } \\
\text { "Can't we have some interim measures in place or something in the form } \\
\text { of pending in order to avoid this type of conflict?" P2 } \\
\text { "What kind of interim measures would be effective? I mean when the } \\
\text { Meneng Council were arguing against the decision made by the } \\
\text { government from issuing licenses to the Chinese. One of the arguments } \\
\text { that the government told the Meneng Council members was that they } \\
\text { couldn't afford to employ people to patrol the coastal areas and police } \\
\text { fishers." P7 }\end{array}$ & $I$ \\
\hline & $\begin{array}{l}\text { "If we develop all these rules and regulations that we come up with, then } \\
\text { who will table them to government to pass this regulation or enact these } \\
\text { laws?" P7 } \\
\text { "It doesn't sound too bad. So we will work under Fisheries and then you } \\
\text { work in-between with the national Government?" P7 } \\
\text { "It is a partnership." AM }\end{array}$ & $I I$ \\
\hline $\begin{array}{l}\text { Role of } \\
\text { communities }\end{array}$ & $\begin{array}{l}\text { "We feel that we need to teach the children to be aware of their coastal } \\
\text { environment and teach them about sustainable use and fishing practices. } \\
\text { For this to happen we need to have volunteers from the districts and we } \\
\text { haven't had too many people volunteering because these people are } \\
\text { scared of others." P7 } \\
\text { "I think the government does not realise that we're not asking them to pay } \\
\text { for patrolmen or fish wardens the communities or people want to look } \\
\text { after their resources because it where they get their food from. The marine } \\
\text { resources and environment is the people's livelihood. The people are } \\
\text { willing to take care of the resources." P7 }\end{array}$ & $I$ \\
\hline
\end{tabular}




\begin{tabular}{|l|l|l|}
\hline & $\begin{array}{l}\text { "I mean we all do [participate in the process] - but [for] the monitoring } \\
\text { and enforcement [this] is done by the communities themselves. And when } \\
\text { communities want [to add] some regulations in place such as an MPA and } \\
\text { they can identify the times when fishing season is open. When people want } \\
\text { to fish in the [closed] areas then another rule [can be put in place] to } \\
\text { identify that should fish first. You can fish tomorrow in the area, after } \\
\text { some time. Something likes that (chuckles)... I think its best to have a one } \\
\text { way process [for the CBFM] to work."P3 } \\
\text { "If we have district reps [representatives] or wardens in place then it will } \\
\text { be easier to spread the awareness programmes [and] inform people about } \\
\text { the regulations in place and penalties."P7 }\end{array}$ & \\
\end{tabular}




\section{APPENDIX 9: Survey questionnaire}

Name:

Head of household: $\mathrm{Y} / \mathrm{N}$

Gender: $\mathrm{M} / \mathrm{F}$

District:

\section{Part 1: Household survey}

INCOME:

1. What is your employment?
a. Public Sector
b. Private Sector
c. Self-employed
d. Unemployed
e. Other

2. Do you go fishing/gathering to earn extra income?
- Yes
- No

3. a) Does your household have access to the following in-house facilities? (Tick Y/N in Table 1 below) and b) Does your household possess the following equipment?

Table 1: Household Economic Indicators

\begin{tabular}{|c|c|c|c|c|}
\hline \multicolumn{2}{|c|}{ Physical economic indicators } & \multicolumn{3}{|c|}{ SITE NO: } \\
\hline & & Yes & No & $\begin{array}{l}\text { Number of } \\
\text { items }\end{array}$ \\
\hline \multirow[t]{5}{*}{ In-house facilities } & Running water & & & $\mathrm{N} / \mathrm{A}$ \\
\hline & Electricity & & & N/A \\
\hline & Radio & & & \\
\hline & TV & & & \\
\hline & Mobile phones & & & \\
\hline \multirow{3}{*}{$\begin{array}{l}\text { Physical indicator } \\
\text { of economic } \\
\text { activities }\end{array}$} & Bicycle & & & \\
\hline & $\begin{array}{l}\text { Fishing boat with } \\
\text { outboard } \\
\text { engine }\end{array}$ & & & \\
\hline & Cast-net & & & \\
\hline
\end{tabular}




\begin{tabular}{|l|l|l|l|l|}
\hline Seine-net & & & \\
\cline { 2 - 5 } & Fishing traps with & & & \\
\hline & $\begin{array}{l}\text { Canoe } \\
\text { outrigger }\end{array}$ & & & \\
\cline { 2 - 5 } & Motor bike & & & \\
\hline & Motor vehicle(s) & & & \\
\hline & Other (specify) & & & \\
\hline
\end{tabular}

\section{Part 2: Individual 'perception' survey}

1. a) What do you think is the present condition of the coral reefs and the marine environment?

- Very good (Please explain below)

- $\quad$ Good (Please explain below)

- $\mathrm{Bad}$

- Very bad

- Don't know/not sure

b) What do you think the future conditions of the coral reefs and the marine environment would be in the next 5 years?

- Better

- Remain the same

- Worse

- Don't know/not sure

2. What do you think are the major problems affecting the coastal and marine environment? (Please rank accordingly. 1 being the lowest and 5 the highest. (-) if not applicable in Table 2)

3. Who do you think is responsible for 'major' problems and who do you think should be responsible to solve these problems found in coastal and marine environments? (Please provide answers in table 2)

Table 2: Perception of major environmental problems

\begin{tabular}{|l|l|l|l|}
\hline $\begin{array}{l}\text { Perceived major } \\
\text { environmental } \\
\text { problems }\end{array}$ & Q2 & Who are the 'creators'? & Who are the 'solvers'? \\
\hline Overfishing & & & \\
\hline Cyanide fishing & & & \\
\hline Crow-bar fishing & & & \\
\hline Group (akida) fishing & & & \\
\hline Cast-net fishing & & & \\
\hline
\end{tabular}




\begin{tabular}{|c|c|c|}
\hline Seine net fishing & & \\
\hline Trap fishing & & \\
\hline Free diving & & \\
\hline SCUBA diving & & \\
\hline Trolling- tuna fishing & & \\
\hline $\begin{array}{l}\text { FAD (enge) fishing } \\
\text { (reef) }\end{array}$ & & \\
\hline Night fishing & & \\
\hline Sand mining & & \\
\hline Coral mining & & \\
\hline Sewage & & \\
\hline Land-based run-off & & \\
\hline Rubbish & & \\
\hline Pollution & & \\
\hline Phosphate mining & & \\
\hline Other (please specify) & & \\
\hline
\end{tabular}

3. Are you aware of any rules or regulations regarding the coastal and marine environment? (National or traditional) If yes, please list and provide with explanation then continue to Q 4a. If no, please go to Q4b and continue.

4. a) Do you comply with these rules (above)? $\mathrm{Y} / \mathrm{N}$

b) Do you think that there is a need to have rules and regulations in the coastal and marine environment? $\mathrm{Y} / \mathrm{N}$

c) Would you be willing to comply with such rules and regulations in the future?

$\mathrm{Y} / \mathrm{N} \quad$ Explain your reasons.

5. a) Do you think you have sufficient knowledge or information to protect or conserve coral reefs and the marine environment? To answer this question, see Table 3 and tick what you think is a credible source, then state type of knowledge or information gained from source and rate on a scale of 1-5 where 1 is the lowest and 5 is highest - as a credible source of knowledge/information.

\begin{tabular}{|l|l|l|l|}
\hline $\begin{array}{l}\text { Source of knowledge and } \\
\text { information }\end{array}$ & $\begin{array}{l}\text { Tick } \\
\text { for Y } \\
\text { and } \\
\text { cross }\end{array}$ & $\begin{array}{l}\text { Type of "knowledge" or } \\
\text { "information" - protecting } \\
\text { the marine environment or } \\
\text { fishing skills related }\end{array}$ & $\begin{array}{l}\text { Credibility of such knowledge and } \\
\text { information on a scale (1-5) }\end{array}$ \\
\hline
\end{tabular}




\begin{tabular}{|l|l|l|l|}
\hline & for $\mathbf{N}$ & & \\
\hline Traditional knowledge- legends & & & \\
\hline $\begin{array}{l}\text { Oration from others (handed } \\
\text { down) }\end{array}$ & & & \\
\hline By experience & & & \\
\hline School & & & \\
\hline Media (specify) & & & \\
\hline Interest groups & & & \\
\hline Other (please specify) & & & \\
\end{tabular}

b) Do you think you need more information about the coral reefs and marine environment? $\mathrm{Y} / \mathrm{N}$ and what type of information you think you will benefit from?

6. How would you prefer to receive this type of information in the future?

- TV

- Radio

- Internet-email

- Newsletter

- Other-(please specify)

7. Are you aware of any existing groups or organizations that are currently involved with protecting coastal and marine environments?

a) If yes, who? If, no- do you think that there should be such a group? Y/N

b) And would you like to be part of such a group in the future? Y/N

8. Do you believe that it is a good idea to have some coastal areas to be zones where the natural environment and the marine life can be protected and preserved?

- Agree

- $\quad$ Not agree (Go to Q9b)

- Don't know/not sure (Go to Q9b)

9. a) If you agree (with Q8), 'who' do you think should be responsible to lead and manage the demarcated coastal area(s)? (Circle all your preference)

- If Government- which agency...

- Communities

- Communities in partnership with Government

- Other (specify)...

- Don’t know/Not sure

b) If you do not agree (with Q8), please explain your reasons. 
10. How important is the coral reef and marine environment to your well-being and rate these on a scale of 15 where 1 is the lowest and 5 is of the highest value.

Table 4: Value of coral reef and marine environment

\begin{tabular}{|l|l|}
\hline Value & Ranking scale \\
\hline Food & \\
\hline Income & \\
\hline Cultural identity & \\
\hline Recreational & \\
\hline Bequest (legacy) & \\
\hline Aesthetic & \\
\hline Biological diversity & \\
\hline Climate change & \\
\hline Other (specify) & \\
\hline
\end{tabular}

NOTE: Continue Part 3 Survey if individual interviewed stated that fishing is either their primary or secondary source of income otherwise ASK for a fisher in the household OR come back later OR THANK THE PERSON for their time and MOVE ON.

\section{Part 3: "Fisher" survey}

NAME of FISHER:

\section{Gender M/F}

History

1. Do you go fishing regularly or only when you need to?

- Regularly

- Only when need

- Don't know

2. Why do you fish/gather (circle all that apply)

- Food for family

- Food for community

- Food to sell 
- Customs

- Recreation

- Picnic

- Other (specify)

3. How long have you been fishing/gathering?

- Less than a year

- Less than 4 years

- $\quad>5$ years

- $\quad>10$ years

4. Who taught you how and where to fish/gather?

5. Have you been passing on your fishing/gathering skills?

- Yes

- No

a) If yes, how have you passed on your skills? If not, why not?

6. Who do you fish/gather with?

- $\quad$ Friends

- Relatives

- Children

- Other

7. Are you a member of any fishing organisation or group?

- Yes, which group?

- $\quad$ No

8. Do you prefer to fish/gather at night or during the day?

- Day

- Night

- Both

a) Any particular reason for your preference? 
9. How much fish/seafood do you collect on a good day versus a bad day?

- $\operatorname{Good}$ day=

- $\quad$ Bad day $=$

- Don’t know

10. a) Do you have traditional beliefs or sacred areas with respect to fishing/gathering?

- Yes

- $\quad$ No

Please explain if you have such beliefs.

b) Are you aware of any customary ownership of marine areas?

- Yes

- $\quad$ No

- Don’t know/Not sure

Please explain.

$\underline{\text { Fishing gears and methods }}$

11. Do you use local fishing/gathering gears?

- Yes (please describe methods below)

- No

12. Do you use modern technology to fish/gather?

- Yes

- $\quad$ No

13. Has modern technology increased or decreased your catch?

- Increase

- Decrease

- $\quad$ Same

14. Which do you use most often now?

- Traditional gears and methods

- Modern gears and methods 
- Both

15. What do you think are the most efficient gears used in fishing/gathering today? And which methods or gears need to be controlled?

\begin{tabular}{|c|c|c|c|}
\hline Gears & Agree & Disagree & Needs control \\
\hline \multicolumn{4}{|l|}{ Spear gun } \\
\hline \multicolumn{4}{|l|}{ Flashlight } \\
\hline \multicolumn{4}{|l|}{ Cast net } \\
\hline \multicolumn{4}{|l|}{ Seine nets } \\
\hline \multicolumn{4}{|l|}{ SCUBA } \\
\hline \multicolumn{4}{|l|}{ Spear } \\
\hline \multicolumn{4}{|l|}{ Rod fishing } \\
\hline \multicolumn{4}{|l|}{ Canoe } \\
\hline \multicolumn{4}{|c|}{ Boat with outboard engine } \\
\hline \multicolumn{4}{|l|}{ Gleaning } \\
\hline Other (specify) & & & \\
\hline
\end{tabular}

Target species and areas

16. When you fish/gather, do you target specific species?

- Yes

- No $_{1}$

- Don't know

If yes, please explain which species you target and why these species are targeted. -methods and gears 
17. Where do you fish/gather? Using map, show at least five sites where you frequently fish/gather. Please provide below reasons why you fish/gather in these areas and the types of habitats you like best for fishing/gathering.

\begin{tabular}{|l|l|}
\hline Sites & Habitats \\
\hline 1. & \\
\hline 2. & \\
\hline 3. & \\
\hline 4. & \\
\hline 5. & \\
\hline
\end{tabular}

$\underline{\text { Perceptions about the productivity of fishing and coastal areas }}$

18. Does it seem like there are more, less or the same amount of fish/seafood in the past 5 years?

- More

- $\quad$ Less

- $\quad$ Same amount

19. Has fish size changed over the past 5 years (or are fish/seafood bigger, smaller, or same size)?

- Bigger

- Smaller

- $\quad$ Same size

20. Are there any species of fish/seafood that have become harder to find or decreased in number over the past 5 years?

21. Are there any species of fish/seafood that have become easier to find or have increased in numbers over the past 5 years?

Perceptions about problems/changes of the marine environment 
22. Have you noticed with any specific sites (Q 15) that are having problems or changed in any manner?

- Yes

- No

- Don't know/Not sure

23. What changes (if any) or events (natural or man-made) have you witnessed in the last 5 years in Nauru? Using map, show site and list specific problems, and if you can provide solutions for these problems.

\begin{tabular}{|l|l|l|}
\hline Site (s) & Problem(s) & Solution \\
\hline 1. & & \\
\hline 2. & & \\
\hline 3. & & \\
\hline 4. & & \\
\hline 5. & & \\
\hline
\end{tabular}

$\underline{\text { Costs }}$

24. How much does it cost to go fishing/gathering on a typical fishing day?

25. Who pays for the cost of fishing/gathering?

- Own expense

- $\quad$ Shared costs

- Business

- Other

26. Does it cost more, less, or the same as 5 years ago?

- $\quad$ More

- Less

- $\quad$ Same

- Don’t know 
27. Does it cost more to fish/gather than buy food from the shops?

- Yes

- No

28. Do you keep all fish/seafood you collect?

- Yes

- No

If you give seafood away, how much on average of your catch do you give away? (Give a fraction)

$\underline{\text { Benefits }}$

29. Do you think you that investing in fishing/gathering (money, time and effort) has been beneficial to you today?

- Yes

- No

- Not sure

a) If yes, explain what benefits you have gained and for whom?

b) State if any improvements can be made to increase your opportunity to benefit more from this livelihood (fishing/gathering)

30. Do you think that your livelihood will benefit from protecting and conserving the coral reefs and marine environment?

- Yes

- No

- Don’t know

\section{Management options}

31. Have you ever heard about community-based management? 
- Yes (whom from?)

- No

- Don't know/Not sure

a) Using the map, draw how you think marine areas should be zoned under this approach OR if not or not sure then picture this- People or communities share the burden of marine management with Government. Now use the map, and draw what comes to your mind with this type management and the 'boundaries' involved?

b) Do you think this approach can succeed in Nauru? Explain your reasons.

32. Do you see the need for a marine reserve or protected area in Nauru, where do you think this reserve should be? Using same map to mark area(s) and give a brief explanation of how this would be governed.

33. Any comments you want to add to any part of this questionnaire?

The end. Thank you for your time! 